\title{
Under the surface: Textural analysis of complex, multi-component Vulcanian bombs produced \\ during the hybrid explosive-effusive phase of the 2011-2012 Cordón Caulle eruption, Chile
}

by

Jack W. Whattam

A thesis submitted to Victoria University of Wellington in partial fulfilment of requirements for the degree of Master of Science in Geology

Geology Department

School of Geography, Environment, and Earth Sciences

Victoria University of Wellington

April, 2018 



\begin{abstract}
The ascent, eruption, and deposition of volcanic pyroclasts is complex, but the resultant rocks have distinctive textural markers that indicate the unseen processes that were operating during a given eruption. These textures can be used to build a picture of the sequence of events and the eruptive environment. Vulcanian eruptions, short-lived, intermittent blasts interpreted as the clearing of a conduit plug, produce ballistic pyroclasts with textures that are directly correlated with the makeup of the plug material. A late phase of the recent eruption of Puyehue-Cordon Caullé (2011-2012, Southern Chile) produced a striking array of, colourful, and texturally diverse Vulcanian bombs. The eruption began on June 4th 2011 with Plinian to Sub-Plinian activity, transitioning to a phase of obsidian lava effusion on June 15th, and then to a hybrid effusive-explosive phase (vulcanian bomb ejection coeval with an effusive obsidian lava flow) in January 2012. Transitions from explosive to effusive activity are often described as singular, definitive, one-way events, at odds with the hybrid effusive-explosive activity seen at Puyehue-Cordón Caulle. Textures in these bombs indicate that the constituent melts have experienced several (possibly countless) episodes of fragmentation, sintering, densification, shearing, and vesiculation within a conduit-scale breccia pack, conceptually equivalent to a conduit-scale tuffisite vein. In all examined bombs, centimetre to micron scale clasts of basaltic-andesite $(\sim \mathrm{SiO} 254-55 \mathrm{wt} \%)$ are found, with textures that indicate a magmatic origin. Although volumetrically minor, co-mingling of a hotter, mafic magmatic component has implications for the anomalously hot rhyolite, as well as the onset and longevity of the hybrid eruption phase. Textural and geochemical characteristics of bombs elucidate complex processes in the shallow conduit and vent, advancing the understanding of tuffisite veins and Vulcanian eruption dynamics, which are far from straightforward.
\end{abstract}




\section{Acknowledgements}

Thanks must first go my supervisor, Ian Schipper; his patient guidance and support throughout the year were invaluable. Your excitement for the project was infectious, and our regular discussions were invaluable. Thank you for taking me on as a student and helping me navigate the wealth of volcanological knowledge out there.

Secondly, thanks go to my parents, Wilf and Nora, whom without, the five years spent at university would have been far more arduous. Your unwavering support, regardless of the cost, and the multitude of grammatical edits on my work, especially in the last year, were much appreciated.

Ben Kennedy, Jon Castro, and the other members of the Puyehue-Cordón Caulle 'dream-team'. Although I am yet to meet many of you, your comments and insights throughout the year helped guide me through a vast range of volcanological material and my thesis is unquestionably the better for your help. Further, my thanks goes to SERNAGEOMIN for access to invaluable resources and the Puyehue-Cordón Caulle volcanic complex itself.

To Monica Handler, Julie Vry, and Warren Dickinson; your enthusiasm for your respective fields within petrology and geochemistry cemented my own interest in these fields. You have always done your utmost to answer my endless, often challenging questions over the years, constantly spurring further curiosity.

Last, but far from least, thanks goes to those that were once strangers, but who I now consider close friends. Lisa, Tom, and Georgia; thanks for the beers and the yarns that dulcified my temper and headstrong decisions. To the flatmates: Tom, Brad, Loz, Lucas, and LG; thanks for the good times and putting up with me. To the others that have been there over the last five years: TJ, Darrah, Adam, Mel, and Maggie; having your friendship made the time far more bearable and it made for some highly memorable moments over the years. 


\section{Contents}

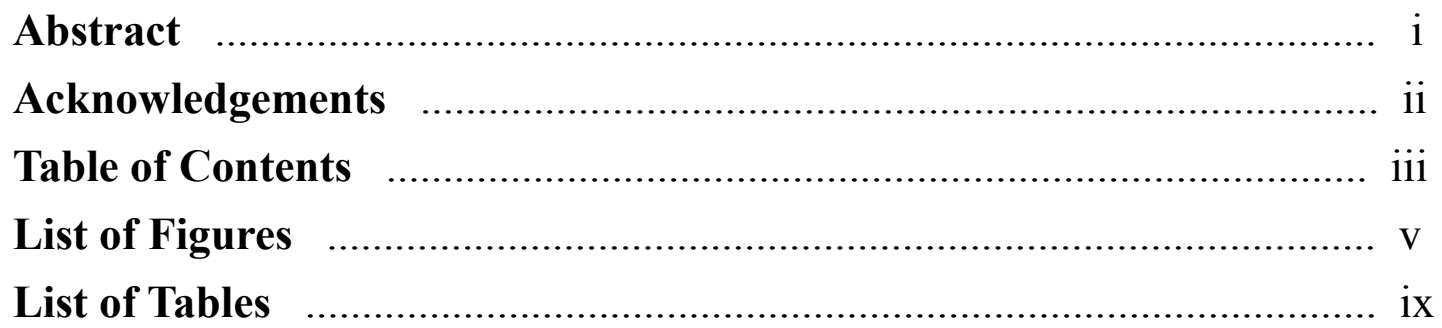

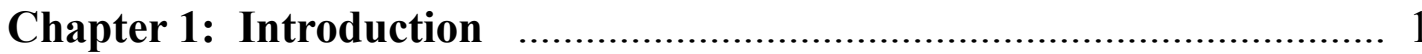

1.1 Research Problem ........................................................... 1

1.2 History, Setting, Evolution, and latest Eruption of the Puyehue-Cordón Caulle Volcanic Complex .............. 2

Chapter 2: General Background ................................................... 7

2.1. Eruption Dynamics ......................................................... 7

2.2. Vulcanian Eruptions and Bombs ..................................... 16

2.3. Magma Mixing and Mingling ........................................... 26

Chapter 3: Samples and Methods ................................................ 33

3.1. Sample Selection and Preparation ….............................. 33

3.2. Thin Section Processing …............................................ 34

3.3. Electron Microprobe Analyses ....................................... 34

3.4. Australian Synchrotron IMBL …….............................. 36

3.5. Heating Experiments …................................................... 36

3.6. ImageJ Analysis ......................................................... 38

Chapter 4: Results

4.1. Macro-Textural Classification ……................................... 41

4.2. Micro-Textural Classification …....................................... 44

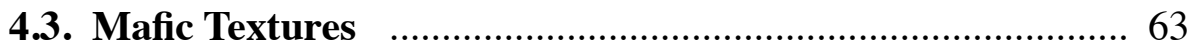

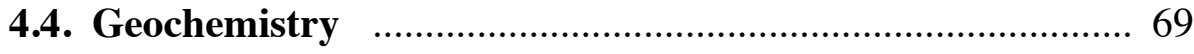

4.5. Tomography Heating Experiments …............................... 79 
Chapter 5: Macro- and Micro-Textures

5.1. Vesicles: Shape, Size, and Deformation

5.2. Sintering Variations 86

5.3. Crystal Populations 88

5.4. Micro-Oxides 92

Chapter 6: Mafic Textures and Geochemistry 99

Chapter 7: Implications 109

Chapter 8: Conclusions and Future Work 117

Reference List 120

Appendix 1: Hand Sample Descriptions 138

Appendix 2 (digital): Full Chemical Analyses 142 


\section{List of Figures}

Fig. 1.1. Map of location and tectonic setting (from Alloway et al., 2015; and Singer et al., 2008).

Fig. 1.2. Simplified timeline for the 2011-2012 Cordón

Caulle eruption. 3

Fig. 1.3. Major element and REE plots for the 1922, 1960, and 2011 eruption products (Castro et al., 2013b).

Fig. 2.1. Schematic examples of common eruption styles (Gonnermann, 2015). 7

Fig. 2.2. Solubility curves $\mathrm{H}_{2} \mathrm{O}$ and $\mathrm{CO}_{2}$ (Gonnermann, 2015). 8

Fig. 2.3. Schematic illustration of fragmentation (Alidibirov and Dingwell, 1996). 9

Fig. 2.4. End-member fragmentation styles (Cashman and Scheu, 2015). 11

Fig. 2.5. Schematic representation of the glass transition (Cashman and Scheu, 2015).

Fig. 2.6. Cartoon diagram of the basic model for tuffisite formation (Kendrick et al., 2016). 15

Fig. 2.7. Field images and schematic diagram of breadcrusted bombs (Isgett et al., 2017; andYamagishi, 1991).

Fig. 2.8. Schematic models for the formation of breadcrusted bombs (Isgett et al., 2017; Saubin et al., 2016; Wright et al., 2007; Yamagishi and Feebrey, 1994). 19

Fig. 2.9. Breadcrust rind and crack formation (Wright et al., 2007). 20 
Fig. 2.10. Bubble coalescence schematic and examples in real samples (Castro et al., 2012a; Martel and Iacono-Marziano, 2015).

Fig. 2.11. Schematic representation of the viscous sintering process

(Vasseur et al., 2013a).

Fig. 2.12. Illustration of common magma mixing and mingling

processes (Perugini and Poli, 2012).

Fig. 2.13. Illustration of the relationship between mixing and mingling in magma (Laumonier et al., 2014a). 28

Fig. 2.14. Schematic diagram of chaotic mixing (Perugini and Poli, 2012). 30

Fig. 3.1. Map of sample locations. 33

Fig. 3.2. Diagram of blowtorch furnace used in heating experiments. 37

Fig. 3.3. Heating profile for the butane blowtorch furnace. 38

Fig. 4.1. Field images of Cordón Caulle bombs (courtesy of C. I. Schipper). 42

Fig. 4.2. Thin sections used for micro-textural analysis. 42

Fig. 4.3. Hand sample examples. 42

Fig. 4.4. Examples of lithic clasts.

Fig. 4.5. Particle size distribution in the sintered domains of B20. 45

Fig. 4.6. Key differences in endmember sintering conditions. 46

Fig. 4.7. Dense particle packing and sintering associated with particle deformation.

Fig. 4.8. Sintering of sub-angular particles in sample B09. 48 
Fig. 4.9. BSE edge effect of thin section topography compared to micro-oxide content.

Fig. 4.10. Colour variations for comparative sintering textures

in B16 and B20.

Fig. 4.11. Complex vesicle shapes with coalescence, deformation, and irregular orientations.

Fig. 4.12. Coalescence textures in vesicular domains.

Fig. 4.13. Deformation and collapse of thin IBFs in highly vesicular domains.

Fig. 4.14. Variations in apparent vesicle alignment between macro-and micro-scale. 54

Fig. 4.15. Vesicularity boundaries in dense samples. 56

Fig. 4.16. Displacement of crystal fragments in B10 roughly parallel to banding. 57

Fig. 4.17. Crystal separation perpendicular to alignment in B11. 58

Fig. 4.18. Smooth micro-oxide bands around a glomerocryst in B10. 59

Fig. 4.19. Discontinuous micro-oxide 'bands'. 60

Fig. 4.20. Mottled glass texture in B11. 61

Fig. 4.21. Collapsed and partially sintered foam. 61

Fig. 4.22. Microlite rich domains in B13 and B21. 62

Fig. 4.23. Basaltic-andesite clasts with cuspate margins, large, simple vesicles, and euhedral crystals. 63 
Fig. 4.24. Fine, acicular crystals in basaltic-andesite.

Fig. 4.25. Micro-oxide association with basaltic-andesite.

Fig. 4.26. Identification of basaltic-andesite at different scales.

Fig. 4.27. Regions of relatively abundant basaltic-andesite in B10 and B20.

Fig. 4.28. Smooth intrusions of rhyolitic glass into basaltic-andesite.

Fig. 4.29. Major-element TAS diagram for 2011-2012 eruption products.

Fig. 4.30. Oxide variation plots fo 2011-2012 eruption products.

Fig. 4.31. Histogram of olivine Forsterite compositions.

Fig. 4.32. Examples of olivine crystals. 75

Fig. 4.33. Ternary plot of plagioclase Anorthite compositions.

Fig. 4.34. Examples of plagioclase crystals. 78

Fig. 4.35. Comparison of pre- and post-heating textures in B11. 80

Fig. 4.36. Comparison of pre- and post-heating textures in B17. 81

Fig. 4.37. Modification of texture after heating in B17. 81

Fig. 5.1. Vesicle elongation and crystal alignment in B10. 86

Fig. 5.2. Sintering between ash and larger lapilli in B09. 88

Fig. 5.3. Simple glomerocrysts in B20. 89

Fig. 5.4. Accumulation of crystals and glomerocrysts in B10. 90 
Fig. 5.5. Macro-scale banding in B13.

Fig. 5.6. Micro-oxide bands in B21 circumscribing vesicles. 95

Fig. 5.7. Micro-oxide presence and absence in B20. 96

Fig. 6.1. Flow banding textures around mafic blobs in B10. 101

Fig. 6.2. Rupture texture in the large basaltic-andesite blob in B10. 102

Fig. 7.1. Cross cutting pumice band in B07.

Fig. 7.2. Cartoon cross-section of conduit and proposed model.

\section{List of Tables}

Table. 4.1. Generalised morphological classifications for Cordón Caulle bombs

Table. 4.2. Representative subset of major element matrix glass analyses 70

Table. 4.3. Subset of major element analyses for Olivine 70 74

Table. 4.4. Subset of major element analyses for Plagioclase 77 


\section{Chapter 1: Introduction}

\subsection{Research Problem}

Vulcanian eruptions (small to moderate scale, discrete, intermittent explosions) are not uncommon, occurring both as isolated eruptions and as part of larger eruption sequences (e.g., Wright et al., 2007). These eruptions commonly produce a variety of ballistic pyroclastic 'bombs' (herein referred to as bombs). However, the bomb-producing Vulcanian eruptions of Chaitén (2008-2009) and Puyehue-Cordón Caulle (2011-2012) are distinctive in that they occurred simultaneously with the emplacement of obsidian lava flows. Moreover, these two recent eruptions are the only rhyolitic eruptions to have been observed in detail with accompanying video footage (e.g., Schipper et al., 2013). The availability of such detailed observations of the simultaneous bomb and lava producing eruption phase presents an opportunity to elucidate the mechanisms that allow seemingly incompatible eruption styles to occur in concert. Recent work (e.g., Cabrera et al., 2015; Castro et al., 2013a; Castro et al., 2012b; Castro et al., 2012c; Kendrick et al., 2016; Saubin et al., 2016; Schipper et al., 2013) on the problem suggests that ash-filled cracks (termed tuffisite veins) allow rapid, cyclic degassing, and that bombs could be thrown out of these cracks during rapid, violent degassing. Authors have characterised the tuffisite veins themselves, and used $\mathrm{H}_{2} \mathrm{O}$ profiles across these features to identify them as degassing pathways (e.g., Tuffen et al., 2003). However, a detailed textural analysis of the bombs themselves, characterising the variation between, and within individual bombs has not been conducted.

The aim of this project was to examine the textures present in ballistic volcanic bombs and use these textures to better understand the mechanisms that produced Vulcanian bombs during the hybrid effusive-explosive phase of the 2011-2012 Puyehue-Cordón Caulle eruption. To achieve this goal this study: (1) imaged bomb samples in 3D at the Australian Synchrotron and cut thin sections of those same samples for backscatter image analysis, (2) examined textures present in the samples, focussing on categorising the distinct textural domains within bombs, the relationship between domains, and the overall bomb types, and (3) addressed the processes responsible for the variety of observed textures, and infer a mechanism of bomb formation for the 2011-2012 Cordón Caulle eruption that is compliant with all observed textures. However, whilst the general aim of this project remained the same throughout, the way in which this was achieved did change due some key textural and compositional findings. Consequently, more focus 
was put on micro-textural and compositional microprobe analyses using thin-sections, with the same goal of forming a better understanding of the processes and sequence of bomb formation during the 2011-2012 eruption.

\subsection{History, Setting, Evolution, and latest Eruption of the Puyehue-Cordón Caulle Volcanic Complex}

The Puyehue-Cordón Caulle Volcanic Complex (PCCVC) sits at $40.5^{\circ} \mathrm{S}$ within the volcanically active Southern Volcanic Zone $\left(\sim 33^{\circ}-46^{\circ}\right.$ S, Fig. 1.1) of the South American Andes (Bertrand et al., 2014; Stern et al., 2007). All volcanic activity in the the Andes results from subduction of the Nazca oceanic plate beneath the South American continental plate (Gerlach, 1985; Gerlach et al., 1988). The PCCVC forms a 15-20 km by $4 \mathrm{~km}$ NW-SE ridge consisting of three distinct volcanic edifices - the Cordillera Nevada caldera, the Cordón Caulle fissure system, and the Puyehue stratovolcano (Gerlach et al., 1988; Lara et al., 2006). Within the central Southern Volcanic Zone, the PCCVC

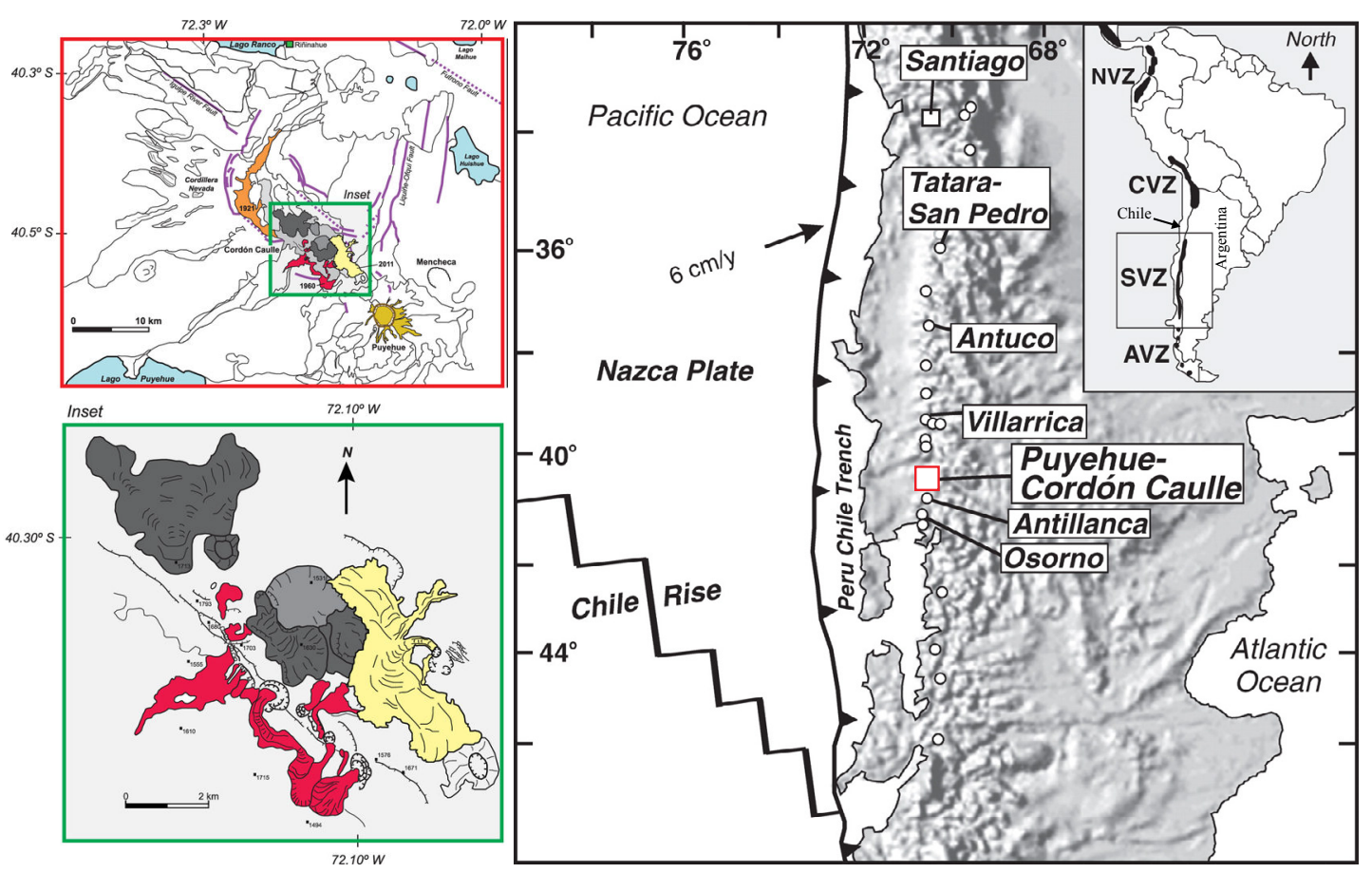

Fig. 1.1. Map of location and tectonic setting of the PCCVC with insets showing the 1921 (orange), 1960 (red), and 2011 (yellow) lava flows and accompanying vents (modified from Alloway et al., 2015; and Singer et al., 2008). 
is a dominant volcanic centre and its products include extensive lava flows, tephra-fall deposits, and ignimbrites (Gerlach et al., 1988; Stern et al., 2007). Geochronology from ${ }^{40} \mathrm{Ar} /{ }^{39} \mathrm{Ar}$ and ${ }^{14} \mathrm{C}$ indicate that eruptive activity began at ca. $500 \mathrm{ka}$ and that the three parts of the volcanic complex evolved from there as separate, but coeval entities. Activity in the last ca. 100 ka has been concentrated in the Cordón Caulle fissure and the Puyehue stratovolcano (Lara et al., 2006).

A striking feature of this system is the unusually large compositional range of eruptive products when compared to other volcanoes in the Southern Andes. Compositions in the southern section of the South American Andes ( $\left.35-55^{\circ} \mathrm{S}\right)$ are dominantly basaltic, both temporally and volumetrically, but compositions at Puyehue-Cordón Caulle have evolved away from this composition (Bertrand et al., 2014; Gerlach et al., 1988; Lara et al., 2006). Eruptions at the PCCVC in the last ca. $100 \mathrm{ka}$ have trended toward silicarich magmas whereas the observed eruption products at other Southern Andes volcanoes have retained low-silica basaltic to basaltic andesite compositions (Lara et al., 2006). Lara et al. (2006) and others have suggested a controlling influence imparted by local structure may be the cause of this anomalous compositional trend - compressive areas having more crustal influence as compared to tensional zones, where magmas would reach the surface with less residence time in the crust.

Historic (ca. 500 years) activity consists of eight relatively small (Volcanic Explosivity Index - VEI $\leq 2$ ) eruptions and three larger (VEI 3-5) eruptions, all centred in the Cordón Caulle fissure system of the PCCVC (Global Volcanism Program, 2013). The most recent eruption (Fig. 1.2) began on June $4^{\text {th }}$, 2011, after four decades of relative quiescence with only one small VEI 1 eruption (Global Volcanism Program, 2013; Lara et al., 2006; Singer et al., 2008). The Servicio Nacional de Geología y Minería (Chilean national geology and mining service - SERNAGEOMIN) reported an increase in seismic activity in the vicinity of Puyehue-Cordón Caulle in late April to early May of 2011, although no indication of increased volcanic activity was found (Global Volcanism Program, 2013;

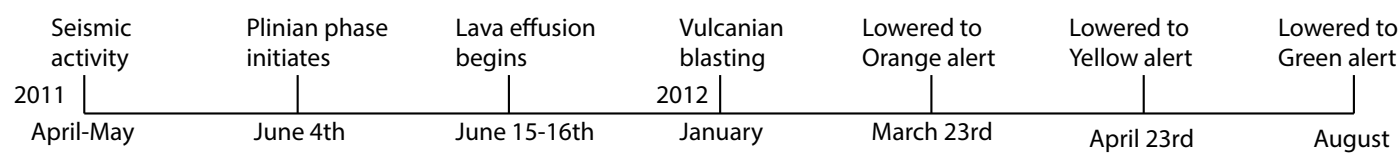

Fig. 1.2. Simplified timeline for the 2011-2012 Cordón Caulle eruption showing key eruptive phases and alert level changes given by Silva Parejas et al. (Silva Parejas et al., 2012). 
Silva Parejas et al., 2012). Roughly one month later Puyehue-Cordón Caulle violently burst into life with an initial phase of plinian to sub-plinian activity producing an ash and gas plume $5 \mathrm{~km}$ wide and $12.2 \mathrm{~km}$ tall (Castro et al., 2013b; Elissondo et al., 2016; Pistolesi et al., 2015; Schipper et al., 2013). Reports of dark skies, ash fall, and audible explosions came from $98 \mathrm{~km}$ southeast of the vent in Bariloche just four hours after the eruption initiated. By June $5^{\text {th }}$ the plume had spread as far as the Atlantic Ocean, about $1800 \mathrm{~km}$ east-south-east of the vent site (Elissondo et al., 2016). The size of the eruption column fluctuated over the proceeding $\sim 10$ days, ranging from 3 to $10 \mathrm{~km}$ in height (Bertrand et al., 2014). A second stage of eruption involving energetic lava effusion, coeval with a slightly reduced plume (4-6 km high) began sometime between the $15^{\text {th }}$ and $16^{\text {th }}$ of June and persisted for several months (Castro et al., 2013b; Elissondo et al., 2016; Silva Parejas et al., 2012). Pyroclastic sub-plinian fountaining declined to mixed ash- and gas-jetting with intermittent Vulcanian blasting in January 2012, whilst synchronous lava effusion continued (Pistolesi et al., 2015; Schipper et al., 2013). Authorities lowered alert levels for the eruption to orange on the $23^{\text {rd }}$ of March 2012, then to yellow on the $23^{\text {rd }}$ of April 2012 with the termination of pyroclastic ejections, and finally to green in August 2012 when SERNAGEOMIN reported an absence of ash emissions (Bertrand et al., 2014; Elissondo et al., 2016).

Exact volumes of ejected pyroclastic material remain poorly constrained. However, based on estimations of ejection volumes in the first $\sim 27$ hours $(0.5-1 \mathrm{~km} 3$; Bertrand et al., 2014; Silva Parejas et al., 2012), along with deposition volumes in Rio Negro and Neuquén (Argentina) in the first few weeks $\left(\sim 1.46 \mathrm{~km}^{3}\right)$, it is thought to be several $\mathrm{km}^{3}$ (Bertrand et al., 2014; Gaitán et al., 2011). Lava effusion volumes contributed a further $\sim 0.45 \mathrm{~km}^{3}$ over an area of $\sim 7 \mathrm{~km}^{2}$ (Bertin et al., 2012; Bertrand et al., 2014). The 2011-2012 Puyehue-Cordón Caulle eruption has since been classified as a VEI 5, making it the largest known eruption for this volcano (Pistolesi et al., 2015). Bertin et al. (2015) reported a maximum time-averaged discharge rate of $72.1 \pm 5.6 \mathrm{~m}^{3} / \mathrm{s}$, an average eruption rate for the opening twenty days of $50 \mathrm{~m}^{3} / \mathrm{s}$, and a mean eruption rate of $16.7 \pm 0.5 \mathrm{~m}^{3} / \mathrm{s}$. However, the measurements of Bertin et al. (2015) are based solely on the effusive phase products. The formula of Sparks (1986) and the plume altitude provide an estimate of the mass eruption rate, $7 \times 10^{3} \mathrm{~m}^{3} / \mathrm{s}$ at its maximum on June $5^{\text {th, }}$ and $2 \times 10^{3} \mathrm{~m}^{3} / \mathrm{s}$, at a more stable level on June $8^{\text {th }}$ (Bignami et al., 2014).

Magma chemistry was analysed by (Castro et al., 2013b), with their findings showing chemical homogeneity (within analytical error) in the Plinian phase pumice with a $\mathrm{SiO}_{2}$ content of $\sim 69.5$ wt.\% (Fig. 1.3). Furthermore, major and trace elements were reported to be identical, within analytical error, to the Puyehue-Cordón Caulle rhyolite produced in the 1960 eruption (Castro et al., 2013b). Groundmass glass composition deviates 
slightly from the bulk composition, showing marginally higher values for $\mathrm{SiO}_{2}$ and other major element oxides. Major element compositions for plagioclase-hosted glassinclusions in both pumice and lava samples are comparable to those of the groundmass glass (Castro et al., 2013b). Fourier Transform Infra-Red spectroscopy measurements of the volatiles in these inclusions shows that $\mathrm{H}_{2} \mathrm{O}$ is variable $(\sim 0.74-2.4$ wt.\%) and $\mathrm{CO}_{2}$ is a minor component at $\sim 40-70$ ppm (Castro et al., 2013b). Full geochemistry for the plinian pumice, lava, groundmass glass, and glass-inclusions can be found in Castro et al. (2013b), and further analyses can be found in Bertrand et al. (2014), and Alloway et al. (2015).

a

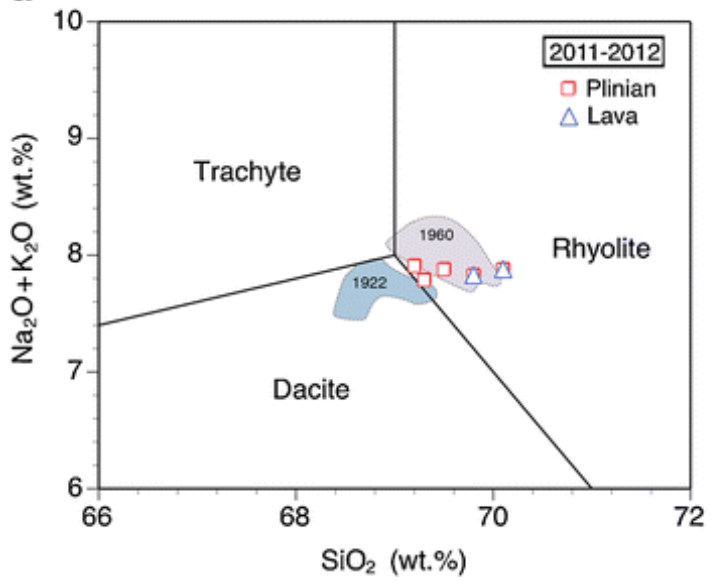

b

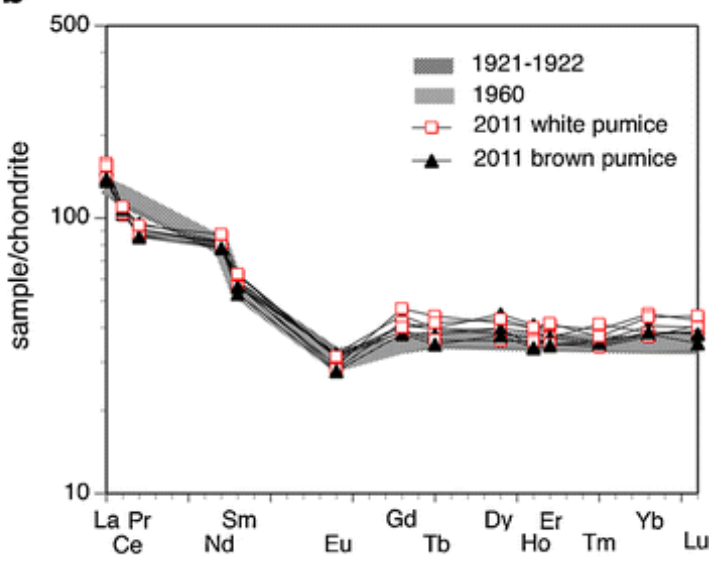

Fig. 1.3. Major element TAS diagram (a) and REE plot (b) of data for the 1922, 1960, and 2011 eruption products (from Castro et al., 2013b). Data for 1922 and 1960 eruptions is from Gerlach et al. (1988), 2011 data are from Castro et al. (2013b). 


\section{Chapter 2: General Background}

\subsection{Eruption Dynamics}

The behaviour observed during any volcanic eruption (Fig. 2.1) is largely the product of variations in properties such as decompression and degassing rates, crystallinity, and fluid dynamics in the conduit (Gonnermann and Manga, 2007). In other words, the processes relating to the nucleation and growth of gas bubbles in the magma exert an overarching control on the manner of an eruption (Navon and Lyakhovsky, 1998). The tectonic regime, magma composition, and conduit geometry also influence eruptions but to a lesser extent. In truth, all processes and magmatic properties present in a volcanic conduit are interconnected and collectively can be termed eruption dynamics (Gonnermann and Manga, 2007). Understanding the processes responsible for changes in eruption style at a given volcano has become central to volcanology, be it for transitions during one eruption or for a series of temporally spaced eruptions (Gonnermann and Manga, 2007).

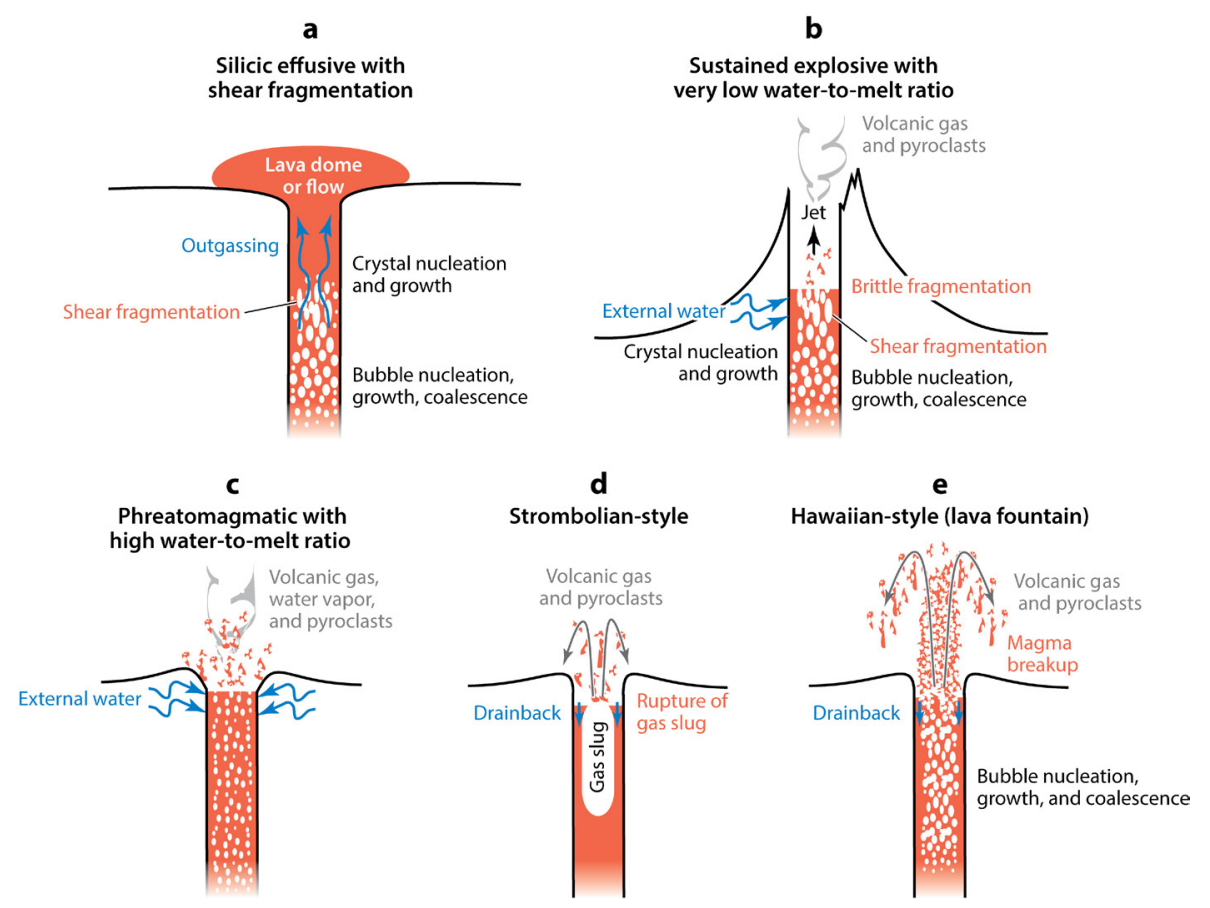

Fig. 2.1. Schematic examples of common eruption styles and the general mechanisms causing variations in style (from Gonnermann, 2015): (a) effusive silicic eruptions of high viscosity magma with an efficient outgassing mechanism, (b) continuous explosive eruptions with fragmentation caused by gas overpressure, (c) hydro-magmatic eruptions (also termed Phreatomagmatic) where fragmentation occurs through interaction with meteoric water or groundwater, (d) Strombolian eruptions caused by the rise of large gas slugs through low viscosity magma, and (e) Hawaiian-style, fire fountains. 
Volatiles (mostly $\mathrm{H}_{2} \mathrm{O}$ and $\mathrm{CO}_{2}$ ) are significant in eruptions as they are the driving force of volcanic eruptions. Exsolution of these volatile species from the melt creates buoyant gas bubbles, lowering a magmas bulk density whilst simultaneously increasing the viscosity, and consequently driving the ascent of a melt toward the surface (especially for highly viscous magmas). Under most circumstances magmas are thought to be saturated in volatiles, predominantly water, and bubbles form when these volatiles exsolve as the system attempts to attain chemical and thermodynamic equilibrium (Gonnermann and Manga, 2007; Mangan et al., 2004). Volatile solubility (Fig. 2.2), and therefore exsolution, is principally pressure dependent, with temperature changes being of secondary importance (Gonnermann and Manga, 2007; Holloway and Blank, 1994). In either case, the driving supersaturation pressure must be large enough to overcome the confining strength of surface tension, which may occur if decompression-driven solubility decrease outpaces rates of volatile diffusion into bubbles (Gonnermann and Manga, 2007). Critically, a melt with a large supersaturation pressure can nucleate and grow bubbles rapidly as it nears the surface, a condition which can lead to explosive eruptions (Gonnermann and Manga, 2003, 2007). Once bubble nucleation occurs it becomes a positive feedback loop, whereby bubbles increase buoyancy which drives magma ascent, thus driving the magma to lower pressures, in-turn increasing decompression and reducing volatile solubility, consequently further increasing exsolution and buoyancy (Gonnermann and Manga, 2007).

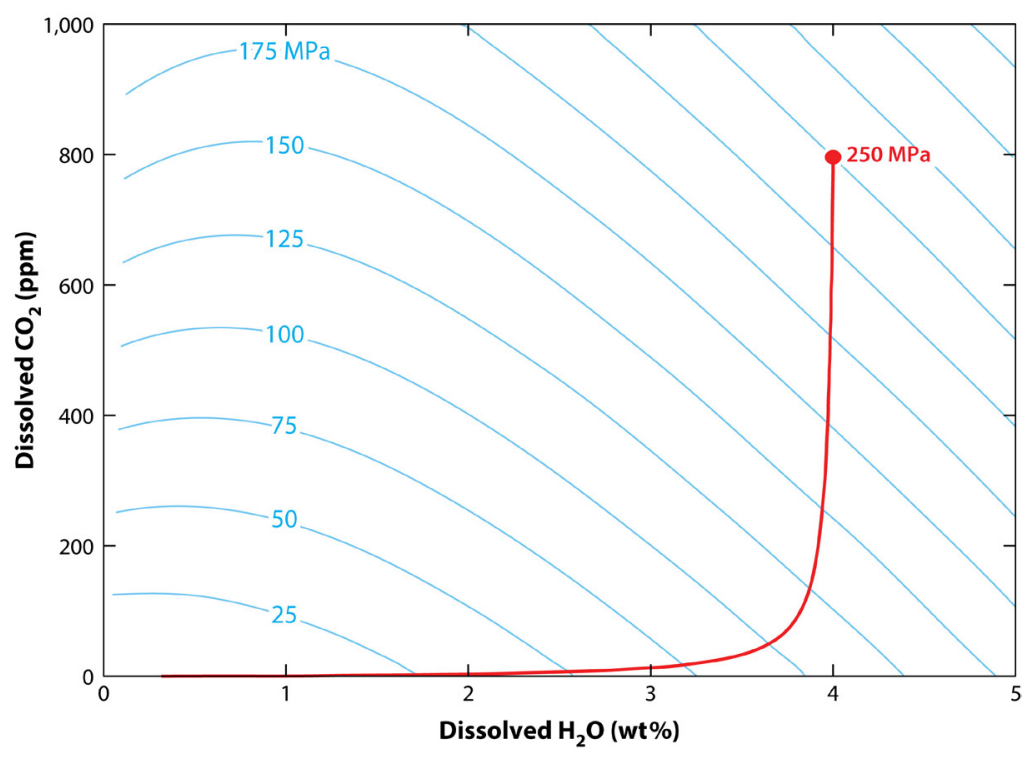

Fig. 2.2. Solubility for primary $\left(\mathrm{H}_{2} \mathrm{O}\right.$ and $\left.\mathrm{CO}_{2}\right)$ magmatic volatiles in a a rhyolite at $875^{\circ} \mathrm{C}$ (from Gonnermann, 2015). The blue lines are pressure isopleths and the red line traces a closed-system, equilibrium degassing path. The initial, almost vertical path indicates the rapid loss of $\mathrm{CO}_{2}$ with decreasing pressure. 
The defining principle of an explosive volcanic eruption is fragmentation (Fig. 2.3); the process by which a continuous melt (melt containing crystals and volatile domains) transitions to a discontinuous melt with a coeval and expanding volatile phase (Dingwell, 1996; Gonnermann, 2015; Gonnermann and Manga, 2003; Papale, 1999). The nature by which fragmentation affects the intensity of magmatic gas release and energy transformation in an eruption (conversion of potential to kinetic energy) is of particular consequence, with a potential for extensive impacts to societal health and wellbeing on a global scale (e.g., Horwell and Baxter, 2006; Self, 2006). Whilst effusive eruptions produce a (generally) lower consequence lava flow, the resultant products of explosive fragmentation are pyroclasts and ash of varying sizes that can be thrown great distances (Cashman and Scheu, 2015; Gonnermann, 2015). The mechanisms driving (primary) magmatic fragmentation fall into four distinct, but not mutually exclusive categories: (1) brittle fragmentation, (2) fragmentation by injection of water (phreatomagmatic

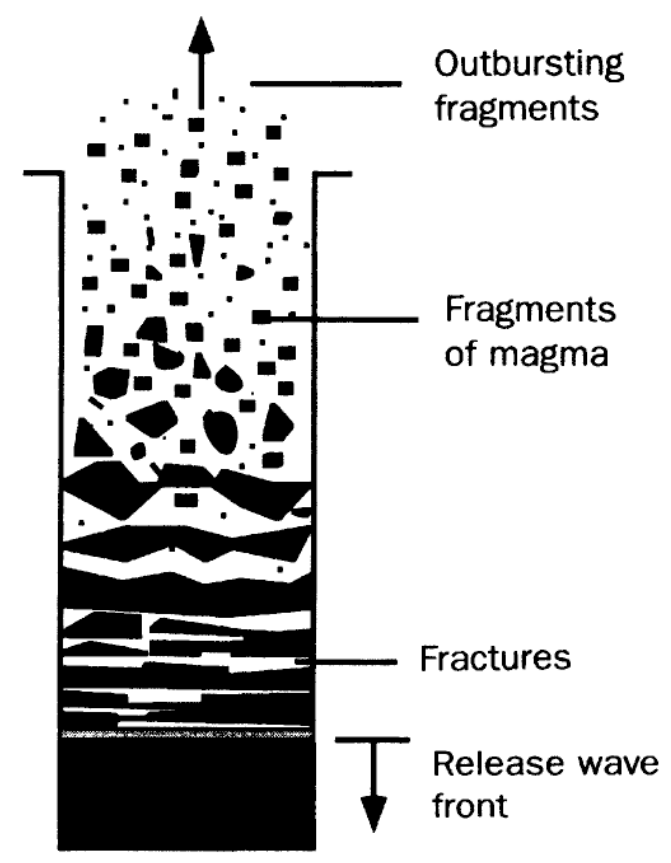

Fig. 2.3. Schematic illustration of decompression fragmentation in a high viscosity magma (from Alidibirov and Dingwell, 1996). The basal section of the column (below release from wave) roughly characterises the pre-fragmentation condition of the magma. Pre-fragmentation the magma would contain pores with a volatile pressure greater than that of the atmosphere. Upon exposure to atmospheric pressures (through dome collapse or landslide) a decompression wave propagates downward in the conduit, and as pressure is released from the pores the magma fragments. 
eruptions), (3) shear fragmentation, and (4) fluid-dynamic breakup (Gonnermann, 2015). Additionally, secondary fragmentation can occur as a result of collisions between pyroclasts during transport through the conduit, after ejection as they travel through the air, or in density currents along the ground (Cashman and Scheu, 2015; Gonnermann, 2015). Statistically, the larger the clast, the greater the likelihood of it being subjected to secondary fragmentation (Gonnermann, 2015). Furthermore, increasing transport time in a plume or conduit, post fragmentation, will increase the chance of secondary fragmentation (Gonnermann, 2015). Regardless, secondary fragmentation modifies the original size distribution of particles toward a smaller size fraction (Jones and Russell, 2017). The above notwithstanding, fragmentation is a process that is highly complex, needing to accommodate breakage of viscoelastic silicic melts that contain gas domains ( \pm crystals). As fragmentation operates within volcanic conduits during periods of highly explosive activity, there is limited opportunity to observe the process, which further compounds the difficulties of a detailed understanding (Blower et al., 2003; Gonnermann, 2015).

\section{Fragmentation Models}

Fragmentation models can be approached from two distinct perspectives (Fig. 2.4): (1) bottom up (acceleration), and (2) top down (decompression) (Cashman and Scheu, 2015; Fowler et al., 2010; Gonnermann, 2015). In the first case, ascent of magma driven by the injection of fresh, hot melt, leads to bubble expansion as the magma moves upwards through a decreasing pressure gradient. As bubbles expand they build overpressure that, if not released through permeable networks or fractures, will drive an increase in ascent speed, eventually erupting at the surface (e.g., Alidibirov and Dingwell, 2000; Cashman and Sparks, 2013; Gonnermann, 2015; Gonnermann and Manga, 2003; Mueller et al., 2008). The second perspective comprises a body of magma under some pressure (due to confining and lithostatic pressure) which is then exposed to a much lower atmospheric pressure through the disruption of a vent plug or collapse of a silicic dome (e.g., Alidibirov and Dingwell, 2000; Alidibirov and Dingwell, 1996; Cashman and Sparks, 2013; Fowler et al., 2010; Spieler et al., 2004). In this case the resulting pressure differential across the decompression boundary causes almost instantaneous expansion of bubbles and magma acceleration toward the area of lower pressure, in an effort to reach a pressure-equilibrium (Spieler et al., 2004). This decompression wave will propagate downward through the conduit until it reaches a point where bubbles are too few, and magma strength is sufficient to remain intact (Cashman and Scheu, 2015). That said, these models should be approached as endmember conditions, not mutually exclusive models, nor should they be considered perfect analogues of silicic fragmentation, as there is no possible way to directly observe such processes. The more 


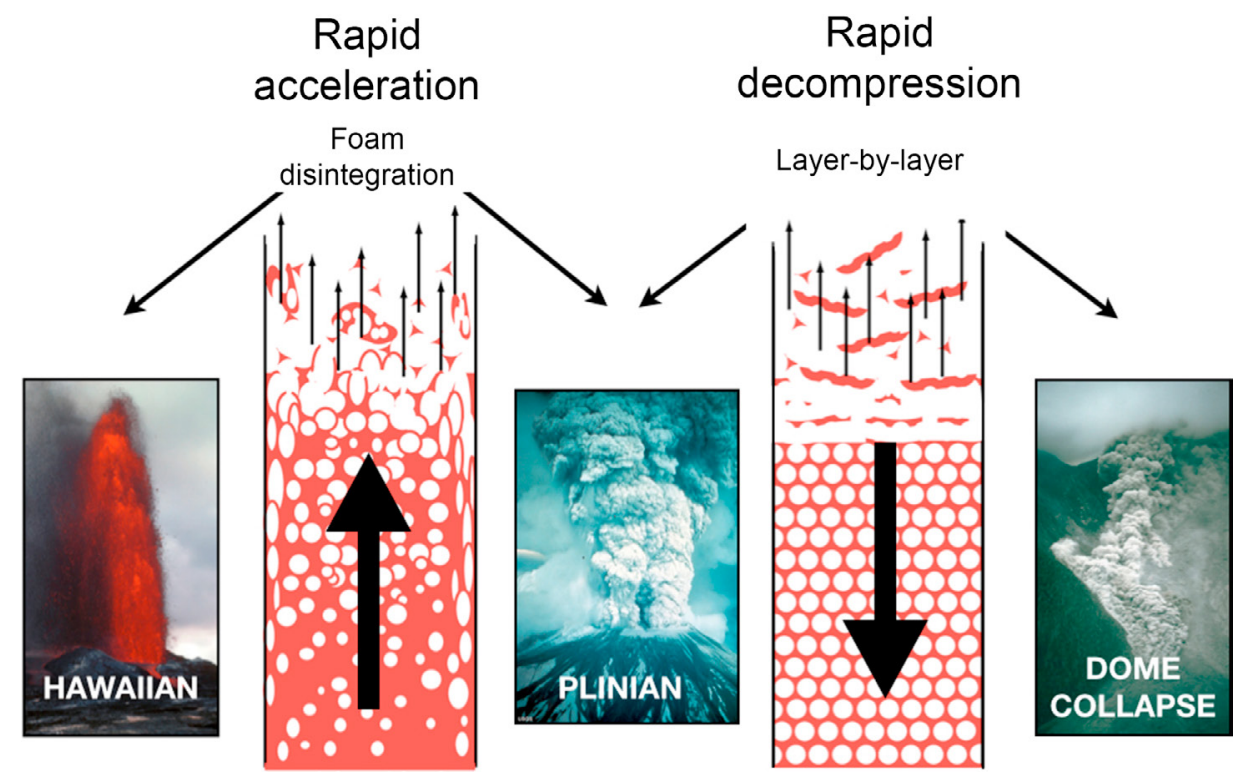

Fig. 2.4. Endmember fragmentation styles (Cashman and Scheu, 2015); acceleration of magma through volatile exsolution and subsequent buoyancy (left), and sudden decompression (i.e., dome collapse) releasing overpressure (right).

probable case is that some aspect of both endmembers coincide during fragmentation, regardless of the initial catalyst, possibly accompanied by some as yet unidentified processes. However, a paradoxical relationship exists between bubble nucleation, a primary driver of fragmentation, and brittle fragmentation of magma (Cashman and Scheu, 2015; Gonnermann, 2015). Bubble nucleation and fragmentation both require a large decompression gradient, but this cannot be sustained over substantial length scales. Furthermore, large decompression rates are thought to be associated with high viscosity, which relies on low concentrations of dissolved water (generally alluding to the presence of bubbles). Yet, for the significant rates of bubble nucleation, which are thought to be fundamental to fragmentation processes, large supersaturations of dissolved water in the melt are required. The codependence of these conditions is likely to be of fundamental importance to fragmentation and explosive volcanism, but the nature of the potential interdependency is obscured by conflicting requirements (Cashman and Scheu, 2015; Gonnermann, 2015).

Early work on the subjects of magma ascent and fragmentation suggested that a critical vesicularity between $60-80 \%$ defined the point at which fragmentation occurred (Gardner et al., 1996; Houghton and Wilson, 1989; Kaminski and Jaupart, 1997; Sparks, 1978). Recent work has shown this theory to be untrue, instead finding that fragmentation can occur at vesicularities significantly less than the assumed critical values, and conversely, that highly vesicular magmas can erupt effusively (Cashman and Scheu, 
2015). These more simplistic vesicularity criteria have been superseded by physical criteria for modern fragmentation models; bubble overpressure exceeding melt strength (overpressure condition; Fowler et al., 2010; Ittai et al., 2011; Koyaguchi et al., 2008), high velocity melt ascent causing fluid instabilities (inertia condition; Namiki and Manga, 2008), and high strain rate inducing brittle-like behaviour in the melt (strain condition; Dingwell, 1996; Dingwell and Webb, 1989; Papale, 1999). For high-viscosity fluids, high acceleration and/or strain rates will cause these melts to cross the glass transition (Fig. 2.5), thereby becoming brittle substances (Cashman and Scheu, 2015; Dingwell, 1996; Dingwell and Webb, 1990).

Fundamental to all three of the above fragmentation formulations is the relationship between the rates of structural relaxation and decompression in the system (Cashman and Scheu, 2015; Kameda et al., 2008). A silicic melt is largely composed of silica tetrahedra that undergo constant breaking and re-creation of Si-O bonds, termed structural relaxation, thereby accommodating stress and strain deformation (Gonnermann, 2015). However, if the applied stress to a silicic melt is sufficiently high over long timescales, the silica tetrahedra structure of the melt will be unable to recreate broken bonds, and thus will be unable to accommodate deformation (structural relaxation), instead failing in a brittle manner (Dingwell and Webb, 1989, 1990; Webb and Dingwell, 1990a, b). The ability of a melt to undergo this structural relaxation is further hindered by decreasing

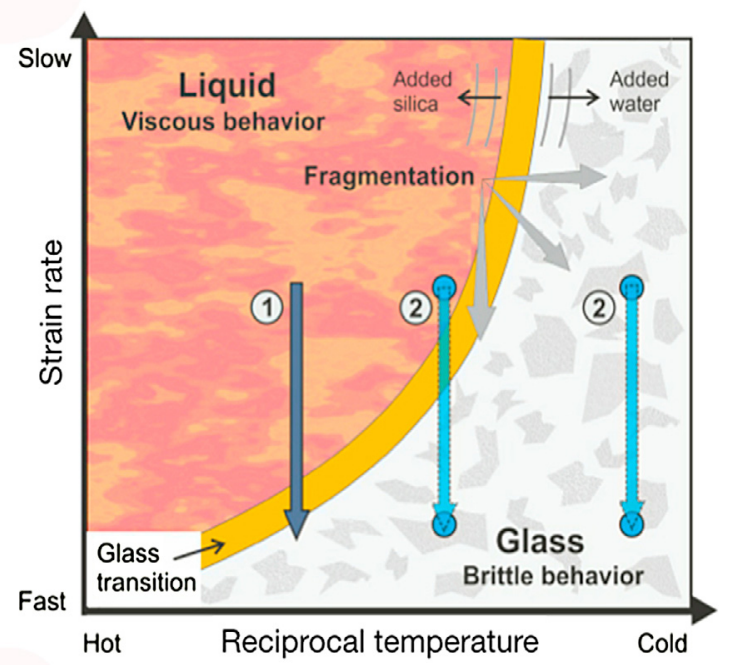

Fig. 2.5. Schematic representation of the glass transition (Cashman and Scheu, 2015). The glass transition will occur at higher temperatures if water is lost (i.e., viscosity increase) and/or strain rate is increased. The grey arrows indicate fragmentation pathways for cooling, increased strain, and a combination of the two. Blue arrows indicate fragmentation by: (1) rapid acceleration in a hot, low viscosity melt, and (2) rapid decompression in a cooler, higher viscosity melt. 
temperature, higher initial silica content, and decreasing dissolved water content, all of which lead to increased viscosity, and therefore a reduced capacity to accommodate deformation (Gonnermann, 2015).

\section{Explosive-Effusive Transitions}

The nature of, and mechanics of explosive-effusive eruptions (explosive activity transitioning to effusive activity) are poorly understood, in large part because few eruptions with this character have been observed (Castro et al., 2013b; Fink et al., 1992; Gonnermann and Manga, 2003; Saubin et al., 2016). Although touted as a semiregularly occurring phenomenon in rhyolitic eruptions (Gonnermann and Manga, 2003; Newman et al., 1988; Saubin et al., 2016; Villemant and Boudon, 1998) the 2008-2009 Chaitén eruption in Southern Chile was the first with this characteristic behaviour to be closely observed; the 2011-20012 Puyehue-Cordón Caulle eruption was the second (Castro and Dingwell, 2009; Castro et al., 2012c; Schipper et al., 2013). Moreover, the eruptions of Chaitén and Puyehue-Cordón Caulle challenge the general model presented in previous studies, wherein there is a single one-way transition from explosive to effusive. Both Chaitén and Puyehue-Cordón Caulle eruptions involved simultaneous ash-jetting, pyroclastic-blasting, and lava-effusion from a common vent (Castro et al., 2012c), requiring some form of cyclic or concurrent explosive and effusive activity.

Explosive eruptions violently eject a gas, ash, and pyroclast mixture from the vent at velocities approaching, or greater than the speed of sound (Wilson et al., 1980; Woods, 1995). Effusive eruptions on the other hand are comparatively quiet, and generally less hazardous, extrusions of lava. The driving processes of magma ascent are, in either case, much the same - pressure in the magma chamber initially drives magma into the conduit, and bubble growth, effected by volatile supersaturation as a result of decompression and crystal growth, increases buoyancy as the melt approaches shallow levels in the crust (Browne and Szramek, 2015). The critical difference between the two endmember eruption styles is the presence or absence of an effective outgassing mechanism (or fundamental differences in volatile contents), whereby effective outgassing permits a comparatively 'gentle' magma extrusion (Eichelberger et al., 1986; Schipper et al., 2013). 
Early ideas of the driving mechanisms behind transitions from explosive to effusive activity focused on volatile stratification in the conduit (Eichelberger and Westrich, 1981; Fink, 1983; Perret, 1935), and later, the permeable foam model of Eichelberger et al. (1986). The stratification model implies explosivity changes as a result of heterogeneous volatile distribution (Fink et al., 1992), whereas the permeable foam model proposes a more consistent distribution of volatiles; with efficient outgassing occurring when a tephra- or magmatic-foam-filled vent funnel is created during an initial explosive phase (Eichelberger et al., 1986; Fink et al., 1992). Furthermore, the model of Eichelberger and colleagues proposed that volatiles could be lost from a permeable foam through fractured and porous conduit walls (Fink et al., 1992). However, this would be applicable only where the host rock has a degree of permeability, due to composition (e.g., a permeable sandstone) or connected fracture-networks. Furthermore, models that propose stratification of magmatic volatiles in the conduit do not agree with petrological and mineralogical observations of products from some effusive-explosive eruptions (Fink et al., 1992). Aspects of these models are likely to be correct in some instances, however they do not provide a satisfactory mechanism for many transitioning eruptions (Fink et al., 1992). Moreover, for the case of hybrid eruptions, the stated mechanisms should be precluded, as they would need to act heterogeneously in the conduit (Castro et al., 2014; Schipper et al., 2013).

Recent work has brought to the forefront the idea of transient features; dome fractures, tuffisite veins, shear fragmentation, and melt fracturing are thought to temporarily accommodate degassing and reduce conduit overpressure (Cabrera et al., 2015; Castro et al., 2012b; Castro and Gardner, 2008; Edmonds and Herd, 2007; Saubin et al., 2016; Schipper et al., 2013; Tuffen and Dingwell, 2005; Tuffen et al., 2003). As magma reaches shallower levels in the conduit it will stiffen, as a result of volatile loss and crystallisation, thereby promoting the brittle failure required for such processes (Browne and Szramek, 2015; Burgisser and Degruyter, 2015; Castro et al., 2014; Gonnermann and Manga, 2003; Saubin et al., 2016). However, Castro et al. (2012b) noted that while fracturing in a rhyolitic melt could assist local marginal and lateral degassing, time-scales of fracture openings were too short (minutes to hours, e.g., Saubin et al., 2016) for sufficient diffusion of volatiles to relieve overpressure, unless fragmentation to millimetre sizes occurred pervasively. 


\section{Tuffisite Veins}

Tuffisite veins (Fig. 2.6) are characterised as fractures, within conduits, lava domes or host rocks (e.g., obsidian pyroclasts), that are filled with variably sintered pumice, ash, and other pyroclastic fragments, and form in response to small scale, shear-induced fragmentation (e.g., Castro et al., 2012b; Farquharson et al., 2017; Kendrick et al., 2016; Saubin et al., 2016; Tuffen et al., 2003). These features are common to both the 20082009 Chaitén and 2011-2012 Puyehue-Cordón Caulle eruptions, where overlap between disparate eruption styles has been observed (Castro et al., 2012b; Castro et al., 2012c; Saubin et al., 2016), and, combined with a common presence of ballistic pyroclasts during these eruptions, it is suggested that tuffisite veins and pyroclastic blasts are key to degassing processes (Castro et al., 2014; Castro et al., 2012c). Castro et al. (2014) used high precision $\mathrm{H}$-isotope and magmatic $\mathrm{H}_{2} \mathrm{O}$ measurements, alongside pyroclastic textures, to elucidate this relationship; their results showing a continuous wet (pyroclasts) to dry (lava) degassing trend in Chaitén samples. They propose that batch-degassing occurs, whereby pressure builds up while lava erupts effusively, and that, when a critical overpressure is reached, the tuffisite veins are forced open to relieve pressure through an explosive ejection of ash, gas, and pyroclastic bombs (Castro et al., 2014).

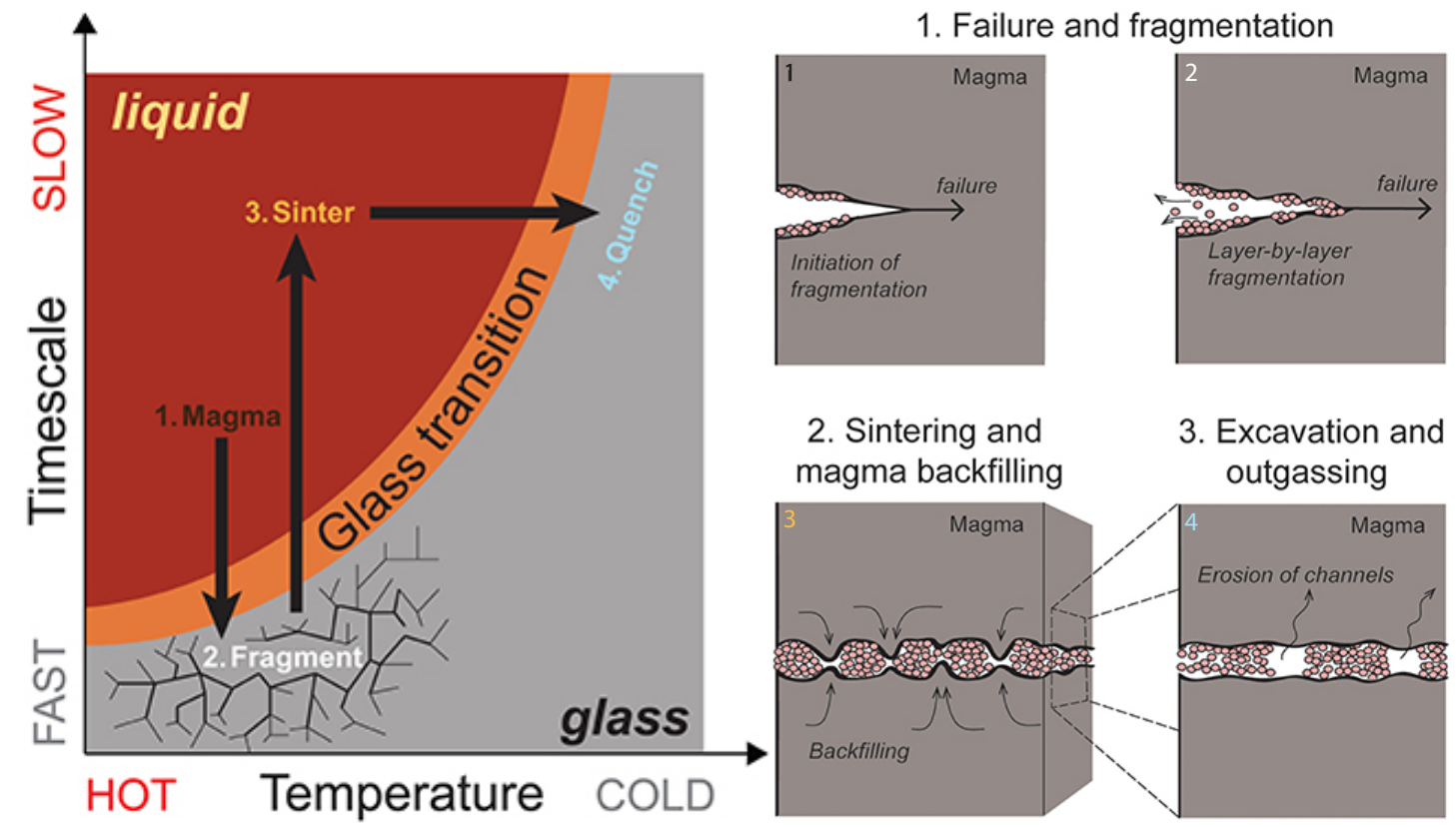

Fig. 2.6. Cartoon diagram of the basic model for tuffisite formation (Kendrick et al., 2016). 


\subsection{Vulcanian Eruptions and Bombs}

\section{Pyroclastic Rocks}

Pyroclasts are diverse; at a macroscopic level they differ in characteristics such as colour, shape, bulk density, and texture, whilst at microscopic levels they vary in absolute properties such as crystallinity, vesicularity, permeability, vesicle shape and size, as well as more abstract properties like bubble number-density (Polacci et al., 2003). Quantification of bulk properties and textures in pyroclastic rocks are used to elucidate the intricacies of magma ascent, fragmentation, vesiculation, the role of volatiles, eruption mechanisms, and post eruption modification (Houghton and Wilson, 1989; Klug et al., 2002; Polacci et al., 2003). One of the first observations of textural significance in volcanic rocks came in the eighteenth century; the French geologist Dolomieu recognised that pumice was the vesicular counterpart of obsidian (Cashman and Mangan, 1994; De Vivo et al., 2009; Krafft, 1993). George Scrope, of Britain, later recognised that magmatic fluids could provide the required energy for eruptions through expansion as a gas phase (Cashman and Mangan, 1994; De Vivo et al., 2009). As understanding and technological ability have advanced researchers have observed, quantified, and interpreted these volcanic textures in increasing detail (Cashman and Mangan, 1994). Howbeit, because direct observations of eruption conditions, fragmentation, degassing, or other conduit processes are difficult, we still rely heavily on the products of an eruption (e.g., Castro et al., 2013a; Castro et al., 2014; Hoblitt and Harmon, 1993; Mercalli and Silvestri, 1891; Miwa et al., 2013; Schipper et al., 2013; Wright et al., 2007; Yamagishi, 1991), experimental simulations (e.g., Cordonnier et al., 2012; Hurwitz and Navon, 1994; Lyakhovsky et al., 1996; Pope et al., 2016; Vasseur et al., 2013b), and numerical models of processes (e.g., Fowler et al., 2010; Ittai et al., 2011; Proussevitch and Sahagian, 1996; Proussevitch et al., 1993; Sahagian and Proussevitch, 1998; Thomas and Neuberg, 2014) to better understand the complexities of eruptions. However, experiments do not elucidate all the complexities of a natural system, and furthermore, the degree of preservation of textures in pyroclasts is relatively unknown; as is the relative contribution of secondary (post fragmentation) processes operating in the conduit and plume (Rotella et al., 2014). Consequently, a gap exists between our understanding of experimental textures and natural textures. Advances in technology and comprehensive observations during recent eruptions present opportunities to improve our understanding in this area. 


\section{Vulcanian Eruptions}

Vulcanian eruptions, which typically produce ballistic pyroclastic bombs, along with smaller pyroclastic fragments (e.g., ash and pumice), are intense, short lived eruptions, in the order of tens of seconds to minutes (Cashman and Sparks, 2013; Clarke et al., 2015; Gonnermann, 2015; Self et al., 1978; Woods, 1995; Wright et al., 2007). Mercalli and Silvestri (1891) defined and characterised Vulcanian eruptions on the basis of subtle differences between eruption styles at Vulcano in the Aeolian Islands and Stromboli volcano nearby (Clarke et al., 2015). Both eruptions were small to moderate in size, and explosions were intermittent. However, the eruptions at Vulcano were significantly louder, with darker ash clouds, lower vesicularity juvenile products, and ejections of ballistic breadcrusted bombs (Clarke et al., 2015). These Vulcanian eruptions are generally thought to be characteristic of intermediate (andesitic to dacitic) composition magmas. That notwithstanding, the type locality of Vulcano (Italy) is a predominantly rhyolitic volcano (Cashman and Sparks, 2013).

Early workers estimated maximum bomb ejection velocities of $\sim 600 \mathrm{~m} / \mathrm{s}$ for Vulcanian eruptions (Fudali and Melson, 1971; Self et al., 1978), a finding that precluded solely overpressure driven eruption mechanisms. Consequently, external water interaction was presupposed (Fisher and Schmincke, 1984; Francis, 1993; Melson and Saenz, 1973; Self et al., 1978; Woods, 1995). Recent work on ballistic velocity modelling indicates that ejection velocities are lower (estimated at $\leq 300 \mathrm{~m} / \mathrm{s}$ ) and can be achieved solely by conduit overpressure (on the order of 10-20 MPa), without the involvement of external water (Clarke et al., 2015; Fagents and Wilson, 1993; Isgett et al., 2017; Morrissey and Mastin, 2000; Wright et al., 2007). The common driver of overpressure is suggested to be a gas impermeable 'plug' of quenched, sintered, and welded magma in the upper conduit (Clarke et al., 2015; Morrissey and Mastin, 2000; Self et al., 1978), often formed in association with dome building eruption phases (e.g., Stix et al., 1997; Voight et al., 1999; Widiwijayanti et al., 2005). Phreatomagmatic Vulcanian eruptions, those produced by interaction of magma with ground water, still occur but are far less common (Clarke et al., 2015).

\section{Breadcrusted Bombs}

Vulcanian eruptions generate a variety of products: pyroclastic avalanches and flows, block and ash flows, distal ash deposits, and breadcrusted bombs, the latter being considered particularly characteristic of Vulcanian eruptions (Wright et al., 2007). Breadcrusted bombs (Fig. 2.7) attributed to purely magmatic origins (i.e., non-phreatomagmatic) are thought to be representative of the heterogeneity in the supposed conduit plug (Wright 

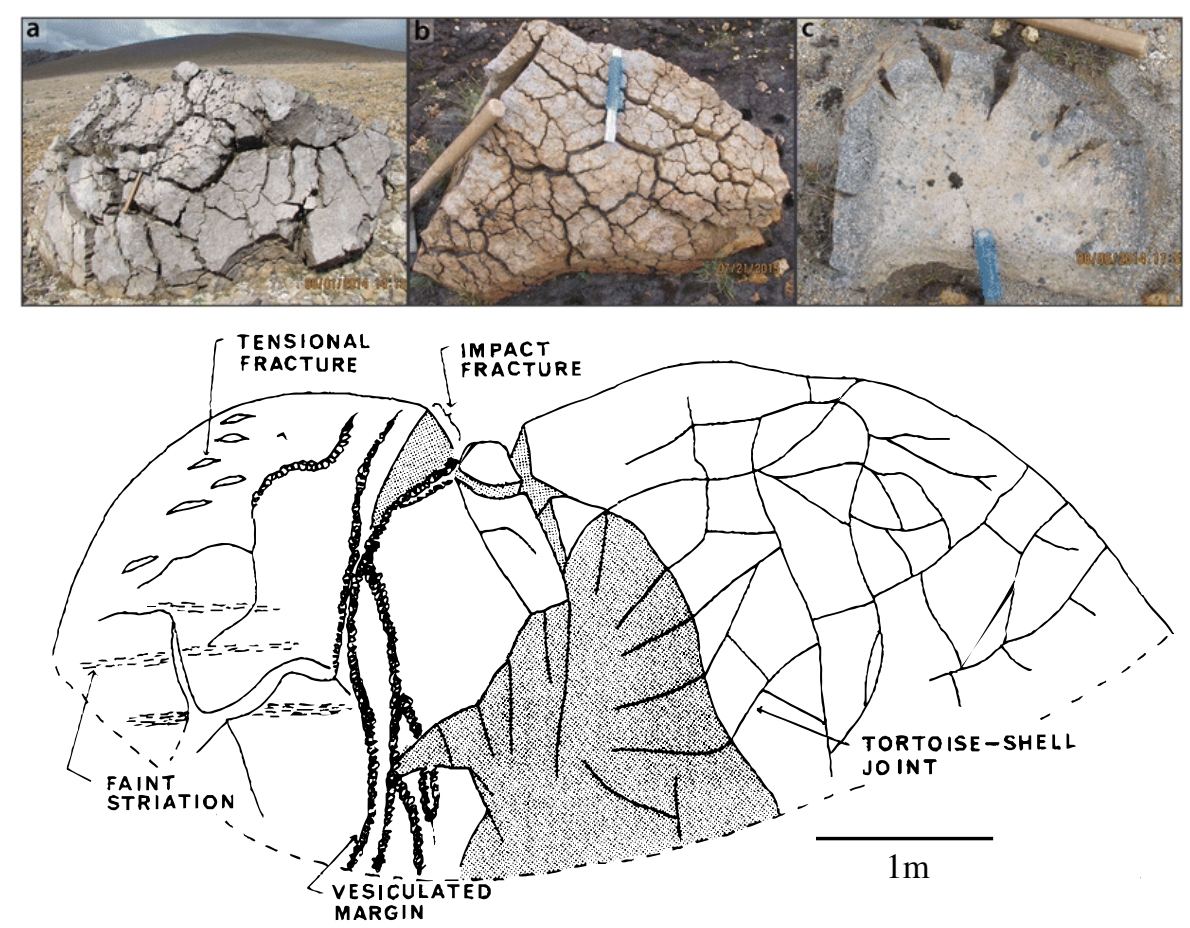

Fig. 2.7. Field examples of breadcrusted bombs (top; Isgett et al., 2017) and a schematic diagram of different fracture types present in breadcrusted rinds (Yamagishi, 1991).

et al., 2007). As such, they can provide information on the composition of the plug, processes operating out of sight, and the mechanisms of Vulcanian eruptions (Wright et al., 2007). However, the discussion surrounding the conduit mechanisms of bomb formation and generation of breadcrusted exteriors is ongoing and varied (Fig. 2.8). Walker (1969) suggested that changes in bomb textures were the result of different cooling times, and accompanying differences in viscosity. For the breadcrusting of pumice clasts ejected during the 1991 Pinatubo eruption, Polacci et al. (2001) suggested that high temperatures and low volatile contents were responsible. For breadcrust bombs produced from the 1980 cryptodome eruption at Mount St Helens, Hoblitt and Harmon (1993) invoked a pre-eruption degassing event, subsequently causing a delay in bubble nucleation during eruption, and thus accommodating the formation of a low vesicularity rind. Yamagishi and Feebrey (1994) accounted for a range a bomb textures from the 1988-1989 eruption of Tokachidake volcano, Japan, by positing that the conduit was stratified with regard to the degree of vesiculation and the distribution of vesicles within the zones of distinct vesicularity. A similar scenario was used to describe bombs produced by Vulcanian activity during the 1912 eruption of Novarupta, Alaska (Isgett et al., 2017). Despite the numerous interpretations for bomb formation, it is clear that identifying and describing the morphological features of bombs, along with quantitative measurements of $\mathrm{H}_{2} \mathrm{O}$ contents or other parameters, can provide an insight into the responsible eruption processes (Yamagishi and Feebrey, 1994). 

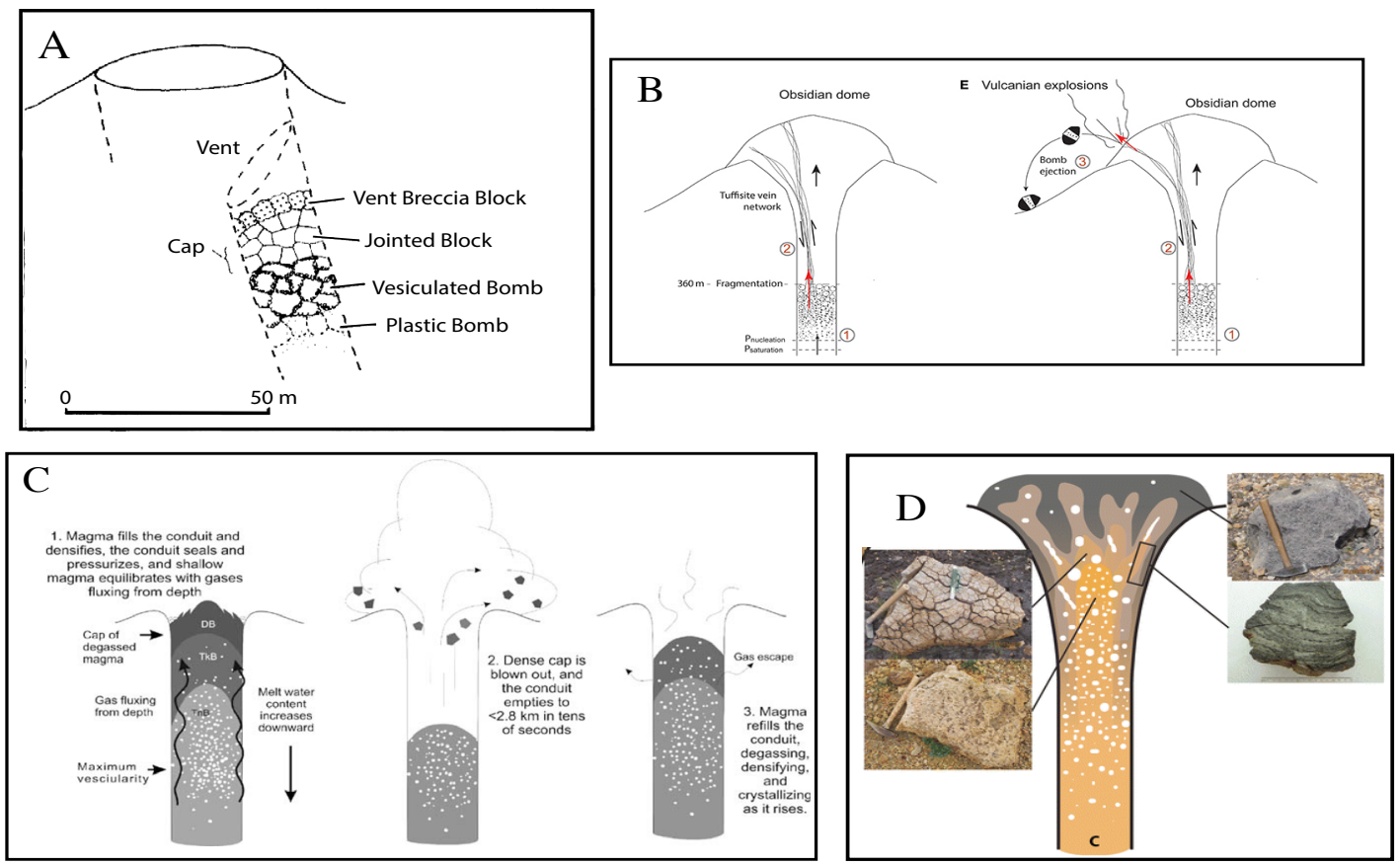

Fig. 2.8. Four models for the formation of breadcrusted bombs illustrating the changing ideas over time: (A) the stratification model of Yamagishi and Feebrey (1994), (B) tuffisite veins within an obsidian dome that act as bomb ejection and degassing pathways (Saubin et al., 2016), (C) a variation of the conduit stratification model (Wright et al., 2007), and (D) a complex architecture model (Isgett et al., 2017).

Studies have imputed breadcrusting (essentially a network of surface cracks) to (1) cracking of a quenched exterior as a result of interior expansion, (2) thermal contraction of a bomb exterior, or (3) impact stresses (Wright et al., 2007). That said, in any given situation there is likely to be a variable contribution of all three mechanisms. The style and extent of breadcrusting, along with the general bomb morphology, has been correlated with formation mechanism (expansion, contraction, impact), pre-fragmentation $\mathrm{H}_{2} \mathrm{O}$ content, delay time between eruption onset and interaction with surface air, transport regime, and conduit stratification (Benage et al., 2014; Giachetti et al., 2010; Wright et al., 2007; Yamagishi and Feebrey, 1994). Differences in surface crack morphology and crack depth relative to rind thickness can distinguish between breadcrusting mechanisms (Fig. 2.9). Wright et al. (2007) found that rectangular domains of deep, widely spaced cracks were associated with thick rinds, whereas thin rinds formed polygonal domains of shallow, closely spaced fractures. Similarly, Yamagishi and Feebrey (1994) found jointed 'tortoise-shell' breadcrust patterns in the products of both the 1926 and 19881989 eruptions of Tokachidake, Japan, comparing them to blocks described in Walker's (1969) study of the 1889 eruption of Vulcano, Italy. Radial fracture domains, transverse 
A Breadcrust bomb morphology:
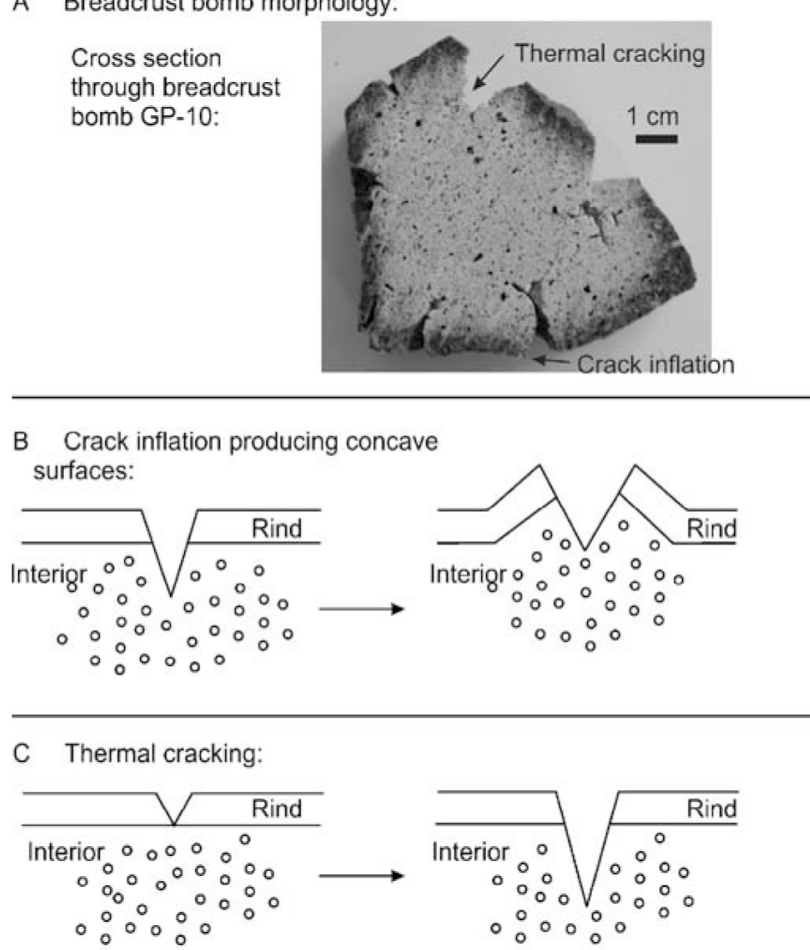

Fig. 2.9. The model of Wright et al. (2007) for the formation of breadcrusted rinds through crack inflation (B), and thermal cracking (C).

fractures, and 'petal-opening' patterns have been interpreted as the result of impact forces on solid and semi-solid bombs, where transverse fractures would be associated with impact forces on a solidified bomb (Wright et al., 2007; Yamagishi and Feebrey, 1994). If fracture depths exceed rind thickness in any given bomb, the implied mechanism is thermal contraction (Wright et al., 2007). This will occur as the bomb cools, and is assumed to begin after vesicle expansion has ceased; cracks could therefore extend into the vesicular interior of the bomb. Conversely, if vesiculation was still underway when these cracks formed, a vesicularity gradient should exist extending inward from the crack tip (Wright et al., 2007). Other studies have simply inferred that all polygonal tortoise-shell jointing style breadcrusting is the result of thermal contraction (e.g., Walker, 1969; Yamagishi, 1991; Yamagishi and Feebrey, 1994).

The formation of a low- or non-vesicular rind on a bomb with a vesicular interior indicates that a bubble nucleation delay must exist (Hoblitt and Harmon, 1993; Wright et al., 2007). That is to say, there must be a delay in the formation and growth of new bubbles during the ejection of bombs to allow the quenching of dense melt to generate the non-vesicular rind. However, syn-eruptive, post-fragmentation bubble growth is largely viscosity controlled, and is therefore considered of lesser importance in silicic 
melts with viscosities $>10^{8}-10^{9} \mathrm{~Pa}$ s (Gardner et al., 1996; Giachetti et al., 2010; Thomas et al., 1994). Nevertheless, Giachetti et al. (2010) attribute all small vesicles (<10's of $\mu \mathrm{m})$ in the breadcrust bombs of the 1997 Soufrière Hills eruption to syn-eruptive growth, as evidenced by their abundant presence in bomb interiors where syn-eruptive expansion is unequivocal. The presence of vesicle-free groundmass within the rinds of coarsely breadcrusted bombs further supports this idea, implying a dense and essentially nonvesicular initial state of the material (Giachetti et al., 2010). Moreover, vesicles within this size limit were found to be highly spherical, and generally isolated, consistent with a rapid period of nucleation and expansion prior to quenching (Giachetti et al., 2010).

\section{Vesicularity in Pyroclasts}

Vesicularity in a volcanic pyroclast is a physical manifestation and measure of the exsolution, expansion, and coalescence of magmatic volatiles during the ascent, expulsion, and deposition phases of an eruption (Cashman and Mangan, 1994; Cashman and Sparks, 2013; Castro et al., 2012a; Gardner et al., 1996; Giachetti et al., 2010; McIntosh et al., 2014). Vesicle size and shape are extremely variable, even within a single sample. A bubble will nucleate as a small, essentially spherical domain of gas within a body of magma when volatiles (predominantly $\mathrm{H}_{2} \mathrm{O}$ and $\mathrm{CO}_{2}$ ) exsolve from a volatile supersaturated magma (McIntosh et al., 2014). At this early stage, the bubbles spherical shape is retained as a result of surface tension (Kennedy et al., 2016). Bubble growth occurs by the combined processes of volatile diffusion, from the melt into the nucleated bubble, and expansion resulting from decompression (Castro et al., 2012a; McIntosh et al., 2014; Proussevitch et al., 1993). Importantly, a volatile mixture at supercritical conditions has a far greater capacity for compression than any associated magma, therefore providing the necessary conditions for rapid volume increase (Gonnermann, 2015). As bubbles evolve they may also coalesce (amalgamate or 'come together'), either statically by bubble wall thinning, or dynamically as the buoyant bubbles rise through a magma and collide with one another (Cashman and Mangan, 1994).

\section{Vesicle Coalescence}

Timescales for coalescence are heavily dependent on magma viscosity, volatile diffusion rates, the original distribution of nucleation sites, and the density of bubbles and/or nucleation sites. These are in turn controlled by the magma composition, temperature, and pressure, all of which can change significantly during magma ascent and storage. However, regardless of the method or timescale, coalescence serves to reduce the total number of bubbles while increasing the average bubble size. Coalescence through bubble wall thinning and film rupture is an inevitable consequence of the expansion of 
a volatile phase within a magma (Cashman and Mangan, 1994), and has traditionally been viewed as the expansion of two adjacent bubbles driving interstitial fluid away from the interstice of the bubbles to either side due to an increasing pressure differential (Cashman and Mangan, 1994). As a result of liquid flow away from the interstice, bubble walls or films are progressively thinned, eventually reaching a critical point at which film rupture will occur. However, more recent work by Castro et al. (2012a), on the bubble-bubble interactions that drive coalescence, suggests that, in high viscosity melts, the most efficient coalescence occurs where bubble-bubble interstices are thinned by stretching rather than by fluid drainage. (Fig. 2.10) This is an important distinction because there are significant differences in the timescales of coalescence for these processes, with the latter being considerably faster (Castro et al., 2012a). The difference in process timescales lies in the behaviour of the bubble-melt boundary; static in the former and shifting in the latter (Toramaru, 1988). Furthermore, extreme instances of film thinning and rupture can also lead to a complete collapse of the foam structure (Cashman and Mangan, 1994).
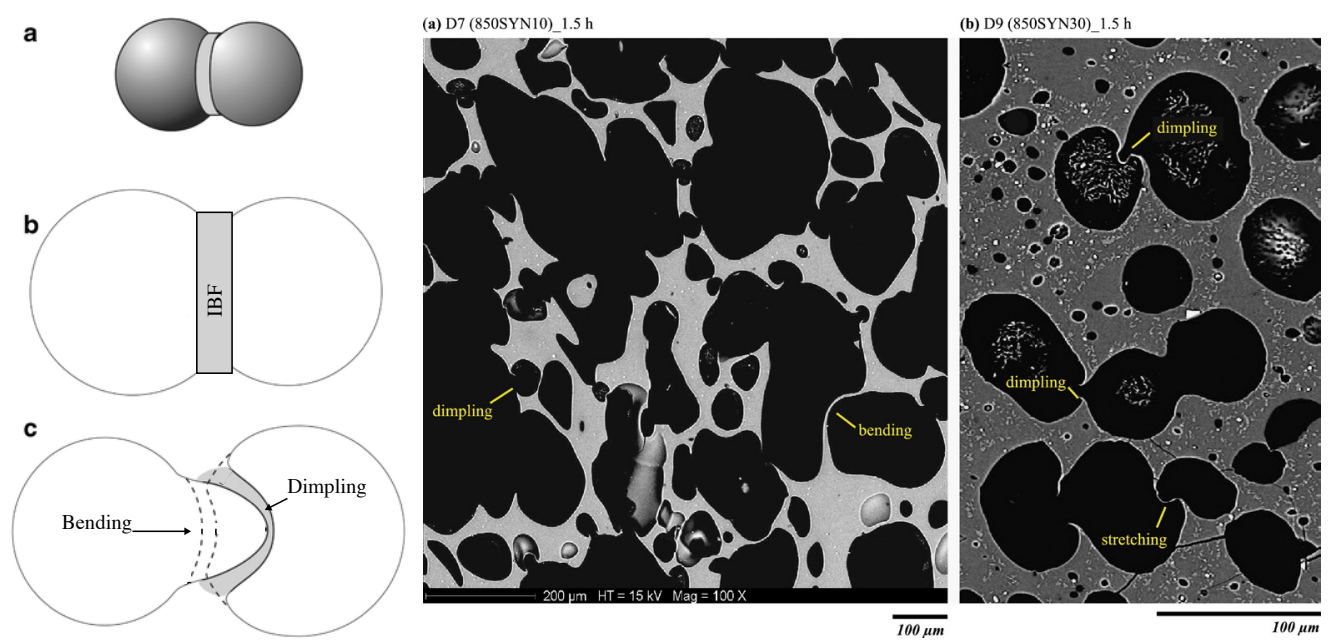

Fig. 2.10. Diagram of coalescence (Castro et al., 2012a); a) planar melt-film showing no deformation, b) cross section of a), and c) advancing deformation with the initial bending shown by dashed lines. The greyscale images show the bending and dimpling in c) as real features in a decompressed sample (Martel and Iacono-Marziano, 2015). 


\section{Vesicle Deformation}

The size and shape of vesicles, preserved in a volcanic pyroclast, provide clues to the nature and extent of aforementioned processes (Rust et al., 2003). Elongation of vesicles, defined by measuring the length to width aspect ratio, is generally indicative of some degree of deformation (e.g., Gardner et al., 2017). Rapid magma expansion, as would be expected in the event of rapid decompression, is expected to produce somewhat homogeneous elongate vesicles (Klug et al., 2002). Conversely, shear strain deformation, caused by interaction of a magma with the conduit wall rock, might instead be anticipated to produce a highly deformed population of vesicles, with some elongation (Klug et al., 2002). At the other end of the deformation spectrum is collapsing or flattening of vesicles. As mentioned above, this can occur when bubble films rupture, and the integrity of the foam structure is compromised (Cashman and Mangan, 1994). The shape of vesicles is therefore an indication of the strain and decompression history of the magma during ascent, eruption, and deposition (Cashman and Mangan, 1994; Herd and Pinkerton, 1993; Saubin et al., 2016). Changes in vesicle surface area are also related to the shape change that is driven by expansion and deformation; surface area increasing as volume increases. That notwithstanding, surface area changes are used to indicate magmatic-foam maturity (Cashman and Mangan, 1994; Herd and Pinkerton, 1993), rather than deformation forces.

\section{Volcanic Sintering}

Sintering is a common phenomenon in volcanic environments, occurring when granular substances (i.e., ash and volcanic particles) are heated to near melting point (Mackenzie and Shuttleworth, 1949), but its importance in volcanoes has only recently become the focus of detailed study (Heap et al., 2014; Quane and Russell, 2005; Vasseur et al., 2013b; Wadsworth et al., 2016a). Ignimbrites, tuffisite veins, shallow conduits, lava flows, lava domes, pyroclasts, and pyroclastic flows can all undergo sintering given sufficient temperature and time (Cabrera et al., 2015; Sparks et al., 1999; Stasiuk et al., 1996; Tuffen and Dingwell, 2005; Tuffen et al., 2003). Crucially, sintering can affect the outgassing capacity of a volcanic system by 'healing' conduit fractures thought to act as permeable pathways for gas escape (Castro et al., 2014; Farquharson et al., 2017; Gonnermann and Manga, 2003; Kendrick et al., 2016; Saubin et al., 2016; Tuffen and Dingwell, 2005). Recent studies have looked to quantify the kinetics and timescales of sintering in volcanic environments with the aim of understanding how this process 
might contribute to explosive volcanism and explosive-effusive transitions (e.g., Castro et al., 2012b; Farquharson et al., 2017; Heap et al., 2014; Kendrick et al., 2016; Quane and Russell, 2005; Tuffen et al., 2003; Vasseur et al., 2013b; von Aulock et al., 2014; Wadsworth et al., 2014; Wadsworth et al., 2016a; Wadsworth et al., 2016b).

Fundamentally, sintering can be said to involve two key processes, (1) particles weld together whilst pores between particles becomes more spherical, and (2) the density of the granular substance increases (Mackenzie and Shuttleworth, 1949). At the time of initial deposition, particles form a granular pack with high interconnected porosity (Wadsworth et al., 2014; Wadsworth et al., 2016a), and with sufficient heat (approaching glass transition temperature), neighbouring particles can undergo a form of consolidation as a result of interfacial tension between the particles and the interstitial pore-space fluid (Wadsworth et al., 2016a). Viscous sintering, commonly invoked for volcanic systems (Quane and Russell, 2005; Wadsworth et al., 2014; Wadsworth et al., 2016b), follows this general condition in a three stage process (Fig. 2.11): (1) viscous necks join melt droplets at contact points, forming a connected pore network, (2) the interconnected pore network undergoes collapse and further coalescence, (3) pore interconnectivity is superseded by a framework of isolated pores suspended in the melt (Vasseur et al., 2013a; Vasseur et al., 2013b).
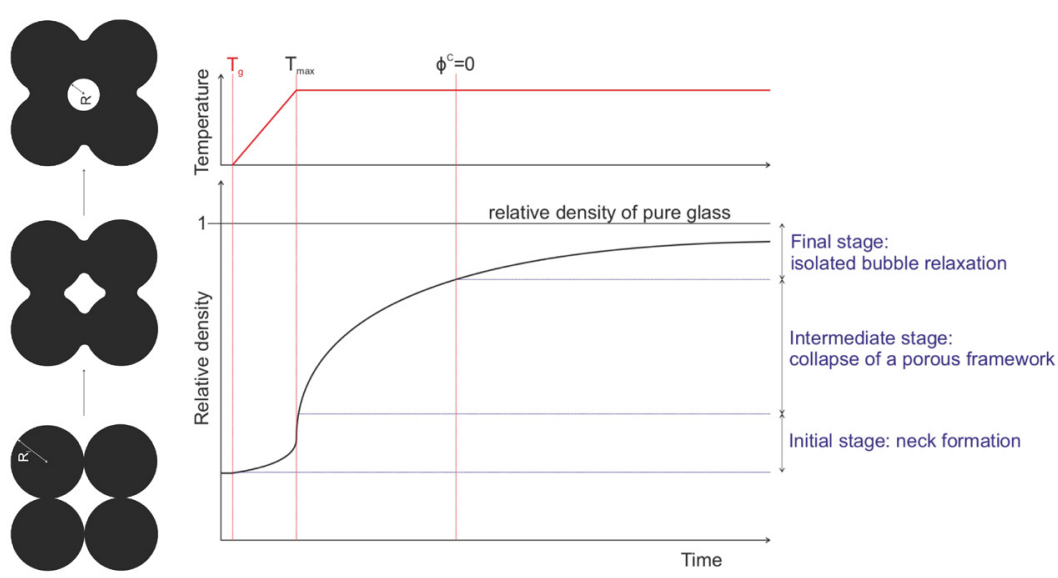

Fig. 2.11. Schematic representation of the viscous sintering process (Vasseur et al., 2013a). Density increases with increasing time and temperature through three stages: viscous neck formation, pore network collapse, and isolated bubble relaxation. 


\section{Sintering Dynamics}

In a simple isothermal system sintering kinetics and timescales are primarily dependent on particle size and melt viscosity (Wadsworth et al., 2014). However, the kinetics and timescales of sintering in volcanic environments have several additional complexities (Wadsworth et al., 2014). The presence of water (meteoric or magmatic) lowers the viscosity of a melt, which in turn is found to significantly lower the required temperature and time for sintering (Sparks et al., 1999; von Aulock et al., 2014; Wadsworth et al., 2014). The experiments of von Aulock et al. (2014) also found that measurable amounts of water were resorbed into the sintering materials (soda-lime silica glass beads) over short timescales ( $\geq 2$ hours; von Aulock et al., 2014), which significantly expedites sintering (Sparks et al., 1999). Conversely, degassing at ash particle surfaces will impede sintering, due to the viscosity increase of melt particles through volatile loss (Wadsworth et al., 2014). Sintering in a volcanic system will also involve temperature variations (i.e., non-isothermal), generally with the passage of time and as a result of some process (i.e., cooling by conduction, fragmentation, and transport, or heating by conduction, friction, and strain; Cordonnier et al., 2012; Lavallée et al., 2014; Wadsworth et al., 2014). Applying pressure in sintering experiments, appropriate for confining and gravitational pressures and/or deviatoric stresses in a volcanic system, is found to shorten sintering and densification timescales (Quane and Russell, 2005; Wadsworth et al., 2014). Furthermore, in volcanic systems, viscous sintering is most commonly seen in deposits were there is a high volume fraction of vitric and pumiceous juvenile clasts (Heap et al., 2014). This material has a higher propensity for viscous sintering than other more crystalline and/or degassed volcanic particles (Heap et al., 2014). Nevertheless, Heap et al. (2014) found that high crystallinity block and ash flow clasts could sinter under conditions of high eruptive discharge, at greater than glass transition temperatures. Their study highlighted the importance of insulating thicknesses to preclude significant cooling, and stress to shorten timescales of viscous sintering. 


\subsection{Magma Mixing and Mingling}

Mixing or mingling of magmas with distinctly different composition has been accepted as a frequently occurring (Anderson, 1976; Bacon, 1986; Kuşcu and Floyd, 2001; Sparks and Marshall, 1986) and important phenomenon in the evolution of magmas (Bunsen, 1851; Kuşcu and Floyd, 2001; Spera et al., 2016; Wilcox, 1999). Evidence for mixing of magmas (Fig. 2.12) in a volcanic, rather than plutonic, system, is given by the eruptions of compositionally mixed pumice (Bacon, 1986; Eichelberger, 1980; Eichelberger et al., 2000), heterogeneities in pyroclasts (Bacon, 1986; Kuşcu and Floyd, 2001; Wilcox, 1999), and melt inclusions in crystals (Anderson, 1976; Donaldson and Brown, 1977; Dungan and Rhodes, 1978). In simple terms, mixing (or hybridisation) is invoked where two or more magmas have homogenised (chemically mixed) to form a new hybrid magma (Bacon, 1986; Dias and Leitch, 2015; Spera et al., 2016). Alternatively, where two or more magmas exist together in a heterogeneous state (physically mixed), resulting in a

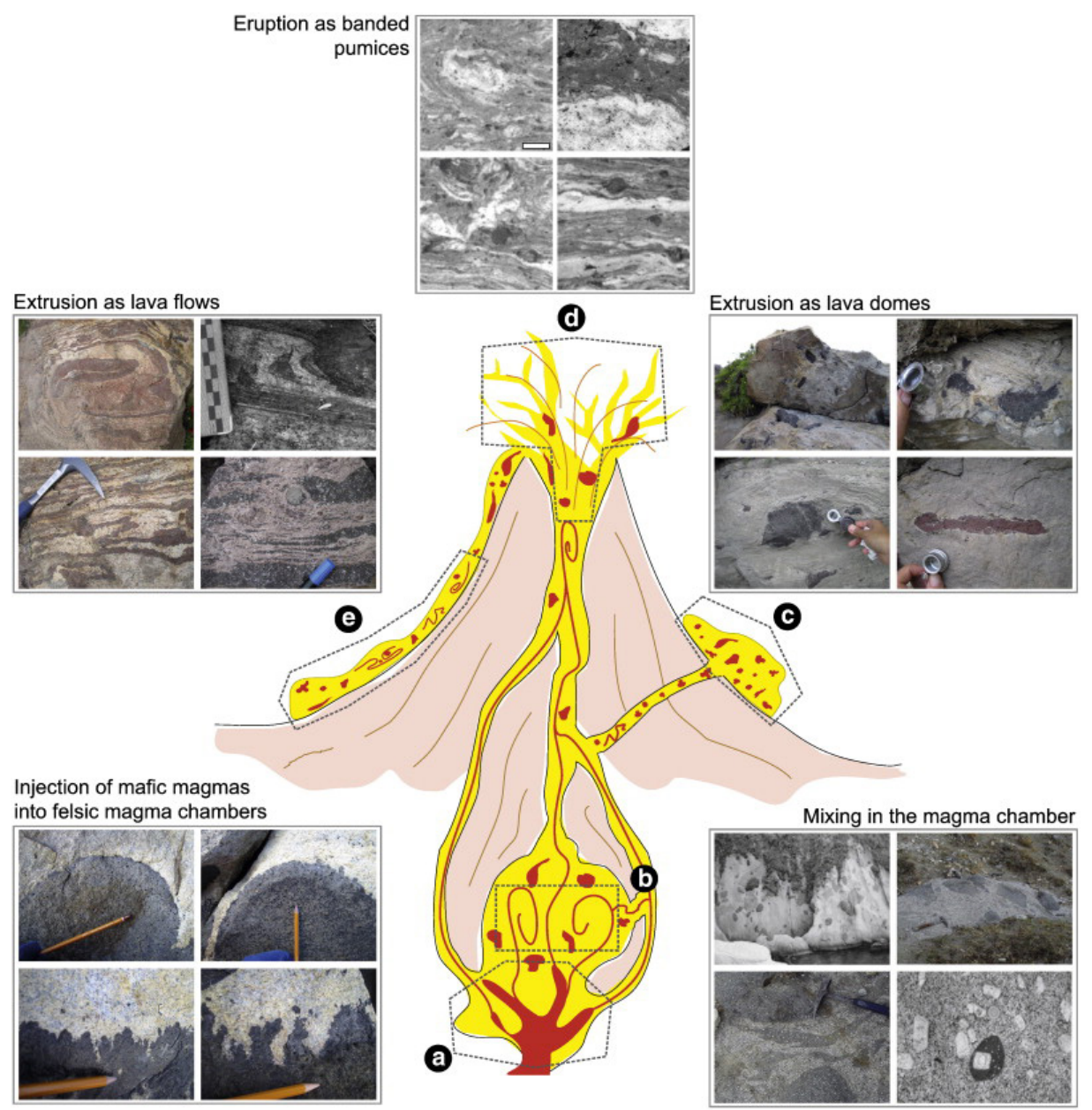

Fig. 2.12. Illustration of some common magma mixing and mingling processes, and their respective products (Perugini and Poli, 2012). 
rock with bands, enclaves, or intrusions of chemically distinct components, mingling (or commingling) is applied (Bacon, 1986; Dias and Leitch, 2015; Kuşcu and Floyd, 2001; Sparks and Marshall, 1986; Spera et al., 2016). Mingling and mixing can be considered the end-member processes of magma-magma interactions (Spera et al., 2016). Two compositions could be irreversibly blended (complete mixing), have no chemical interaction whatsoever (mingling), or undergo a degree of interaction through solid-state element diffusion, while retaining some heterogeneity (mingling with some mixing) (Sparks and Marshall, 1986). The mingling magmas may both have the same basic composition (e.g., two andesites), or may sit at completely opposite ends of the compositional spectrum (e.g., a basalt and a rhyolite) (Sparks and Marshall, 1986). That said, pure magma mingling (i.e., sans chemical exchange) in natural systems is purportedly rare, attributed to the increasing probability of chemical exchange as inclusions decrease in size (Perugini and Poli, 2012). Moreover, mixing and mingling do not explicitly require the interaction of two endmember magmas (i.e., basalt and rhyolite); these processes could occur in a system that has undergone fractional crystallisation, partial melting, assimilation, or other such petrological processes (Perugini and Poli, 2012).

The ability of, or timeframe required for, two magmas to mix, either partially or completely, is thought to be largely dependent on compositional contrasts (i.e., differences in density, viscosity, rheology; Fig. 2.13), where increasing compositional and or density contrast decreases the likelihood of complete mixing (Laumonier et al., 2014a; Melekhova et al., 2013; Semenov and Polyansky, 2017; Sparks and Marshall, 1986). That notwithstanding, the idea that magma hybridisation is achievable only at, or is more feasible at, low viscosity contrasts (Sparks and Marshall, 1986) has not been definitively proven with real magmatic mixtures (Laumonier et al., 2014b). Additionally, the intensity and geometry of mixing at a given volcano are important to the final product (Dias and Leitch, 2015; Melekhova et al., 2013). Disequilibrium textures such as reverse crystal zonation, crystal resorption, and conspicuously wide mineral assemblage ranges, have been found in many porphyritic magmas of andesitic to dacitic composition (Couch et al., 2001). However, disequilibrium features could also be interpreted as convective self-mixing or stalling during ascent (among other things) of a single magma, and the presence of a distinct second composition may be the result of inclusion of conduit wall rocks from older eruptions. A variety of textural and geochemical approaches to decode the origin of these features now exist, aiding any subsequent interpretation of the rocks containing said features. 


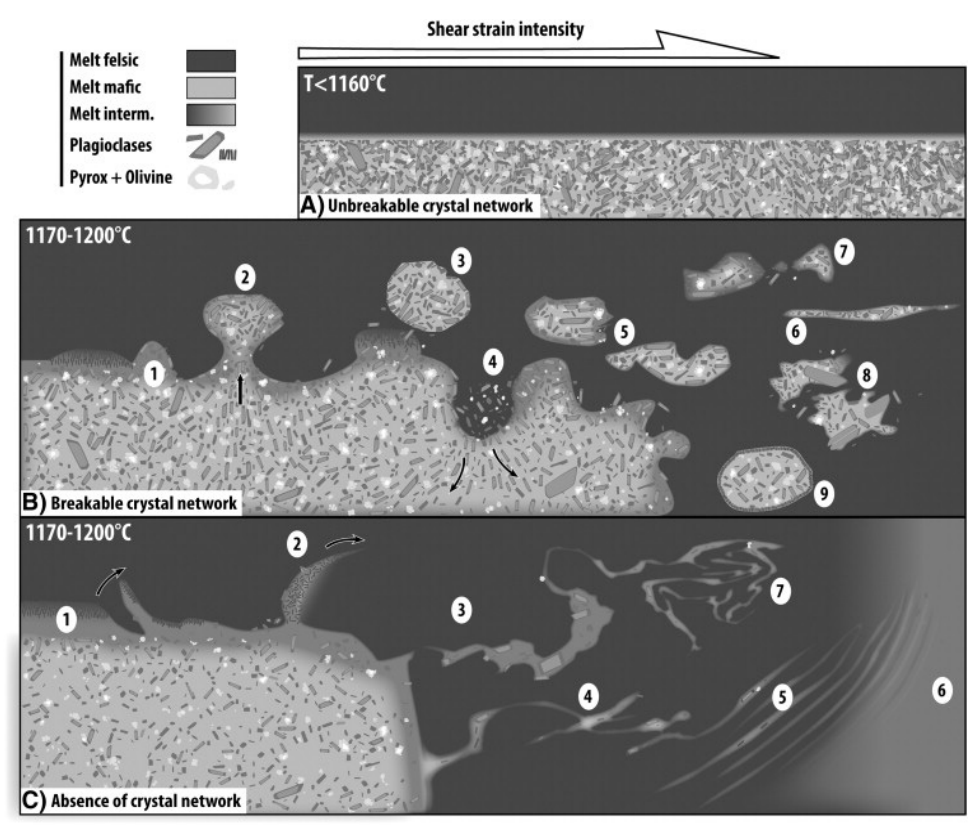

Fig. 2.13. Illustration of the relationship between mixing/mingling and magma strength in torsion experiments (Laumonier et al., 2014a). In A) the strength imparted by the interlocking crystal network prevents mingling, in $B$ ) the crystal network is breakable and mingling occurs, and in $C)$ both mixing and mingling are seen due to the lack of a coherent crystal network.

\section{Mixing and Mingling Textures}

Eichelberger (1980), Kuşcu and Floyd (2001), and Perugini and Poli (2012) provide criteria for identification of mixing and mingling in three distinct categories, based on a review of work by many authors: (1) petrographic identification of mixing/mingling using mineral disequilibrium textures such as embayed edges, sieve textures in plagioclase, and juxtaposition of chemically distinct mineral phases (e.g., Dungan and Rhodes, 1978; Stimac and Pearce, 1992; Tsuchiyama, 1985), (2) textural identification using the presence of ellipsoidal enclaves of mafic material (e.g., Bacon, 1986; Bacon and Metz, 1984; Feeley and Dungan, 1996; Stimac et al., 1990), and (3) geochemical identification through the presence of mineral compositions at odds with the rock composition, crystal zoning (reverse, oscillatory, and reverse and normal in one sample), and strong compositional changes in minerals from core to rim (e.g., Heiken and Eichelberger, 1980; Luhr and Carmichael, 1980; Nakada, 1991; Sakuyama, 1981; Wallace and Carmichael, 1994).

Texturally, a magmatic (rather than lithic or xenolithic) origin for inclusions of a minor secondary composition within a volcanic rock (lava, dome rock, bombs etc) is elucidated by high groundmass vesicularity, groundmass crystallinity indicative of undercooled 
conditions, and ellipsoidal clast shapes (Bacon, 1986; Eichelberger, 1980). An aphanitic or glassy groundmass texture indicates rapid chilling of a blob under conditions of high thermal contrast (undercooling), such as the contrast that would exist between a felsic and mafic magma. With increasing thermal contrast between two components (increasing undercooling) there will be progressively less groundmass crystallisation (Bacon, 1986). The cooling and equilibration of the subsidiary component drives saturation of the vapour phase within the clast boundaries, thus leading to vesiculation of blobs. The rapid quenching of a more mafic blob within a felsic host also serves to rapidly increase the viscosity of the blob, thereby creating a physical barrier to mixing, mingling, volatile release, or chemical diffusion (Bacon, 1986; Eichelberger, 1980; Melekhova et al., 2013; Sparks and Marshall, 1986; Sparks et al., 1977). Mechanical shearing of blobs or enclaves to a small scale, where chemical diffusion between the two magmas can operate efficiently, is impeded by the increasing rigidity of the cooling, crystallising blob (Melekhova et al., 2013). Retaining volatiles further helps to incorporate the subsidiary mafic component as a constituent clast by lowering the relative density, thus preventing mechanical separation such as settling (Bacon, 1986). Under these conditions, blobs of the more mafic subsidiary component are entrained as discrete solid lumps with comparable density (Bacon, 1986). However, in many cases the resultant texture of the mafic blob will be significantly different to the host material because of this crystallisation and inflation within impermeable boundaries (Eichelberger, 1980).

\section{Mechanisms of Mixing and Mingling}

Laboratory experiments indicate that the incorporation of a mafic component within a more felsic host occurs either during ascent through a conduit (Koyaguchi, 1985), or under convective mixing in a magma chamber (Huppert et al., 1982; Huppert et al., 1984; Kouchi and Sunagawa, 1983). These processes are generally suggested to occur at the interface between components in a stratified chamber (Eichelberger, 1980). Nonetheless, for the formation of inclusions, there must exist an inceptive process that overcomes the initial density contrast. If a mafic component in a stratified chamber underwent crystallisation and volatile exsolution at the interface with a more silicic magma, then the density contrast would be reduced, such that gravitational instabilities might allow mafic blobs to rise into the felsic component (Bacon, 1986; Eichelberger, 1980; Huppert et al., 1982, 1983). However, a density reducing mechanism involving volatile exsolution contradicts the volatile exsolution and crystallisation suggested to occur after entrapment in the felsic component (Bacon, 1986). Alternative mechanisms involving magma-fracture and/or forcible injection have been suggested for the formation of mafic blobs in silicic magma (Bacon, 1986; Campbell and Turner, 1985; Campbell 
and Turner, 1986; Hodge et al., 2012; Laumonier et al., 2014b). Fracturing of the silicic host magma can occur as a result of non-Newtonian behaviour (i.e., a viscosity increase under shear), thus opening a pathway for a mafic injection (Bacon, 1986; Walker, 1969). The injection, especially where small, may then be segregated through compressional 'pinching' as the host magma recovers (Bacon, 1986). Forcible injections without magma-fracture may occur during conduit ascent. Koyaguchi (1985) demonstrated that, while density stratification is relatively stable in a chamber, the lower viscosity, and thus higher velocity, of a more mafic component causes turbulent flow and disruption of the once stable stratification. While the above outlines conceivable ways in which to overcome a strong density and viscosity stratification, the act of physically mixing two components is governed by fluid-dynamics (Perugini and Poli, 2012). Experiments show that physical mixing is achieved by stretching and folding fluids (i.e., advection, Fig. 2.14) in a simplistic form of chaotic dynamics (e.g., De Campos et al., 2011; Flinders and Clemens, 1996; Perugini et al., 2003a; Perugini et al., 2003b; Welander, 1955).
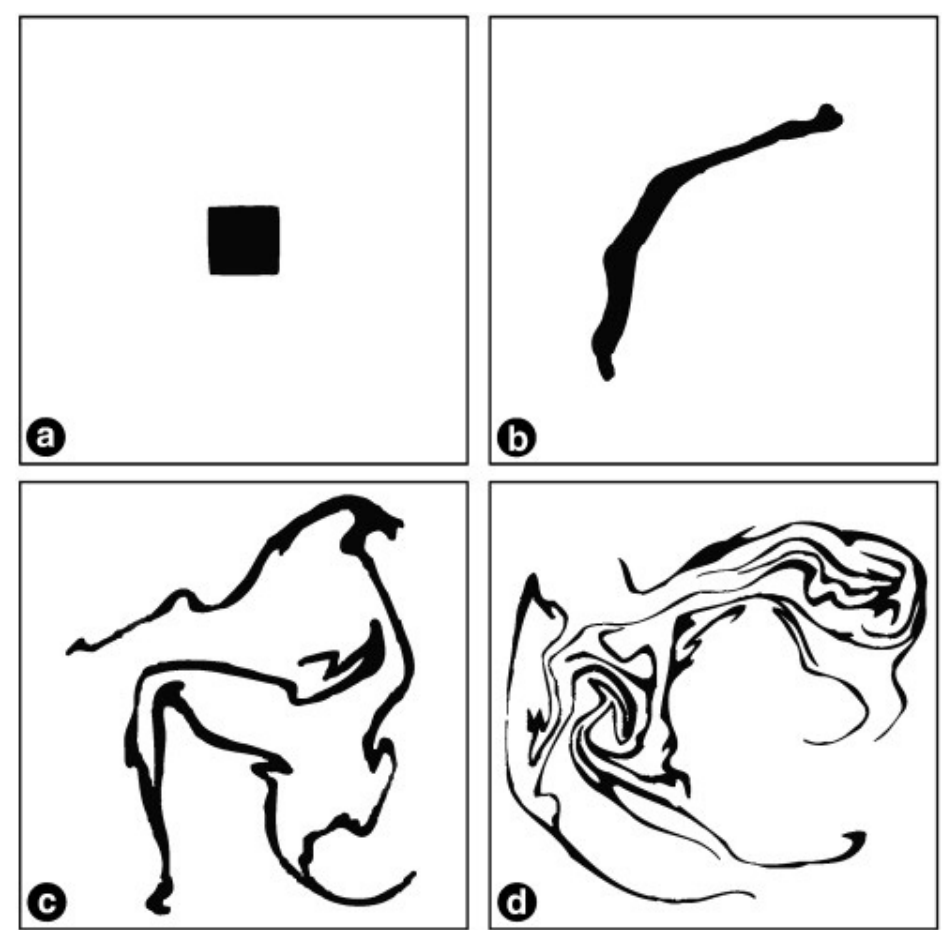

Fig. 2.14. Schematic diagram of chaotic mixing between a white magma and a black magma from Welander (1955; in Perugini and Poli, 2012). 
Sparks and Marshall (1986) noted however, that regardless of the mixing mechanism, it is the relative proportions and initial temperatures of the two components that primarily control whether a system will form a hybrid magma or remain as distinct components. In a system where the temperature difference between the components is large, and the ratio of silicic to mafic magma is high, the final product is more likely to be a silicic magma with discrete mafic inclusions. Conversely, in a system where the mafic component is equal or dominant, and the temperature difference is lesser (i.e., mixing a basalt and andesite), the likelihood of complete mixing to a hybrid magma increases (Bacon, 1986; Laumonier et al., 2014b; Sparks and Marshall, 1986). Furthermore, hybridisation will be less efficient where the constituent magmas are relatively dry (i.e., bubble-free and/ or volatile-poor systems); the bimodality of dry magmatic systems is therefore more likely to be preserved (Laumonier et al., 2014b; Melekhova et al., 2013).

\section{Magma Recharge and Re-heating}

Alongside the textural, chemical, and mineralogical changes that may be correlated with magma mixing/mingling, the addition of a mafic magma to a felsic magma (i.e., recharge) is often suggested to act as an eruption trigger (Pallister et al., 1992; Ruprecht and Bachmann, 2010; Sparks et al., 1977). Moreover, Ruprecht and Bachmann (2010) propose that the degree of mixing and heat transfer between two magmas in a chamber has a fundamental control on the overarching style (effusive or explosive) of the proceeding eruption. They state that fragmentation is impaired when efficient reheating of a silicic magma occurs as a result of thorough hybridisation with a higher temperature mafic recharge-magma. Conversely, if hybridisation is incomplete or non-existent (i.e., mingling), then reheating of the silicic magma will be minimal and explosive behaviour more likely (Ruprecht and Bachmann, 2010). It is estimated that equilibration of two magmas with a temperature difference of $\sim 200^{\circ} \mathrm{C}$ could occur over minutes to hours (Ruprecht and Bachmann, 2010), however, the calculation does require convective stirring to shorten the heat transport length-scale. Thus, while equilibration can proceed rapidly, the key aspects relevant to controlling eruption style are the ratio of silicic to recharge magma, and the temperature difference between the two magmas (e.g., Sparks and Marshall, 1986). Moreover, while complete hybridisation is not necessary to inhibit fragmentation, the breakup of a recharge magma into smaller enclaves or blobs (i.e., increased surface area) will expedite thermal exchange, promoting efficient degassing and effusive behaviour (Melekhova et al., 2013; Ruprecht and Bachmann, 2010). 


\section{Chapter 3: Samples and Methods}

\subsection{Sample Selection and Preparation}

Samples were collected from the proximal slopes of Cordón Caulle fissure system of the PCCVC. Figure 3.1 shows the location of all samples collected during the 2016 field expedition. Samples were selected with the aim of obtaining a representative subset of the 2011-2012 ballistic eruption products. All samples were subsequently characterised through macro-scale observations and separated into four categories, similar to those of Pistolesi et al. (2015) and Castro et al. (2013a).

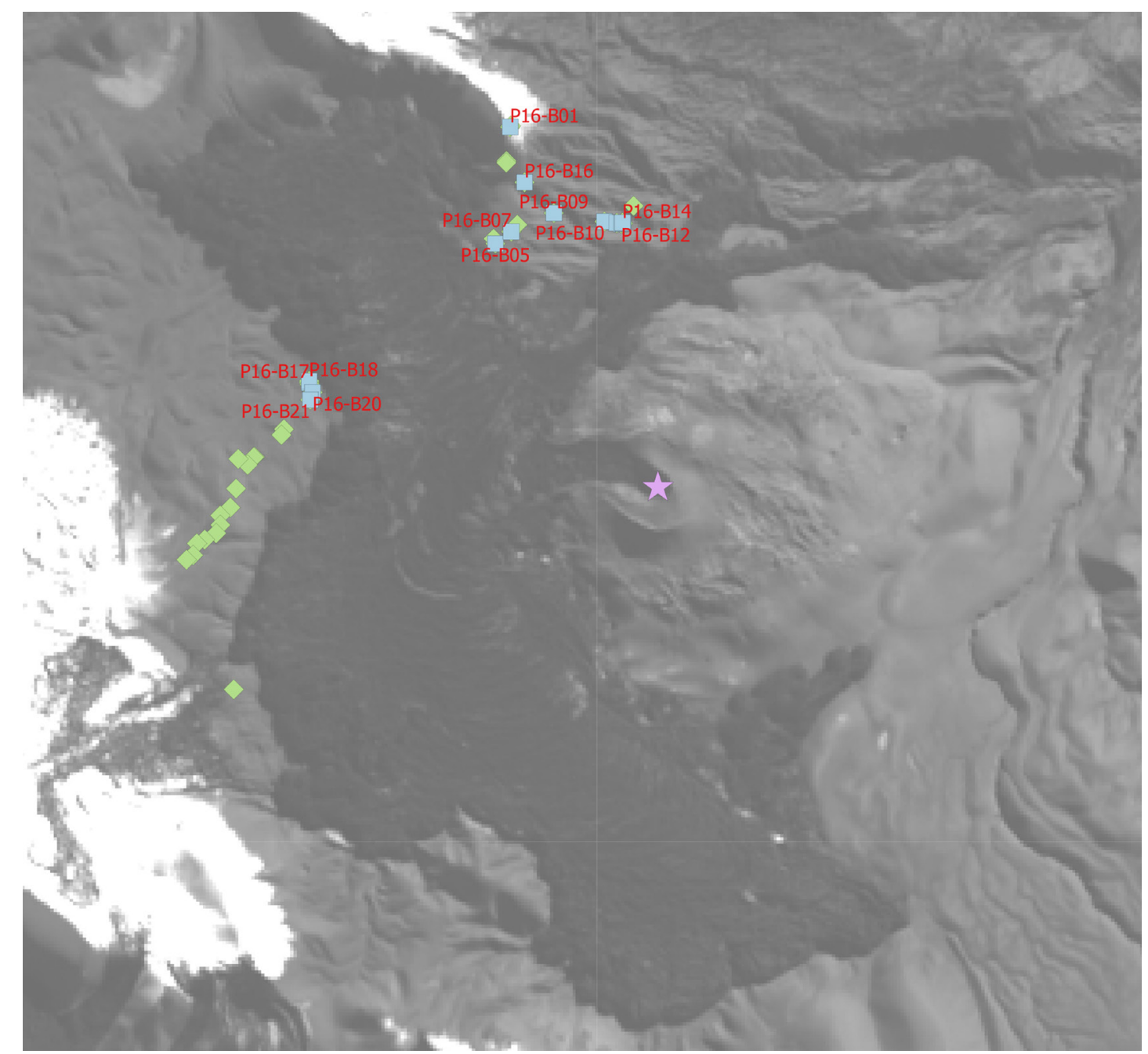

Fig. 3.1. Map of the 2011-2012 Puyehue-Cordón Caulle lava flow and vent with the location of all bombs sampled during the 2016 field expedition (blue squares), and supplementary bombs collected by other workers and during earlier field expeditions (green diamonds). The vent location is marked by the pink star. 


\subsection{Thin Section Processing}

After examining the images obtained from the Australian Synchrotron it was determined that the resolution was not sufficient for quantification of textural domains or variation within domains. Therefore, thin sections were cut from all large samples that were imaged at the Australian Synchrotron (see section 3.4), with the aim of providing enhanced textural detail. The resolution of large images from the Australian Synchrotron was $14 \mu \mathrm{m}^{3}$ per voxel whereas the backscatter imaging function of the JEOL JXA-8230 Superprobe allows sub-micron detail to be seen (albeit not in perfect clarity).

Thin sections were also used to establish if sample compositions were consistent, thus allowing textural variations to be related solely to eruption dynamics rather than compositional variations. Two thin sections were cut from samples that had been imaged at the Australian Synchrotron, one or two were cut from all other samples. The thin sections were cut perpendicular to colour and textural banding whilst also trying to include as many of the visible boundaries clast and domain boundaries as possible. Due to the fine nature of some textures, and especially the mafic domains, some features in thin sections were included entirely by chance. However, with 40 thin sections cut from the full range of samples (many from similar bomb types) most textural variations are expected be included in the sample set.

After examining all thin-sections under a petrographic microscope, a representative sample subset was chosen for electron microprobe analysis. The samples in this subset were then polished on trident polishing disks with $6 \mu \mathrm{m}, 3 \mu \mathrm{m}$, and $1 \mu \mathrm{m}$ diamond solution. Polishing times varied depending on the bomb type - dense samples required more time with $6 \mu \mathrm{m}$ and $3 \mu \mathrm{m}$ diamond solution to achieve a good polish whereas the more pumiceous samples required careful use of $6 \mu \mathrm{m}$ diamond solution so as not to destroy sections of the samples.

\subsection{Electron Microprobe Analyses}

A JEOL JXA-8230 Superprobe was used for detailed textural and compositional analysis of a representative set of polished thin sections using the backscatter electron (BSE) imaging function. The selected thin sections are thought to express the full range of compositional, mineralogical, and textural features of the bomb sample set collected 
from Puyehue. All thin sections were first imaged on a flat bed scanner to allow accurate translation of compositional and textural features between the backscatter image and the sample as a whole. Furthermore, this technique clarified the influence of textural and compositional changes on the colour variations in thin sections.

Magnification settings for observations were dependent on the specific observations being undertaken. For textural observations the backscatter electron image was selected and the beam was set at relatively low power $(15 \mathrm{kV}, 8 \mathrm{nA})$. More important in textural observations is the adjustment of the brightness and contrast settings to improve the distinction between differing compositions, crystals, and to highlight specific features. No specific brightness and contrast settings were used for any one sample, the most successful approach being to start with the automated brightness/contrast balance feature of the JEOL JXA-8230 Superprobe and adjusting from there to achieve the required result. Energy Dispersive Spectrometry (EDS) analysis, to verify compositional differences and identify minerals, was undertaken concurrently with textural observation and imaging using identical beam settings.

Wavelength Dispersive Spectrometry (WDS) analyses of major element concentrations for glassy groundmass and two crystal phases (Plagioclase and Olivine) were determined by electron probe microanalysis (EPMA), with the JEOL JXA-8230 Superprobe. Major element oxides $\left(\mathrm{SiO}_{2}, \mathrm{TiO}_{2}, \mathrm{Na}_{2} \mathrm{O}, \mathrm{K}_{2} \mathrm{O}, \mathrm{CaO}, \mathrm{P}_{2} \mathrm{O}_{5}, \mathrm{Al}_{2} \mathrm{O}_{3}, \mathrm{FeO}, \mathrm{MgO}, \mathrm{MnO}\right)$ in the groundmass (glass + microlites) were analysed using $15 \mathrm{kV}, 8 \mathrm{nA}$, a 30 second peak analysis period with a defocused $10 \mu \mathrm{m}$ beam. Volatile elements in the groundmass ( $\mathrm{S}$ and $\mathrm{Cl}$ ) were analysed using $15 \mathrm{kV}, 60 \mathrm{nA}$, a focused beam, and a 60 second peak analysis period. Groundmass analyses were standardised using natural and synthetic compounds, and verified with reference to basaltic glass standard VG-2, VG-568, and VGA-99 (Jarosewich et al., 1980). Crystal phases were measured for all major and some minor elements using a focused beam, $15 \mathrm{kV}, 12 \mathrm{nA}$, and 30 second peak period. Olivine was measured for $\mathrm{SiO}_{2}, \mathrm{TiO}_{2}, \mathrm{CaO}, \mathrm{FeO}, \mathrm{MgO}, \mathrm{MnO}, \mathrm{NiO}$, and $\mathrm{Cr}_{2} \mathrm{O}_{3}$, standardised against San Carlos (NMNH 111312-44) and Springwater (USNM 2566) Olivine crystals. Plagioclase was measured for $\mathrm{SiO}_{2}, \mathrm{TiO}_{2}, \mathrm{Na}_{2} \mathrm{O}, \mathrm{K}_{2} \mathrm{O}, \mathrm{CaO}, \mathrm{Al}_{2} \mathrm{O}_{3}$, $\mathrm{FeO}, \mathrm{MgO}, \mathrm{BaO}$, and $\mathrm{SrO}$, standardised against Lake County Labradorite (USNM 115900), Great Sit-in Island Anorthite (USNM 137041), and Kakanui Anorthoclase (USNM 133868). Standards were run both during the WDS analyses as unknowns, and 
as standalone analyses of known standards. Secondary standards were added every 20-25 points in a quantitative analysis run.

\subsection{Australian Synchrotron IMBL}

A subset of the full suite was selected for imaging using the Imaging and Medical BeamLine (Hutch 3B) X-Ray tomography facility of the Australian Synchrotron (Clayton, Victoria, Australia). The subset was selected to cover as much variation as possible within the sample set in the allotted time. Large $2-3 \mathrm{~cm} \times 2-3 \mathrm{~cm}$ x $5-8 \mathrm{~cm}$ cuboids were cut from the bomb samples to be imaged at the Australian Synchrotron and used for detailed texture and porosity characterisation. The sample size was varied due to (1) the size of the block they were cut from, and (2) the distribution and size of the textural domains and boundaries that were to be incorporated in the final cuboid. Rather than cutting all samples perpendicular to a textural alignment, samples were cut with the sole aim of capturing as many textural variations as possible across the full sample set.

X-Ray tomography imaging at the Australian Synchrotron employed their "Ruby" detector with X-ray energy of $45 \mathrm{keV}$. Scans were made through a $180^{\circ}$ sample rotation and $0.3 / \mathrm{sec}$ exposure per radiograph, collecting a total of 1,800 radiographs per sample. Large samples had to be imaged in several overlapping sections, the number of sections being dependent on the size of each sample and the scan resolution. Each section was reconstructed to build a 3D volume of 2D image slices (slices orientated perpendicular to the long axis of the sample) with the X-Tract Imaging Toolbox on the parallel computing cluster of the Australian Synchrotron (MASSIVE). Overlapping volumes were subsequently stitched together to yield large rendered volumes with voxel edge lengths of $14 \mu \mathrm{m} / \mathrm{px}$ and $5.85 \mu \mathrm{m} / \mathrm{px}$ (large samples and smaller heating samples respectively). Reconstructed image stacks were manipulated as 3D volumes and individual 2D image slices using the freeware ImageJ (Rasband, 2011; Schneider et al., 2012).

\subsection{Heating Experiments}

Samples to be used for foaming experiments were small $\sim 1 \mathrm{~cm} \times 1 \mathrm{~cm} \times 2-3 \mathrm{~cm}$ cuboids cut from larger blocks of the denser obsidian sample material. The size of these smaller samples was dictated by the size of the graphite crucible (a diameter of $2.5 \mathrm{~cm}$ ) used for the foaming experiments. The crucible was used to both contain the foaming or melting samples and to create a more even heat distribution around the sample. 
Exploratory qualitative heating experiments were performed on the densest samples in the suite of rocks, with the intention of producing a degassing reaction and formation of new textures. Whilst the experimental conditions were not sufficiently well constrained for publication, there is merit in the experimental idea. To determine the viability of conducting heating experiments at the Australian Synchrotron, initial heating experiments were conducted at Canterbury University. These initial experiments employed a Thermo Fisher Scientific high temperature furnace (model M110, maximum temperature $\sim 1100^{\circ}$ C), with an inbuilt temperature gauge and small viewing window through which samples could be photographed, running at essentially dry and at atmospheric pressure conditions. A much smaller butane furnace was tested in further experiments (Fig. 3.2); the setup consisting of a hollow fire-brick cylinder wrapped in a thin steel sheet, with butane power blowtorches inserted in either side, samples being placed in a graphite crucible in the centre of the fire brick cylinder. Temperatures for this experimental setup were measured using a thermocouple, reading a maximum temperature of 1053

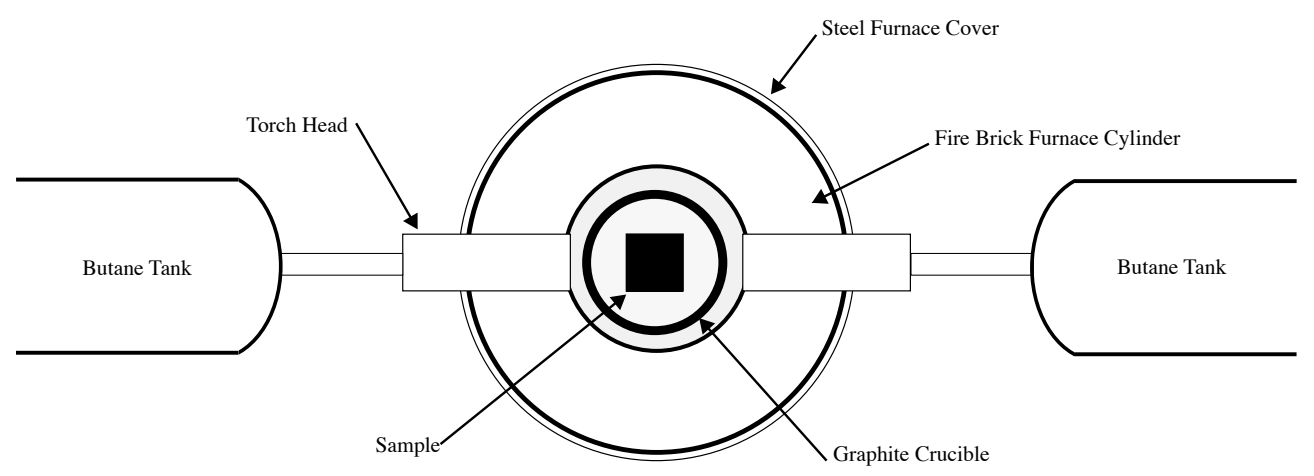

Fig. 3.2. Schematic drawing of the blowtorch furnace for the heating experiments conducted at the Australian Synchrotron.

${ }^{\circ} \mathrm{C}$ after $\sim 8$ minutes (complete temperature series shown in Fig. 3.3). Although less well constrained for heating rates and maximum temperatures, the portability of the small butane furnace was particularly advantageous for further heating experiments at the Australian Synchrotron.

Three things needed to be established in the initial experiments: (1) that samples would react in some way to the heating, (2) what effect heating rate and maximum temperature had on samples, and (3) if the smaller butane furnace was sufficient to conduct experiments. The experiments showed that some samples reacted to heating whilst others did not, and that the small butane furnace was not only sufficient for the 


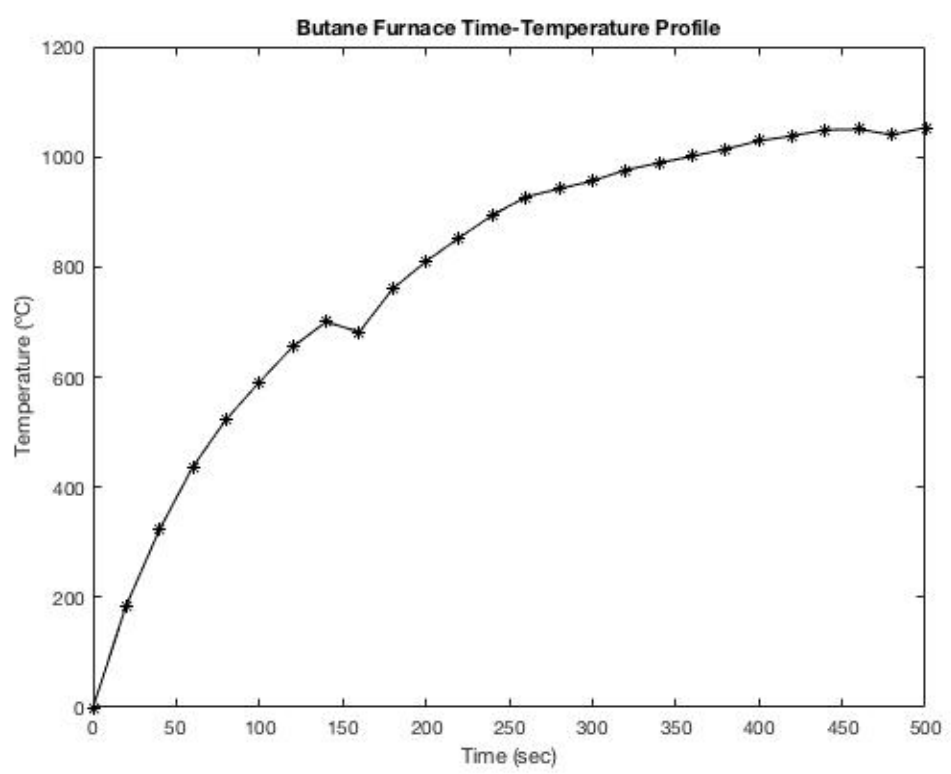

Fig. 3.3. Heating profile for the butane blowtorch furnace as measured with a thermocouple. Note the probable erroneous measurement at 160 seconds and the slight downturn of $10^{\circ} \mathrm{C}$ at 480 seconds.

experiments but it was quicker to produce a reaction. Starting temperature and heating rate did not appear to change sample reactions, whereas maximum temperatures did.

For the experiments conducted at the Australian Synchrotron the samples were first imaged in their unaltered state. Samples were then heated for either 7.5 or 30 minutes in the butane furnace. Observations of state changes were made throughout the heating after which all samples were re-imaged in the IMBL. Fresh samples of those that reflected the range of reactions were selected for a second experiment with a 30 minute period of heating. A single pumiceous sample was selected to see what how the reaction would differ given a different initial state.

\subsection{ImageJ Analysis}

Tomographic volumes and BSE images show density differences as greyscale variations; high density objects (e.g., iron-oxide crystals) are white, whereas air space (lowest density) is black. ImageJ was used for quantitative and qualitative analysis of both the tomographic volumes and the thin-section BSE images. A new method of image stack processing and analysis was devised to obtain information on the structure of samples imaged at the Australian Synchrotron. 
To create a time-efficient dataset, able to be analysed with the available software and hardware, image stacks invariably required several pre-processing steps to be undertaken; foremost being the removal of blank air space around the sample that was imaged, often contributing $>40 \%$ of the image file size. An initial crop in the XY plane can remove significant amounts of blank space, but the majority of sample images did not sit square to the bounding frame. Images therefore required a rotation, relative to the bounding frame, for a complete crop of blank space; this also applied to the ZY and XY planes of the image stack. An angle measurement tool is incorporated into ImageJ and can be used to accurately determine the degrees of rotation required to square the sample with the bounding box, thus allowing for all extraneous blank space to be removed. Completing the same task in the ZY and ZX planes required that the image stack be rendered from a different viewpoint - this utilises a 'reslicing' tool. A 're-slice' from east to west across the image renders an image stack for the $\mathrm{XZ}$ plane, whereas re-slicing the image stack in the north-south direction renders the $\mathrm{YZ}$ plane. A representative subset was chosen from the cropped image stack, to further reduce computational load and expedite analysis, chosen to be a $1000 \times 1000 \times 2000$ pixel stack taken from the centre of the original stack to avoid any bias. The central 2000 images were selected to import into ImageJ, then the images were cropped using a canvas re-size tool that uses the centre of the images as it's starting reference point. This technique allowed for reproducibility across the entire sample set.

Tools used for analysis of 3D space within the image require that the input image be in binary form (i.e., black and white), as opposed to 8-, 16-, or 32-bit greyscale. A threshold can be applied to a specified greyscale range (i.e., vesicles, groundmass, or crystals) and a binary image created based on this selection wherein the objects of interest should be designated white. The underpinning concept of $3 \mathrm{D}$ analysis here is the relationship between any given voxel and its neighbouring voxels in orthogonal $\mathrm{X}, \mathrm{Y}$, and $\mathrm{Z}$ axes (diagonal axes can be included for increased detail). Given a binary image, where white and black are assigned the values of 0 and 1 respectively, the program connects all equal values as far as possible in any direction.

Qualitative analysis of heating experiment samples used the MorphoLibJ package (Legland et al., 2016) to find, threshold, and connect vesicles. Using the 'connected components labelling' and 'labels to RGB' tools of this package renders an image stack with coloured vesicles and black backgrounds. These image stacks can then be viewed in the $3 \mathrm{D}$ volume viewer function of imageJ, for quantitative and qualitative analysis. 


\section{Chapter 4: Results}

\subsection{Macro-Textural Classification}

Macro features observed in the field, and in hand samples, were the primary motivation for this study and are important when considering the big picture. Hand sample descriptions of all collected samples were undertaken initially to break down the full sample set into morphological categories, and can be found in Appendix 1. Guided by the previous morphological classifications of Castro et al. (2013a), Wright et al. (2007), and Pistolesi et al. (2015), the sample set was split into four macro-morphological categories: (1) dense bombs, (2) composite bombs, (3) grey pumice bombs, and (4) honeycomb bombs. Defining characteristics of the bombs, sample and thin-section numbers, and classifications are shown in Table 4.1; field, thin-section, and hand sample images are shown in Figs. 4.1, 4.2, and 4.3 respectively. The composite bombs are considered to be the most common of the above macro-textural types. Additionally, although morphologically distinct, honeycomb bombs (B16, Fig. 4.1H \& I) could be considered a variant of composite bombs, whereby they are composed of two texturally distinct components.

Table 4.1. Generalised morphological classifications for Cordón Caulle bombs.

\begin{tabular}{|c|c|c|c|c|}
\hline Category & $\begin{array}{l}\text { General } \\
\text { Morphology }\end{array}$ & Defining Characteristics & Sample Numbers & $\begin{array}{l}\text { Thin Section } \\
\text { Numbers }\end{array}$ \\
\hline Type 1 & Dense & $\begin{array}{l}\text { Dense, glassy black to dark-grey. } \\
\text { Some samples are colour banded (grey } \\
\text { and black), visible vesicles are rare in } \\
\text { all samples, visible crystals present to } \\
\text { varying degrees. }\end{array}$ & $\begin{array}{l}\text { B10, B11, B13, } \\
\text { B14, B18 }\end{array}$ & $\begin{array}{l}\text { B10-AS01, B10- } \\
\text { AS01-S2, B11- } \\
\text { AS09, B13-AS02 }\end{array}$ \\
\hline Type 2 & Composite & $\begin{array}{l}\text { Clasts of pumice and obsidian within a } \\
\text { matrix. Pumice clasts are variable in } \\
\text { size and colour, commonly white to } \\
\text { grey, but some brown and grey-black } \\
\text { banded clarets present. Matrix is fine } \\
\text { grained with red-orange-brown colour. } \\
\text { All samples contain flow banding to a } \\
\text { degree, sometimes crosscutting other } \\
\text { bands, and bombs contain central } \\
\text { cavities. }\end{array}$ & $\begin{array}{l}\text { B } 07, \text { B09, B12, } \\
\text { B17, B20 }\end{array}$ & $\begin{array}{l}\text { B09-AS06, B20- } \\
\text { AS04 }\end{array}$ \\
\hline Type 3 & Grey Pumice & $\begin{array}{l}\text { Glassy black obsidian rinds with } \\
\text { heavily vesiculated grey cores. } \\
\text { Banding of obsidian and pumice } \\
\text { (generally perpendicular to rind), } \\
\text { some smaller pumice clasts visible } \\
\text { within the grey cores, bombs have } \\
\text { central cavities. }\end{array}$ & B01, B21 & $\begin{array}{l}\text { B21-AS26, B21- } \\
\text { AS27, B21-AS27-L }\end{array}$ \\
\hline Type 4 & Honeycomb & $\begin{array}{l}\text { Dense black to dark red matrix with } \\
\text { highly vesicular white to dark grey } \\
\text { grey clasts in a honeycomb texture. } \\
\text { Some Banding present, defined by } \\
\text { vesicles distributions. Rind is } \\
\text { comparatively rich in obsidian } \\
\text { fragments, and pumice clast frequency } \\
\text { increases away from rind. }\end{array}$ & $\mathrm{B} 16$ & B16-AS18 \\
\hline
\end{tabular}




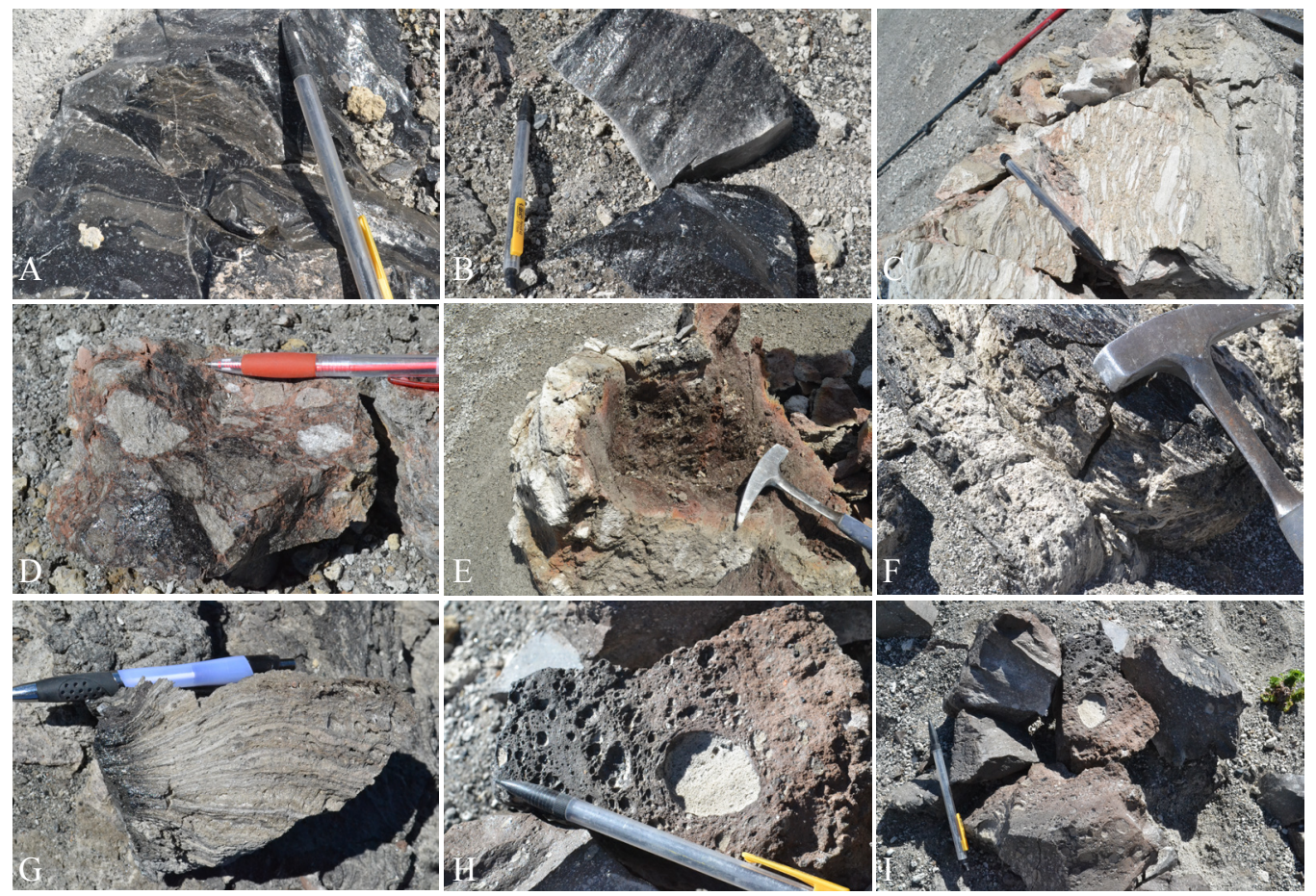

Fig. 4.1. Field images of Cordón Caulle bombs (courtesy of C. I. Schipper). Dense bombs displaying different styles and degrees of banding ( $A \& B)$; Composite bombs showing elongate clasts $(C)$ and rounder clasts with the presence of denser, obsidian clasts (D); An example of a central cavity (dark red region by head of hammer) in a composite bomb (E); Grey pumice bombs with obsidian rinds and fine wisps of obsidian extending perpendicular to the rind ( $F \& G)$; B16 showing the 'honeycomb' texture with a transition from a reddish coloured matrix to a black matrix further away from the rind $(H \& I)$.

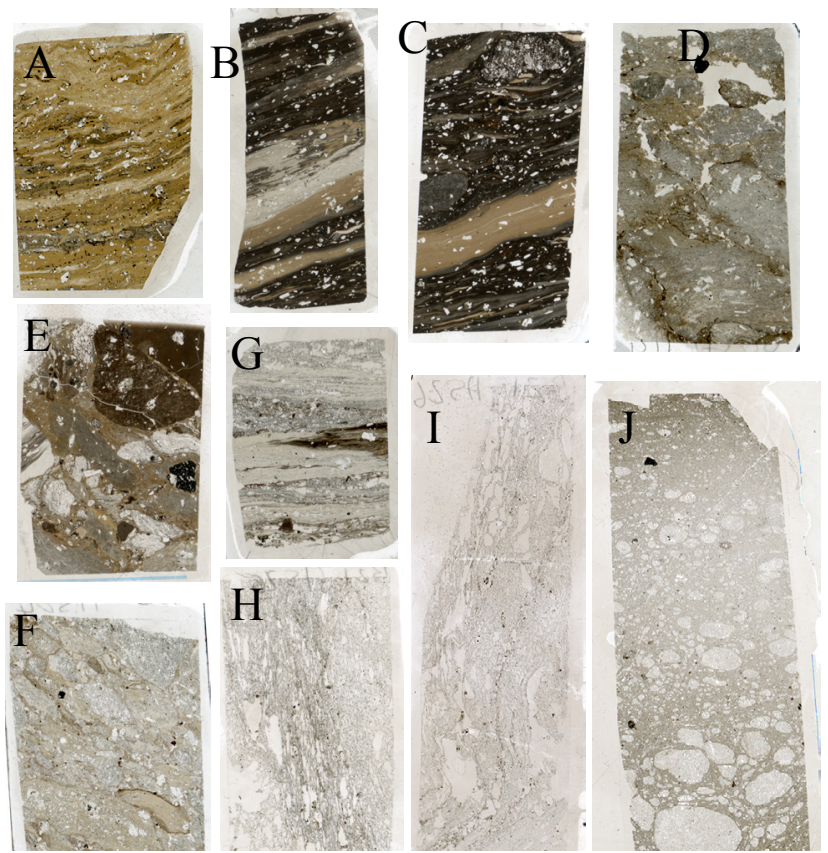

Fig. 4.2. Thin sections used for micro-textural analysis; B13-AS02 (A) B10-AS01 (B), B10-AS01-S2 (C), B11-AS09 (D), B09-AS06 (E), B20-AS04 (F), B21-AS27 (G), B21-AS26 (H), B21-AS26-L (I), $B 16-A S 18(J)$. 

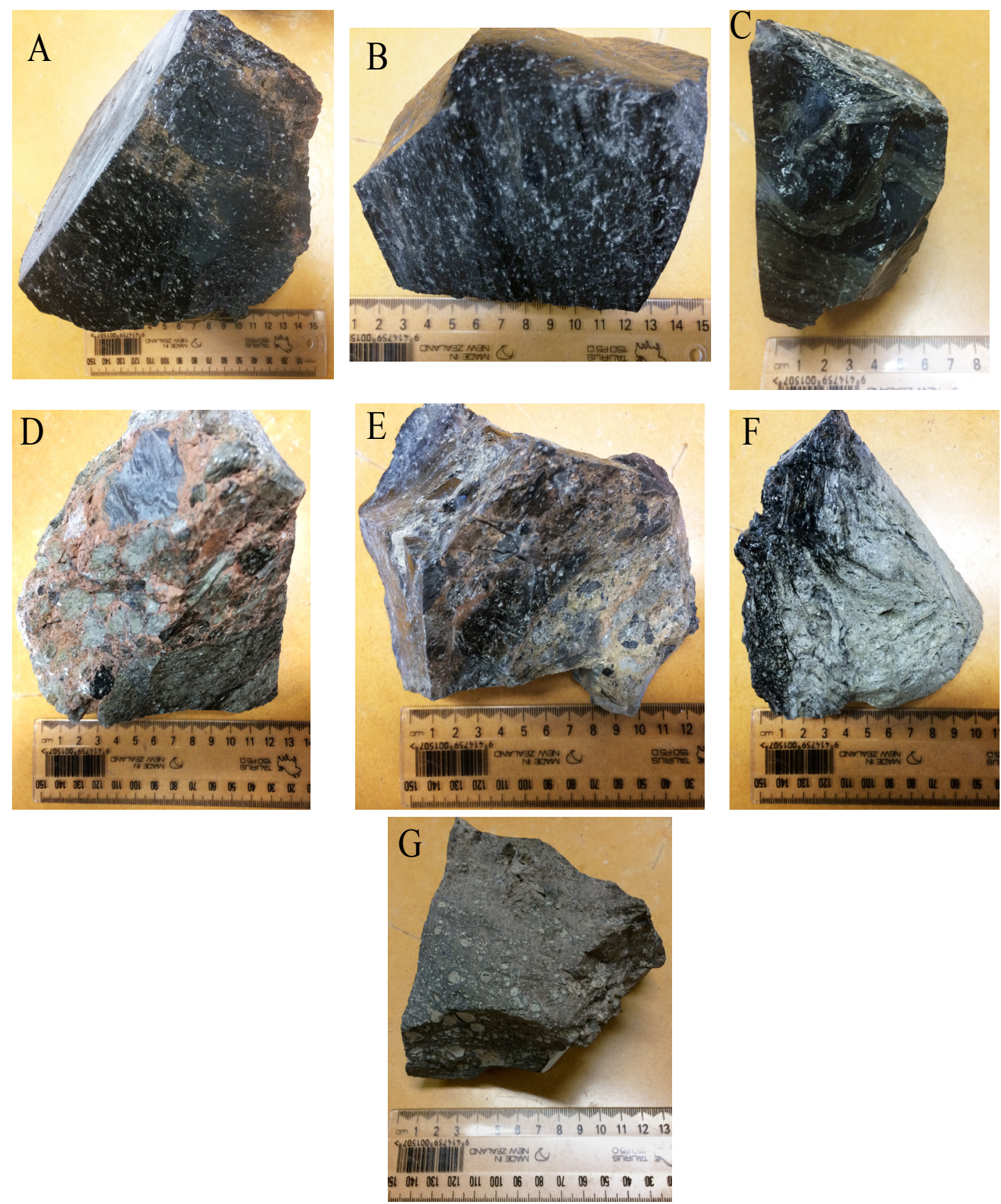

Fig. 4.3. Hand Sample examples of the thin sections shown in Fig. 4.3. Bomb numbers are: B11 (A), $B 10(B), B 13(C), B 20(D), B 09(E), B 21(F)$, and $B 16(G)$. 


\subsection{Micro-Textural Classification}

The macro classification of bombs given above was decomposed to constituent microtextural domains. Any one bomb could contain all the micro-textural domains (e.g., composite bombs), or be composed of a single micro-textural domain (e.g., dense bombs). Initially, thin-sections were cut from all bombs, with multiple thin-sections from those showing particularly complex textural relationships (total of 40 thin-sections). After examination of all thin-sections under a petrographic microscope, 10 were chosen (listed in Table 4.1 under 'thin-section numbers') as a representative subset that displayed all observed macro-textural variations. Similar textures observed during a comprehensive examination of these thin-sections were lumped together to simplify characterisation. Four domain categories are herein defined: (1) sintered, (2) vesicular, (3) dense, and (4) mafic. Domains are defined by texture, with the exception of mafic domains, which are defined by composition. Lithic fragments (Fig. 4.4), a fifth component of bombs, are present in many samples as highly crystalline clasts and fragments of palagonite (e.g., Stroncik and Schmincke, 2002). However, they are noted here, but omitted from further analysis as this study is focused on the juvenile products of the eruption.
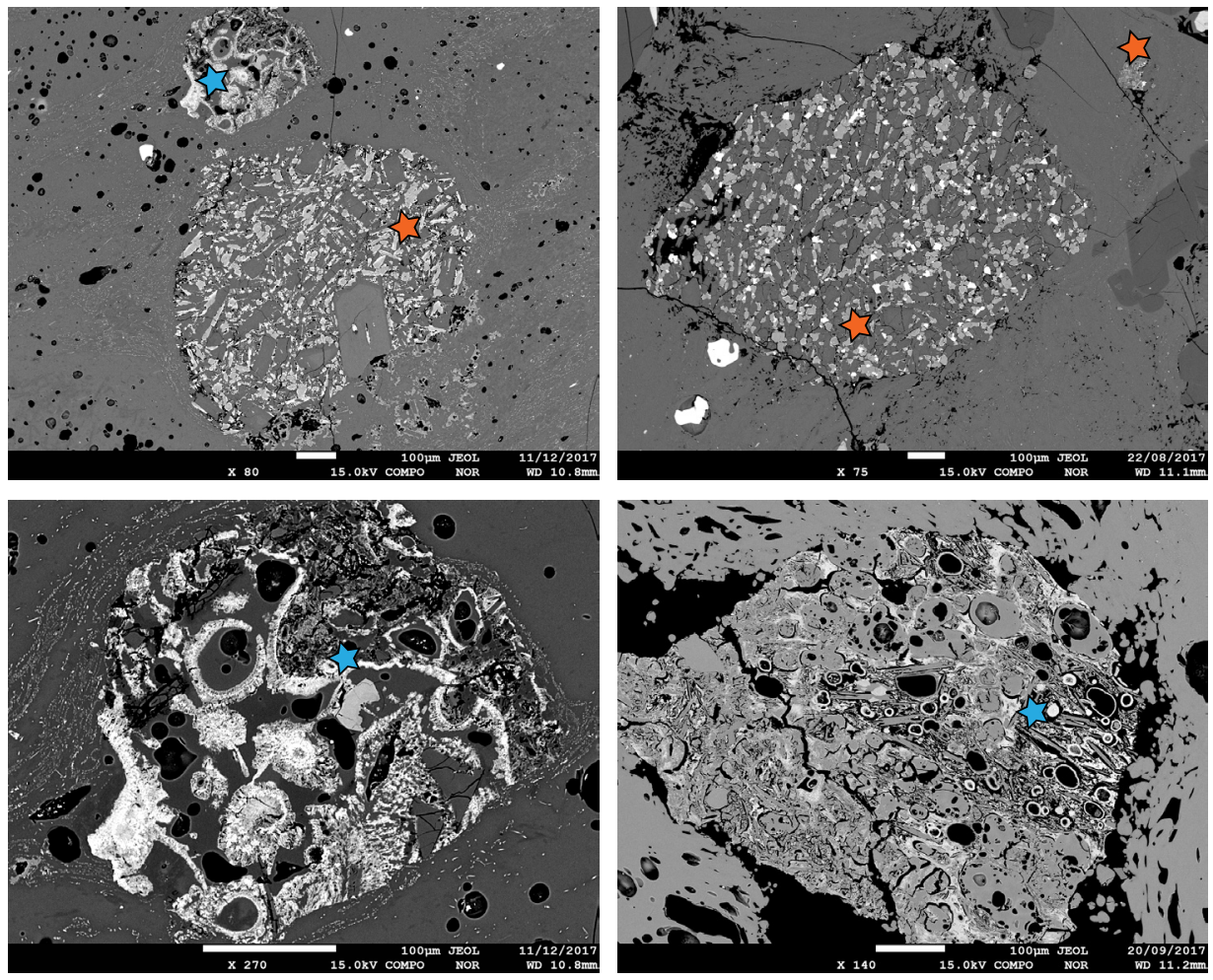

Fig. 4.4. Examples of lithic clasts. Blue stars indicate Palagonite, a volcanic (mafic) glass alteration product caused by extended interaction with water, while orange stars indicate examples of highly crystalline fragments with brittle textures (e.g., internal fractures, rough edges). 


\section{Sintered Domains}

Sintered domains are defined here as any material that consists of an assemblage of particles, able to be seen as being once discrete, held together by viscous necks (e.g., Vasseur et al., 2013b; Wadsworth et al., 2014) or by contact at particle boundaries (e.g., Olgaard and Gerald, 1993), and preserved as a coherent domain within a rock (e.g., Fig. 4.5). Size, shape, and angularity of particles, along with the degree of neck formation or sintering varies between, and within samples. That notwithstanding, any region, whether continuous matrix or a discrete domain, that fits the general description above will herein be referred to as 'sintered' material.

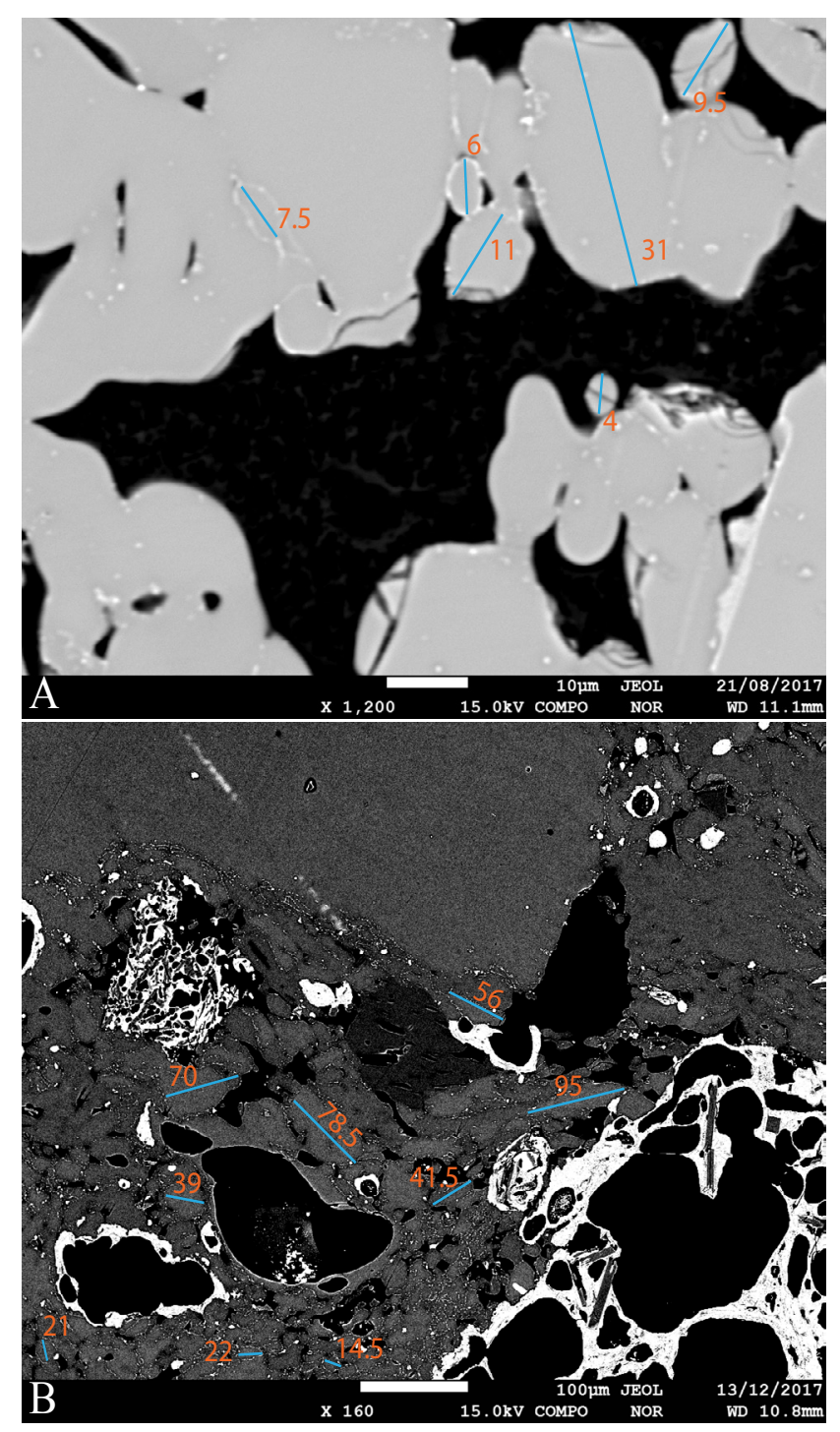

Fig. 4.5. Representative example of particle size distribution in sintered domains of B20 (both images). Blue bars show scale and the measurements (orange numbers) are given in microns to the nearest half micron. Average particle size distributions in sintered domains across all examined samples do not deviate significantly from the range shown in the above images. 
The total size range for sintered particles across all samples is approximately $<2-160$ $\mu \mathrm{m}$, average particle size ranges are however much more limited (Fig. 4.5). Particles larger then $\sim 200 \mu \mathrm{m}$, although still within the classical definition of ash, are so rare within these sintered domains that they standout as distinct clasts. Particle shape variations range from highly circular (presumed spherical in 3D) to convoluted, elongated shapes (Fig. 4.6). The majority of particles within sintered domains are rounded to subrounded, although the sintered domains of B09 consist of particles that are clearly less spherical(Fig. 4.6A). Furthermore, 'fitting' of some particles around others is clear in some domains (Fig. 4.7).

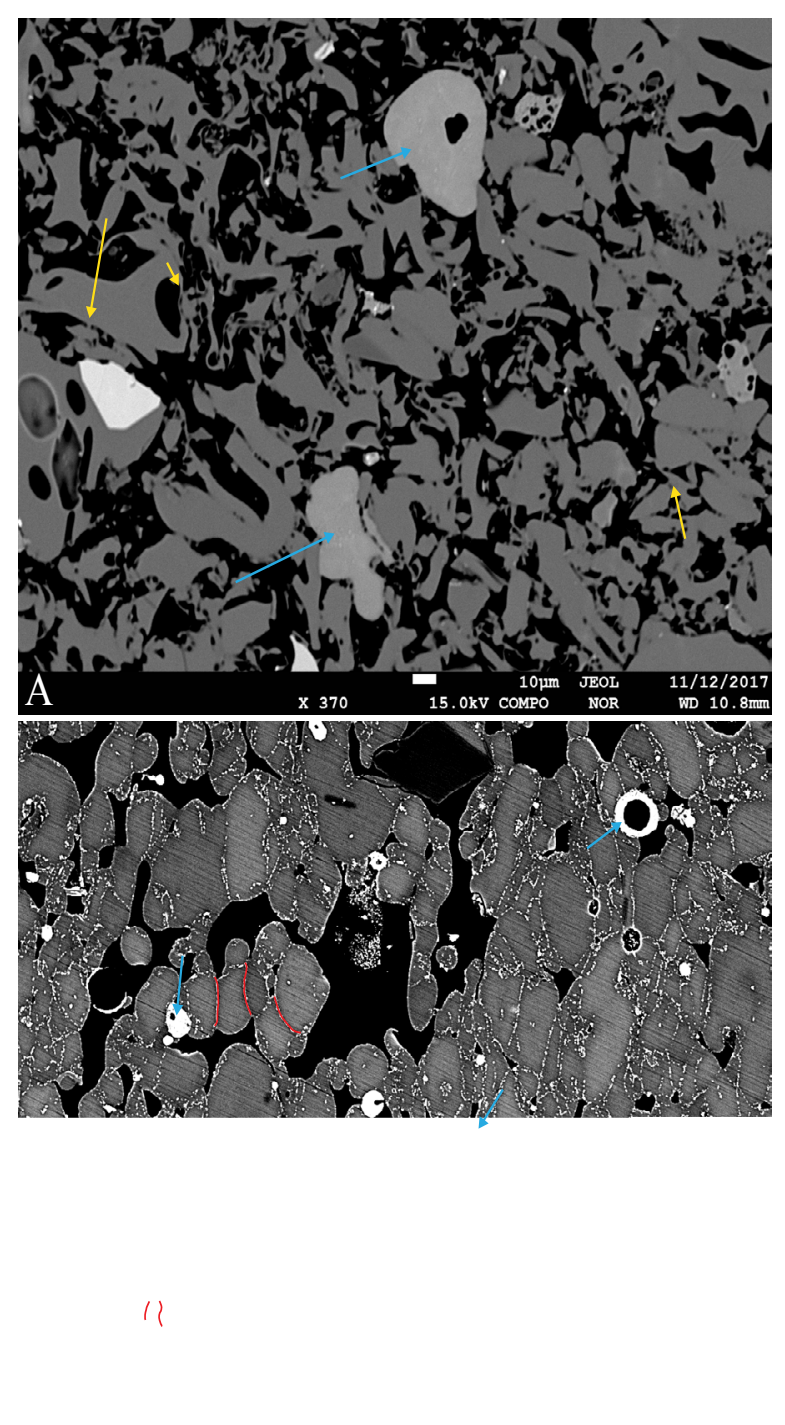

Fig. 4.6. Key differences in endmember sintering conditions can be seen in B09 (A) and B16 (B). B09 largely consists of angular to sub-angular particles connected by fine viscous necks, and at most, incipient micro-oxide presence. Conversely, B16 is heavily sintered along particle edges with very few discernible viscous necks and a strong presence of micro-oxides decorating particle surfaces. Deformation or squashing of particles (indicated by red lines) is ubiquitous in heavily sintered samples such as B16. Blue arrows in both images indicate mafic particles. 


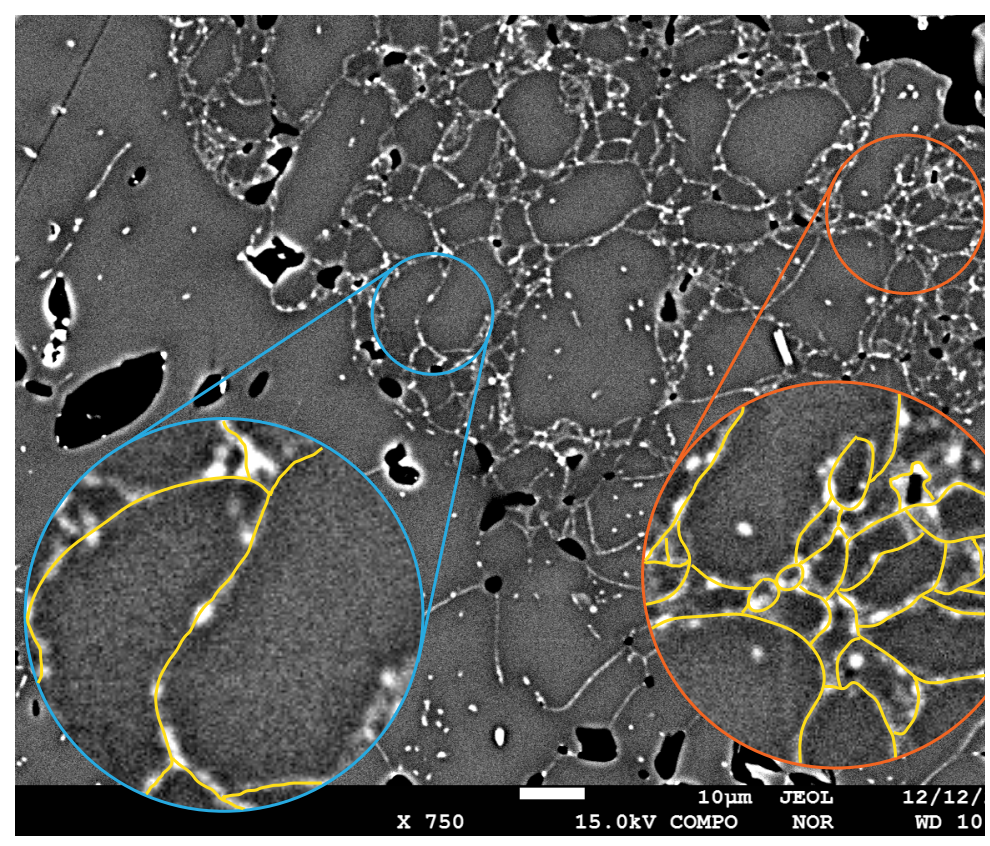

Fig. 4.7. Dense particle packing (orange circle) and sintering in sample B11 associated with particle deformation (blue circle) and pervasive micro-oxide decoration. This example represents the most intense particle packing seen across all sintered domains. Yellow lines highlight particle edges and shapes.

Particle-particle connections in sintered domains are a mix of fine filaments (Figs. 4.6A $\& 4.8$ ), wherein two otherwise separated particles are connected by a bridge of glass (termed 'viscous necks'), and edge connections (Figs. 4.6B \& 4.7), where two particles are connected along touching boundaries without the presence of discernible viscous necking (i.e., hot pressing, Olgaard and Gerald, 1993). The aforementioned variation in connections can be considered endmembers, with combinations of the styles occurring both within and between samples. Furthermore, the degree of sintering in any given sample is variable. These features of sintered domains are consistent with industrydefined variations in sintered materials (e.g., Mackenzie and Shuttleworth, 1949; Pope et al., 2016; Skorokhod, 2017; Vasseur et al., 2013b; Wadsworth et al., 2014). Viscous necks (Fig. 4.8) range from extremely fine (sub-micron widths) to comparatively broad (2-4 $\mu \mathrm{m}$ widths). Similarly, some edge connections span the entire length of a particle whilst others form only a small percentage of a particle length. This second instance generally occurs where two particles have their long axes orientated perpendicular to one another. However, particles with more irregular shapes sometimes have short edge connections relative to the particle size. 


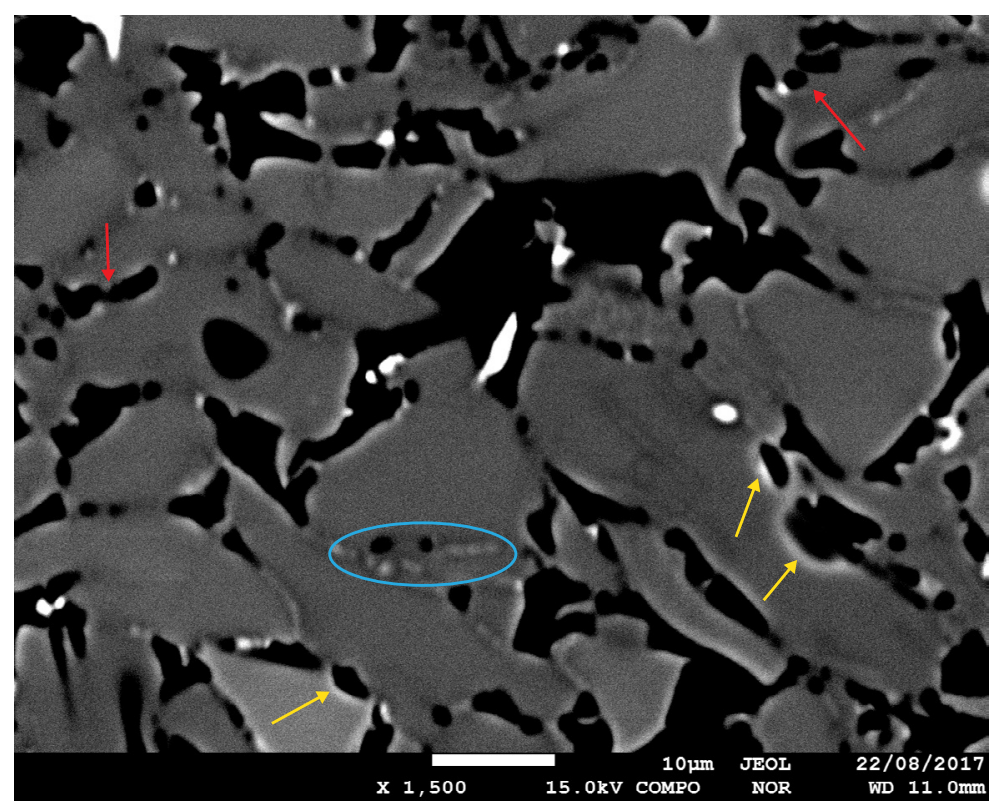

Fig. 4.8. Sintering of sub-angular particles in sample B09. Red arrows indicate examples of early stage viscous neck formation between particles, necks measure $<1 \mu \mathrm{m}$ in many places and are not yet connected in others. Incipient micro-oxides are present in this sample where heavier sintering along particle edges has occurred (blue oval). 'Edge effects' of BSE images are similar in appearance to micro-oxide presence but are related to the three dimensional nature of the sample (yellow arrows).

Sub-micron scale crystals (herein termed 'micro-oxides'), that appear bright white in BSE images, pervasively decorate the outer surface of particles in sintered domains (e.g., Fig. 4.7). One exception is sample B09, wherein the sintering particles are less rounded, and are sintered with viscous necks rather than edge connections (Fig. 4.6A $\& 4.8$ ). In the sintered domains of this sample there is a conspicuous lack of microoxides, however, where edge connections are forming, incipient micro-oxide formation is observed (Fig. 4.8). The small size $(<1 \mu \mathrm{m})$ of these micro-oxides precludes detailed compositional analysis by EPMA. That notwithstanding, it is well understood that heavier element species more strongly backscatter electrons, thus appearing bright white in BSE images (Reed, 2005). Therefore, the colour-density relationship in a greyscale BSE image indicates that white objects are abundant in heavier element species (i.e., metals); hence the suggestion that they are a metal oxide of some unknown composition. Edge 


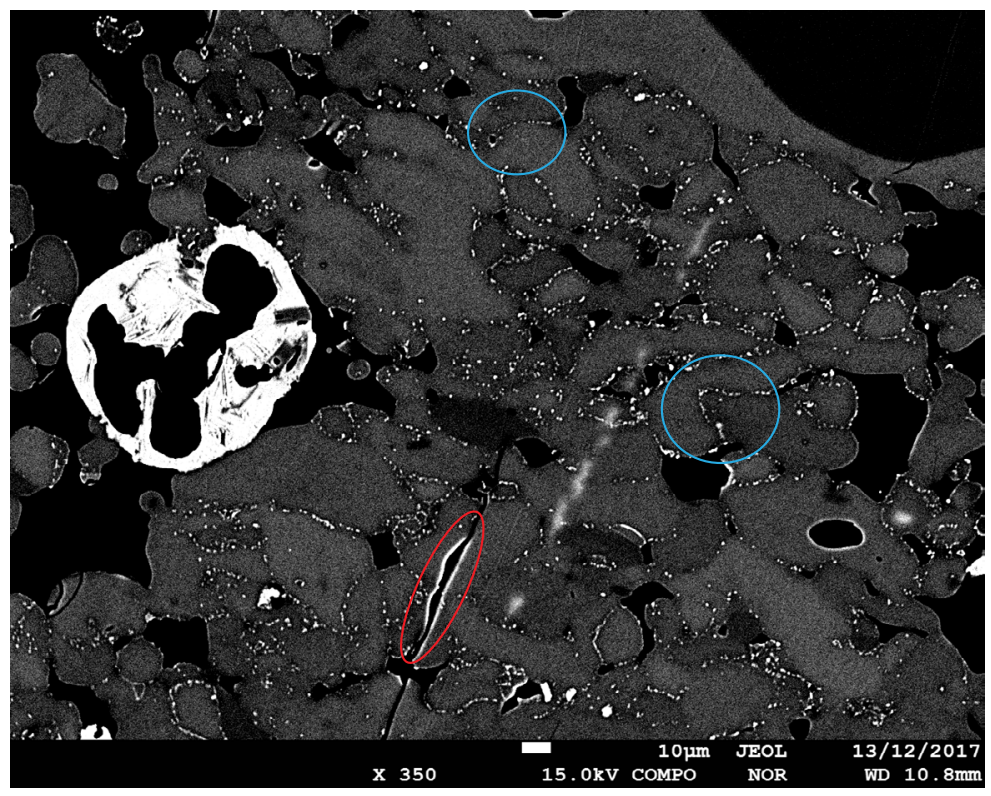

Fig. 4.9. BSE edge effect of thin section topography (red ellipse) compared to micro-oxide content (blue circles). Micro-oxides also provide a clear outline of particle deformation and 'fitting' in highly sintered regions. The larger white clast in the image left is a mafic particle.

effects in BSE images, the result of the three dimensional nature of a thin-section, also appear as bright white, but are clearly distinguishable from the micro-oxides (Fig. 4.9). A consistent observation is that micro-oxides decorate the outer surfaces of particles in sintered domains, but are never seen within particles.

At a macro-scale most sintered domains have a distinct reddish-orange colour, a feature that could be seen as indication of oxidation. The field photos of B16 (Fig. 4.1H \& I) show a transition from red to black colouration. The examined thin-section of B16 is all black material, but the minor regions of red material observed in hand sample show no textural difference. The sample is almost entirely sintered material with a heavy micro-oxide presence (Fig. 4.6B). Therefore, no reliable relationship can be drawn between the colouration and micro-oxide presence or absence. Nonetheless, reddishorange colouration is still indicative of micro-oxide presence, and possibly oxidation. In other words, reddish-orange colouration always indicates the presence of micro-oxides in these bombs, but lack thereof does not indicate the absence thereof (Fig. 4.10).

It is important to note here that some particles within sintered domains are of mafic composition (Figs. $4.6 \& 4.9$ ) - this subsidiary compositional component is detailed in sections 4.3 and 4.4. That said, mafic components within rhyolitic sintered domains are ubiquitous and generally occur as small circular particles (Fig. 4.6B). 

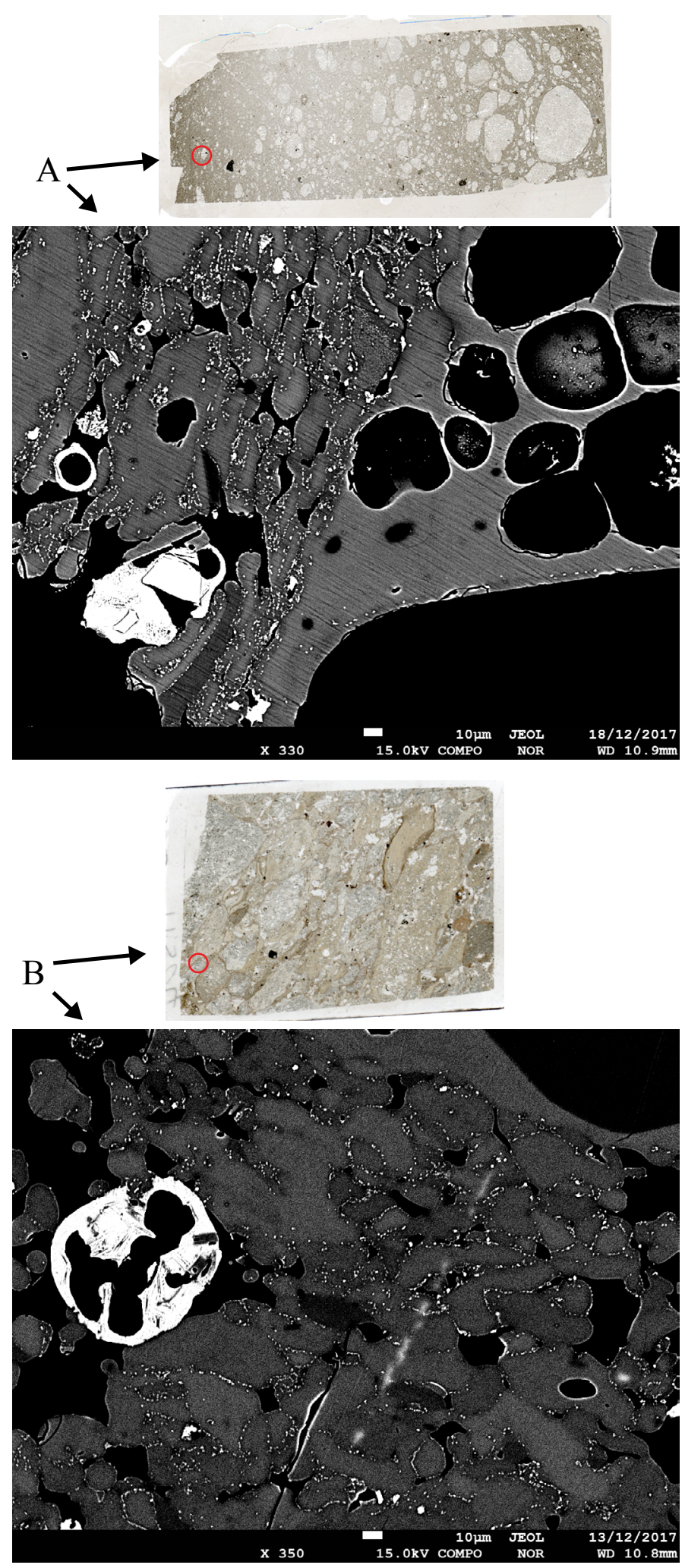

Fig. 4.10. Colour variations for comparative sintering textures in B16 (A) and B20 (B). The BSE images show sintered ash with micro-oxides in both samples, but there is a clear difference in the matrix colour in the thin-section images (black in B16 and reddish-orange/brown in B20). There is no compelling difference in micro-oxide content, particle size or shape, or style of sintering. 


\section{Vesicular Domains}

Vesicular domains are defined here as quenched magmatic foam formed by volatile exsolution and the growth of gas bubbles. Pore space, that is, void space of unspecified provenance, is present in almost all domains to some degree. In some instances pore space might consist of gaps between sintering particles (a feature of particle packing, compaction, and degree of sintering), or fractures that could be the result of deposition or sample preparation. Accordingly, vesicular domains are defined as any region that cannot be seen to involve the sintering of individual particles and has a vesicularity greater than $20 \%$ (following the classification of Houghton and Wilson (1989) for poor vesicularity to distinguish from dense regions). No maximum vesicularity need be defined, however, the observed maximum is $\sim 83 \%$ (B21-AS26, e.g., Fig. 4.11). Within vesicular domains there is significant variation in size, shape, connectivity/isolation, and arrangement or fabric, among other characteristics.

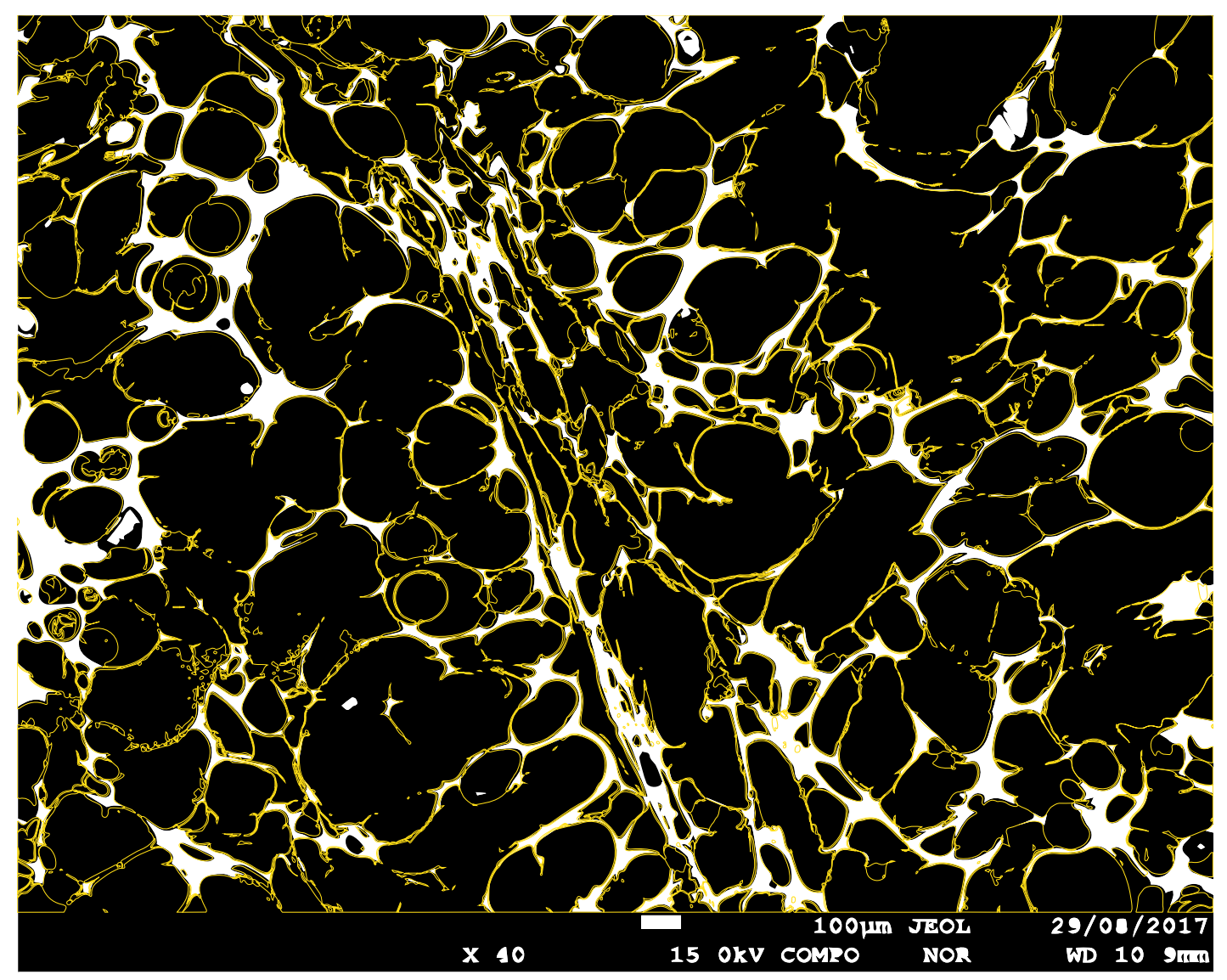

Fig. 4.11. Simplified BSE image to highlight complex vesicle shapes with coalescence, deformation, and irregular orientations in B21. White regions outlined in yellow are glass ( \pm crystals, microoxides, and mafic material), black regions are pore space (i.e., vesicles). 
Vesicles vary from spherical to highly convolute, elongate shapes (Fig. 4.11 \& 4.12). In general, the larger the vesicle the more convolute and elongate the shape will be. Small $\leq 100 \mu \mathrm{m}$ vesicles and vesicles that lack clear evidence for coalescence are generally more spherical in shape than those that are polylobate, and obviously coalesced. Moreover, where inter-bubble melt films (IBFs, after Castro et al., 2012a) are relatively thick, vesicle shape is spherical to a greater degree (Fig. 4.12D). However, although far less common, spherical vesicles can be found surrounded by thin IBFs, showing evidence for coalescence, and as relatively large $>100 \mu \mathrm{m}$ vesicles (Fig. 4.12B).
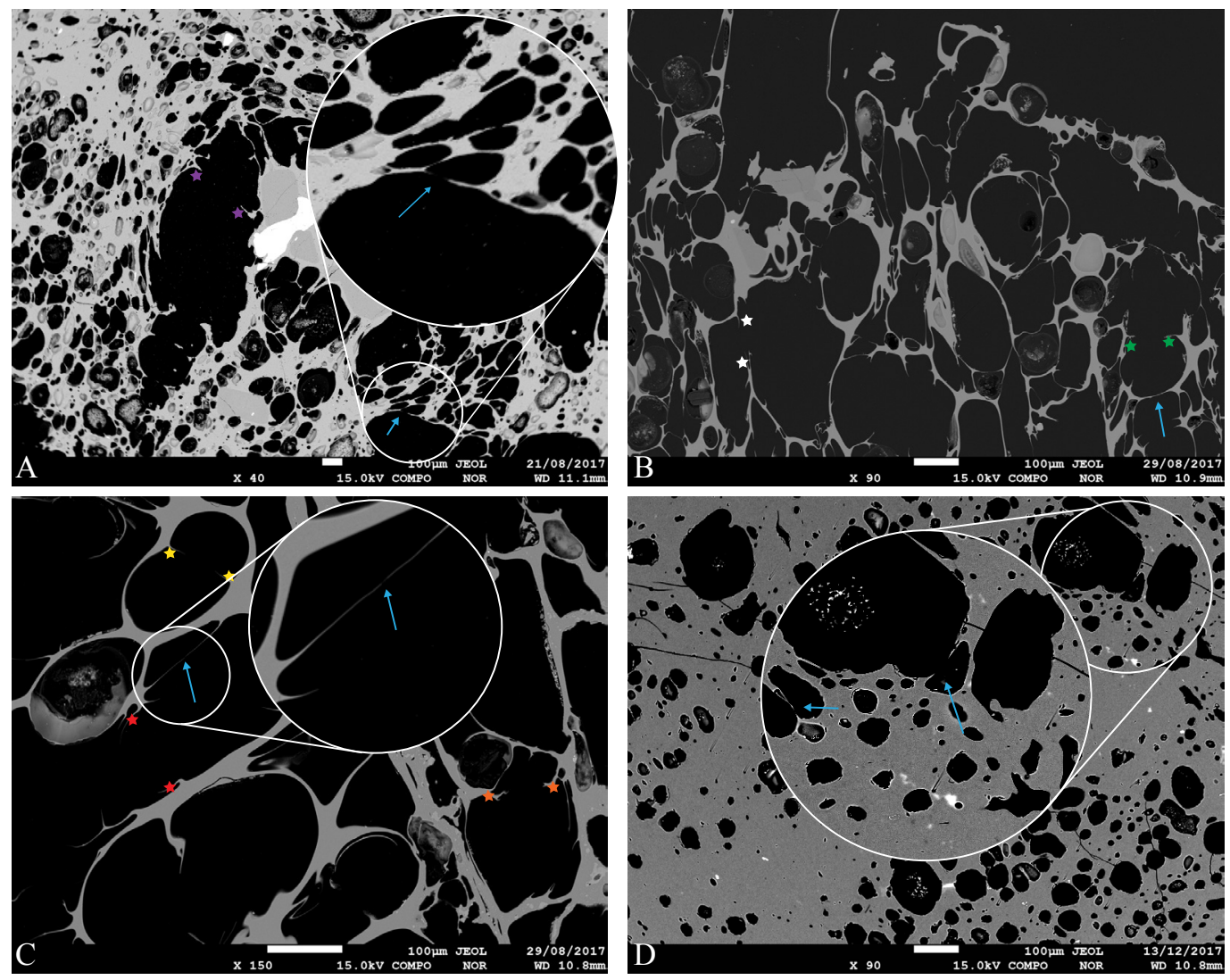

Fig. 4.12. Coalescence textures in vesicular domains. Examples of incipient coalescence in vesicular domains (blue arrows) in B20-AS04 (A, D), and B21-AS26 (B,C). Coloured stars denote suggested filament pairs that indicate relict IBFs.

The range in vesicle size within vesicular domains across all samples is $\sim 14 \mathrm{~mm}$ to $<10$ $\mu \mathrm{m}$ (measured on the long axis of vesicles). However, given the variation in vesicle shape seen in these samples, such measurements cannot provide an accurate measure of vesicle volumes. Large vesicles $\geq 150 \mu \mathrm{m}$ are invariably the product of coalescence, as indicated by the presence of fine glass filaments extending inward from IBFs toward 
vesicle centres (Fig. 4.11). These are understood to be the remnants of old IBFs that have ruptured during growth (e.g., Herd and Pinkerton, 1993). These fine filaments are commonplace in vesicular domains but show varying degrees of separation prior to final quenching (Fig. 4.12). Some filaments have only minor separation from a corresponding filament ( $\leq 20 \mu \mathrm{m}$ gap between tips) and can therefore be recognised as a pair that constitute parts of a remnant IBF. Others are short $(5-10 \mu \mathrm{m})$ points that have no clear corresponding point but are nonetheless indicative of a relict section of IBF. These are endmembers of the spectrum of coalescence in these samples, although, there may be advanced coalescence that has removed all visual trace of relict IBFs.

Deformation of IBFs, or conversely, the deformation of vesicles is a prevalent feature of vesicular domains (Fig. 4.13). One of the most distinctive deformation features is where relatively thin (generally $<10 \mu \mathrm{m}$ ) IBFs have become sinuous, as opposed to relatively simple convex/concave forms; similar to but more complex than the examples given
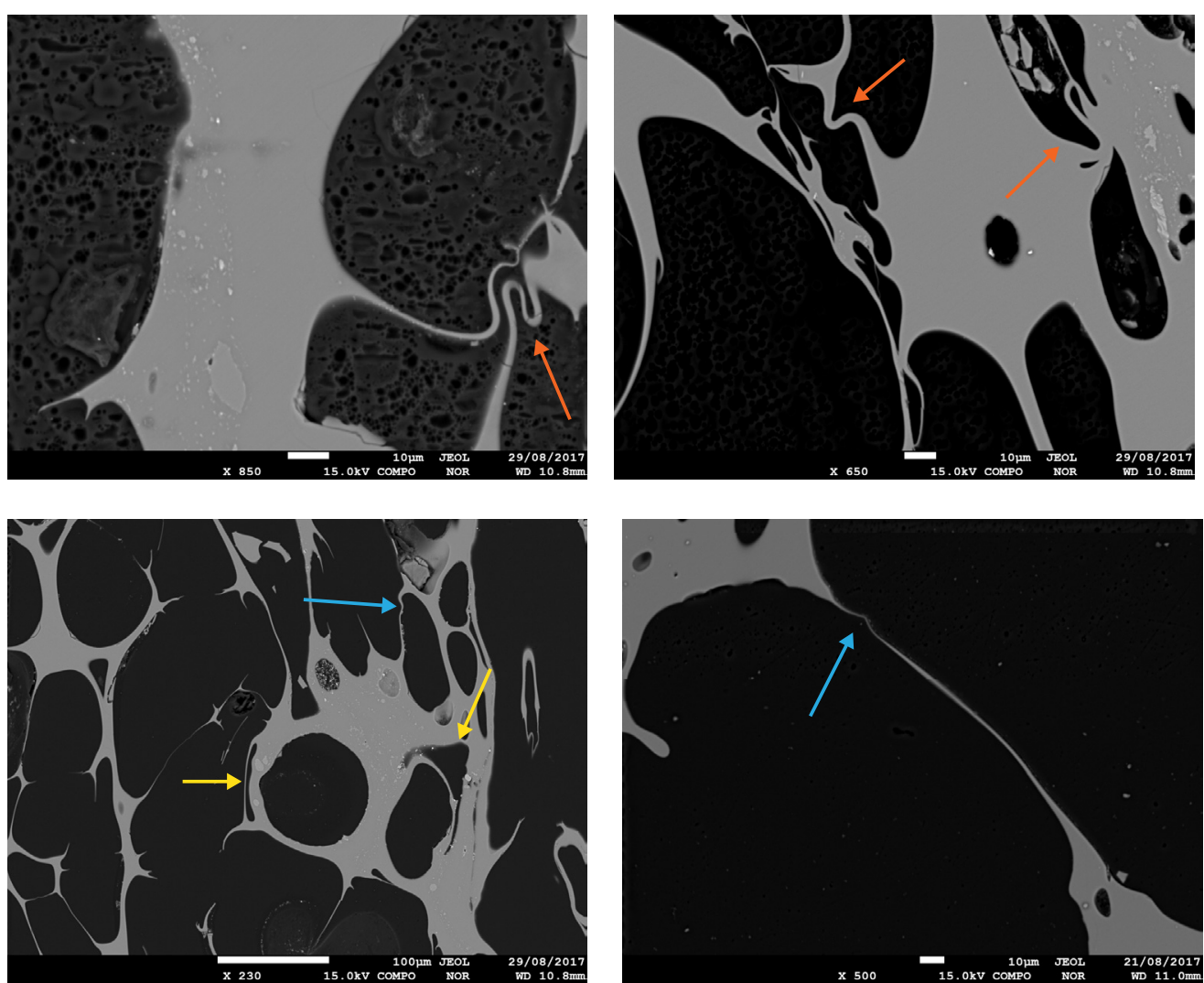

Fig. 4.13. Deformation and collapse of thin IBFs in highly vesicular domains of B21. Sinuous deformation of IBFs (orange arrows), kinked or wrinkled IBFs (blue arrows), and vesicle embayments (yellow arrows). 
in Castro et al. (2012a, Figs. 1, 2, \& 3) and Martel and Iacono-Marziano (2015, Fig. 2). Another common deformation feature is the embayment of one vesicle by another. This feature does not follow any discernible relationship (i.e., it is not always a larger vesicle embaying a smaller vesicle), although it does appear to be more common where a larger and smaller vesicle are juxtaposed.

Observations of vesicle alignment within vesicular domains is largely dependent on the scale of examination (Fig. 4.14). Coarse vesicle alignment is present in some vesicular domains, however, fine scale examinations expose the complexity of vesicle arrangements. At finer scales, vesicular domains are clearly less ordered in orientation, although local vesicle alignments can be seen in some domains they are not ubiquitous within any given domain.

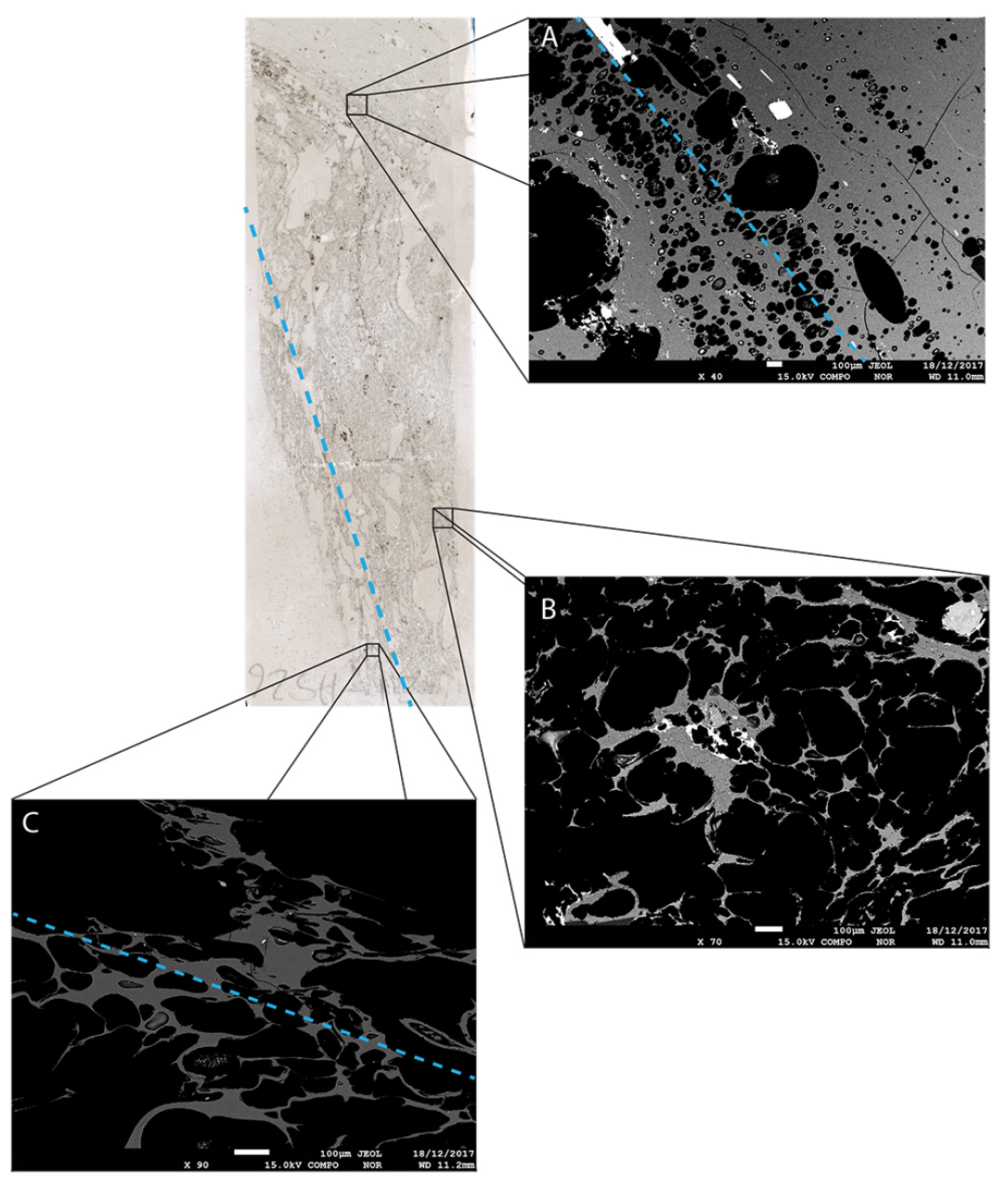

Fig. 4.14. Variations in apparent vesicle alignment between macro- (thin-section) and micro-scale (BSE images, $A, B$, and $C$ ) in B21. Blue dashed lines indicate the apparent general alignment; note that $B$ does not show any alignment. 
A relationship can be drawn between variations in the features mentioned above and the type of vesicular domain in question. In vesicular individual clasts found within a composite sample (i.e., B20: Fig. 4.12D), the vesicles are generally more rounded, with thicker IBFs, and less evidence for deformation or collapse, (also true for the denser rinds of grey pumiceous bombs: Fig. 4.14A). Conversely, samples such as B21, that appear more homogeneous, have more convoluted vesicle shapes, and, for the most part, very thin IBFs (Fig. 4.14B \& C). Crystal size ranges are approximately equal for all vesicular domains, and crystal abundances (relative to melt), are approximately equivalent across all vesicular domains.

Further to the above is an absence of micro-oxides in the vesicular clasts of composite samples and a presence of micro-oxides in more homogeneous samples such as B21. The vesicular clasts of composite bombs (i.e., B20) are invariably micro-oxide free, whereas, grey pumice bombs (i.e., B21) have micro-oxides in linear to curvilinear, non-continuous bands. The dense rind of B21 contains fairly linear bands, whilst in the vesicular inner zone of the bomb the micro-oxide bands are heavily curvilinear.

\section{Dense Domains}

Dense domains are defined as any regions that have a vesicularity less than $20 \%$ and cannot be seen to consist of individual particles that have been sintered together. To distinguish dense domains from lithics, which here invariably fit the criteria of $<20 \%$ vesicularity and no evidence of sintering, a crystallinity and alteration condition can be applied. Lithics in these bombs (Fig. 4.4), although dense, are either highly crystalline fragments, or fragments of palagonite (altered mafic volcanic glass), both of which are distinctly different in texture from the juvenile products.

Vesicles in these dense domains are generally more circular, smaller, and more dispersed (i.e., thicker IBFs) than those in vesicular domains. However, elongated and aligned vesicles occur throughout dense samples, seemingly as bands between regions with circular vesicles (Fig. 4.15). The largest vesicle present in any observed dense domain measures $\sim 514 \mu \mathrm{m}$ (longest axis), whereas the majority of vesicles are in the range of $\sim 5$ $\mu \mathrm{m}$ to $\sim 60 \mu \mathrm{m}$. Furthermore, in thin-sections that consist only of dense domains, vesicle populations often occur in discrete bands or lenses of higher and lower vesicularity. Usually, a band or lens of $5-20 \%$ vesicularity, $\sim 300 \mu \mathrm{m}$ to $1 \mathrm{~cm}$ wide, is juxtaposed with a region of less than $1 \%$ vesicularity (Fig. 4.15). The band or lens of higher vesicularity can be continuous (within the limitations of the thin-section, $\sim 2.5 \mathrm{~cm}$ max) 
or discontinuous. In some cases the juxtaposed higher vesicularity domain still fits the conditions of a dense domain, but in others the vesicularly is greater than $20 \%$ and could thus be categorised as a vesicular domain. This is however marginal, as in general the vesicularity is only $2-3 \%$ over the given threshold of $20 \%$, and is strongly dependent on where the boundaries for a given band are defined. If the boundaries shown in Fig 4.15A are narrowed marginally ( $\sim 300-500 \mu \mathrm{m}$ narrower), the vesicularity in these bands would be slightly over the $20 \%$ threshold.
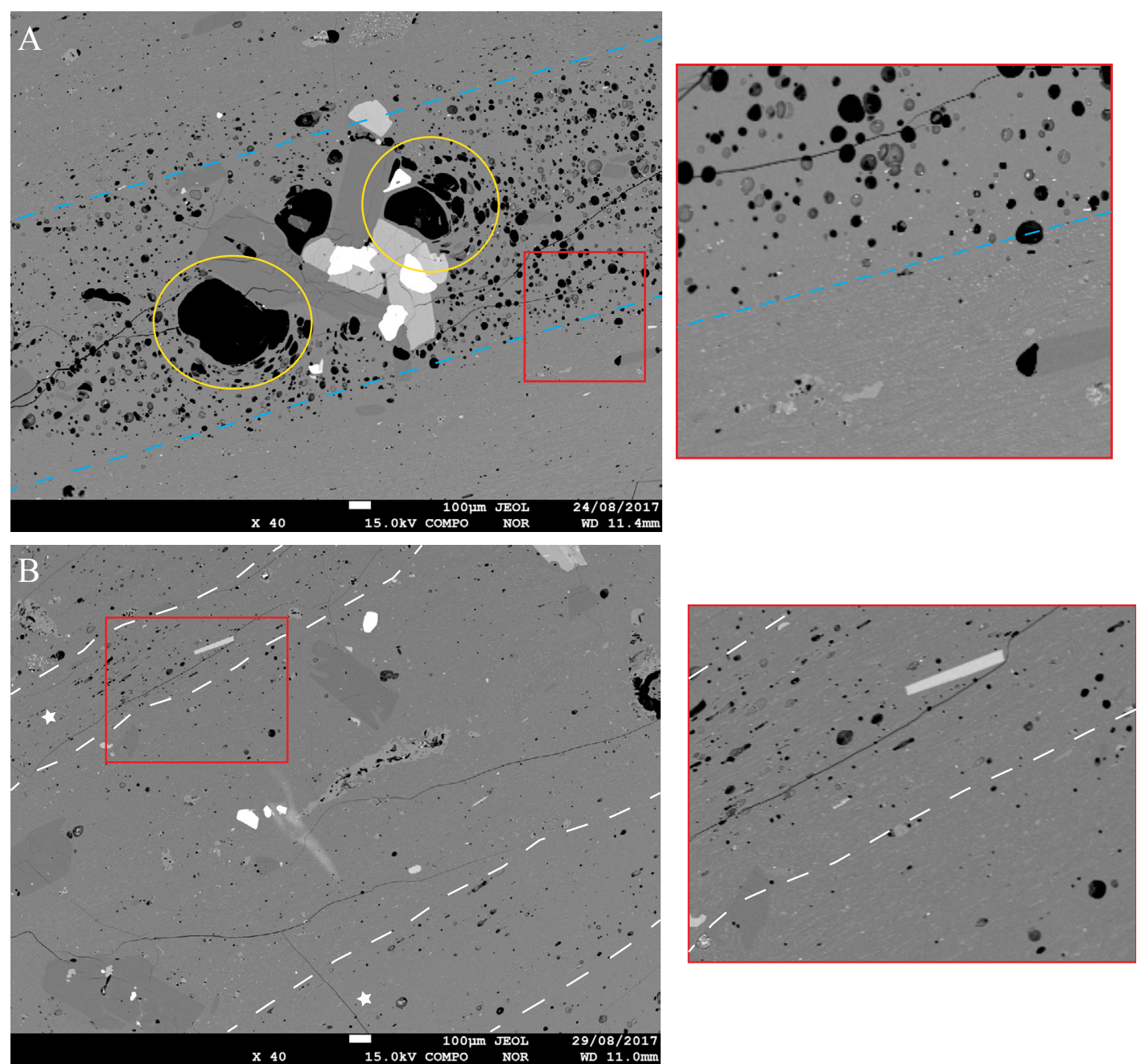

Fig. 4.15. Two images from B10-AS01 showing boundaries between higher and lower vesicularity bands (Blue dashed lines in $A$ ) and vesicle elongation (white dashed lines in B; white stars indicate bands with elongation). Image $A$ has approximate vesicularities of $3.5 \%, 19 \%$, and $2 \%$ above, between, and below the blue dashed line respectively The abundance of micro-oxides in A is strongly correlated with the vesicularity, above and within the blue dashed lines only minor amounts of microoxide banding are seen. Vesicularity varies marginally $(<2 \%)$ between the bands in B, micro-oxides are constant. Yellow circles indicate regions where smaller vesicles are deformed by the growth of larger vesicles. 
Crystal abundances are approximately equal to vesicular domains, however, in dense domains, larger crystals are generally concentrated into finite regions or bands, as opposed to the random dispersion in vesicular domains. Larger crystals $(>200 \mu \mathrm{m})$ are invariably cracked, possibly as a result of the thin-sectioning and polishing processes. However, many large, cracked phenocrysts also have segments that have partially separated along fracture planes with no observable displacement or cracking of the surrounding glass (Fig. $4.16 \& 4.17$ ). Therefore, at least some of the cracking in large phenocrysts must be a real feature of these dense domains.
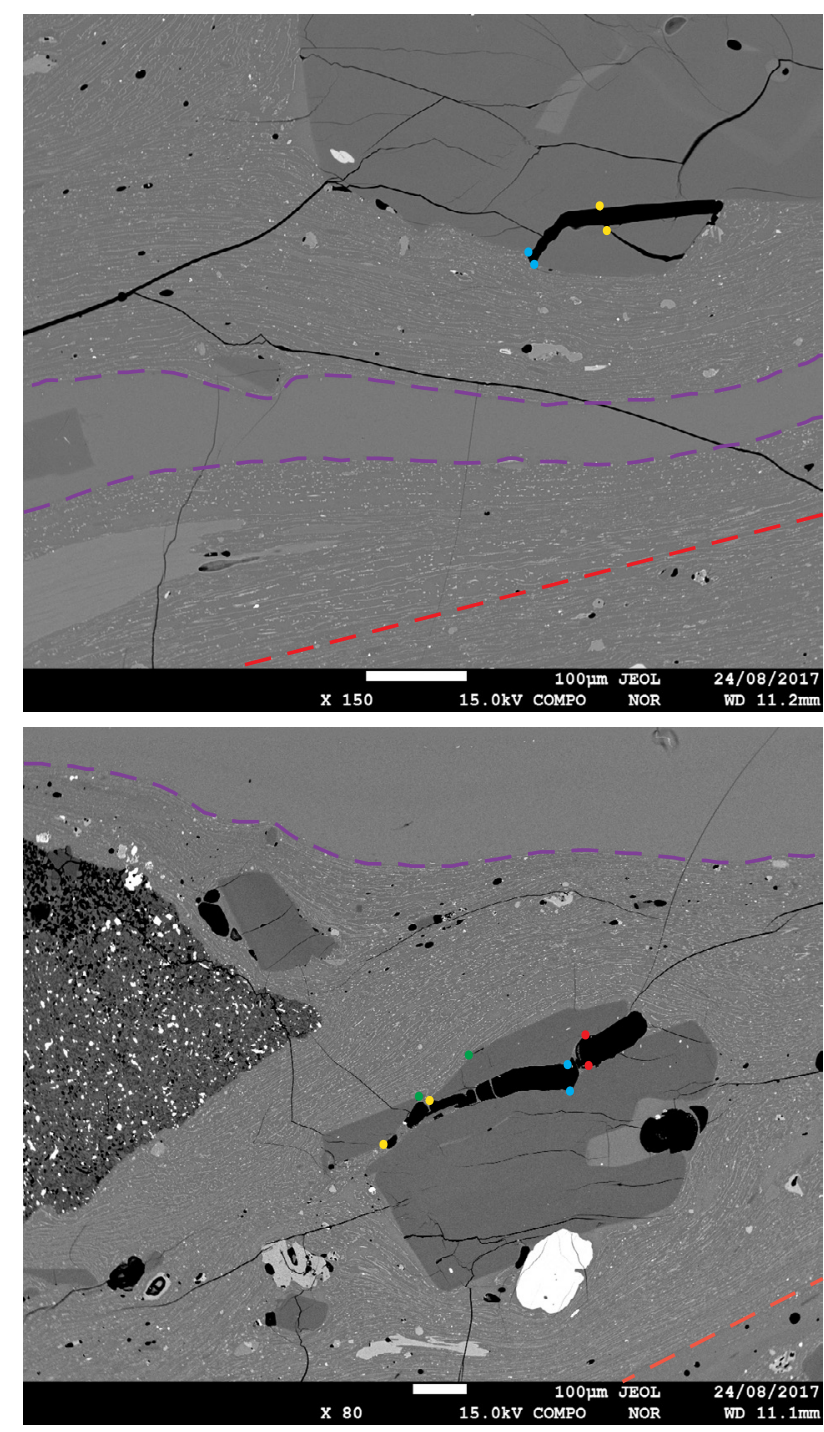

Fig. 4.16. Displacement of crystal fragments in B10-AS01 (top and bottom) roughly parallel to banding alignments. The dashed red lines indicate the approximate orientation of banding in this sample while the coloured dot pairs indicate tie points for the displacement of the fragments. The areas within and above the dashed purple line respectively is not indicative of the orientation of banding. The glass and oxide banding proximal to displaced fragments shows no signs of brittle deformation as a result of crystal fragment separation. The fractures that are present can clearly be seen to affect crystals, glass, and lithics so are likely the result of thin-sectioning. 


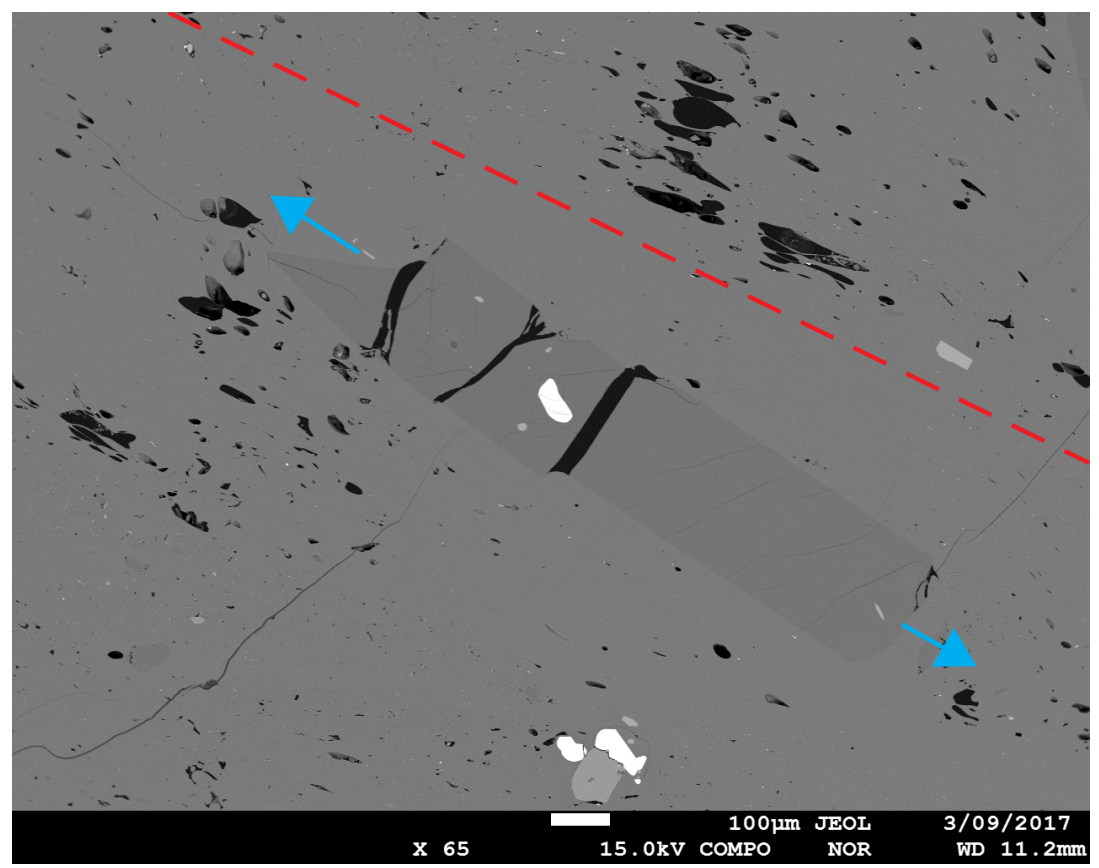

Fig. 4.17. Crystal separation perpendicular to alignment in B11-AS09. The dashed red lines indicate the approximate orientation of banding/vesicle elongation in this sample. The blue arrows indicate the azimuth of displacement, slightly sub-parallel to the orientation of banding. Note also that the glass surrounding the crystal is largely crack free and undisturbed.

Some (typically larger) phenocrysts have also agglomerated to form glomerocrysts (Fig. $4.15 \& 4.18$ ), and whilst this feature is also present in some vesicular domains, it is more extensive in dense domains. Individual crystals in the glomerocrysts of dense domains are slightly subhedral and vary greatly in size and orientation (based on the long axes). The majority of glomerocrysts are polymineralic, and the less abundant monomineralic glomerocrysts are usually composed of Plagioclase crystals. Glomerocrysts are usually associated with a band or lens of greater vesicularity and occasionally have cavities with spiral-like patterns of elongated vesicles around a larger central vesicle (Fig. 4.15A). Small to medium crystals $(<10 \mu \mathrm{m}$ to $\sim 100 \mu \mathrm{m})$ dominate the lower vesicularity bands of dense domains and often show an alignment, even where vesicles have no obvious alignment. Of these, it is the smallest crystals that have the most consistent alignment. Some larger crystals are aligned with smaller crystals and vesicle elongation (Fig. 4.17), but this is less common than for smaller crystals. 


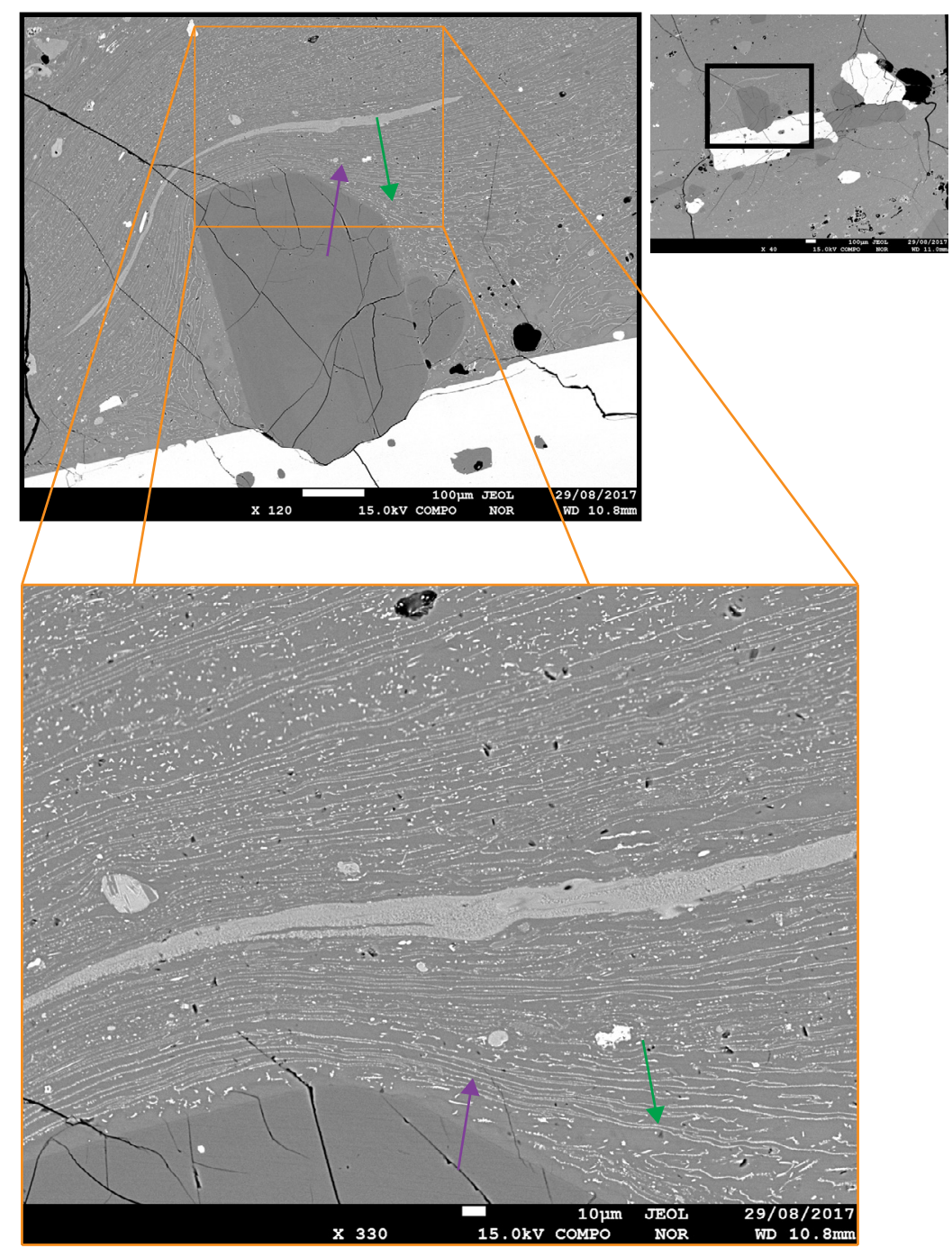

Fig. 4.18. Smooth 'flowing' micro-oxide bands around a section of a glomerocryst in B10-AS01. The light grey lens provides a good visual indication of the general trend of all banding features in the proximal area. Bands cluster tightly at the away from/immediately next to the glomerocryst (purple arrows) and are more dispersed closer to the main body of the glomerocryst (green arrows).

Micro-oxides are also pervasive within dense domains, they do however differ significantly in their arrangement with respect to those in sintered domains, and are far more pervasive than in the vesicular regions of grey pumice bombs. In these dense domains they are present as non-continuous, sub-linear bands that follow the general orientation of vesicularity bands, vesicle elongation, and crystal alignment (Fig. 4.15, 4.18, \& 4.19). Furthermore, some regions are notably absent of micro-oxides. Some bands with glomerocrysts and higher vesicularity are absent of micro-oxides, except at the margins where different zones of contrasting vesicularity converge (Fig. 4.15). Contrarily, glomerocrysts and greater vesicularity regions can also be found with micro-oxides present (e.g., Fig. 4.15B), and lenses with micro-oxide absence are found with no vesicles or crystals whatsoever (e.g., between and above purple lines in Fig. 4.16). 


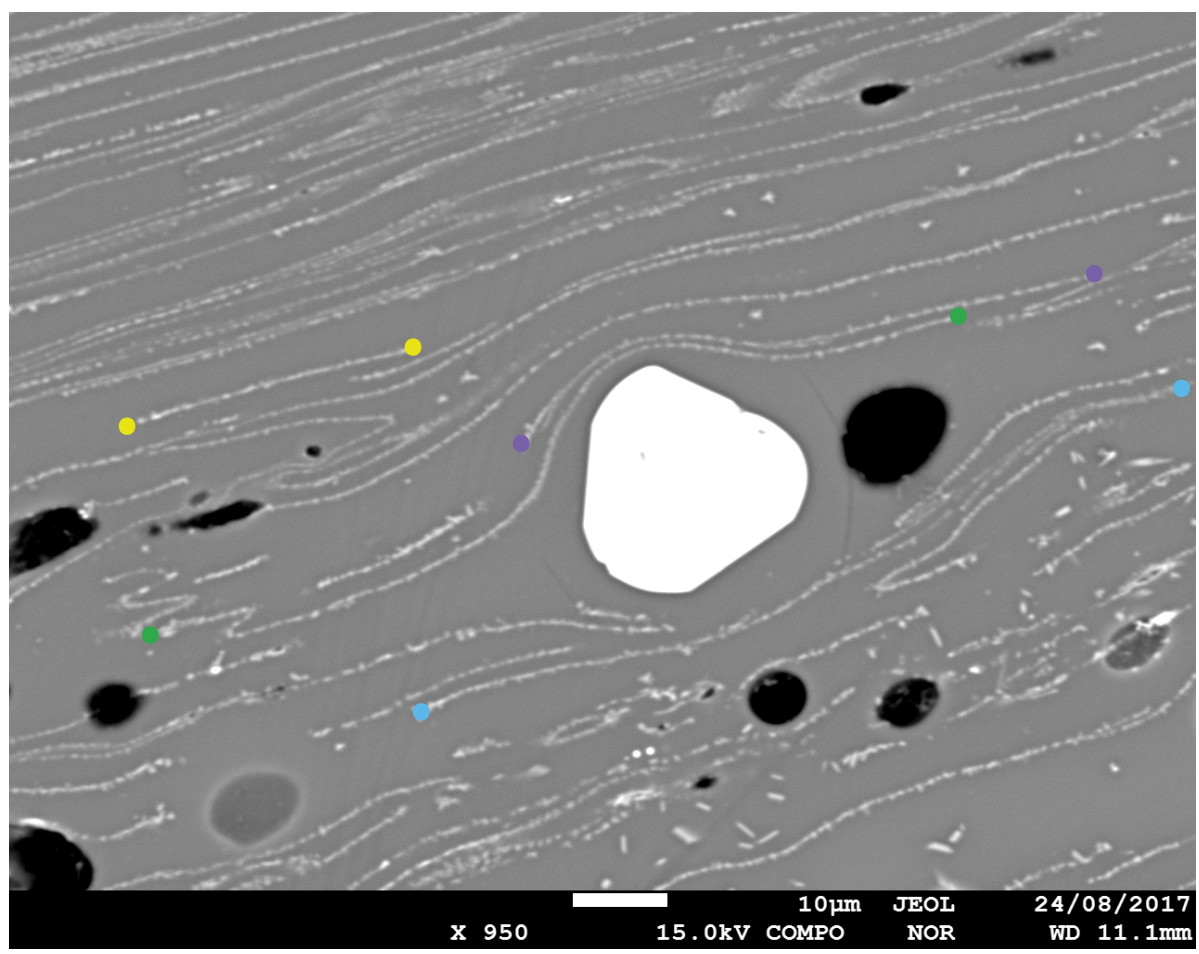

Fig. 4.19. Close up of micro-oxide banding illustrates the discontinuous nature of these 'bands'. The coloured dot pairs indicate the start and end points of four micro-oxide 'bands'. While some appear to be continuous this is at a very fine scale.

Slight greyscale variations can be found in the glass of dense domains and EDS analysis points to slight (1-2 wt.\%) variations in $\mathrm{SiO}_{2}, \mathrm{~K}_{2} \mathrm{O}$, and $\mathrm{Na}_{2} \mathrm{O}$ (increase in $\mathrm{Na}_{2} \mathrm{O}=$ less $\mathrm{SiO}_{2}+\mathrm{K}_{2} \mathrm{O}$ and vice versa), where darker coloured glass has a higher wt. $\%$ of $\mathrm{Na}_{2} \mathrm{O}$ relative to the lighter coloured glass (Fig. 4.20). The mottling largely appears splotchy but some areas contain noticeably acicular forms. Splotches and acicular forms are invariably darker material, whilst the lighter glass makes up the background, and furthermore, there is a distinct lack of micro-oxides in the mottled areas.

A distinctly different dense texture is observed in sample B09 (Fig. 4.21). This texture fits into the dense domains classification, as it has a vesicularity of $11 \%$ and has no evidence for particle-particle sintering. That notwithstanding, this dense texture shows similar features to the vesicular domains with sinuous IBFs, only here the folds have been compressed tightly together, and in some cases sintering of opposing vesicle walls has taken place. The vesicles in this dense domain are also more irregularly shaped than those in other dense domains, and the micro-oxides mentioned above are not present. 


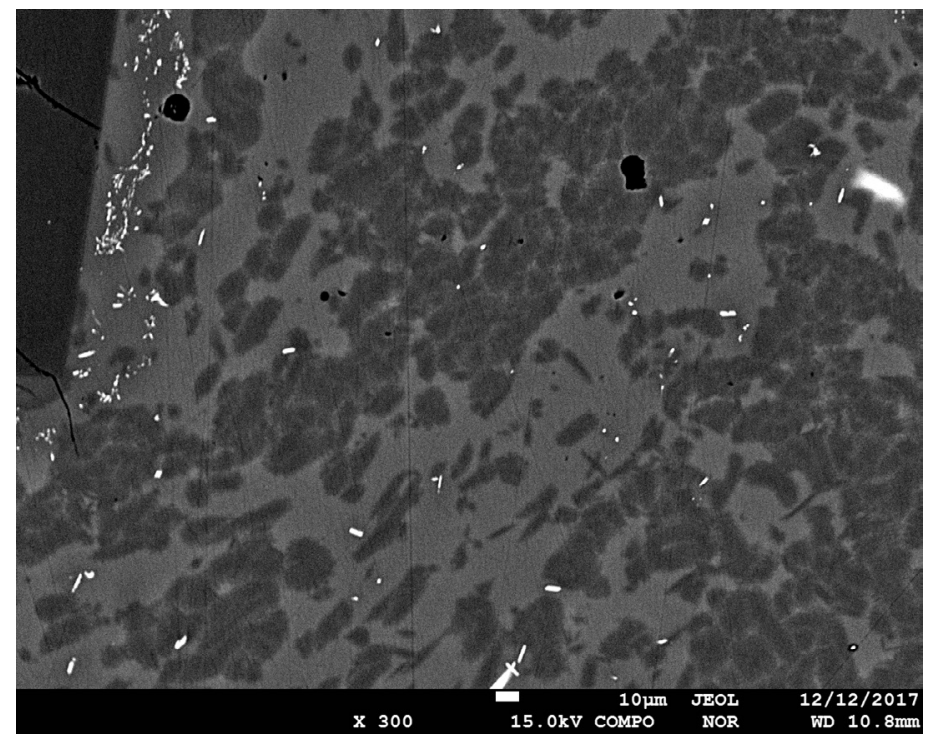

Fig. 4.20. Mottled glass texture in B11, where darker regions are higher in $\mathrm{Na}_{2} \mathrm{O}$, and lower in $\mathrm{SiO}_{2}$ and $\mathrm{K}_{2} \mathrm{O}$ relative to lighter regions.

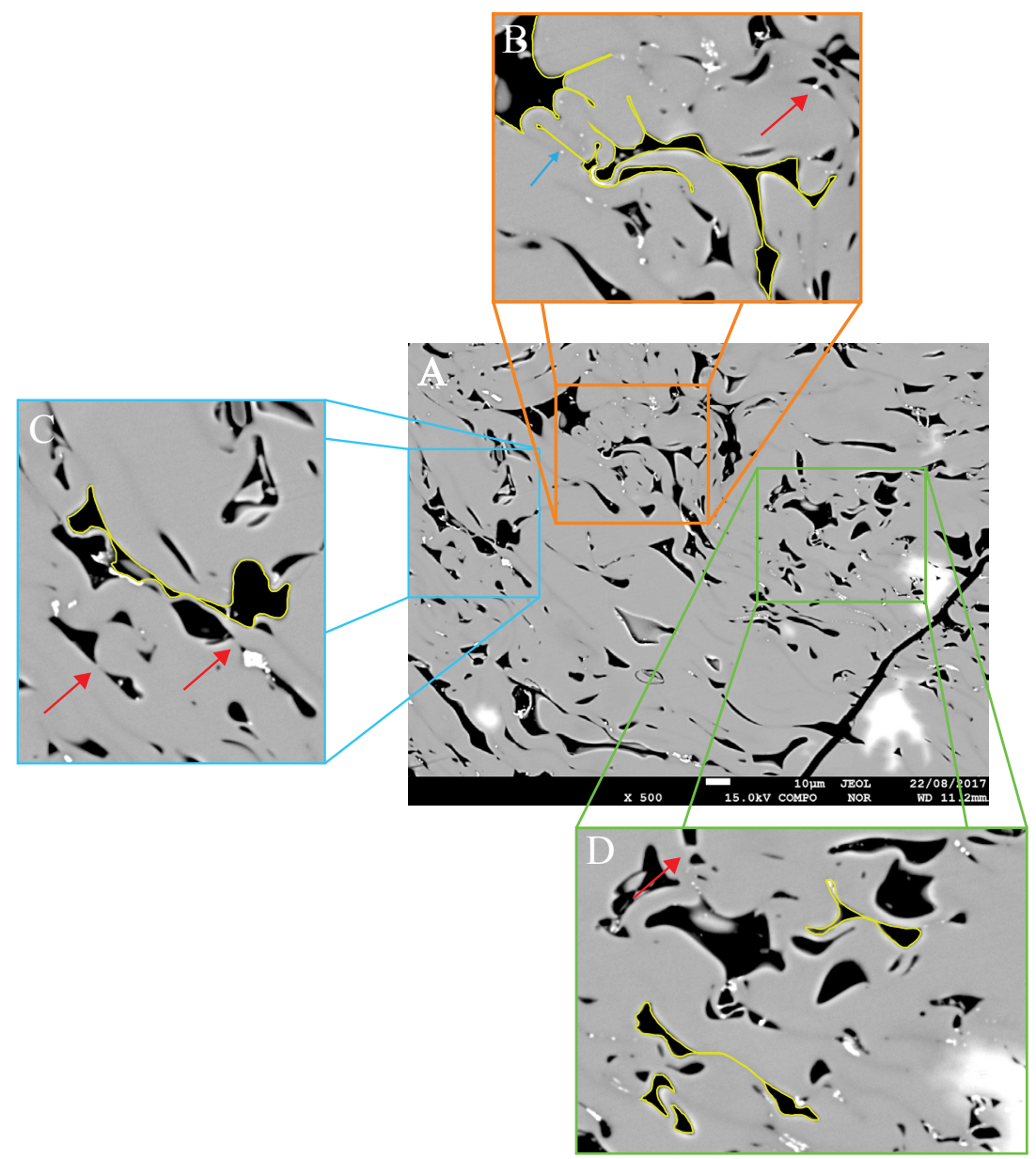

Fig. 4.21. Suggested collapsed and partially sintered foam. Yellow lines in B, $C$, and D trace the margins of collapsed vesicle structures. Note the sinuous collapse structure in $B$, indicated by a blue arrow and outlined in yellow. Red arrows indicate examples of the sintering of opposing vesicle walls after collapse. 
Dense, microlite-rich clasts (Fig. 4.22) are found in most samples, albeit infrequently, but are significantly different in texture from other dense domains. Under EDS analysis, these microlite rich clasts show no distinct compositional divergence from the bulk rhyolitic material. They are distinguished solely by texture and they are exceptionally similar in texture to lava flow samples from the same eruption (Schipper et al., 2015).

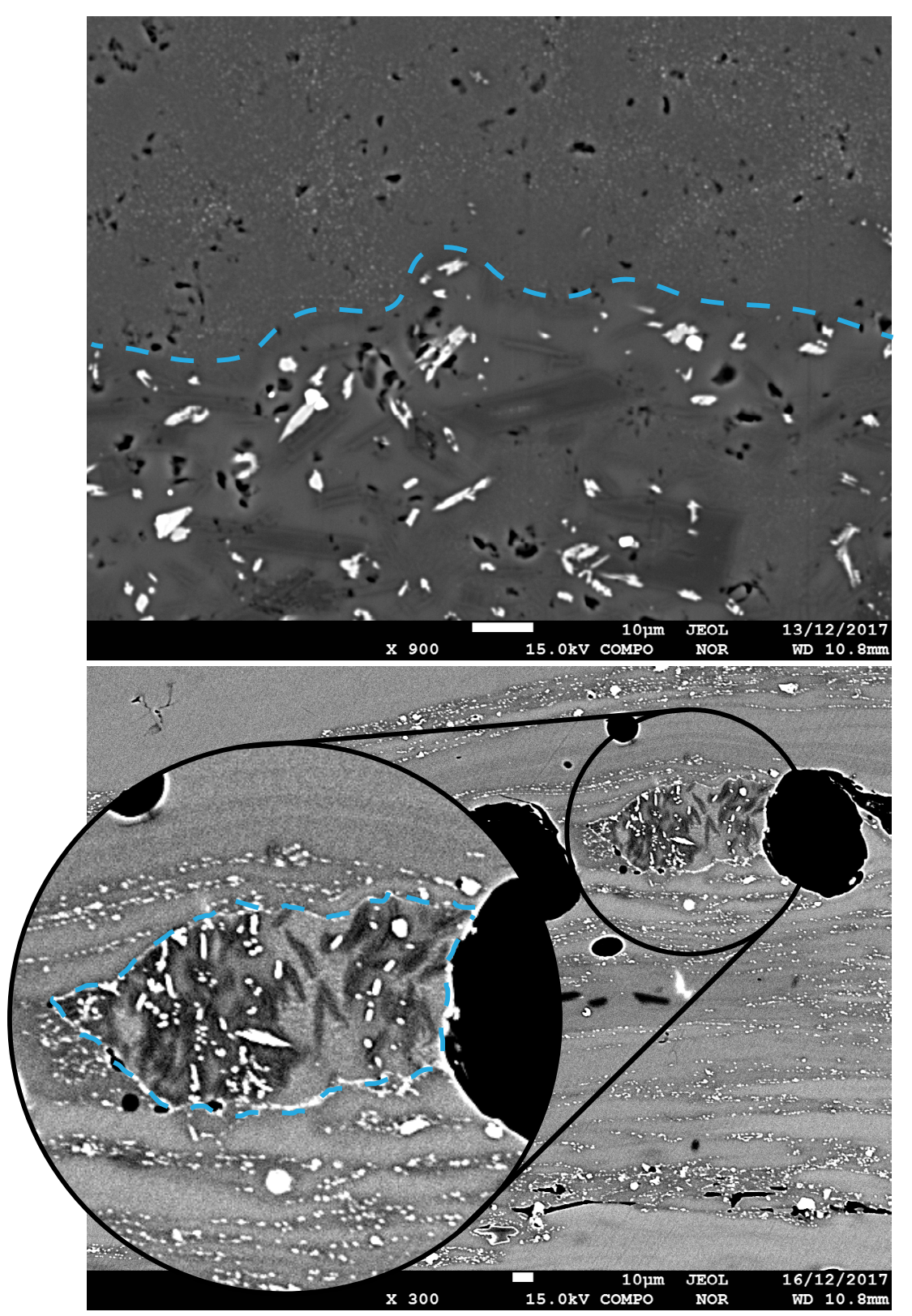

Fig. 4.22. Examples of observed microlite rich domains in B13-ASO2 (top image) and B21-AS27 (bottom image). Boundaries are indicated by blue dashed lines. This microlite rich texture is rarely observed and only in small quantities $(<2 \%$ by area). 


\subsection{Mafic Textures}

The subsidiary mafic material is easily distinguishable in BSE imaging; compared to rhyolitic glass, the mafic domains have a lighter greyscale colour, and compared to lithic fragments they are less crystalline, with greater vesicularity. The vesicles in basalticandesite domains are usually more globular forms with cuspate or embayed margins, and in general are less complex, with less evidence for coalescence relative to the vesicle populations of rhyolite domains (Fig. 4.23). Larger mafic blobs $(\leq 2 \mathrm{~cm})$ are vesicular
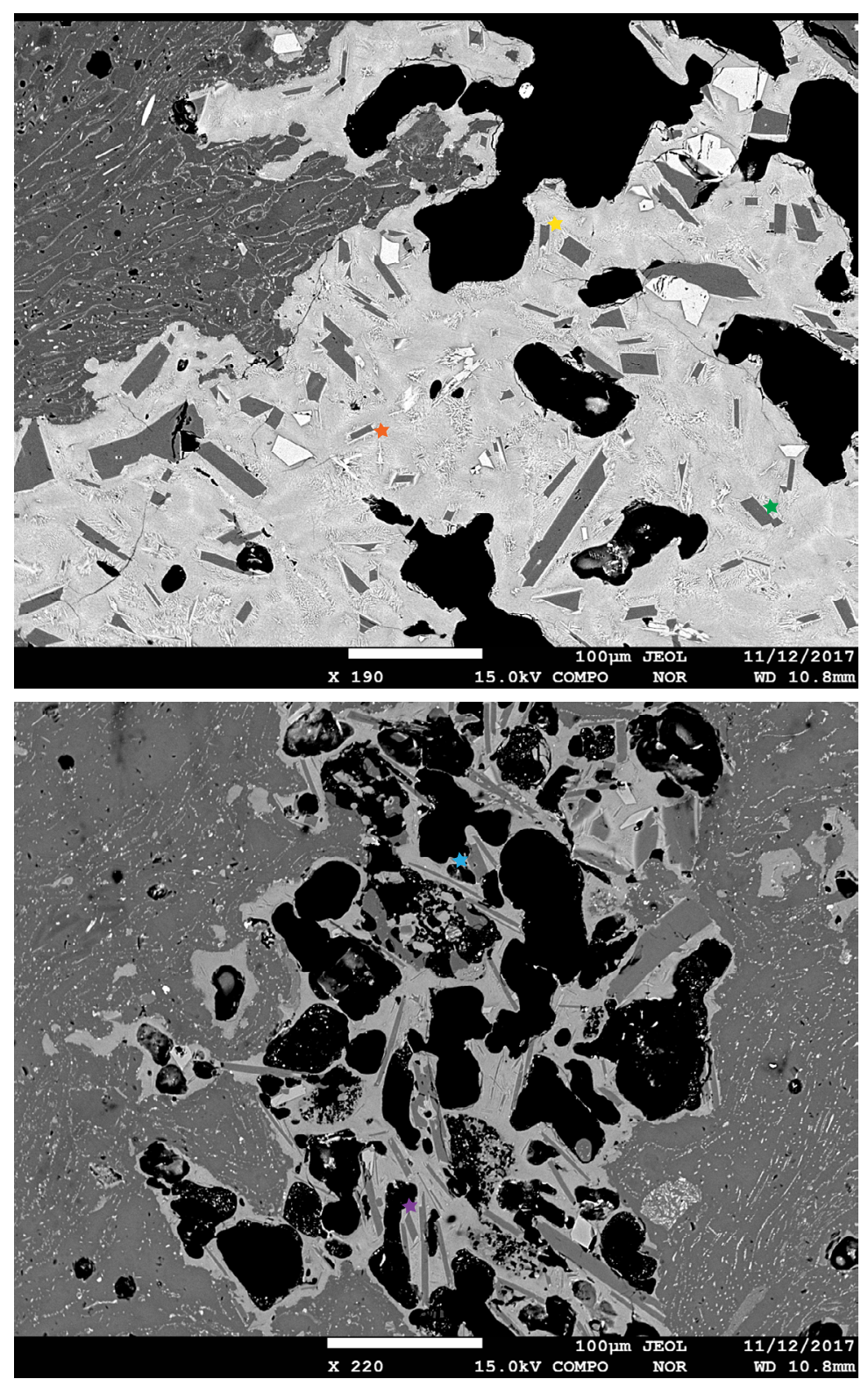

Fig. 4.23. Basaltic-andesite clasts in B10-AS01-S2 with roughly cuspate margins, large, simple vesicles, and comparatively abundant and euhedral crystals in basaltic-andesite glass (see Fig. 4.15A for comparison). Coloured stars indicate microlites with lengths: $21 \mu \mathrm{m}$ (blue), $14.5 \mu \mathrm{m}$ (purple), $17.9 \mu \mathrm{m}$ (orange), $15.5 \mu \mathrm{m}$ (yellow), and $23.8 \mu \mathrm{m}$ (green). 
( $\leq 60 \%$ vesicularity), with crystals up to $\sim 2 \mathrm{~mm}$ in length but mostly less than a few hundred microns. These larger blobs also have fine acicular crystalline rims around some vesicles and healed fracture planes (Fig. 4.24). The mafic blobs invariably have a greater abundance of crystals than rhyolitic glass (for comparative melt volumes), especially in the micro-phenocryst $(0.3-0.03 \mathrm{~mm})$ and microlite size fractions $(<0.03$ $\mathrm{mm}$ ) (Fig. 4.23). Additionally, and in contrast to crystals in rhyolitic domains, the crystal populations of mafic domains are markedly euhedral. Smaller blobs $(<1 \mathrm{~mm})$ generally occur as fine, round particles or stretched and heavily deformed fragments. These smaller clasts can still be vesicular and contain fine crystals, the smallest fragments ( $\sim 30 \mu \mathrm{m}$ or less) are non-vesicular and sub-spherical however (e.g., Fig. 4.6).

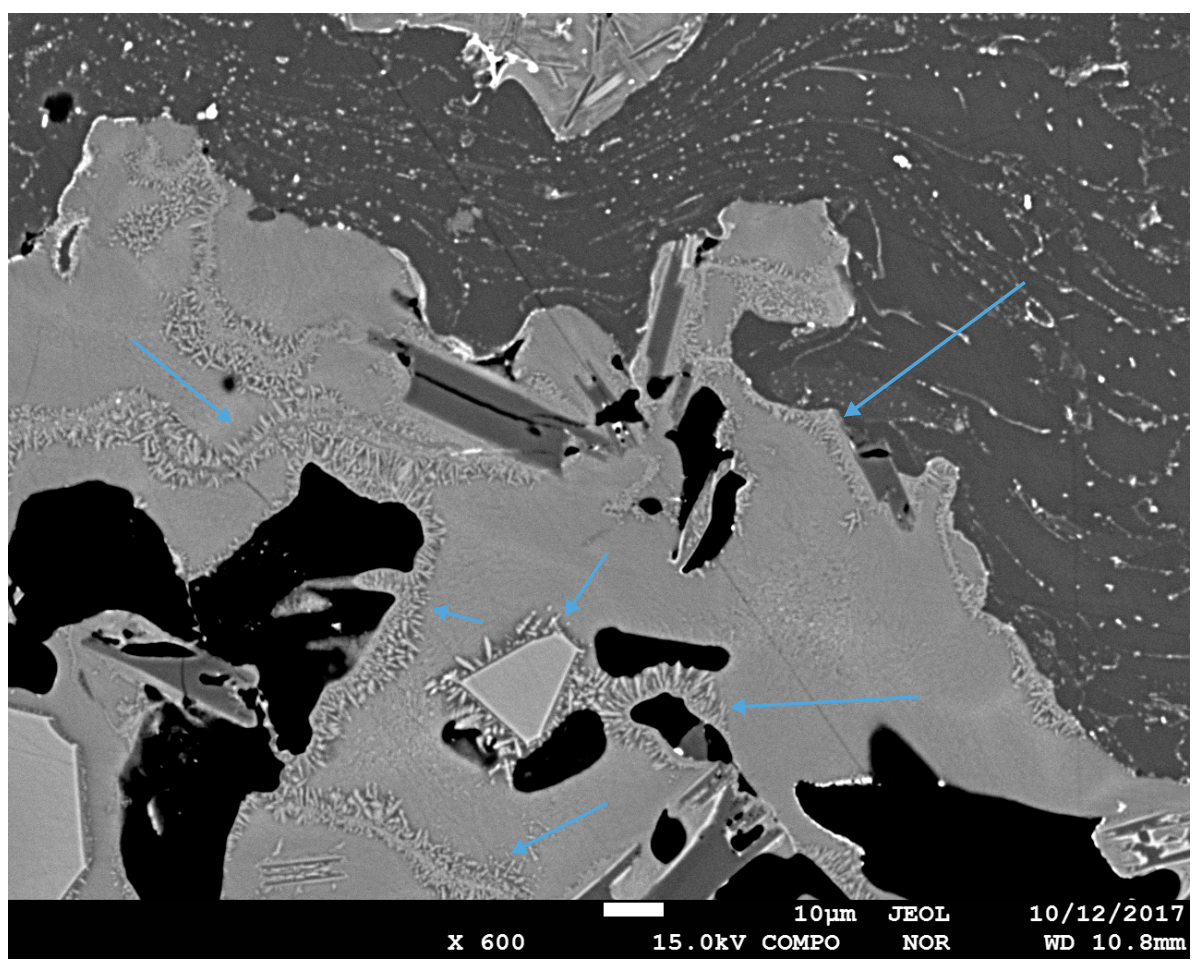

Fig. 4.24. Fine, acicular crystals (blue arrows) along healed fracture planes, and around vesicle rims and crystals. 
Enclaves and fine particles of material with a basaltic-andesite composition (reported in section 4.4) occur across all, but not in every instance of, the aforementioned textural domains. Mafic domains are found in all sintered and most dense domains, they are also found in some, but not all, vesicular domains. The vesicular domains of heavily foamed grey pumice samples contain mafic blobs, but the pumice clasts of composite bombs do not. While mafic blobs themselves do not contain micro-oxides, the presence or absence of mafic material within these domains is synchronous with the presence and absence of micro-oxides in adjacent rhyolitic matrix glass (Fig. 4.25). This synchronicity is also seen in the pumice clasts of B20, and dense glassy regions with a devitrification texture (Fig. 4.20), which are both unconditionally absent of both mafic clasts and micro-oxides. In discordance, sintered domains of B20 and other dense domains in B11 have significant (relative) proportions of both micro-oxides and mafic domains.
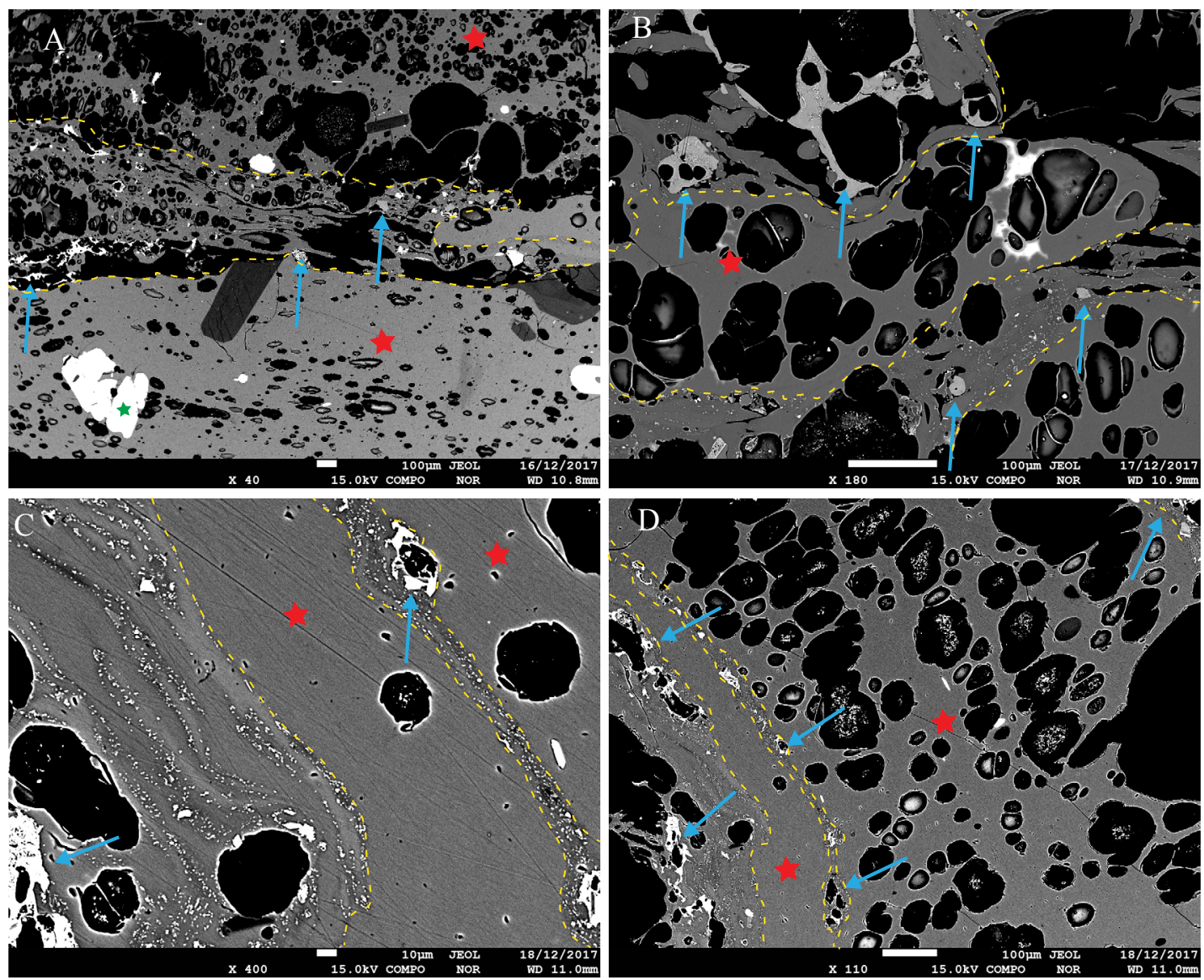

Fig. 4.25. Bands of micro-oxides (dashed yellow lines) associated with the presence of basalticandesite clasts (blue arrows) in B21-AS27 (A, B), B21-AS26 (C), and B21-AS26-L (D). Regions absent of micro-oxides (red stars) are also absent of basaltic-andesite clasts. Note that for images $A, C$, and $D$ the contrast was significantly increased for clarity between rhyolite, mafics, and microoxides. However, this results in a white colouration for some crystals (e.g., green star in A), care should therefore be taken when distinguishing between these components. 
At most, the mafic material contributes a few percentage points to the bulk rock in the examined thin-sections. Given the fine scale of some domains, the large variations in abundance, even within a single thin-section, and the difficulty of differentiating between felsic, mafic, and lithic components using a petrographic microscope, this is hard to accurately measure. While the JEOL JXA-8230 Superprobe allows for accurate identification of mafics, the minimum magnification setting does not allow the user to view or image an entire thin-section at once (Fig. 4.26). That said, mafic abundance was no more than $6 \%$ by area in any single observed BSE image (Fig. 4.27), and this is significantly more than the quantity seen in many regions. Overall, dense, banded bombs (e.g., B10) appear to have the greatest abundance of mafics, although, all samples examined contained some degree of mafic material.

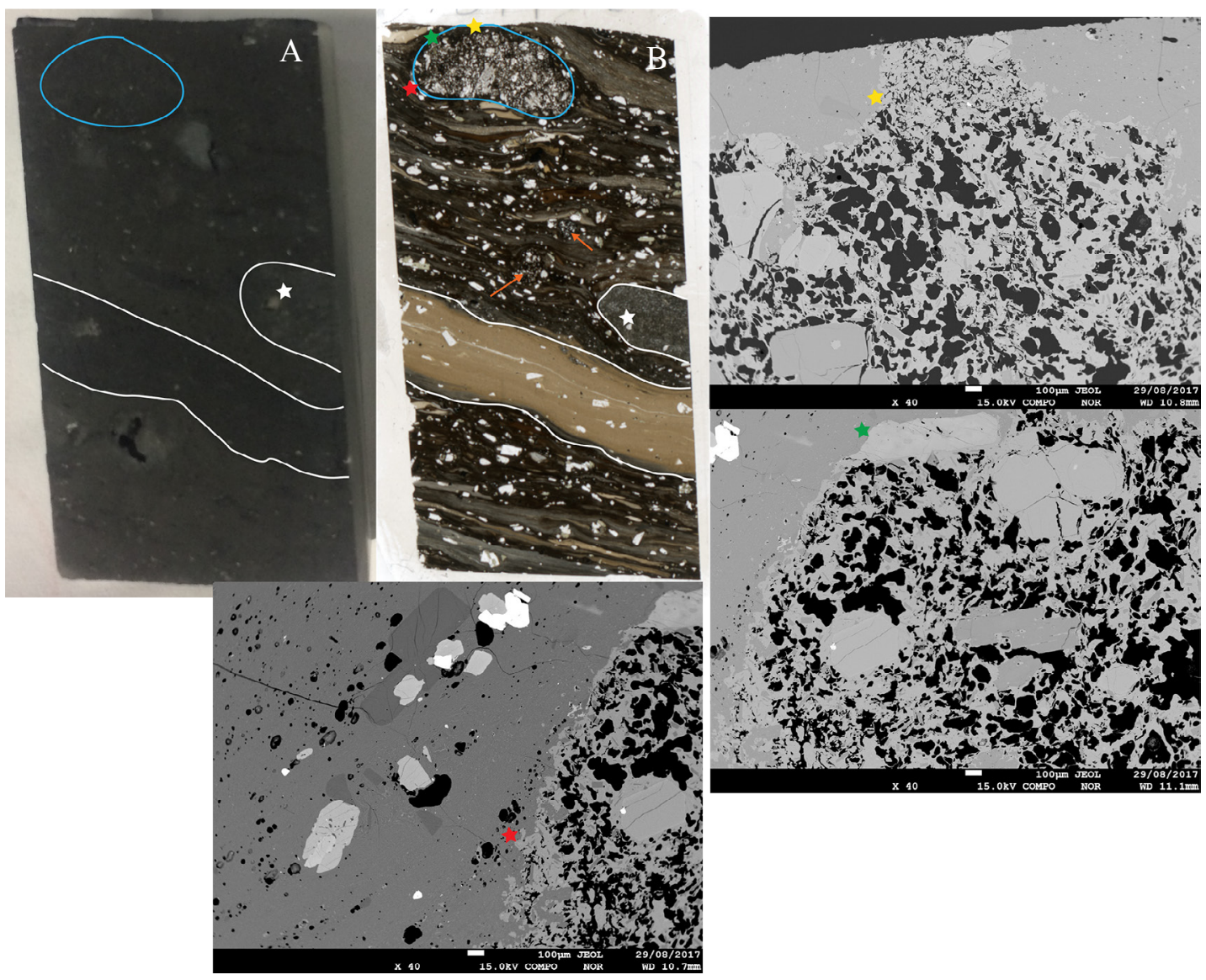

Fig. 4.26. Identification of basaltic-andesite in a sample elucidated by the use of BSE imaging. White trace's in $A$ and $B$ are used as tie points between the remaining thin-section block (A) and the thin-section (B), the blue trace in both images outlines a large clast of basaltic-andesite. In hand sample (A) basaltic-andesite regions cannot be distinguished from the surrounding rhyolite. A thin section cut from this plane reveals the presence of a large basaltic-andesite clast (blue trace) smaller basaltic-andesite clasts (orange arrows) are still difficult to identify though, and lithic clasts (white star) appear similar, although less vesicular. In BSE images the distinction between the two magmatic components is clear, coloured starts indicate tie points between $B$ and $C, D$, and $F$. 

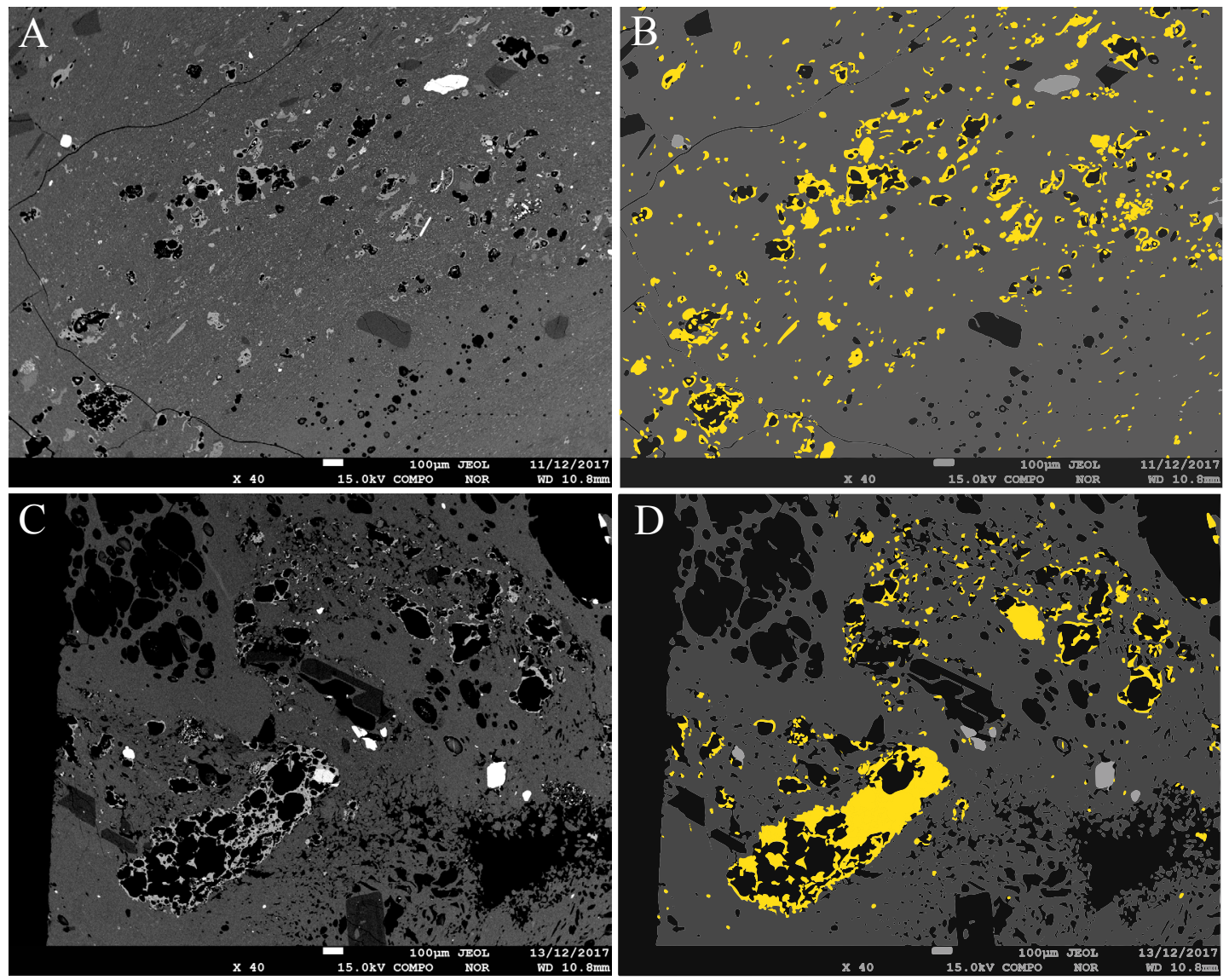

Fig. 4.27. Regions of relatively abundant basaltic-andesite in B10-AS01-S2 (A \& B) and B20-AS04 $(C \& D)$. Original images $(A \& C)$ were traced and isolated for basaltic-andesite clasts (highlighted yellow in $B \& D)$ to quantify contribution to bulk rock. The regions shown in these images are indicative of maximum contributions: basaltic-andesite makes up 5.77\% by area in B, and 5.65\% by area in D (calculations made with blank margins removed). It is important to note that the BSE image area is $\sim 1 \%$ of the thin section area, the values given are therefore absolute maximums.

In some dense-banded samples mafic domains were found with rhyolite glass intruding into rim pores through collapsed/broken pore walls, and in isolated central pores. Although the supposed isolated central pores may have been connected to the edge of the particular mafic domain in some other plane (such is the limitation of 2D samples), there is clear evidence for intrusion in the 2D plane at the edge of some mafic clasts (Fig. 4.28). The smooth shapes of the intruding rhyolite material suggests that it was ductile at the time of intrusion, as opposed to the basaltic-andesite that shows evidence for brittle fracturing. 

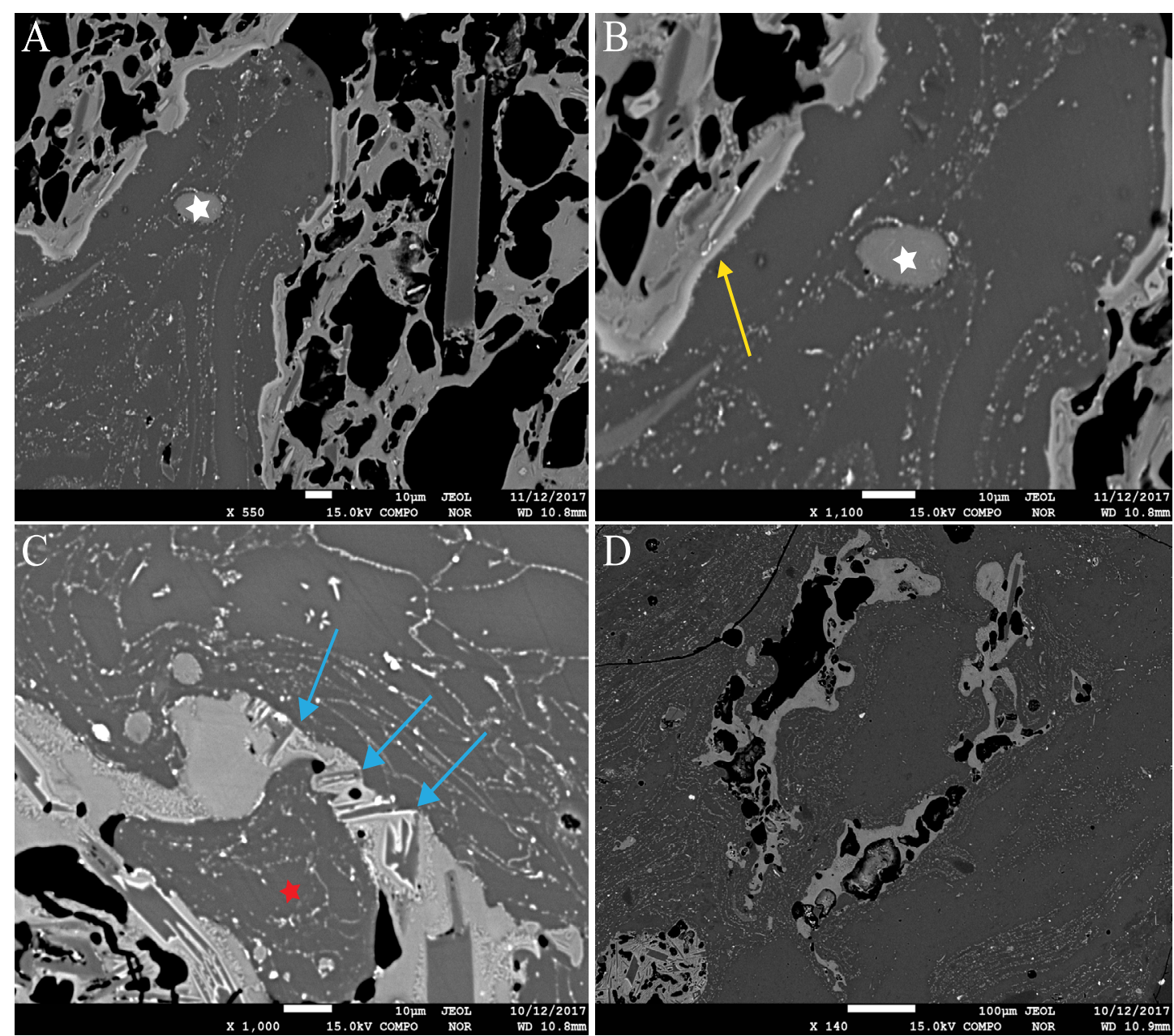

Fig. 4.28. Smooth intrusions of rhyolitic glass (dark grey) into basaltic-andesite clasts (light grey) that show evidence for more $(C)$ and less $(A, B, D)$ brittle behaviour. In $C$, microlite fragments (blue arrows) indicate evidence for brittle behaviour at some stage. The other examples shown here indicate more ductile behaviour with some microlite alignment with the edges around intrusions. A fine $\sim 3 \mu \mathrm{m}$ rim of clean, crystal and vesicle free glass can be seen in A and B (yellow arrow) indicative of rapid quenching of the basaltic-andesite clast perimeter. Some rhyolitic intrusions are isolated from the rest of the rhyolite melt (e.g., red star in C), but this may only be a product of examining a 2D section (i.e., could have been connected in another plane). 


\subsection{Geochemistry}

\section{Matrix Glass Chemistry}

A representative subset of the glass chemistry analyses for Cordon Caullé bombs is given in Table 4.2. Full unnormalised analyses can be found in Appendix 2. The analyses cover a $\mathrm{SiO}_{2}$ range of 55 to $73 \mathrm{wt} \%$, with a compositional gap between 58 and $67 \mathrm{wt} . \%$ $\mathrm{SiO}_{2}$, clearly defining two glass populations. On a total alkali-silica (TAS) plot (Fig. 4.29, after Le Bas et al., 1986) the felsic population sits in the rhyolite domain, whilst the mafic component straddles the boundary between basaltic-andesite and andesite domains (predominantly basaltic-andesite). The rhyolitic glass component geochemistry presented here is marginally higher in alkali's ( $2 \mathrm{wt} . \%$ maximum) than the matrix glass and glass inclusion data reported in Castro et al. (2013b). The plinian pumice and lava (bulk rock) data presented by those authors are more concordant to the new data with regards to alkali weight percents, but are slightly depleted in $\mathrm{SiO}_{2}$ relative to the new data. $\mathrm{SiO}_{2}$ compositions for the felsic glass analyses given here span approximately the same range as that reported by Castro et al. (2013b). The mafic basaltic-andesite component sits between 55.2 and 58.1 wt.\% $\mathrm{SiO}_{2}$, with an average of 56.2 wt.\%. Three analyses fall in the andesite domain, however, they are only marginally separate from the main cluster of mafic points, and are not incongruous when considering the spread of mafic analyses. The mafic analyses correlate well with another analysis of Cordon Caullé bombs and vent samples conducted using the Victoria University of Wellington JEOL JXA-8230 Superprobe (pers comm. R. Paisley, 2017). Oxide-oxide plots (Fig. 4.30) of both magmatic components show limited variability; the minor fluctuations can be ascribed to late stage quench crystallisation within domains, and standard deviations in the analyses. 
Table. 4.2. Representative subset of major element analyses for matrix glass of basaltic-andesite (left) and rhyolite (right) in Cordón Caulle bombs. Compositions determined by EPMA and reported as raw unnormalised values.

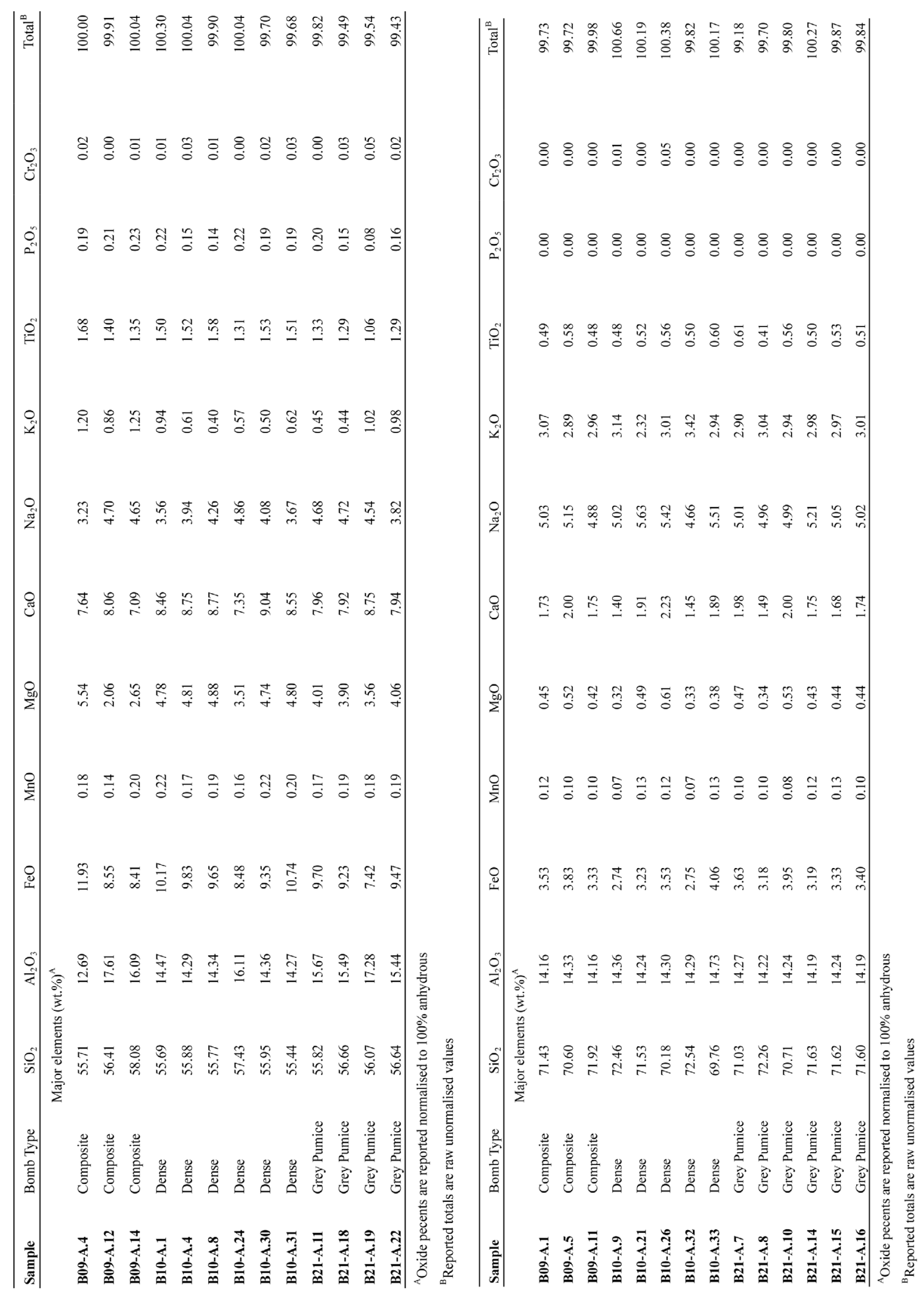




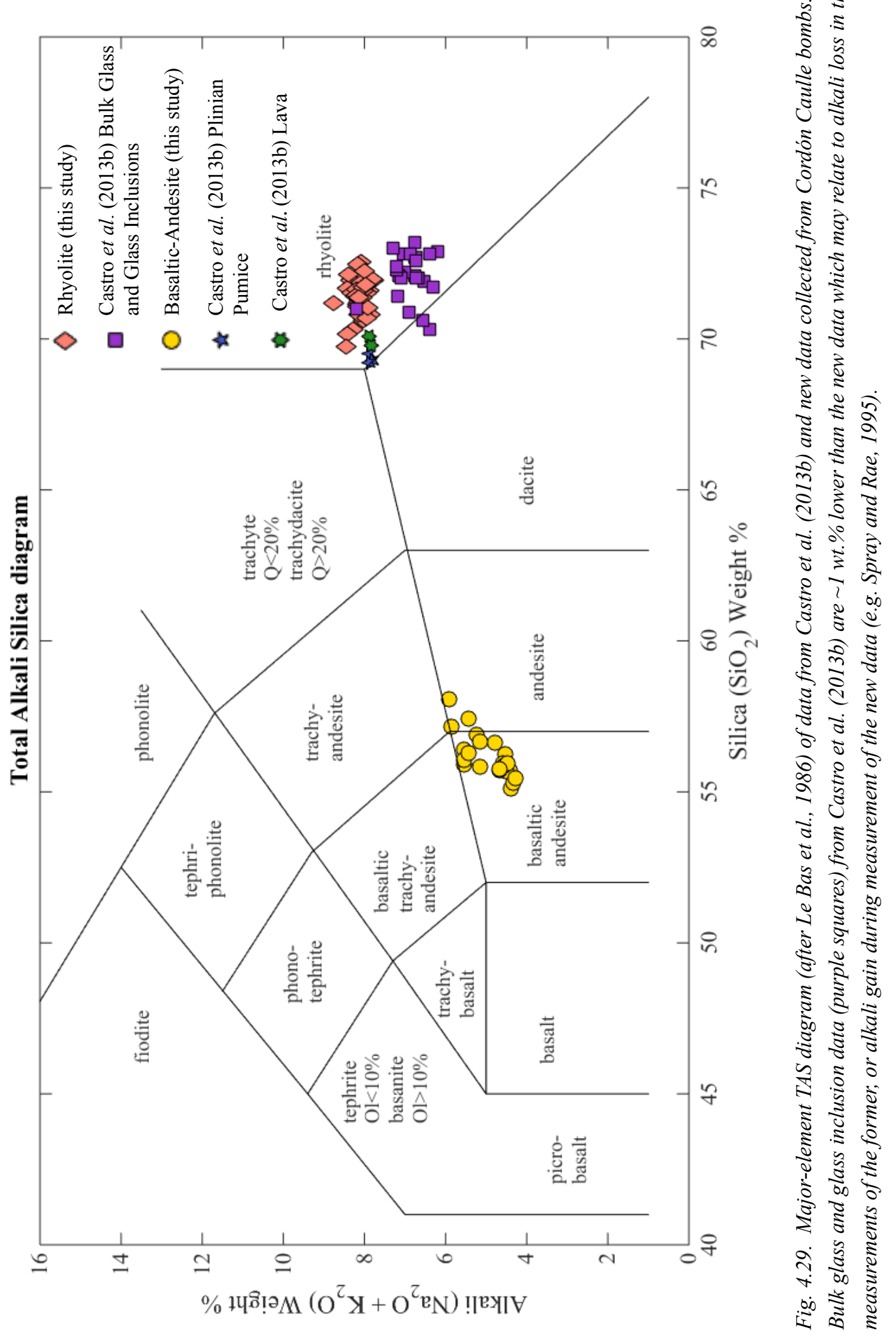




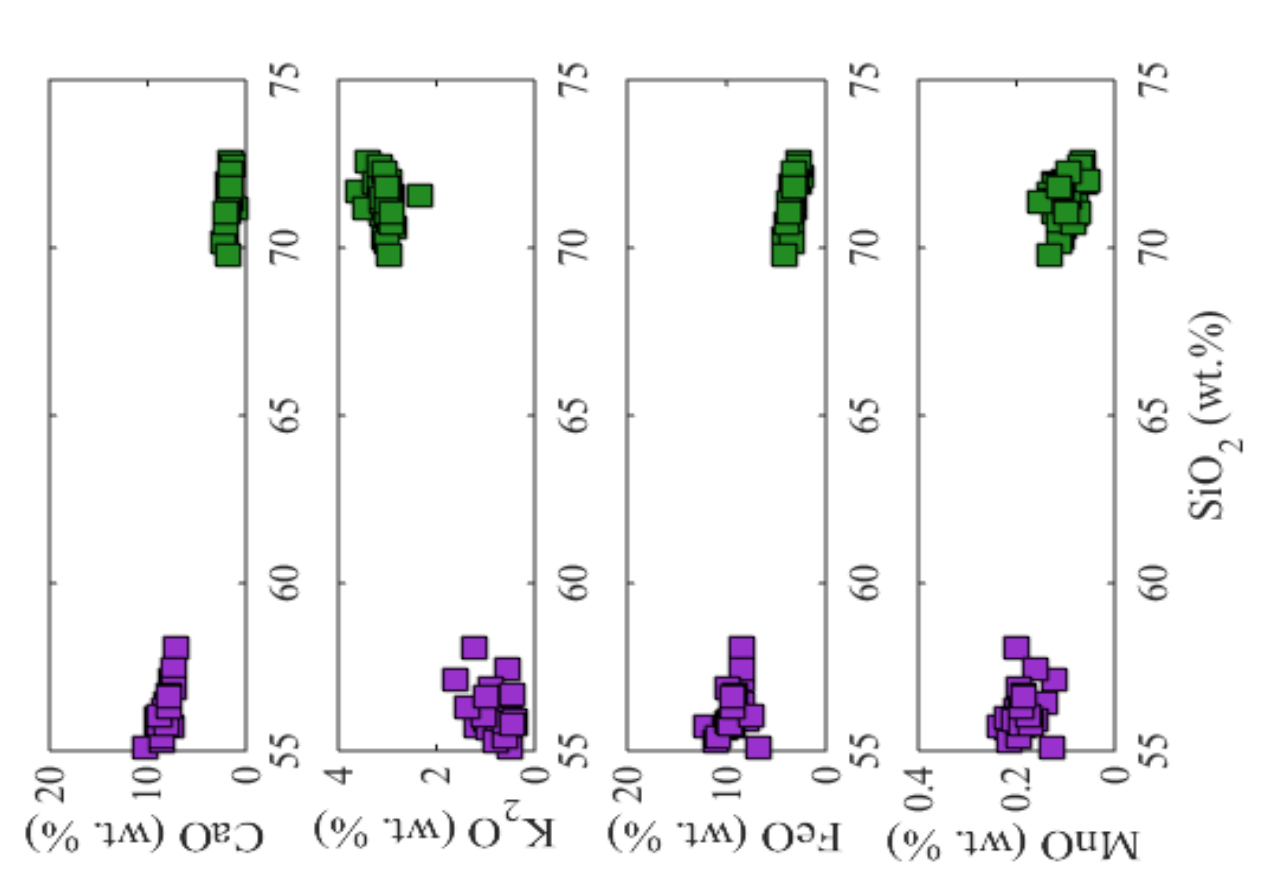

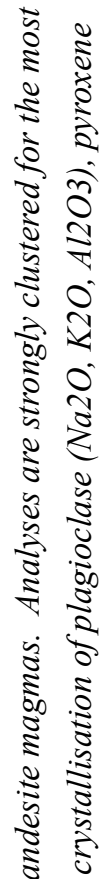

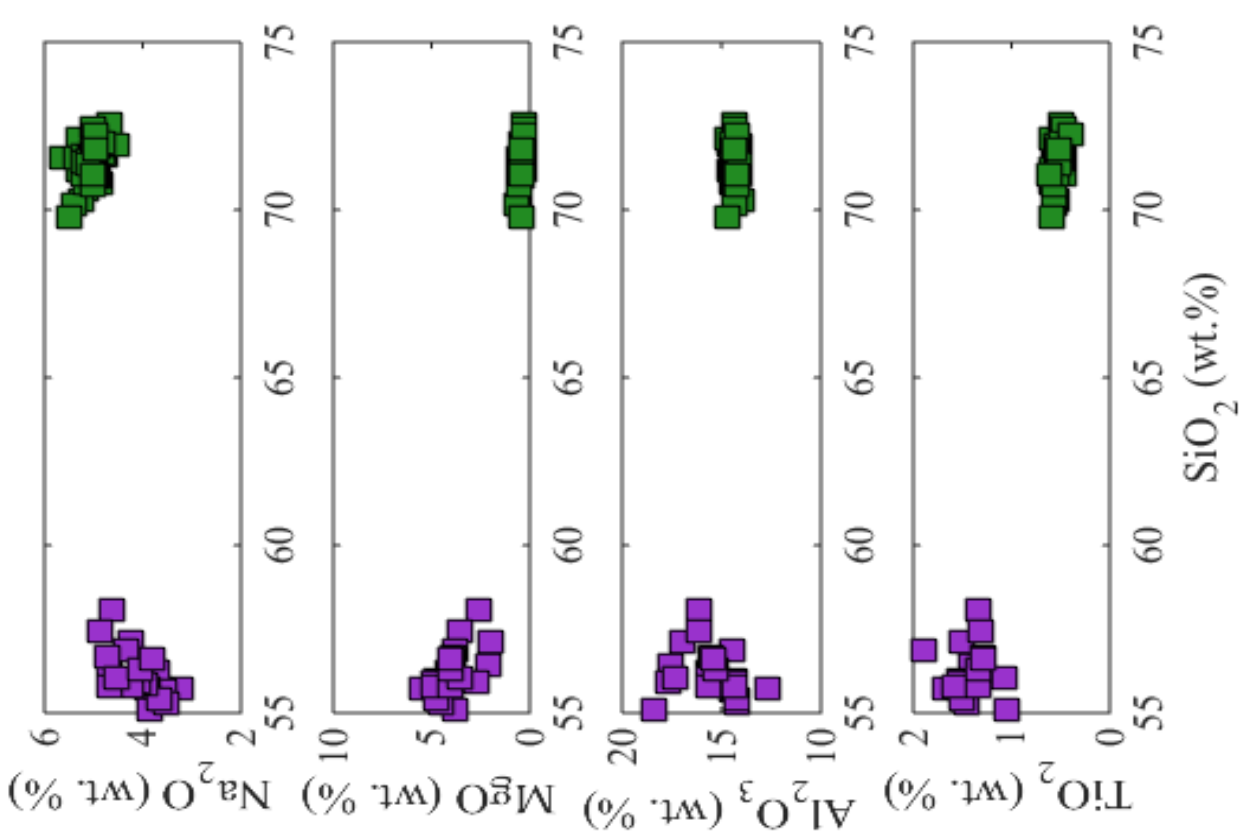

苟

$\dot{s}$

ฐ

ㄴำ

용

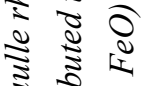

ป ह

:

ปิ

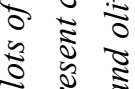

ล

है ईे

)

¿

0.5
0.5
0.5

$\begin{array}{lll}4 & 8 \\ \pi & 0\end{array}$

运 


\section{Crystal Chemistry}

Major oxide crystal chemistry was measured for plagioclase, olivine, and orthopyroxene in felsic and mafic regions. All crystals had multiple analysis points; for plagioclase to investigate compositional changes in zoning textures, and for olivine to bolster the total analyses as these crystals are comparatively rare and small $(<\mu \mathrm{m})$. Of 130 analyses, 73 are of plagioclase (from 28 crystals), 18 are of olivine (4 crystals), and 39 are of orthopyroxene (13 crystals). A representative summary of the full crystal data can be found in Tables 4.3 and 4.4, full unnormalised analyses can be found in Appendix 2. Plagioclase major oxide chemistry for the felsic population exceeds the compositional range presented in Castro et al. (2013b). No author has yet presented data for the mafic olivine, or mafic plagioclase crystal populations reported here.

The olivine data consists of a distinct compositional population (Table 4.3 \& Fig. 4.31; crystal examples given in Fig. 4.32) found exclusively in the mafic material (Fig. 4.29), ranging in composition from $\mathrm{Fo}_{76.2}$ to $\mathrm{Fo}_{80.4}$. Olivine crystals are predominantly found as isolated crystals with a single monomineralic glomerocryst in a large mafic clast in B10. The greatest Fo variation in a single crystal was 0.5 mol.\% in B10-Ol1. The felsic material was thoroughly explored for olivine crystals to elucidate crystal cargo transfer, with a strong focus on areas proximal to mafic clasts, however, no olivine crystals were found.

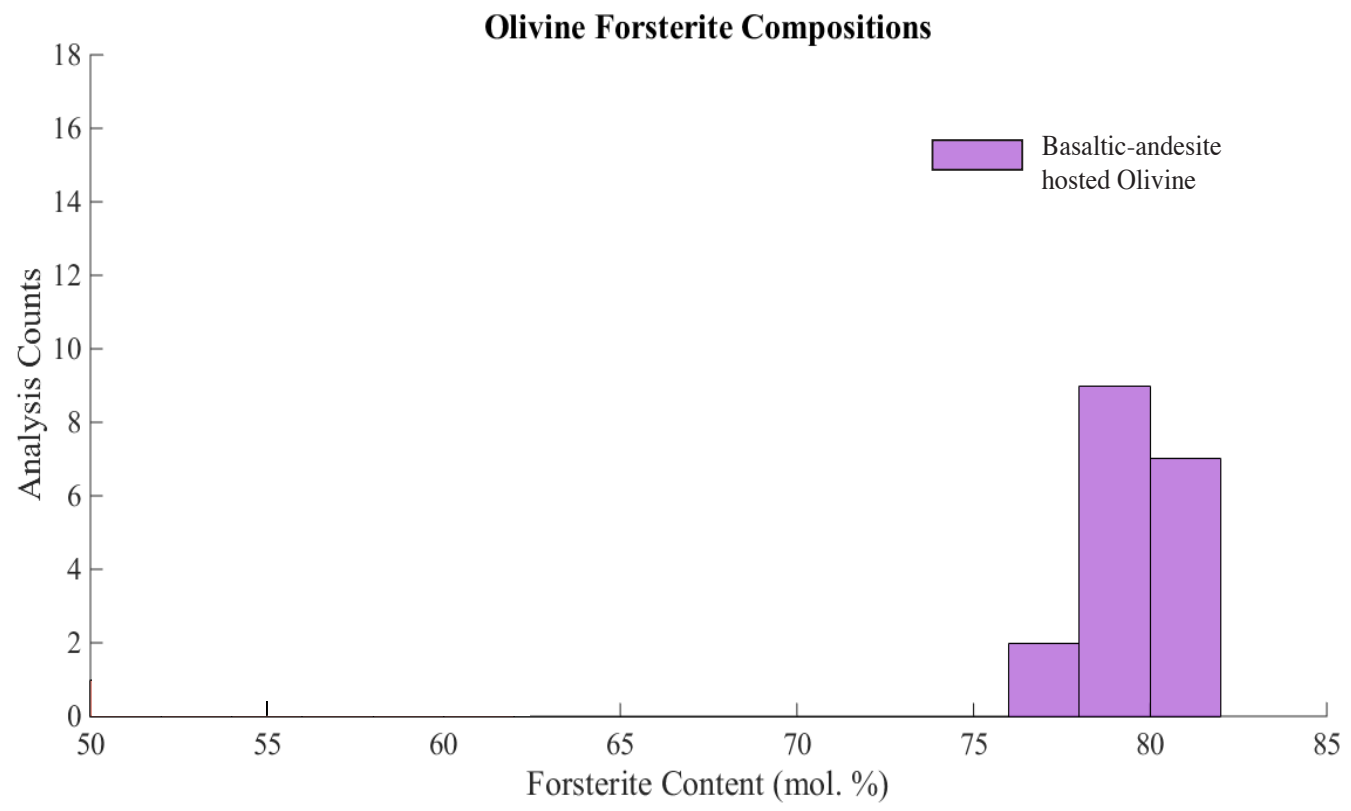

Fig. 4.31. Histogram of Olivine Forsterite compositions showing a single, well-clustered population. The population has a compositional peak between Fo78 and Fo80. The paucity of mafic hosted Olivine crystals, and subsequent scarcity of measurements, may be partially responsible for the poorly defined peak. 


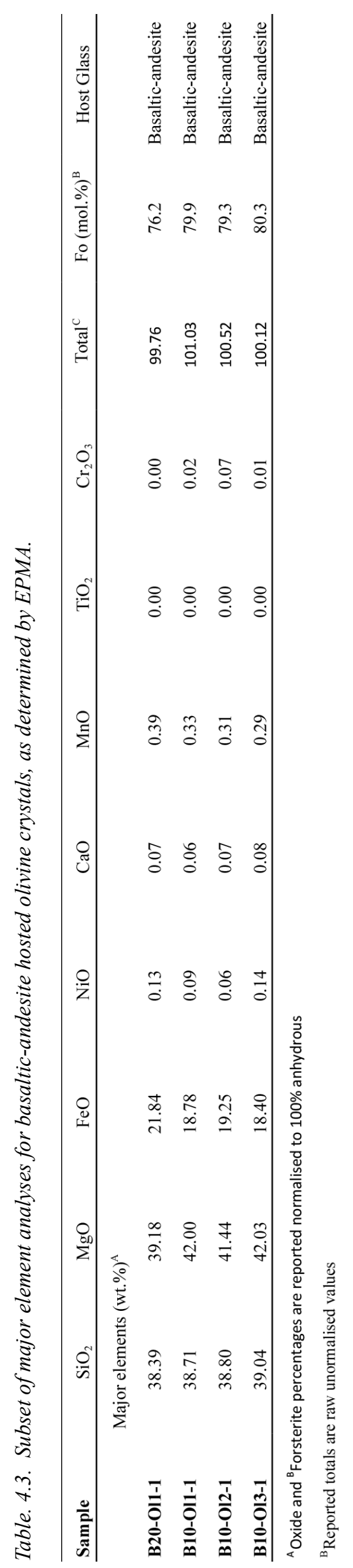



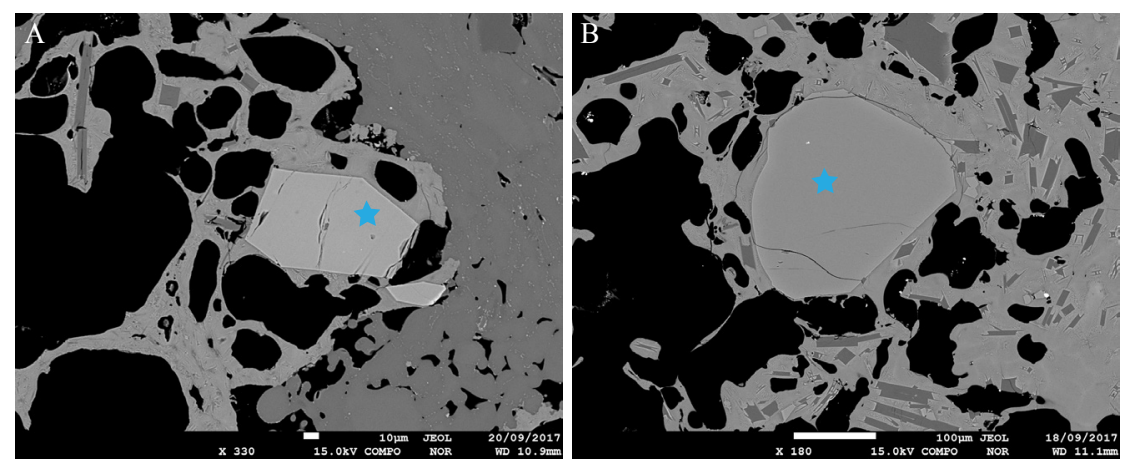

Fig. 4.32. Examples of olivine crystals (indicated with blue star) in B20-Ol1 (A), and B10-Ol3 (B).

Plagioclase crystals reported here cover a significantly larger compositional range than those reported in Castro et al. (2013b), the compositional ranges are $\mathrm{An}_{33.7}$ to $\mathrm{An}_{84.5}$ and $\mathrm{An}_{33.2}$ to $\mathrm{An}_{39.2}$ respectively (Table 4.4 \& Fig. 4.33; crystal examples given in Fig. 4.34). Zoning patterns of plagioclase crystals in the felsic glass were also analysed for evidence of chemical interaction with the mafic magma. The results of this analysis show no compelling deviations in major oxides associated with zoning patterns. Changes in $\mathrm{CaO}$ and $\mathrm{Na}_{2} \mathrm{O}$ of $\sim 2$ and $\sim 1 \mathrm{wt} . \%$ respectively occur along analysis transects in some plagioclase crystals, and plagioclase crystals hosted in basaltic-andesite are consistently more calcic than those hosted in rhyolite, as is expected. 
Castro et al. (2013b)

Lava plagioclase

Plinian plagioclase

\section{Present study}

Rhyolite hosted plagioclase

Rim

Core

Basaltic-Andesite plagioclase 0.3

Rim

Core

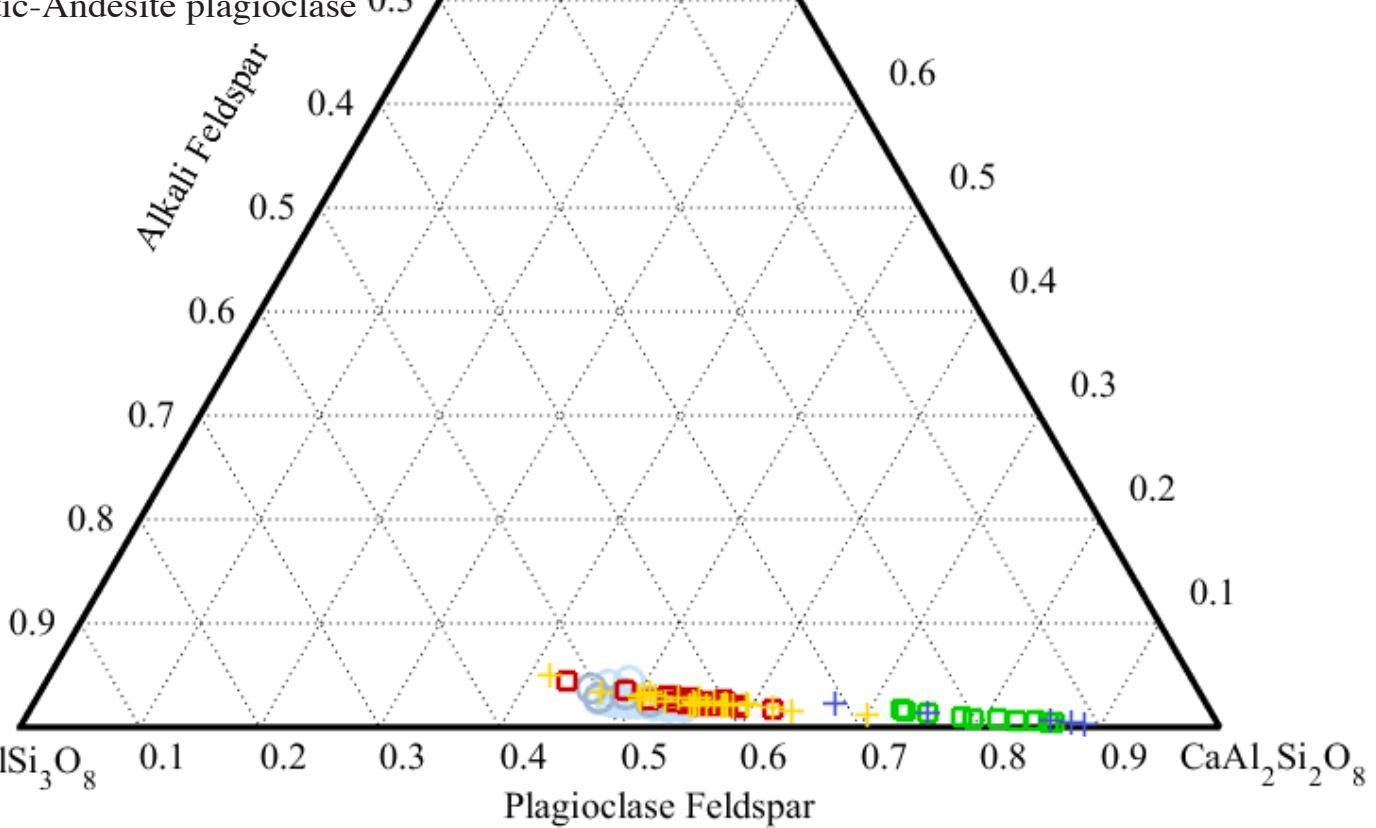

Fig. 4.33. Plagioclase compositions from Castro et al. (2013b) and Cordón Caulle bombs (this study). New data from Cordón Caulle bombs has significantly more spread than that presented by Castro et al. (2013b), and shows slight overlap at $\sim$ An68-70. 


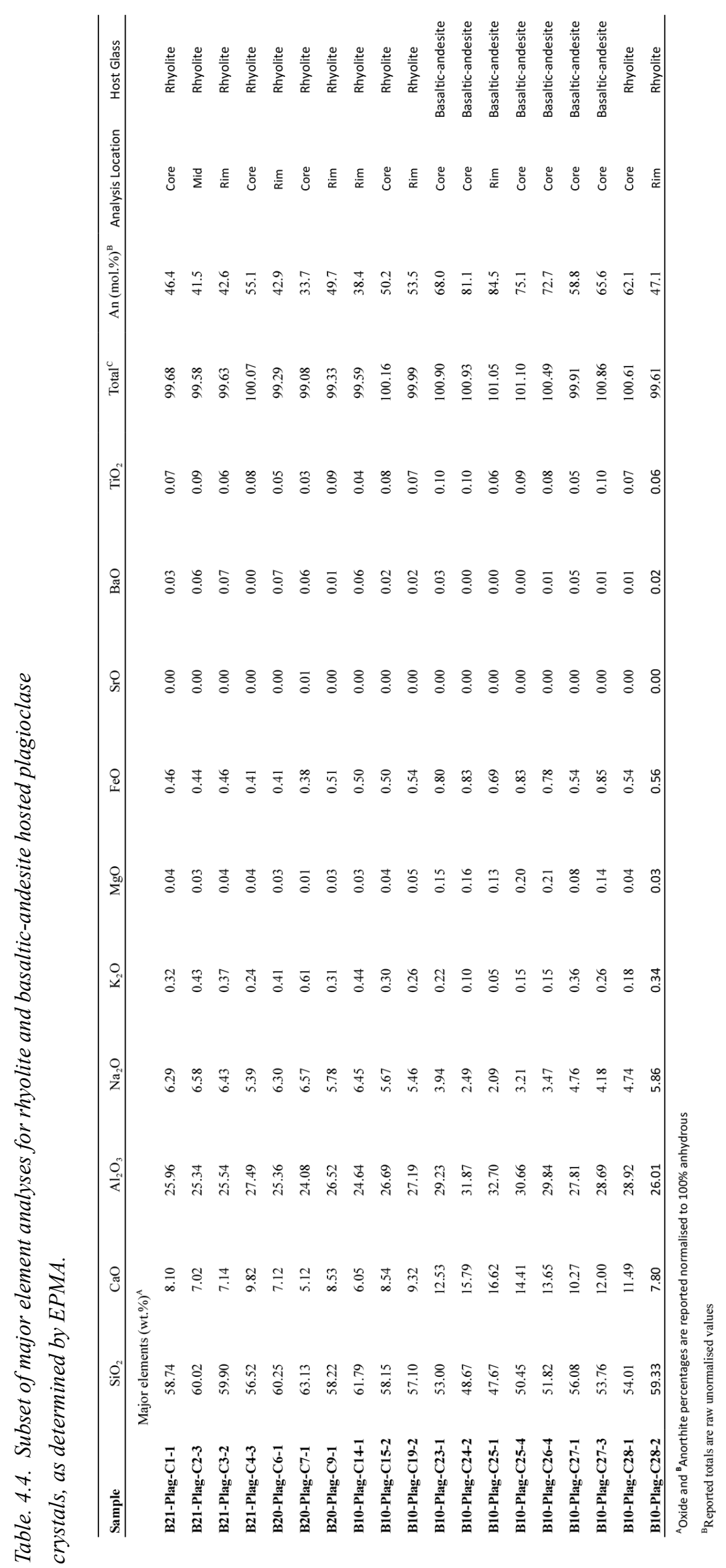




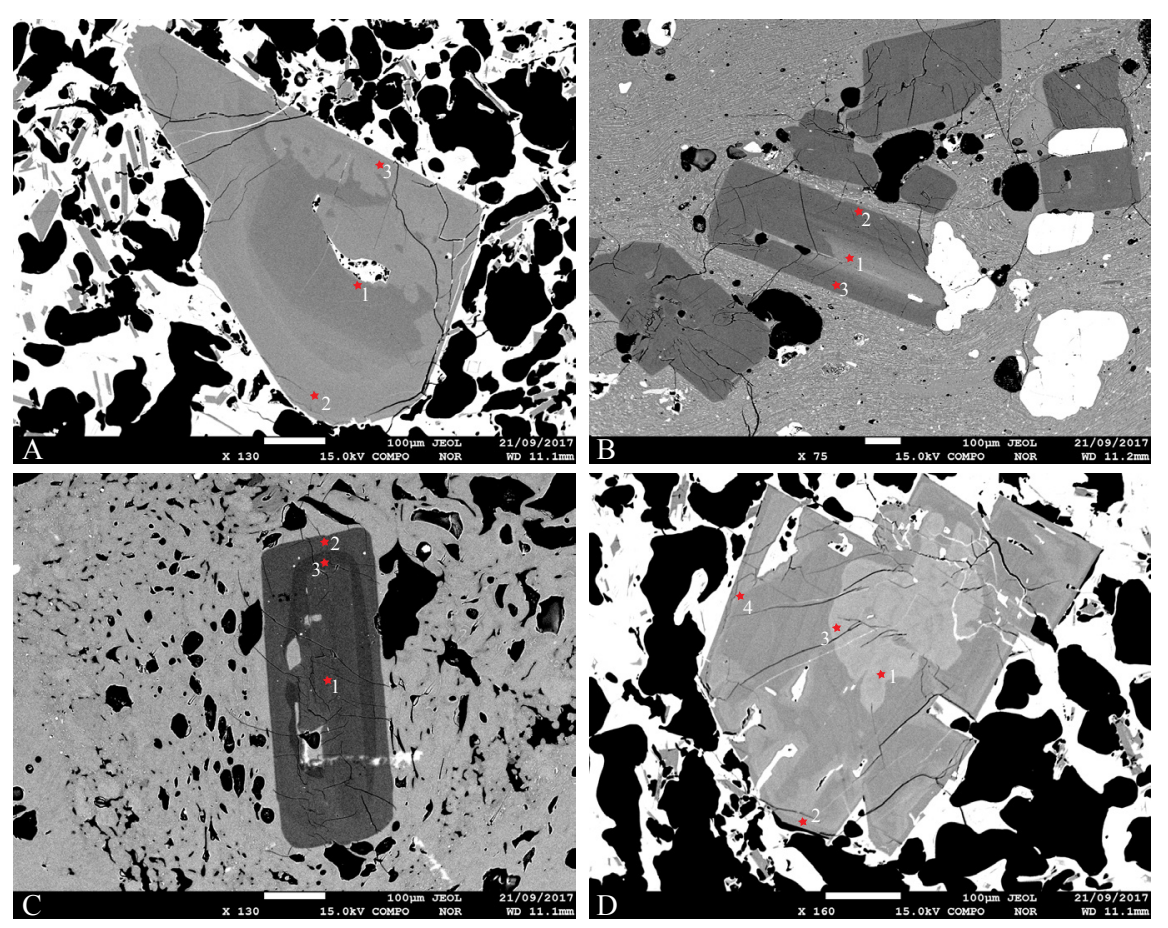

Fig. 4.34. Examples of Plagioclase crystals in rhyolite $(A \& B)$ and basaltic-andesite $(C \& D)$. Crystals shown are B10-Plag-C27 (A), B10-Plag-C28 (B), B20-Plag-C6 (C), and B10-Plag-C25 (D). Rhyolite hosted crystals are sometimes marginally less euhedral than those hosted in basalticandesite glass, however this is not significant. Red stars indicate analysis spots for these crystals, the associated number corresponds to the analysis numbers (e.g., B10-Plag-C28-1, B10-Plag-C28-2).

\subsection{Tomography Heating Experiments}

Heating experiments conducted at the Australian Synchrotron were conducted in an exploratory manner; poor constraints on maximum temperature, volumetric changes during heating, and the textural detail, or lack thereof, observable in the resultant tomography data means that the results are inconclusive. Nonetheless, useful observations can be made from these experiments. The initial experiments at Canterbury University were used to assess the viability of further experiments at the Australian Synchrotron; volumetric changes in the samples were observed but not measured. The tomographic scans of heating experiments conducted at the Australian Synchrotron allow accurate volume change quantification. However this should be considered a minimum, as the bombs may undergo some syn- or post-heating contraction, analogous to the natural contraction in vulcanian bombs (e.g., Wright et al., 2007). This is supported by the disparity of resultant textures and forms for samples of the same bomb at different heating lengths (7.5 minutes and 30 minutes). Under short heating, most samples retain their 
general form (roughly cuboid), and the final shape could be approximately correlated (qualitatively) with the original. In contrast, long heating experiments essentially eradicate the original form and internal structure (i.e., vesicle arrangement).

\section{Foaming}

Dense bombs (samples) were found to foam variably under heating (Fig. 4.35), whereby some regions of a sample undergo significant modifications in vesicularity, while other regions appear to have minor changes (foaming and shrivelling), or no discernible change at all. Foaming appears to be the result of both expansion of preexisting vesicles (i.e., vesicle growth) and of apparent nucleation of new vesicles (especially on crystals). Large, round vesicles form in samples, sometimes nucleating on, or around, crystals, but also seemingly with no particular nucleation point.

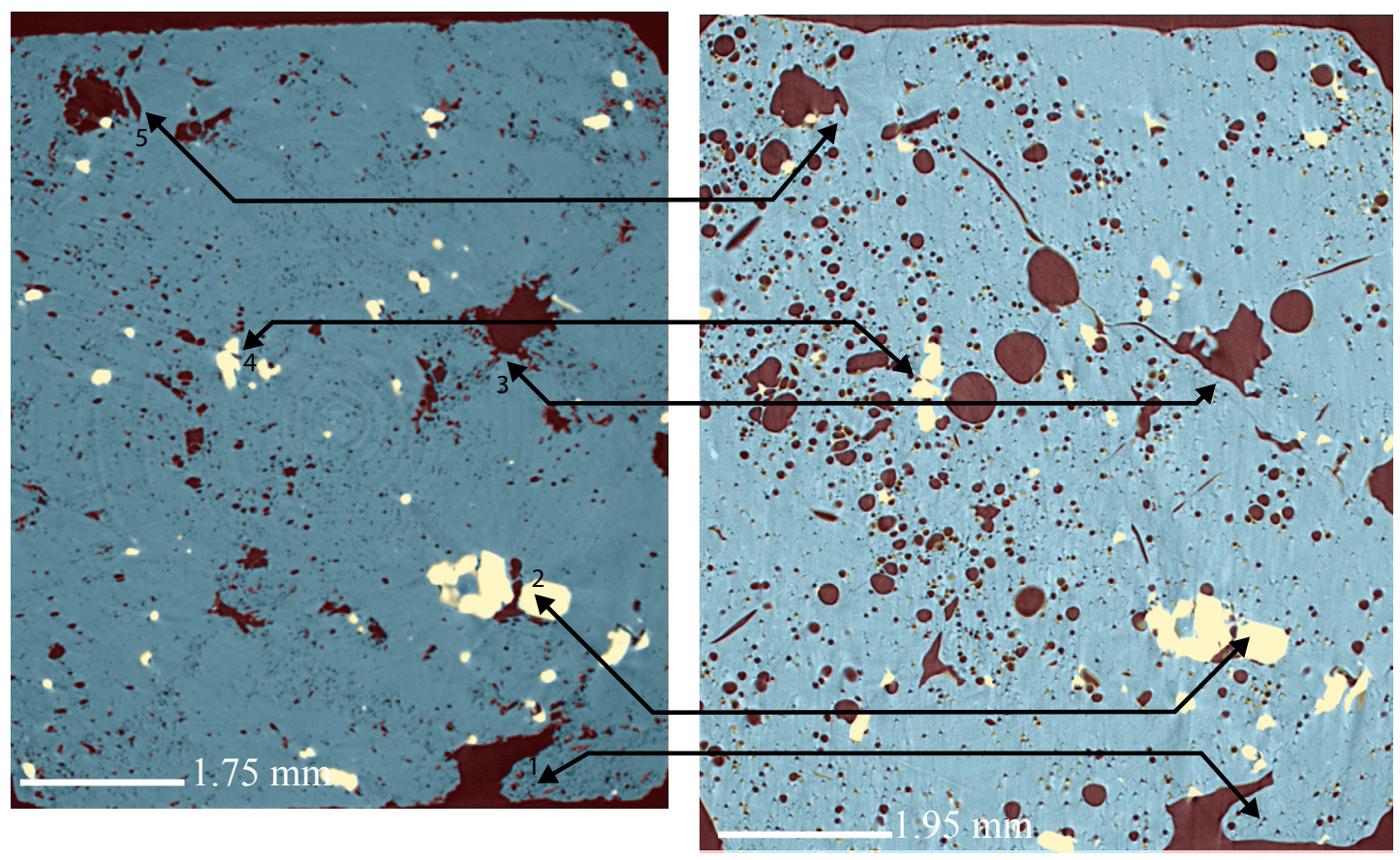

Fig. 4.35. Comparison of pre- and post-heating (left and right respectively; 7.5 minute heating period) textures in B11. Black arrows indicate key tie points between the pre-and post-heating images. Vesicles at point 1 have become more rounded but not significantly changed in size. The crystal cluster at point 2 have shifted slightly closer together (vesicle shrinkage) and vesicles have nucleated around the edge of the cluster. Larger vesicles at points 3 and 5 have approximately retained their size and general shape but have become more rounded. Point 4 indicates where there has been a shift in the crystal organisation along the $z$ axis (perpendicular to view plane). 


\section{Shrivelling}

Whilst dense bombs are found to variably foam when subjected to heating, vesicular bombs shrink or collapse under the same heating (Fig. 4.36). This collapse or shrinking of vesicular volcanic material (e.g., pumice and magmatic foams) is analogous to the well documented phenomenon of magmatic foam collapse (e.g., Eichelberger et al., 1986; Kennedy et al., 2016). A small cuboid $(\sim 1 \mathrm{~cm} \mathrm{x} 1 \mathrm{~cm})$ of B17 was heated for 7.5 minutes to assess the reaction of vesicular bomb material to further heating. While fine scale detail is hard to see in the post-shrivel image stack, the general shapes of collapsing and newly formed vesicles are observable. Interestingly, vesicle collapse produces many cuspate and convolute forms, rather than the simple format that might be expected from a collapsing sphere. The densification of the sample is significant; the area of the XY plane is $\sim 2.5$ times smaller in the post heating image stack. Finding points of clear correlation (i.e., crystals) is difficult in this particular sample, in large part due to the significant reorganisation of components (Fig. 4.37).

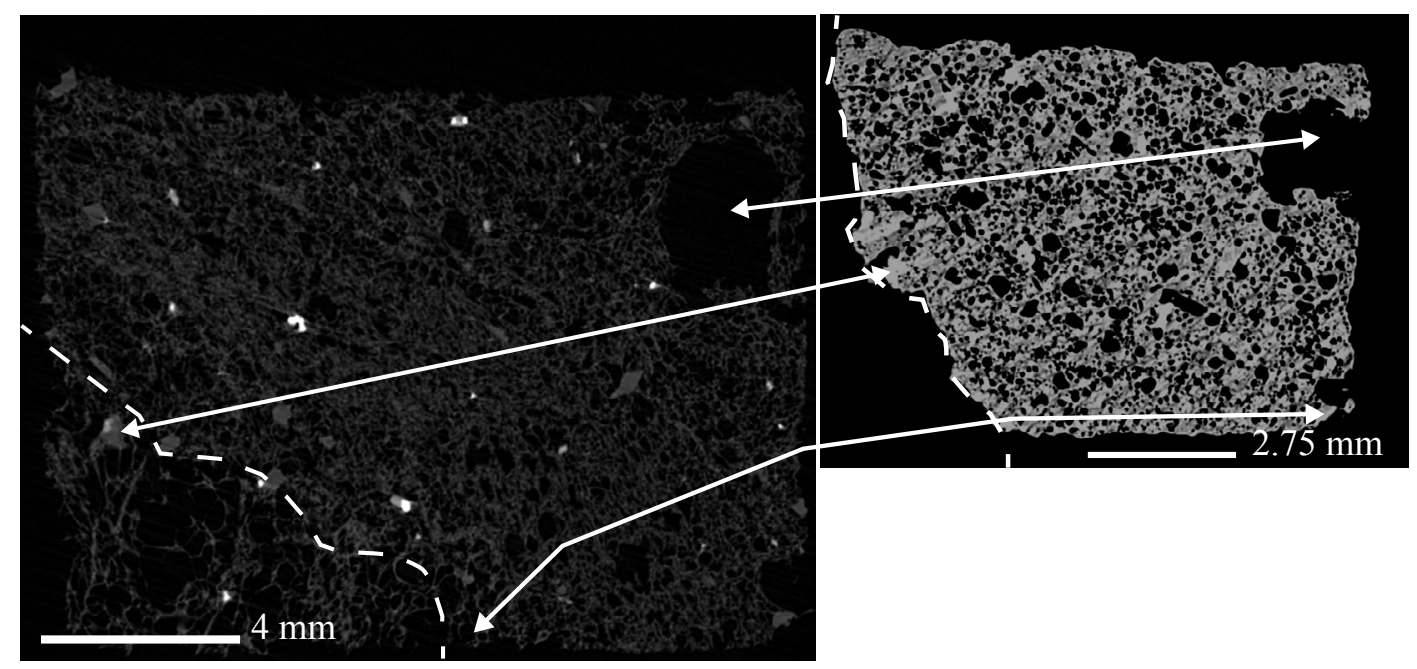

Fig. 4.36. Comparison of pre- and post-heating (left and right respectively; 7.5 minute heating period) textures in B17. The area to the left of the white dashed line in the left image shrinks to nothing in the post-heating sample. The white arrows indicate ties points between the two images, however, the significant modification in the post-heating samples makes the comparison difficult. 

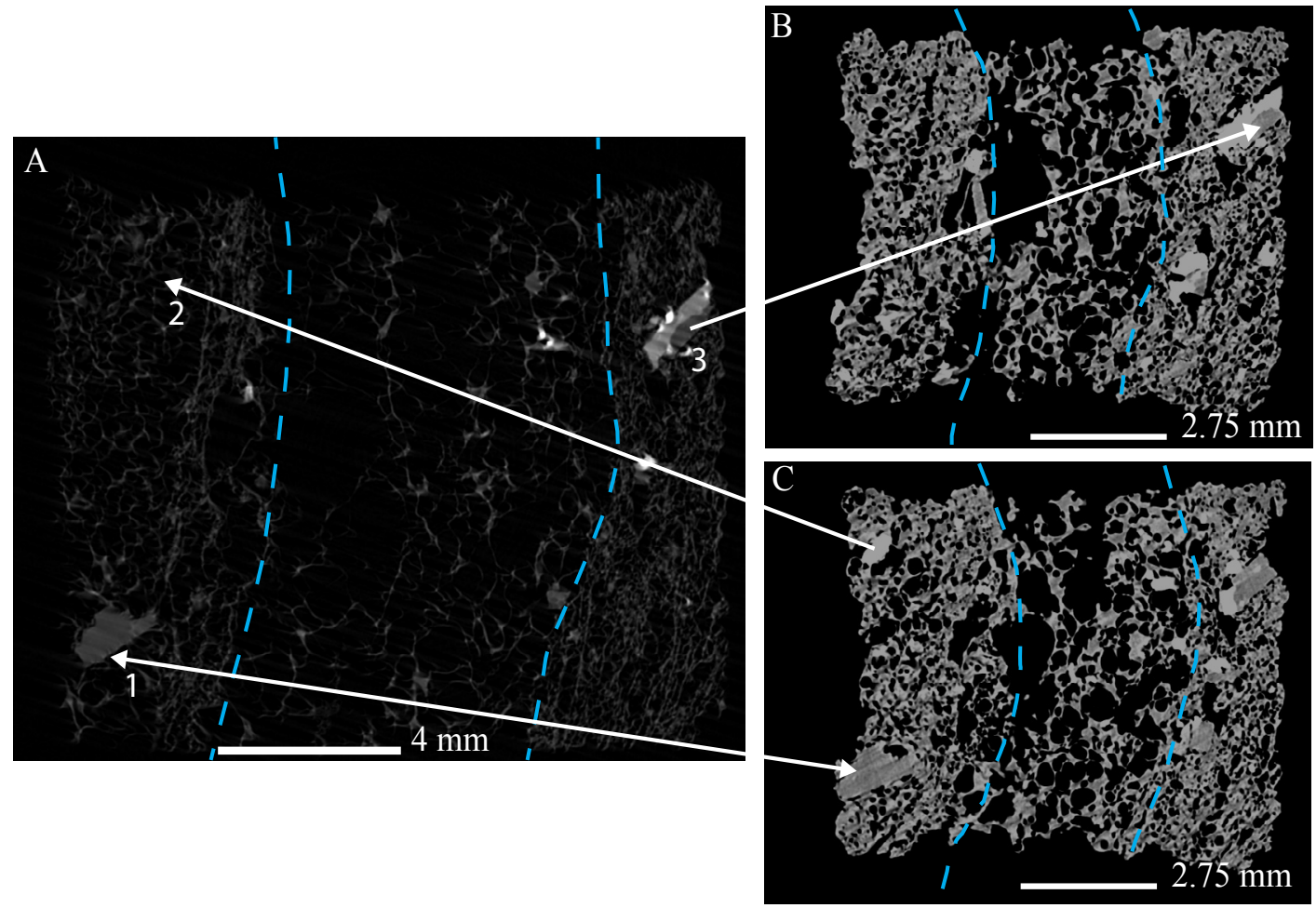

Fig. 4.37. Comparison of pre- and post-heating (left and right respectively; 7.5 minute heating period) textures in B17. The variable presence of tie points (indicated by white arrows) indicates the modification of textural and crystal arrangement. Crystal 1 is present in C but not in B, Whereas crystal 2 is present in neither, and crystal 3, although present in both, matches image B better. 


\section{Chapter 5: Macro- and Micro-Textures}

\section{Implications of Observed Textures for Bomb Formation Processes}

Textural observations of volcanic rocks and deposits are regularly used to understand eruption phenomena. The following discussion aims to illustrate the assorted processes required to generate the macro- and micro-textural variations observed in the vulcanian bombs of the 2011-2012 Cordón Caulle-Cordón Caulle eruption. Although the results above are separated into textural domain types, the most comprehensive and comparative format, for the following discussion, is separation by textural components (e.g., vesicles, crystal content, micro-oxides etc.). Textural features of the mafic component and geochemistry are principally addressed separately in Chapter 6.

\subsection{Vesicles: Shape, Size, and Deformation}

\section{Bubble Melt Films}

In vesicular domains, particularly those in grey pumice samples, fine glass filaments extending inward from vesicle rims are ubiquitous. These glass filaments are relict inter-bubble melt films (IBFs) and therefore indicate that both vesicle growth and vesicle coalescence have occurred extensively (Cashman and Mangan, 1994; Toramaru, 1988). In the foamed domains of composite bombs, coalescence indicators are present but far less common (e.g., Fig. 4.12D), indicating fundamental differences in volatile contents and/or growth histories. Whilst the data to elucidate volatile contents of samples with different vesicularities was not obtained in this study, previous work at Cordón Caulle has shown that products of widely varying textural type are ubiquitously degassed (e.g., Castro et al., 2014). There is therefore good evidence to support different bubble growth histories for the larger, heavily coalesced vesicles in grey pumice samples, and the foamed domains of composite bombs.

Deformation of an IBF is suggested to be a presage of rupture and coalescence (Castro et al., 2012a). However, an alternative interpretation is that this deformation is the result of syn-quench bubble-shrinkage, with volatile resorption (McIntosh et al., 2014). Breadcrusting is evidence of syn-eruption and post-deposition bomb expansion (Wright et al., 2007), and the presence of incipient coalescence (i.e., separation in IBFs of a few $\mu \mathrm{m}$ ) would suggest that rupture and coalescence are responsible. However, the 
presence of deformed vesicles, with no indicators of coalescence, and rounded vesicles in a range of sizes, suggests that volatile resorption (e.g., McIntosh et al., 2014) and surface tension (e.g., Kennedy et al., 2016) processes are also operating. Alternatively, if the inner bomb is still relatively hot and ductile, which is evidenced by the presence of central cavities (Fig. 4.1E), then as some areas expand others may collapse under their own weight (Cashman and Mangan, 1994), as vesicle gas pressure dissipates with increased permeability; analogous to the collapsing foam model of Eichelberger et al. (1986). Without the availability of detailed water profiles around vesicles, where these deformation features are present, the process driving the formation of such features cannot be confidently understood. That notwithstanding, coalescence is strongly indicated by the presence of shorter, separated IBFs (Fig. 4.12), whereas some features suggested to indicate resorption (sub-planar cracks extending out from bubbles and dark water-rich bubble halos: Fig. 4, McIntosh et al., 2014), are not seen.

\section{Vesicle Nucleation Delay}

The juxtaposition of relatively dense rinds and highly vesicular interiors (Fig. 4.14) indicates syn- and post-eruptive vesiculation (Wright et al., 2007), and the rind is inferred to approximately represent the original pre-foamed state of any given bomb (e.g., Giachetti et al., 2010; Hoblitt and Harmon, 1993; Wright et al., 2007). Wright et al. (2007) assert that rind thickness is also indicative of pre-fragmentation water content, suggesting that a minimum of $\sim 0.9 \mathrm{wt} . \% \mathrm{H}_{2} \mathrm{O}$ is required to form a bomb with a glassy rind and vesiculated interior, with increasing water contents leading to thinner, denser rinds. This suggests that pre-fragmentation $\mathrm{H}_{2} \mathrm{O}$ contents of grey pumice bombs may have been greater than other vesicular domains. Wright et al. (2007) further suggests that pre-eruptive $\mathrm{H}_{2} \mathrm{O}$ for dense bombs, or bombs lacking quenched rinds is $<\sim 0.9$ wt.\%, implying that the grey pumice bombs of Cordón Caulle, the only studied type that possesses a discernible rind/core juxtaposition, had greater pre-eruptive water contents than other bomb types.

\section{Vesicularity Differences}

Compared to grey pumice bombs, foamed domains in composite bombs (e.g., B20) show limited evidence for coalescence, and have retained thicker IBFs. Furthermore, both B16 and B20 have vesicular clasts that are texturally distinct from the sintered domains in which they are hosted (see thin-sections in Fig. 4.2), unlike grey pumice bombs. Juxtaposition of dense rinds and vesicular cores in grey pumice bombs can be easily linked to cooling rate and vesiculation (as above), but inter-clast material in composite bombs (i.e., sintered ash) has no such link, implying that, prior to the final 
arrangement, all constituents of a composite bomb essentially acted independently (i.e., a composite bomb represents a multitude of individual components). The same process of volatile exsolution is responsible for the formation of vesicles in pumice clasts, but those in B20 have not expanded to the same extremes as those in the foamed domains of grey pumice (B21) or honeycomb (B16) bombs. This suggests lower water contents, greater volatile resorption (i.e., modification), faster quenching, or vesiculation under greater confinement. Conversely, the uniformity of the texture and colour in the foamed clasts of B16 (where they are not of basaltic-andesite composition) suggests they have a single origin and history; the presence of obsidian fragments in the bomb rind suggest that vesicular clasts foamed from dense obsidian fragments. However, this is speculative, and furthermore, the pre-eruption $\mathrm{H}_{2} \mathrm{O}$, and the effect of resorption modification (e.g., Kennedy et al., 2016; McIntosh et al., 2014; Wright et al., 2007) are unknowns. Nonetheless, the pre-ejection history and assembly of grey pumice bombs, and B16, can be considered disparate from that of composite bombs such as B20. Grey pumice bombs and the pumice clasts of B16 are evidenced to have undergone posteruption vesiculation from a dense, relatively homogeneous mass, whereas pumice clasts in B20 have, at a minimum, experienced some post vesiculation modification.

\section{Vesicle Elongation}

In dense domains, the alternating bands of round and elongated vesicles (Fig. 4.15) imply that there was a strain between the bands (Gardner et al., 2017). Elongated vesicles are generally attributed to stretching during transport in a fluid state, or shearing during ascent near conduit margins (e.g., Klug et al., 2002). This shearing model can be substituted for one where small amounts of relative movement occur between layers of marginally different strengths within a hot ductile rock. The inference of shearing, based on the presence of elongated vesicles at these boundaries, is further supported by crystal alignment (Fig. 5.1), unambiguous in bands with incipient vesicularity and arguable in places for the higher vesicularity bands. The lack of brittle fracturing along the vesicle elongation boundaries, and around aligned crystals (Figs. 4.15, 4.17, \& 5.1), indicates that the material behaviour was relatively ductile. The presence of glomerocrysts and/ or comparatively abundant crystals, in some regions of higher vesicularity, may provide an explanation as to why those regions show less evidence of shearing. The general properties of crystal structure (compared to that of the melt or glass) dictates that crystals impart a finite yield strength to the host rock, increasing the overall strength (Saar et al., 2001). Therefore, a higher abundance of crystals will locally increase the host rock strength, and shear stress will be accommodated in regions of lower crystal content. 


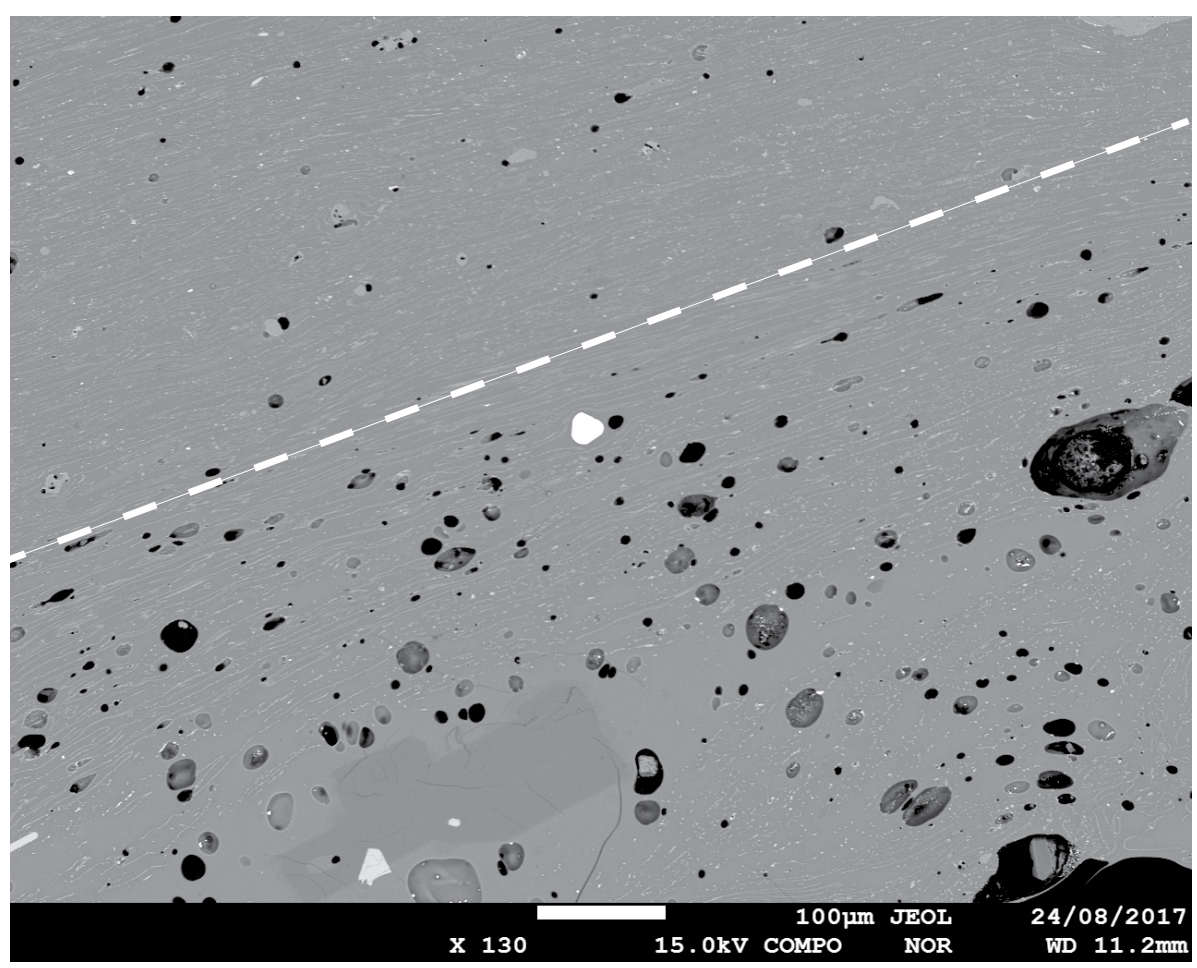

Fig. 5.1. Vesicle elongation and crystal alignment in B10-AS01-S2. Mafic particles (light grey) are also dispersed throughout and shown slight elongation along the same azimuth and vesicles.

\subsection{Sintering Variations}

\section{Sintering extent and style}

Sintering of magmatic ash particles can be simplified into three key steps: (1) particle rounding, agglutination, and viscous neck formation, (2) viscous collapse of permeable network, and (3) relaxation and rounding of isolated pores (Pope et al., 2016; Vasseur et al., 2013b). If angular ash particles are reheated above their glass transition temperature, it is expected that surface tension processes will cause the particles to become spherical (Wadsworth et al., 2017). The formation of fine viscous necks in the initial stage of sintering (Fig. 4.6A) causes the onset of rounding at the contact points between angular particles (Wadsworth et al., 2016a). This suggests that the more angular, or irregularly shaped, particles in Cordón Caulle bombs, with fine to thick viscous necks (i.e., B09), represent an earlier stage of sintering relative to the sintered regions of B20 and B16 (Fig. $4.5 \& 4.6 \mathrm{~B}$ respectively), which would represent a more advanced stage of sintering. However, the sintering along particle edges and coeval deformation of particles seen in 
B20 and B16, suggests that hot-pressing, such as that applied in ceramics (e.g., Wang et al., 2002), and in conduit faults (e.g., Ryan et al., 2018), is also a key process. The sintered domains of B09 are marginally more porous than those of B20 and B16, whilst the latter two samples have edge-sintering in abundance relative to B09. Furthermore, densification is expected to occur as sintering becomes more advanced (Gardner et al., 2017; Vasseur et al., 2013b). Placing the sintered domains of Cordón Caulle bombs in this context, they represent different sintering timescales, and/or varying depths (and therefore temperatures, e.g., Heap et al., 2014) at which sintering occurred.

Experimental sintering of homogeneous synthetic glass beads has shown that sintering is not only time and temperature dependent, but also controlled by grainsize (Vasseur et al., 2013b; Wadsworth et al., 2014), therefore, sintering should be expedited where particle distributions tend toward smaller sizes. However, recent experiments on a rhyolitic Cordón Caulle bomb contradict this, showing that neck formation was approximately identical for all particle sizes at a given temperature (Pope et al., 2016). Moreover, the sintered domains in the Cordón Caulle bombs studied here have a limited particle-size distribution of $\sim 1-200 \mu \mathrm{m}$, and no discernible correlation between particle size and the extent, or style, of sintering. However, when considering the larger constituents of composite bombs (i.e., lapilli size clasts of pumice and basaltic-andesite), they do not appear to form viscous necks, even where that is the dominant sintering style in the adjacent sintering material (Fig. 5.2). In other words, although obscured by a discontinuous, approximately bimodal particle population (fine ash and pumice lapilli), sintering is limited by particle size in Cordón Caulle bombs. Therefore, the pervasive sintering essential to the assembly of composite bombs is achieved only because matrix ash is limited to a small size fraction. 

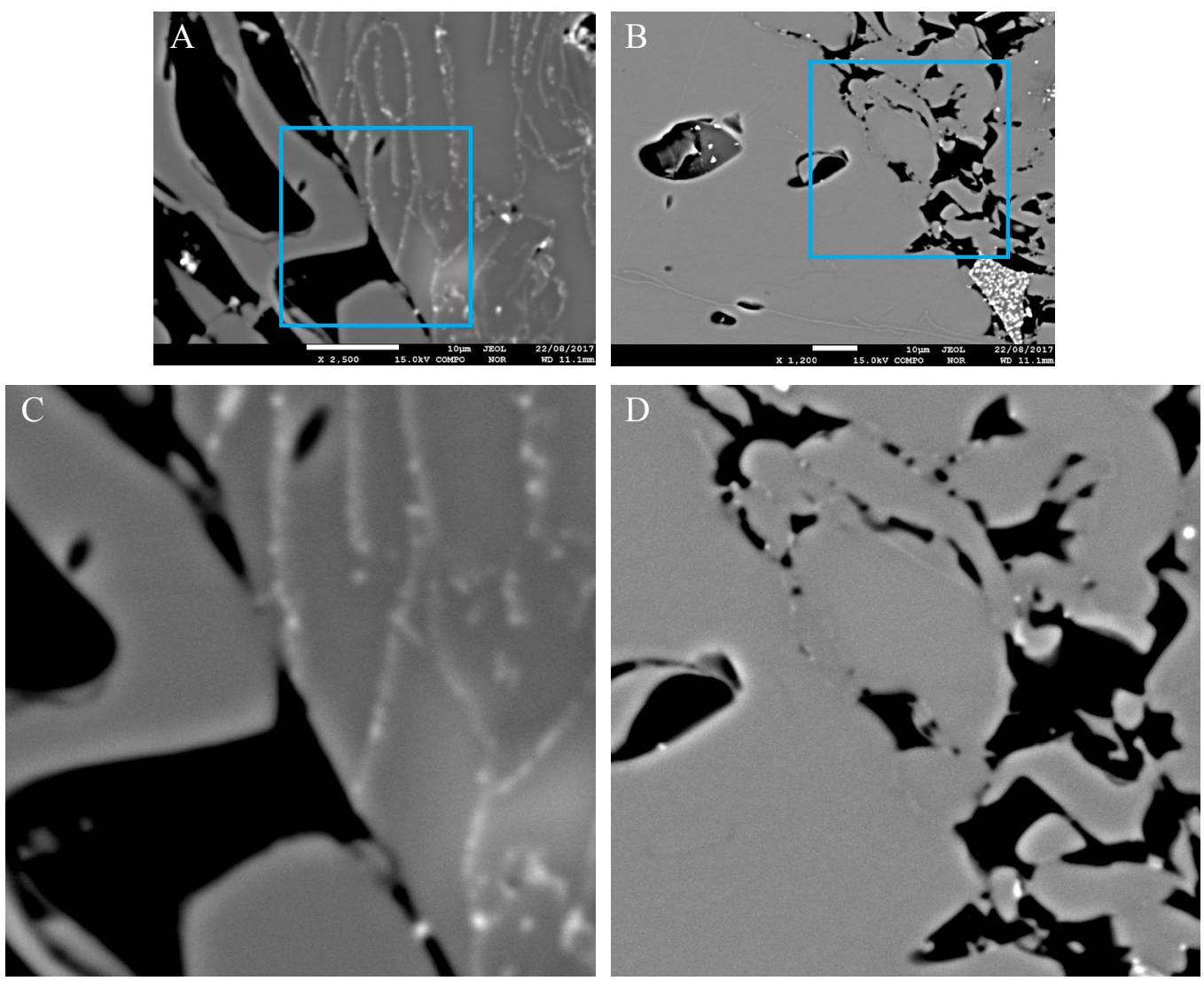

Fig. 5.2. Sintering between ash and larger lapilli in B09. The ash particles appear to form the sintering connections, at short length scales relative to the size of the large lapilli clast, either by forming viscous necks or edge connections. $C$ and D are enlarged images of the blue squares in $A$ and $B$ respectively.

\subsection{Crystal Populations}

Micro-phenocrysts, phenocrysts, and glomerocrysts are present in all textural domains and samples to varying degrees. Two important inferences can be made from the variation in crystal populations across domains and samples. The first is that, although present in all domains, glomerocrysts appear to be more complex in dense domains, involving more individual crystals, and more crystal phases. The second concerns the orientation of crystals, whereby, some domains have strong crystal alignments, with long axes in line with those of other crystals, and parallel with vesicle elongation, colour banding (observed under a petrographic microscope), and micro-oxide banding, whilst these features are conspicuously absent in other domains. 


\section{Glomerocryst Formation}

In vesicular and sintered domains glomerocrysts involve only two or three crystals of Plagioclase, sometimes with a few associated micro-phenocrysts of a different crystal phase (Fig. 5.3). The glomerocrysts observed in dense domains are significantly more complex, often including crystals of Plagioclase, Pyroxene, Olivine, and Apatite in a larger glomerocryst (Fig. 4.15A). Glomerocryst aggregation occurs by synneusis, a term coined by Vogt (1921) for the "swimming" or "drifting together" of crystals in a magma (Schwindinger and Anderson, 1989; Stull, 1979; Vance, 1969). Synneusis is related to magmatic turbulence and consolidation, wherein minerals of a single composition are thought to have a stronger affinity for aggregation than are dissimilar minerals (Vance, 1969; Zhu et al., 2017). A welding, of sorts, occurs as crystals continue to grow in close proximity to one another (Vance, 1969). Dowty (1980) suggests that, if synneusis controls glomerocryst formation, then the three stages of agglomeration must be (1) crystal accumulation through hydrodynamics forces, (2) crystal cohesion through atomic forces, and (3) cementation by continued growth.

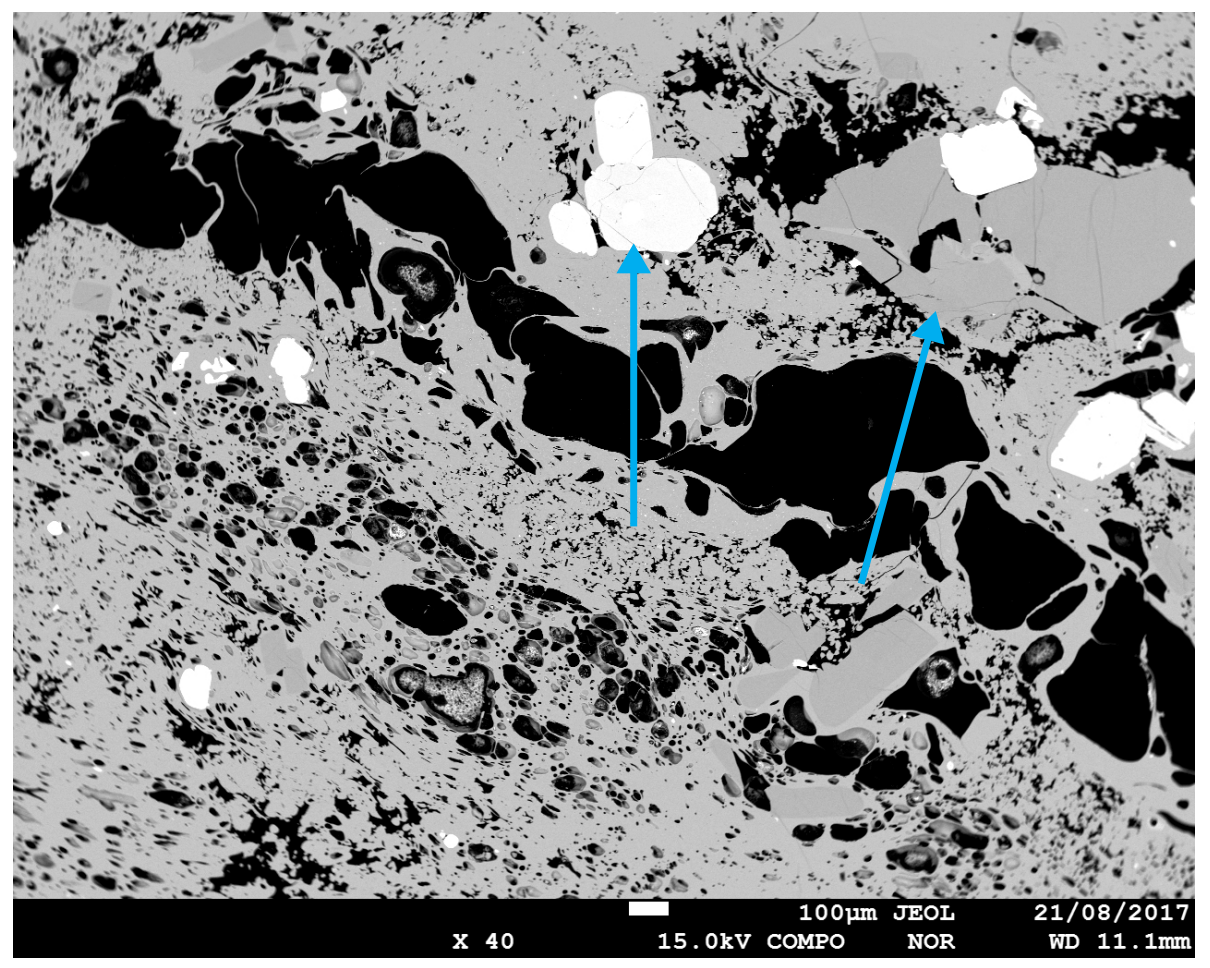

Fig. 5.3. Comparatively simple glomerocrysts (blue arrows) in B20-AS04. Each glomerocrysts here is predominantly composed of a single crystal phase, pyroxenes in the left example and plagioclase in the right example. 
It is conceivable that the less complex glomerocrysts are the product of synneusis, whilst further growth of glomerocrysts to form the more complex crystal associations in dense domains is the result of compression and shearing. Further support for this is seen in the accumulation of crystals in finite regions of dense domains (Fig. 5.4); accumulations mostly consisting of larger crystals and sometimes associated with one or more glomerocryst(s). Additional compression and shearing in the proximity of these crystal accumulations might cause the formation of the observed glomerocrysts (e.g., Fig. 4.15). Continued growth of the crystals, as suggested by previous workers (e.g., Dowty, 1980; Vance, 1969; Vogt, 1921), is likely still relevant for the formation of a cohesive glomerocryst, and the exceptionally high temperatures of these eruptive products (Castro et al., 2013b) would likely allow for that.

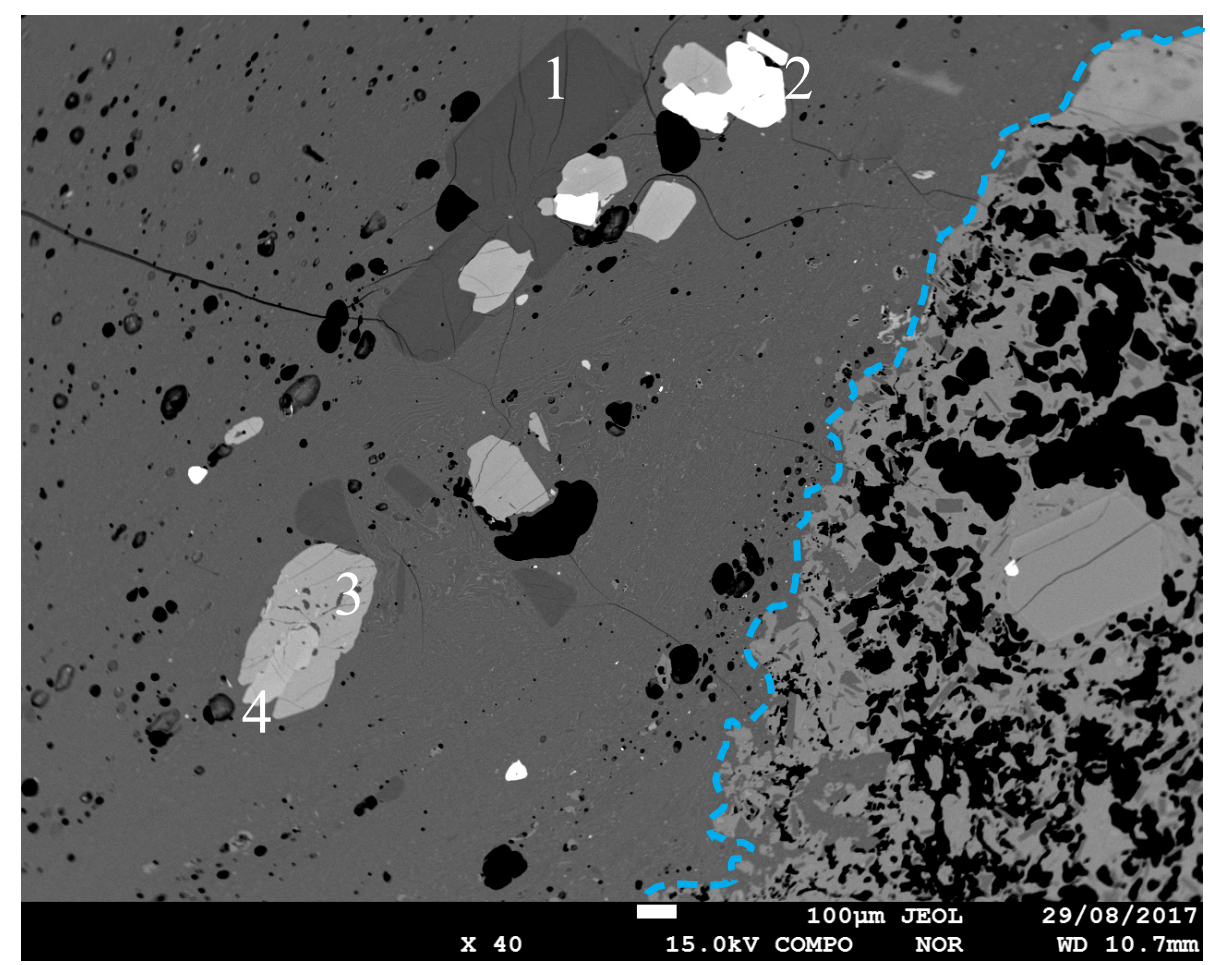

Fig. 5.4. Accumulation of crystals and glomerocrysts in B10-AS01-S2. These accumulations are common in this sample, and other dense samples (i.e., B11 and B13) Crystals phases present are plagioclase (1), Fe-Ti oxide (2) Pyroxene (3), and Apatite (4). Region to the right of the blue dashed line is a large basaltic-andesite clast.

\section{Crystal Alignment and Fracturing}

Additional evidence for shearing, the suggested mechanism for vesicle elongation and the formation of large polycrystalline glomerocrysts, is shown by crystal alignments and the separation of small crystal fragments away from the main body of the crystal. 
Dense domains have strong crystal alignments, and fractured crystals with marginally separated fragments that follow those alignments (Figs. $4.16 \& 4.17$ ). Sintered and vesicular regions lack discernible crystal alignments, with the exception of some pumice clasts that have alignment of acicular $\sim<100 \mu \mathrm{m}$ crystals, but contain many fractured crystals. However, even without clear crystal alignments to match, the separation of crystal fragments along fractures is apparently randomly orientated. The partial infilling of cracks with melt indicates that the crystal fracturing in all samples occurred while the material was still ductile. Kennedy et al. (2005) suggest shear along the conduit margins, with co-eruptive lateral expansion, as the process responsible for the alignment of crystals containing cracks parallels with that alignment. The samples in which they find these features are dense and banded, with variations in porosity, analogous to the dense regions in Cordón Caulle bombs, and similar to conduit margin samples discussed in Stasiuk et al. (1996). One deviation from this in the Cordón Caulle bombs is B11 (a dense obsidian bomb), which shows some separated fractures perpendicular to vesicle elongation and crystal alignment (Fig. 4.17); suggesting that there may be more than one source for obsidian bombs. Crystal alignment and separated fractures are largely absent in all but dense regions, and can be simply explained by the same shear processes suggested by Kennedy et al. (2005). Additionally, Rust et al. (2003) assert that simple shear, or two-dimensional pure shear, are the prescribed processes where banding in obsidian is not planar in all directions (i.e., original heterogeneity is preserved in one plane); as is seen in some of the obsidian bombs of Cordón Caulle (Fig. 5.5). For pumice samples with fracture orientations perpendicular to alignment, Kennedy et al. (2005) suggest an origin in the central conduit, positing vertical expansion during eruption. However, the lack of discernible orientation and the seemingly random orientation of fractures in Cordón Caulle composite bombs suggests that the co-eruptive expansion in these bombs is more complex.

\section{Microlites}

Microlites are exceedingly rare in the rhyolitic glass of all samples, however, some small clasts of microlite rich rhyolite are found in these samples (Fig. 4.22). A comparison of electron backscatter images of these small clasts with samples of the Cordón Caulle lava flow in Schipper et al. (2015) suggests that they are sourced from the lava flow. Given that the lava effusion was coeval in both time and space with the Vulcanian blasting (Castro et al., 2012c; Elissondo et al., 2016; Silva Parejas et al., 2012), a suggestion would be that fragments were torn from the lava flow in the upper conduit and vent regions, similar to the arrangement in the model of Schipper et al. (2013). 

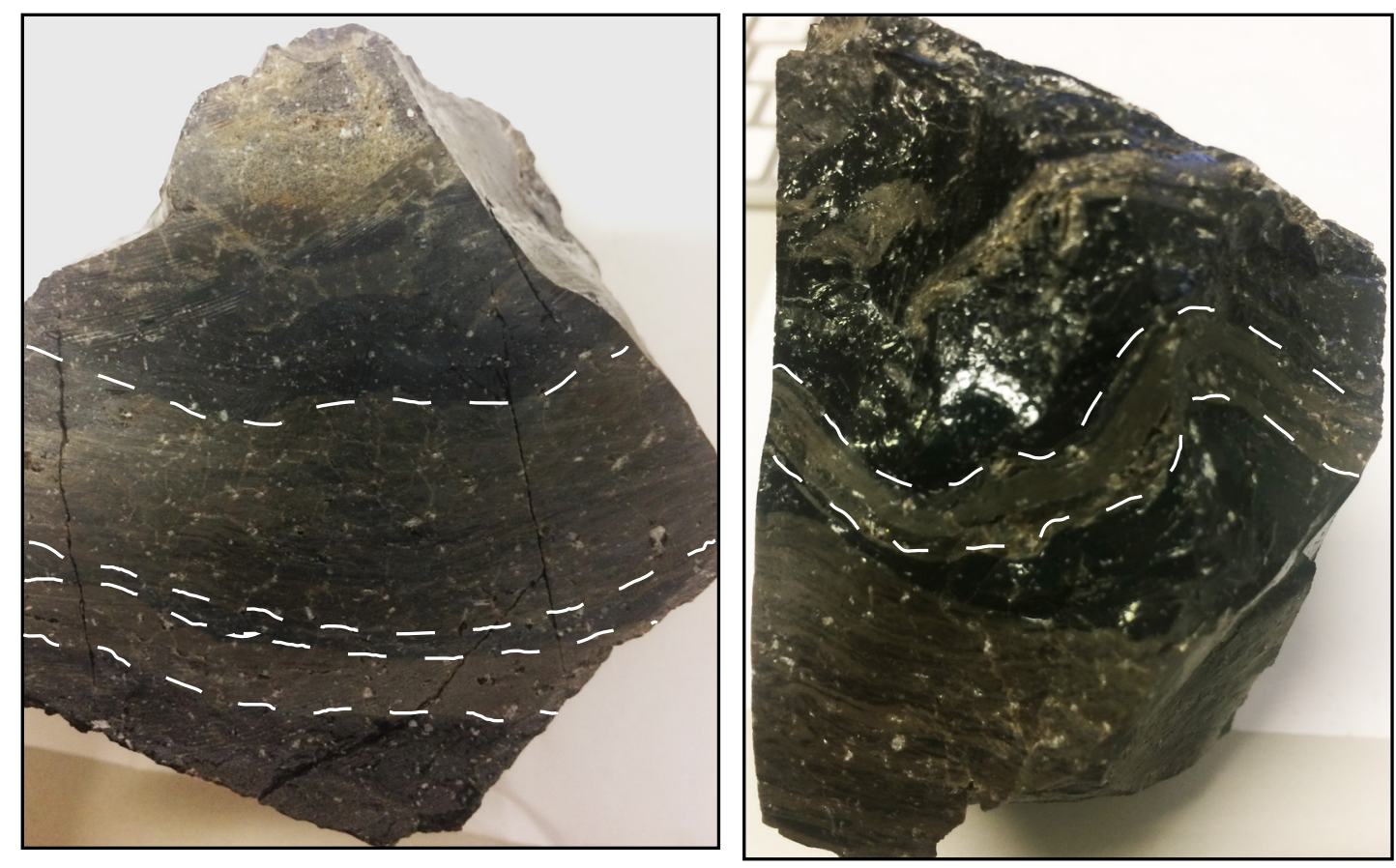

Fig. 5.5. More (left) and less (right) planar, grey and black bands in B13. The view direction in the left image is perpendicular to that of the right image.

\subsection{Micro-Oxides}

Micro-oxides, in the $1 \mathrm{~nm}$ to $10 \mathrm{~nm}$ size range, are often found in welded tuff deposits as precipitates of magnetite and/or hematite within volcanic glass shards (e.g. Schlinger et al., 1988a; Schlinger et al., 1988b; Schlinger et al., 1986; Wolff et al., 1989). They are thought to grow at temperatures of $700-1000{ }^{\circ} \mathrm{C}$ during eruption and subsequent cooling, and magnetic susceptibility studies suggest that magnetite microcrystals are responsible for producing darker coloured volcanic glass (Schlinger et al., 1988a; Schlinger et al., 1986). Growth of these micro-oxides has been reproduced experimentally by heating colourless glass at temperatures of 1000-1250 K for 17 hours (coldest) to 5 minutes (hottest); all samples grew micro-oxides (Schlinger et al., 1988a). While we do not have the same level of data (i.e., magnetic susceptibility measurements and transmission electron microscopy), given this prior understanding it is possible to make some inferences on the nature of micro-oxides in Cordón Caulle bombs. 
Micro-oxides are present in several textural domains in varied arrangements, while conspicuously absent in others. Dense samples are generally rich in micro-oxides, except in some bands of higher vesicularity (Fig. 4.15A), regions of devitrified glass (Fig. 4.20), and some lenses of clean glass (above and between purple lines in Fig. 416). If this is a primary organisation, then nucleation sites for the crystals would have to be distributed into bands and lenses, for which there is no obvious mechanism. The observed organisation of micro-oxides (decorating sintered particles and discontinuous bands in dense regions) suggest that they form in sintering regions and are re-organised into bands in dense regions. Modification of micro-oxide arrangement, from randomly ordered (particle decoration) to discontinuous bands, could be achieved by shearing and flattening as a result of loading (increasing overburden), confinement (overburden with increasing gas pressure below), or movement proximal to conduit walls, potentially expedited by increased temperatures (e.g., mafic input), or sustained temperatures and/ or slower cooling rates as a result of insulation from overburden (Heap et al., 2014). Explaining the modification of arrangement from discontinuous bands to randomly ordered particle decoration would however be much more difficult (semi-ordered to chaotic organisation). That they do not appear in all dense regions, especially where dense regions that lack micro-oxides are juxtaposed with those that are replete with them, strongly suggests that they did not precipitate in that environment. Furthermore, the incipient micro-oxide presence where particle-particle edge sintering is occurring in B09 (Fig. 4.8), alludes to a potential nucleation setting. The curvilinear ear bands of micro-oxides in B21 could therefore indicate both densified sintered ash, where thicker bands are present, or sintering between two larger clasts, where narrow micro-oxide bands are seen (e.g., Fig. 5.6).

\section{Micro-Oxide Re-Organisation}

Micro-oxide re-organisation can be understood as the densification of composite bombs to form dense bombs, or more correctly, the densification and re-ordering of materials comparable to those found in a composite bomb. The regions absent of micro-oxides in dense and vesicular domains can be explained by collapse and shearing of the pumice clasts (invariably absent of micro-oxides) in composite bombs, or alternatively, the shearing and minor foaming of obsidian chips also found in composite bombs (e.g., B16). Regions with micro-oxides can then be interpreted as domains of collapsed and sheared sintered ash, notwithstanding the lack of discernible, individually sintering particles due to complete textural overprinting. B16, for example, is composed of heavily sintered ash (micro-oxide rich), along with pumice clasts and obsidian fragments (no 
micro-oxides) in a honeycomb-like texture. If this underwent densification through pure and simple shear, then the resultant rock might look much like B10, largely rich in micro-oxides with discontinuous lenses entirely absent of micro-oxides. Hence, the presence and absence of micro-oxides is considered an important marker in these bombs, signifying prior fragmentation. Furthermore, the minor bands of micro-oxides in B21 are suggested to represent a similar, but scaled up scenario; the bigger micro-oxidefree domains represent larger clasts that have undergone heavy sintering (evidenced by thin micro-oxide bands) with or without ash involvement. Thus, micro-oxides suggest two origins for similarly dense domains: (1) collapse and shearing of micro-oxide free pumice (e.g., the collapsing foam model of Eichelberger et al., 1986) and obsidian, and (2) complete sintering and densification of micro-oxide decorated ash (e.g., Gardner et al., 2017).

\section{Vesicularity Association with Micro-Oxides}

Different vesicularities and histories of clasts or domains can also be linked to, or inferred from, the presence and absence of micro-oxides in Cordón Caulle bombs. Where vesicularity is concerned, there is a strong correlation between a lesser presence of micro-oxides and increased vesicularity (e.g., grey pumice bombs and the higher vesicularity regions in dense bombs, Fig. $5.6 \& 4.15 \mathrm{~A}$ respectively). It follows that, if micro-oxides indicate that the material was once heavily fragmented ash, then volatile diffusion length scales would be short $(<<200 \mu \mathrm{m}$ in these bombs), much shorter than they would be for larger pumice clasts for example. Combined with a permeable network of inter particle space, at least early on in the sintering process, sintering ash would favour more thorough volatile loss. However, a recent study of Mono Craters (Ca, USA) obsidian pyroclasts containing tiny Fe-Ti oxides in similar arrangements to that seen here, found no correlation between abundance or composition of the microoxides and volatile content (Gardner et al., 2017), although they did conclude that the obsidian pyroclasts were formed by sintering ash. Furthermore, the samples Gardner et al. (2017) studied have micro-oxides in all but a few samples, a greater abundance of microlites, and no pumice or composite pyroclasts, suggesting that their conclusions are not wholly applicable here. Thus, bombs or domains that contain abundant microoxides are inferred to have had significantly lower volatile contents then those that have little to no micro-oxide content. This can be illustrated using B10 and B21. The rind of B21 (Fig. 4.14A), with minor, isolated bands of micro-oxides, indicates that, prior to final ejection, it was approximately equal in density to B10 (Wright et al., 2007), which 


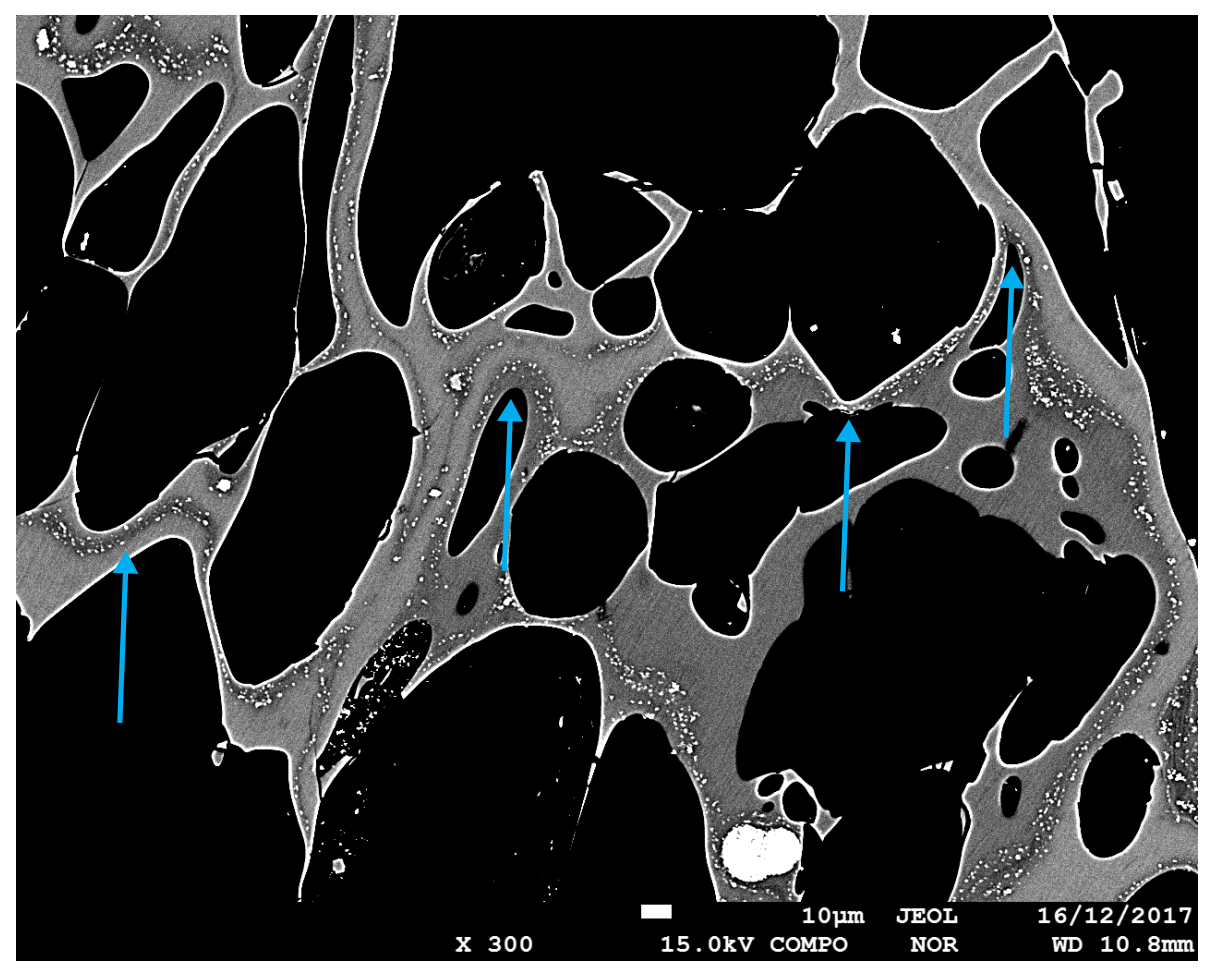

Fig. 5.6. Micro-oxide bands in B21-AS26 circumscribing vesicles (blue arrows). The match between the shape of the micro-oxide bands with the vesicle shapes is conspicuous, especially when considering the arrangement show in the rind of this sample (see Fig. 4.13A).

is rich in micro-oxides (almost) throughout (Figs. 4.15, 4.16, \& 4.18). However, the lack of micro-oxides in the higher vesicularity bands of B10 (Fig. 4.15A) and the strong vesiculation in the core of B21 (Fig. 4.14B \& C) implies that micro-oxide absence is important. This is not likely indicative of causation, but is supportive of the idea that micro-oxides are indicate strong volatile loss from heavily fragmented ash.

\section{Coexistence of Micro-Oxides and Basaltic-Andesite}

The presence of Basaltic-andesite particles or clasts (see Chapter 6) is also strongly linked with micro-oxide presence; in other words, wherever micro-oxides are present, basaltic-andesite particles are also found (Fig. 4.25). The pumice clasts of B20 for example are invariably free of both micro-oxides and basaltic-andesite, yet the sintered ash they are contained within are full of both (Fig. 5.7); hinting at different histories for two intimately related components in a single bomb. If micro-oxides were formed before the fragmentation of ash and pumice clasts in composite bombs, then complete mechanical segregation of micro-oxides from pumice clasts is implausible. A brief BSE examination of plinian pumice and lava samples revealed that these products are both free of micro-oxides, implying that micro-oxide formation is exclusive to the 
bomb forming regime of the eruption. Ruprecht et al. (2017) and a recent (Dec 2017: pers comm. C. I. Schipper, 2017) field expedition each found mafic enclaves in the lava, thus the basaltic-andesite cannot be confined to presence in the bombs. Howbeit, the above relationship is not evidence of causation, a chemical link between the two products being not established. Indeed, the sintered domains of B09 contain roughly comparable amounts of the basaltic-andesite component as B20 (e.g., Fig. 4.6), yet B09 contains far fewer micro-oxides (Fig. 4.8). Greater time, heat, pressure, or some other

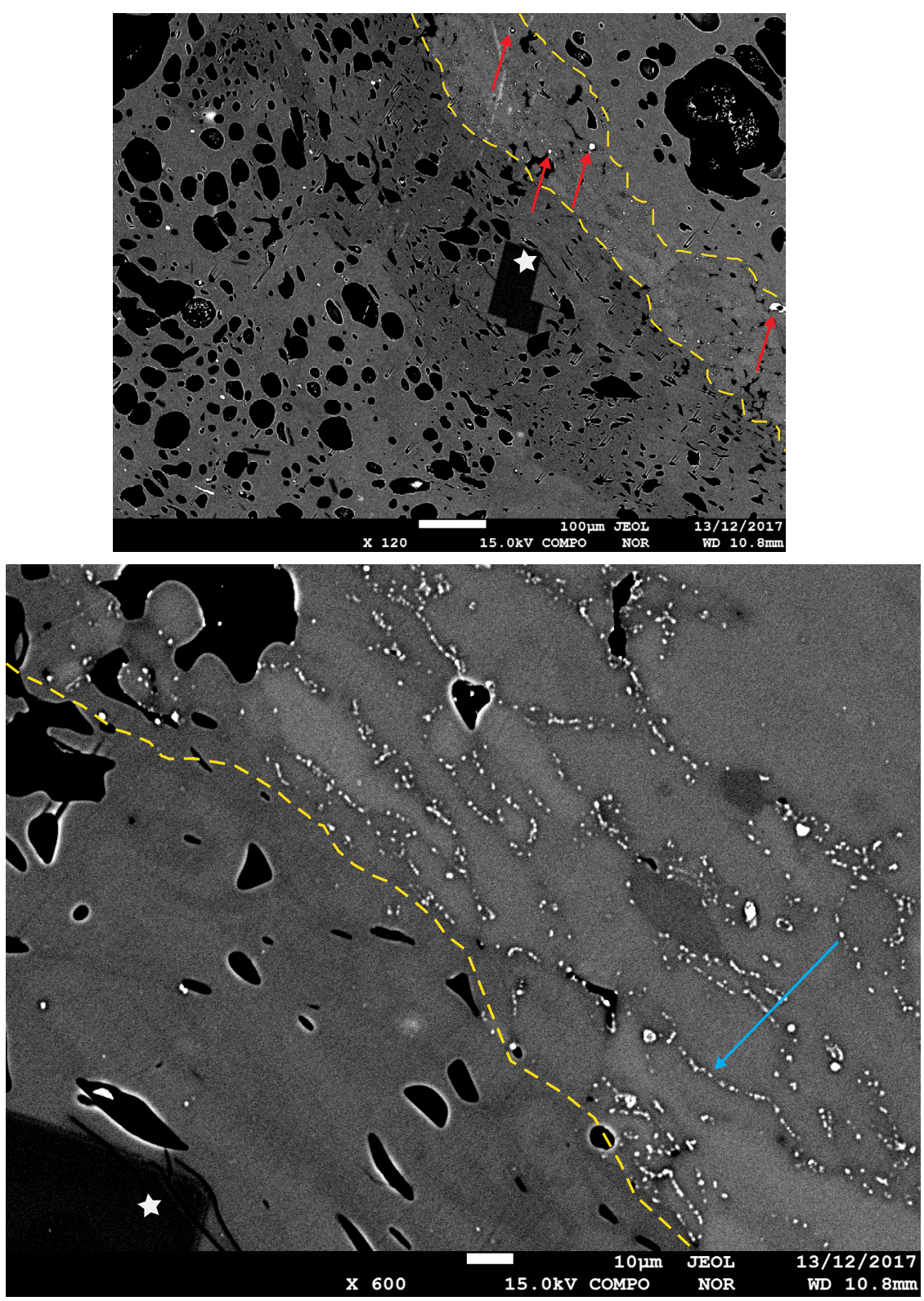

Fig. 5.7. Micro-oxide presence and absence in B20-AS04; the bottom image is a close up view of the upper image, the plagioclase star indicated by the white is shown in both..The band denoted by the dashed yellow lines is composed of sintered ash with micro-oxides (blue arrow) and mafic particles (red arrows), while the regions to either side are pumice lapilli with no micro-oxides or mafic particles. 
unknown variable might be the requirement to form significant micro-oxides in B09. It is possible that the relationship between micro-oxides and basaltic-andesite clasts is entirely coincidental; rather, that the micro-oxides form in sintering ash, and that the basaltic-andesite is injected into those selfsame regions of the conduit or vent through sub-surface fragmentation events. Basaltic-andesite particles would be excluded from already formed obsidian fragments and/or pumice lapilli, and micro-oxides, evidenced to form on particle surfaces, would not occur within these same clasts. Regardless, micro-oxides and mafic domains always occur together in these bombs, and whether this relationship is coincidental, or chemically (e.g., Fe and Ti exchange) and/or thermally linked, a pre-fragmentation origin for micro-oxides is implausible.

\section{Colouration Indicating Composition}

As regards the relationship between colour and micro-oxide presence (Fig. 4.10), that is, red colouration observed in hand sample indicates the presence of micro-oxides, but a lack of colour does not denote the absence of micro-oxides. Compositional variation of the micro-oxides could provide an answer. Schlinger et al. (1988b) stated that microoxides in welded tuffs consisted of both magnetite and hematite. From their survey of ash deposits from the 2011-2012 Cordón Caulle eruption, Botto et al. (2013) also suggested the presence of both hematite and magnetite as microcrystal phases. The red colour of some sintered regions (e.g., B20, Figs. 4.1D, 4.2F, \& 4.3D) could thus be the result of the micro-oxide content being dominated by hematite microcrystals, as opposed to magnetite (black crystals) in some of the sintered regions of B16 (Figs. 4.1H, I, 4.2J, \& 4.3G). This hematite could occur either by primary growth or alteration of magnetite (Schlinger et al., 1988b), possibly by meteoric water interaction, or by exposure to atmospheric oxygen in the vent region or post deposition. Unfortunately, the extremely small size of the micro-oxides in Cordón Caulle bombs precludes the determination of their composition by EPMA. 


\title{
Chapter 6: Mafic Textures and Geochemistry
}

\section{Significance and Implications of the Subsidiary Mafic Component and Anomalous Geochemical Features}

\begin{abstract}
Although much work has been done on the 2011-2012 eruption of Cordón Caulle, including detailed textural and chemical analysis of some components (e.g., Alloway et al., 2015; Bertrand et al., 2014; Botto et al., 2013; Castro et al., 2013b; Collini et al., 2013; Daga et al., 2014; Jay et al., 2014; Pistolesi et al., 2015; Ruprecht et al., 2017; Schipper et al., 2013; Schipper et al., 2015), only one group (Ruprecht et al., 2017) noted the presence of a mafic component contained in the eruption products. Ruprecht et al. (2017) assert that mafic enclaves in the 2011-2012 Cordón Caulle lava flow are "rare but ubiquitous", although a recent field expedition found only one mafic enclave, in a search that was thorough, but limited to a small section of the lava flow (pers comm. C. I. Schipper, 2017). This could be attributed to the small volume present $(<5 \%)$, small size of the inclusions $(\sim<2 \mathrm{~cm})$, and a similarity in colour and texture at hand-sample and thin-section scales in the bombs (Fig. 4.26). Furthermore, the holocrystalline mafic enclaves observed in the lava flow have not been compositionally or genetically linked to the mafic domains observed in the bombs. Regardless, the results of this study demonstrate the presence of a compositionally distinct, basaltic-andesite component, ubiquitously present in the Cordón Caulle bombs. Texturally, the basaltic-andesite domains exhibit similar diversity to rhyolitic domains, however, the texture of a basaltic-andesite domain is not always concordant with the texture of the host rhyolite, and moreover, the mafic groundmass textures are markedly different to those of the rhyolitic groundmass. The involvement of this secondary basaltic-andesite component has implications for anomalous eruptive temperature, eruptive style (i.e., hybrid effusive-explosive activity), eruption continuity, sintering timescales, and textural features.
\end{abstract}

\section{Magmatic Origins}

A magmatic origin (i.e., quenched from melt), for mafic domains within a silicic host, is suggested by ellipsoidal shapes, cuspate margins, and acicular groundmass crystal phases (Bacon, 1986; Browne and Vitale, 2011; Coombs et al., 2003). All of these features are observed in the basaltic-andesite domains found in the Cordón Caulle bombs (e.g., Fig. 4.23). Margins of finer grained material are also expected in rapidly quenched domains (Bacon, 1986), however, it is possible that quenching occurred throughout domains almost instantaneously, or alternatively, that the margins of these domains are 
too fine to distinguish in BSE imaging. Some larger mafic domains do have very fine margins that appear to be finer grained (Fig. 4.28B), but they cannot be confidently defined as quench margins. Nevertheless, the general shape of mafic domains, especially as compared to the margins of highly crystalline and palagonite lithic inclusions (Fig. 4.4), suggests they were quenched rapidly from a melt.

If mafic material was not injected, and is in fact a proto-lithic or lithic fragment, we would possibly see sharper, more defined boundaries, and less foamed clasts (e.g., Eichelberger, 1980). However, mafic lithics could still contain dissolved volatiles, and therefore could foam during decompression or reheating (e.g., Gonnermann, 2015; Spieler et al., 2004) during the assembly and eruption of bombs. That said, other lithic inclusions are: 1) invariably un-foamed, 2) highly crystalline, 3) have more planar and/ or jagged boundaries compared to the cuspate boundaries of many mafic domains, 4) have minimal textural variation, and 5) show no evidence of ductile interaction with the rhyolite. As above, mafic material is also found as enclaves in the obsidian lava flow (Ruprecht et al., 2017), and although not confirmed as genetically linked, the mafic enclaves in the lava could be related.

\section{Domain Vesicularity}

Rapid crystallisation within a mafic domain is thought to occur after entrainment, and quenching, against a relatively cool silicic host (Bacon, 1986; Stimac et al., 1990). If the margin of the mafic domain is chilled quickly, it can function as an impermeable barrier, thus trapping any volatiles that exsolve within the domain. This is most clearly evident in dense Cordón Caulle bombs where basaltic-andesite domains have significantly greater vesicularities than the host rhyolite (Fig. 4.23), but is slightly more ambiguous where basaltic-andesite domains are found in composite bombs (Fig. 4.27). That notwithstanding, vesiculation in basaltic-andesite domains is observed to be independent of the vesicularity of the rhyolite host material; as noted by Eichelberger (1980) for mafic domains in a lava. Vesiculation of the basaltic-andesite domains in this way is important, as the resultant reduction in bulk density enables mafic domains to 'float' in the rhyolite host, thereby lowering the chance of mechanical separation (Bacon, 1986).

\section{Domain Deformation}

Flow banding textures in the rhyolite host immediately surrounding vesiculated basalticandesite domains (Fig. 6.1) is evidence that the rhyolite was relatively hot and ductile, either during or at some point after the inclusion of the domains. Some basaltic-andesite 


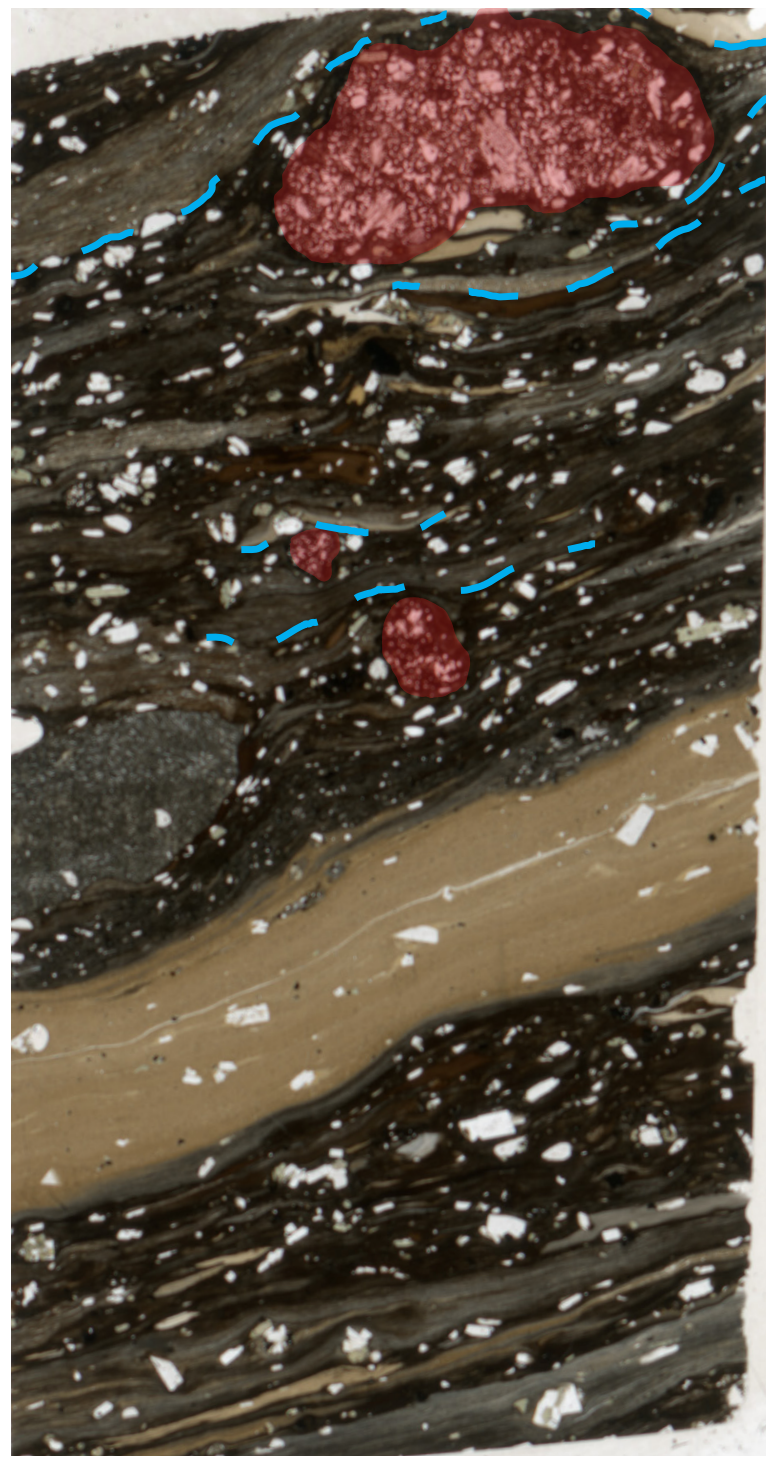

Fig. 6.1. Flow banding textures around mafic blobs in B10-AS01-S2. Red areas indicate basaltic-andesite blobs and the dashed blue lines trace good examples of the ductile banding features.

domains with rhyolitic inclusions also suggest ductile behaviour at some stage (Fig. 4.28A \& B). Additionally, a large domain with a 'rupture' texture (Fig. 6.2), surrounded by rhyolite host material with no evidence for brittle deformation, suggests that at least some basaltic-andesite domains underwent partial vesiculation within their final host domain. However, healed fracture planes and cut-off crystals (e.g., Figs. 4.24 \& $4.28 \mathrm{C}$ ) point toward periods of comparatively brittle behaviour in the basaltic-andesite. Where and when these features were formed is unclear. However, the implication of micro-oxide association with basaltic-andesite, is that all basaltic-andesite domains were incorporated in sintering ash regions. Thorough densification of sintered ash, involving deviatoric stresses (Quane and Russell, 2005; Vasseur et al., 2013b; Wadsworth et al., 2014), is suggested to result in the formation of the dense regions and bombs at Cordón Caulle (e.g., the model of Gardner et al., 2017), thereby providing a explanation for the brittle deformation and breakup of basaltic-andesite domains. 


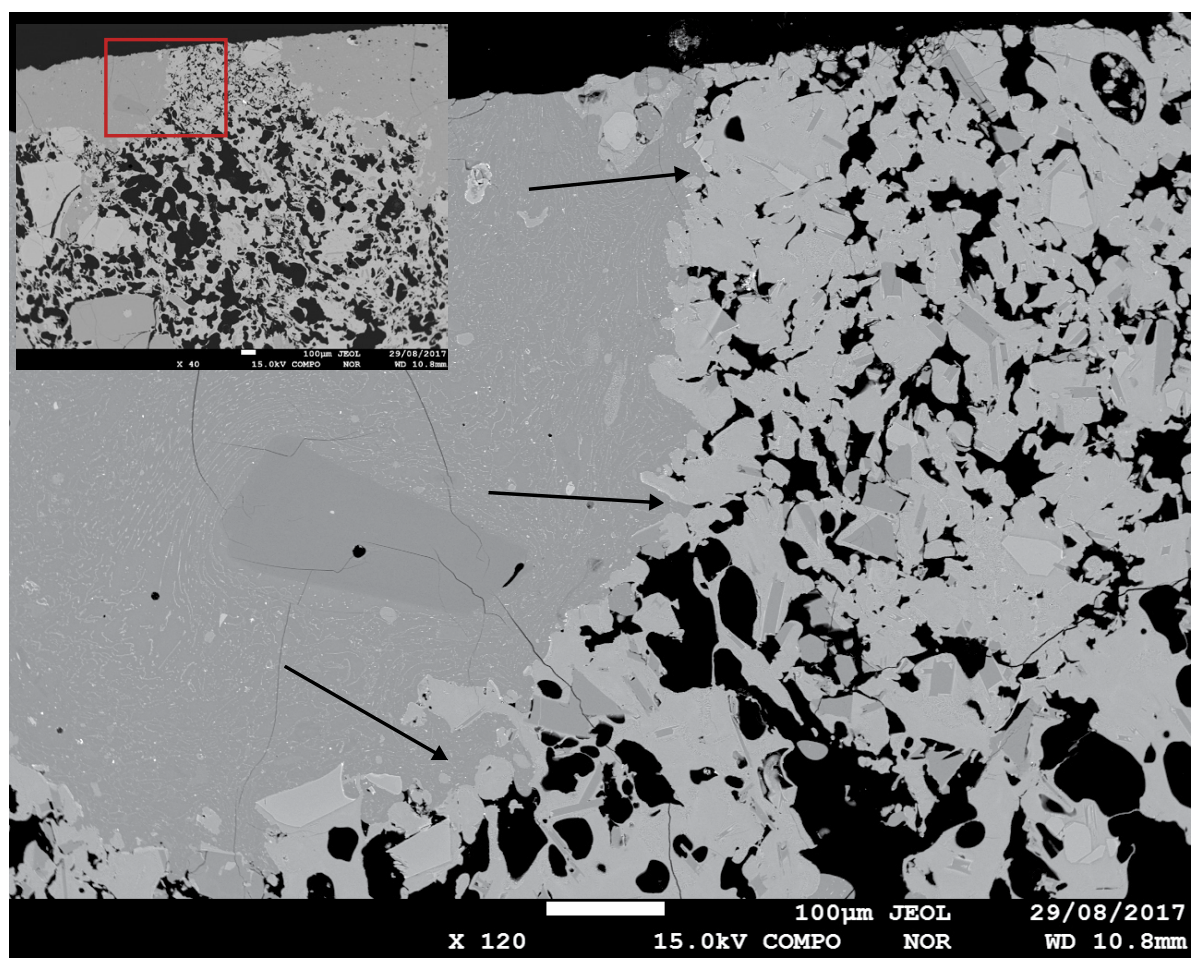

Fig. 6.2. Rupture texture in the large basaltic-andesite blob in B10-AS01-S2. Red box in inset image shows the area of the larger image, black arrows in the main image indicate areas where smooth lobes of rhyolite (i.e., ductile intrusions) into the blob can be seen. The neck area of the basaltic-andesite blob that is proposed to be indicative of rupture is composed of sintered fragments, whereas the main body of the blob is vesiculated but not sintered.

\section{Mixing and Mingling Signatures}

Viscosity increase in the mafic domains is driven by decreasing temperature through thermal equilibration with the comparatively cooler rhyolite, and additionally through volatile exsolution and increases in crystal fraction (e.g., Bacon, 1986; Laumonier et al., 2014b). This rapid increase in viscosity serves not only to retain volatiles, but also creates a physical barrier to hybridisation through breakdown and chemical diffusion. Although banded pumice, suggested to result from magma mingling (Anderson, 1976) or mixing (e.g., Sparks and Marshall, 1986), is present in the Cordón Caulle bombs, the results of Alloway et al. (2015), and the lack of strong chemical distinction between bands, suggests that this is the result of several silicic magma bodies feeding the eruption (e.g., the white and brown rhyolite pumice of Castro et al., 2013b). None of the chemical analyses conducted for this study suggest that there has been chemical exchange between the basaltic-andesite and silicic magmas, although more detailed chemical work, such as that in Alloway et al. (2015), could reveal more nuanced mixing signatures. 
The interaction between a mafic and silicic magma is expected to favour mingling (i.e., no chemical exchange) where the mafic component is volumetrically low and significantly hotter. The maximum observed volume of basaltic-andesite in any region for the Cordón Caulle bombs is $<5 \%$, thus the first condition is met. In the absence of phase petrology data, the temperature of the basaltic-andesite is an unknown. However, Jay et al. (2014) suggest $\sim 1100{ }^{\circ} \mathrm{C}$ from an inherited plagioclase core in a Cordón Caulle bomb, and the experimental phase petrology conducted by Castro et al. (2013b) suggests that the rhyolitic component was stored at 870 to $920{ }^{\circ} \mathrm{C}$, at a depth of 2.5 to $5.0 \mathrm{~km}$. Although the inherited plagioclase of Jay et al. (2014) may or may not to be related to the current basaltic-andesite (see Plagioclase Zoning section below), their estimation is based on a plagioclase composition of $\mathrm{An}_{88}$, which is only marginally higher then the maximum of $\mathrm{An}_{84.5}$ measured in mafic plagioclase crystals here. This suggests a minimum temperature difference of $\sim 200{ }^{\circ} \mathrm{C}$ between the rhyolite $\left(\sim 900{ }^{\circ} \mathrm{C}\right.$ : Castro et al., 2013b; Jay et al., 2014) and basaltic-andesite. Furthermore, the presence of sharp, cuspate margins is suggested to occur where the thermal contrast between two magmas is large (Bacon, 1986).

\section{Plagioclase Zoning}

Some plagioclase crystals also show minor $(<6$ mol.\%) changes in An content from core to rim (see Appendix 2 for full analyses), indicating that there may have been a change in crystallisation just before eruption of the bombs. No such variations have been reported for plagioclase from the 2011-2012 eruption by other authors (Castro et al., 2013b; Jay et al., 2014), and the spread of An compositions measured here (Fig. 4.33 ) is far greater than that reported by those authors. Howbeit, the previous work has focused on samples of the Plinian pumice and lava flow. The fact that reverse zoning is not present in the plagioclase crystals of the Plinian pumice or lava (Castro et al., 2013b), and appears to occur proximal to, or at crystal rims in the bombs (Fig. 4.34), suggests continued crystallisation under changing conditions. Diffusion timescales of $\mathrm{Ca}$ in plagioclase are far too slow for this to be a signal of re-equilibration (e.g., Grove et al., 1984). Ginibre et al. (2002a) rule out magma reheating through mafic replenishment as a cause for small changes in An ( $\leq 5 \mathrm{~mol} . \%)$, and instead suggest that minor variations result from convection in a magma chamber. Although such minor reversals in An could result from convection within the magma chamber (e.g., Ginibre et al., 2002a; Ginibre et al., 2002b), if convection was a dominant process, reverse 
zoning should also be seen in the plagioclase crystals in Plinian and lava samples. A third possibility is suggested by the work of other authors; Alloway et al. (2015) suggest that the eruption involved three distinct magmas based on Ca compositions in the Plinian pumice, and InSAR measurements, studied by Jay et al. (2014), show two distinct co-eruptive deflation regions. Multiple magma sources provide a potential explanation for the discordant crystal compositions and textures, whereby the bombs might show all three suggested rhyolitic magmas (Alloway et al., 2015), along with the basaltic-andesite as a fourth component. However, despite no definitive evidence of magma mixing or crystal inheritance in the rhyolite, the large spread in plagioclase An values (Fig. 4.33), similar to that shown by Laumonier et al. (2014a), could indicate some minor chemical interaction.

\section{Inherited Plagioclase}

Two plagioclase crystals with anomalous compositions were found in the Cordón Caulle bombs; B10-Plag-C27 in basaltic-andesite glass (Fig. 4.32A), and B10-Plag-C28 in rhyolite glass (Fig. 4.32B). The anomalous mafic plagioclase has a core composition of $\mathrm{An}_{58.8}$, with rim composition of $\mathrm{An}_{65.3-65.6}$ (two rim measurements), whereas all other mafic hosted plagioclase crystals are normally zoned, and have greater core An compositions $\left(\mathrm{An}_{68-84.5}\right)$. The crystal contains a vesiculated melt inclusion at its centre (Fig. 4.32A), and the core analysis spot was close to this. Contamination of the crystal by re-equilibration with the vesiculated glass inclusion, or an analysis spot that overlapped with the glass inclusion, are possible explanations for the anomalously low An core. Whilst the anomalous felsic plagioclase has a higher An core $\left(\mathrm{An}_{62.1}\right)$, the rim of the crystal has a composition $\left(\mathrm{An}_{47.1-48.9}\right)$ concordant with other felsic hosted crystals. Jay et al. (2014) describe an inherited plagioclase crystal in the Plinian pumice of the

2011-2012 Puyehue-Cordón Caulle eruption; however, the core composition of $\mathrm{An}_{88}$ is significantly higher than that seen here. Though that does not rule out inheritance, it does suggest a different origin for their high An plagioclase core, possibly signifying the involvement of multiple mafic magmas over time as suggested by Singer et al. (2008). Moreover, a thorough examination of the felsic material for olivine crystals, especially proximal to mafic clasts, found no presence of olivine, further suggesting that crystal inheritance did not take place.

\section{Eruption Triggering}

Based on the $\mathrm{MgO}$ zoning in the inherited plagioclase crystal mentioned above, Jay et al. (2014) argue that the 2011-2012 Cordón Caulle-Cordón Caulle eruption was not triggered by mafic replenishment. They calculate a residence time of $\sim 200$ years 
for the $\mathrm{MgO}$ profile, and therefore a $\sim 200$ year interaction timescale for the original host melt with the 2011-2012 magma. The presence of rapidly quenched basalticandesite domains in bombs is inconsistent with this finding, instead suggesting mafic injection shortly prior to the eruption onset. Several pre-eruption flank-swell events, thought to be the result of silicic magma intrusions, were measured between 2007 and May 2011 (Fournier et al., 2010; Jay et al., 2014); however, the presence of rapidly quenched mafic domains suggests that these deformation events may have involved some mafic magma intrusion. Additionally, the pre-eruptive deformation and syneruptive subsidence indicates multiple magma sources (Jay et al., 2014); therefore it is possible that mafic replenishment was confined to a single magma chamber. This provides a possible explanation for the lack of basaltic-andesite inclusions in the early Plinian material and the lava that erupted synchronously with the bombs. Moreover, in the absence of a conclusive eruption-trigger (e.g., Jay et al., 2014), the presence of the rapidly quenched basaltic-andesite component suggests that mafic replenishment may have been a contributing factor to eruption onset (e.g., Ruprecht et al., 2017), although this cannot be invoked as the eruption trigger with absolute confidence.

Rather than triggering the eruption, the mafic injection may have instead had a sustaining effect on the eruption. To this point, magmatic mafic material has been found in the bombs and lava only, however, the holocrystalline mafic enclave discovered in the lava flow by C. I. Schipper and colleagues has not yet been established as magmatic. Furthermore, the mafic enclaves of Ruprecht et al. (2017) have not yet been established as having the same origin and composition as the mafic material presented here. Nevertheless, the presence of mafic material in late stage products suggests that the mafic magma may have contributed to the change from purely extrusive to hybrid effusive-explosive, and subsequently sustained the eruption through thermal input (e.g., Pichavant et al., 2009; Roberge et al., 2009) and possibly volatile input that promotes continued magma ascent. Other workers suggest that the eruption sustaining effects of a mafic magma is significantly increased if the mafic magma is broken down into smaller domains (as they are in these samples), due to a greater capacity for thermal exchange when the surface area to volume ratio is increased (Melekhova et al., 2013; Ruprecht and Bachmann, 2010). Furthermore, the overpressure build up that is proposed for bomb blasting episodes might have been contingent on, or at least bolstered by, the presence of auxiliary volatiles from the mafic recharge, although this is heavily speculative. Thus, although volumetrically minor, thermal ( \pm volatile) inputs from an intimately mingled mafic magma may have played an important role in sustaining the long-lived hybrid explosive-effusive activity at Cordón Caulle. 


\section{Chapter 7: Implications}

\section{Conceptual Model for Bomb Formation at Puyehue-Cordón Caulle}

Textural variations in ejected bombs have been interpreted as being the result of stratification of volatiles and density in the upper conduit magma (Giachetti et al., 2010; Isgett et al., 2017; Kennedy et al., 2005; Yamagishi and Feebrey, 1994), variations in the vesicularity and density of a conduit plug (Wright et al., 2007), or a combination of these (Castro et al., 2013a). Castro et al. (2013a) suggest that dense obsidian and breadcrusted pumice bombs record flow through a conduit, whereas heterogeneous amalgam bombs record multiple episodes of fragmentation in the conduit. Furthermore, they suggest that these components are connected through a mixing process within some boundary layer between the endmembers. However, the findings in this study indicate that all bombs are the products of multiple fragmentation and reassembly events, not necessarily in disagreement with prior work, but rather as a consolidation and reconsideration of the prevailing ideas of Vulcanian bomb formation.

The idea of stratification causing textural differences in bombs (e.g., Yamagishi and Feebrey, 1994) can be thought of as the influence of depth on texture. This is often modelled as a magmatic heterogeneity produced as a result of steadily decreasing volatile exsolution (i.e., degassing and outgassing) with decreasing depth, resulting in a depth-texture relationship (e.g., Giachetti et al., 2010; Isgett et al., 2017; Wright et al., 2007). However, a conduit depth-stratification model, alongside the general model for Vulcanian blasts (a 'throat clearing' blast that clears the conduit: Self et al., 1978), is at odds with the requirement of multiple fragmentation episodes for Cordón Caulle bomb textures. The textural evidence presented here suggests that all bombs require at least two fragmentation episodes, one to create the constituent particles (e.g., ash and pumice clasts), and a second to eject this new agglomerate (e.g., Castro et al., 2013a), although the true number of fragmentation events could be incalculable. Moreover, B09 (a composite bomb) contains clasts with textures equivalent to those of B10 (i.e., dense, with micro-oxide banding), and small inclusions of the lava can be found in many bombs. Although textural crossover could occur at boundaries in a stratified conduit, these textural types would, based on previous models (e.g., Yamagishi and Feebrey, 1994), be significantly separated in the conduit, and juxtaposition in a single bomb would therefore be unlikely. 
Furthermore, basaltic-andesite inclusions are found in all bombs, but although they are common in the sintered regions of B20 (a composite bomb), they are never found in the pumice clasts of the same bombs. This suggests either that these pumice clasts were vesiculated and quenched from the melt with absolute mechanical separation from the basaltic-andesite, that they vesiculated from juvenile obsidian that had not incorporated basaltic-andesite, or that they formed at an earlier time when the basaltic-andesite was not present in the upper conduit. Moreover, fine $(\geq 5 \mu \mathrm{m})$ basaltic-andesite particles, suggestive of strong fragmentation, are seen in dense, micro-oxide-rich domains, and all sintered regions. The occurrence of these fine particles in both sintered regions and some dense domains, coincident with those clasts that lack basaltic-andesite and microoxides, implies that dense bombs have incorporated sintering ash that has subsequently undergone densification. Thus, the significant textural crossovers and juxtapositions in Cordón Caulle bombs cannot suitably be explained by a simple conduit stratification model.

A relatively recent theory proposes that tuffisite veins in the upper conduit plug act as bulk volume degassing pathways to relieve pressure, and allow for lava effusion (Castro et al., 2014; Castro et al., 2012b; Kendrick et al., 2016; Saubin et al., 2016). When sufficient gas pressure builds below a conduit plug, the ash and clast filled fractures (i.e., tuffisite veins) are forced open, allowing rapid degassing (Kendrick et al., 2016). In this way, the powerful, but transient, ejection of gas is suggested to also cause the ejection of bombs (Castro et al., 2013a; Saubin et al., 2016), wherein granular, sintered material represents choked tuffisite veins, whilst dense and obsidian rinded pumiceous bombs represent sub-plug material (Castro et al., 2013a). However, whilst tuffisite veins might play a role in rapidly degassing magma (Castro et al., 2012b; Saubin et al., 2016), such that a lava flow can exist coevally with vulcanian blasting, the current understanding is in partial disagreement with the observed textures in the Cordón Caulle bombs (i.e., does not work for dense bombs). Gardner et al. (2017) provide an alternative model for the formation of heterogeneous obsidian, suggesting that fragmented material undergoes sintering, relaxation, and shearing in the region between the fragmentation front and vent. Together, these models provide explanations for the majority of textural variations seen in the Cordón Caulle bombs, but the proposed conduit models are somewhat disparate; the obsidian forming model of Gardner et al. (2017) is for Sub-Plinian activity, whilst the models suggested by Saubin et al. (2016), Schipper et al. (2013), and Castro et al. (2013a) are set around bomb forming Vulcanian eruptions. Therefore, a new model is required, combining the pertinent features of models by previous authors. 
Cordón Caulle bombs are herein suggested to form through progressive sintering and densification of a variety of materials in the upper conduit and vent regions. The microtextural features of the Cordón Caulle bombs suggest that they are all assembled by sintering of volcanic debris (ash. pumice clasts, obsidian fragments, and blocks) within a volcanic breccia pack in the conduit/vent. Supplementary video S2 in Schipper et al. (2013) shows fallback of volcanic debris in the vent region, Rust and Cashman (2007) suggest the formation of some obsidian at Newberry Volcano (Or, USA) by welding of fallback material, and Gardner et al. (2017) conclude that the formation of obsidian from the sintering and shearing of particles is common. This fallback is suggested to supply material to the upper regions of the breccia pack, whereas subsurface fragmentation generates the majority of the volcanic breccia plug. Here, the proposed fallback is extrapolated to include the full range of pyroclasts generated by the 2011-2012 Cordón Caulle eruption, including earlier plinian pumice that contributes to the pumice clasts in composite bombs, along with fragments of juvenile obsidian and fragmented lava flow material. Gardner et al. (2017) reject the possibility of foam collapse for the formation of obsidian in their model, but the variable occurrence and associations of micro-oxides and mafic particles suggest that small-scale foam (i.e., pumice clasts) collapse is an accordant process. Subsurface fragmentation and fallback of volcanic breccia is thus proposed to form a breccia pack in the vent region, where material is heated through insulation and thermal conduction from the magma below. Increased burial, overpressure, and re-heating of the breccia result in progressive densification (i.e., pore/vesicle collapse), strength recovery (i.e., sintering), and therefore consolidation. In this sense, all bombs can be considered under the heading of 'composite bombs', differentiated by the degree of compaction, sintering, and deformation prior to final ejection. The fact that not all domain types, or textural variants of domains types, are represented in all bombs is a function of variable sampling of the breccia pack: e.g., a grey pumice bomb has sampled a larger homogeneous domain, whereas, a true composite bomb has sampled a greater variety of smaller domains.

To explain the significant syn- and post- deposition vesiculation of grey pumice bombs (dense material pre-ejection) compared to that of the other bomb types, the distribution of constituent particle types is considered. The diffusion length-scale for volatiles, and therefore diffusion time, will be significantly shorter in fine ash than for larger particles (i.e., pumice clasts and obsidian fragments), therefore the bomb that contains a greater relative proportion of the former will be dryer. Where the pre-eruptive water content is lower the growth rate of vesicles is expected to be slower, therefore cooling rates can arrest vesicle growth earlier, leading to a denser final product (Hoblitt and Harmon, 1993). The textural juxtaposition of dense rinds and high vesicularity cores, in grey pumice bombs, is therefore suggested to indicate the incorporation of greater 
proportions of juvenile (quenched directly from the magma and comparatively volatile rich) components relative to sintered ash. Conversely, dense Cordón Caulle bombs with micro-oxide banding are suggested to represented heavily sintered and densified ash. Consequently, vesicle growth rates would be slower, and termination of vesicle growth would occur before significant vesiculation in dense bombs (Hoblitt and Harmon, 1993), whereas, in grey pumice bombs, the initial volatile content is suggested to be higher (e.g., Wright et al., 2007), and vesicle growth is therefore protracted. Furthermore, Sparks et al. (1999) assert that volatile resorption occurs in sintering deposits, and additionally speeds up the process of sintering, while Watkins et al. (2017) show that erasure of volatile heterogeneity can be accomplished in a matter of hours at magmatic temperatures ( $\sim 800^{\circ} \mathrm{C}$ : Watkins et al., 2017). The decrease in sintering timescale, if significant water was present, might explain why they appear more texturally homogeneous (i.e., less evidence of antecedent textures). The evidence of volatile through-flow (Rust et al., 2004), and batch degassing (Castro et al., 2014), further suggest that the breccia pack would be constantly re-equilibrating with comparatively volatile rich gasses. Surface manifestations of these processes during the Vulcanian blasting phase of the 2011-2012 Cordón Caulle eruption can clearly be seen in the supplementary videos (S1 and S2) of Schipper et al. (2013). However, this re-gassing is envisioned to occur more so in the central region of the proposed breccia pack due to the expectation of greater volatile through-flow in large, well-developed fractures in the conduit centre, as opposed to conduit margins that have many small and tortuous fractures (e.g., Kushnir et al., 2017). Whilst these arguments provide an explanation for the observed differences in vesicularity, and fit with the observed textures (e.g., central cavities and significant posteruption expansion), the data to corroborate variations in the $\mathrm{H}_{2} \mathrm{O}$ content of constituent particles within bombs is not currently available for these samples.

The proposed breccia pack can be understood as a complex, multifaceted, conduit scale tuffisite that is stratified with respect to both vertical and horizontal position. Previous work considers tuffisites as essentially individual fractures, on millimetre to metre scales (e.g., Castro et al., 2014; Kendrick et al., 2016; Saubin et al., 2016; Stasiuk et al., 1996; Tuffen et al., 2003), that act as gas ejection pathways (Castro et al., 2014; Saubin et al., 2016; Schipper et al., 2013), and, where larger choked tuffisites occur, bomb ejection pathways. Millimetre- to centimetre-scale examples of tuffisites are seen within Cordón Caulle vent samples (pers comm. R. Paisley, 2017) and bombs (Castro et al., 2014), and cross-cutting bands of ash and pumice, suggested to depict the recurrent nature of tuffisites (Saubin et al., 2016), can been seen in field images of bombs (Fig. 7.1). Hence they are considered common for the 2011-2012 eruption. In the proposed 
model these are treated as auxiliary to the conduit scale tuffisite (i.e., breccia pack). However, they are considered to play a vital role in outgassing, supplementing volatile flow-through (Rust et al., 2004) in the larger breccia pack, with batch outgassing (Castro et al., 2014). Given the low vesicularity of many samples (or domains within samples), the conduit breccia pack would have highly variable porosity (and correspondingly variable permeability), and volatile flow-through would therefore be retarded in some regions. The tuffisite veins would allow for rapid degassing of all permeable layers through which the vein cuts (i.e., the batch degassing of Castro et al., 2014).

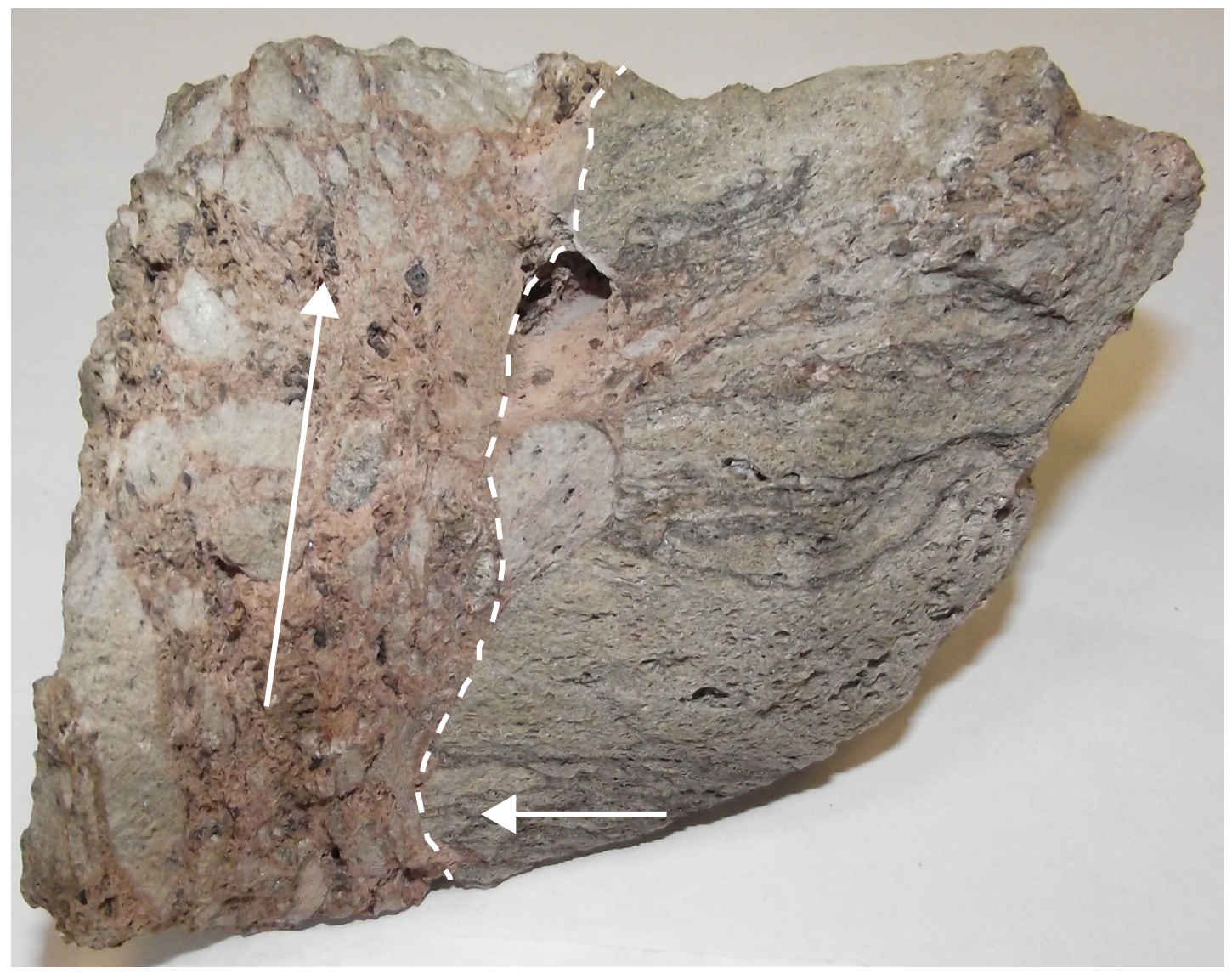

Fig. 7.1. Cross cutting pumice band in B07. The dashed white line marks the sharp boundary between two regions of composite pumice and ash with different elongation and 'flow' azimuths (indicate by white arrows). 
The above considered, the general model proposed for bomb formation at Cordón Caulle is a conduit scale tuffisite, with multiple generations of transient fractures (Fig. 7.2), providing outgassing and bomb ejection pathways that can rapidly alleviate conduit overpressure in a cyclical manner. A bomb sourced from greater depth in the breccia pack, or alternatively, proximal to conduit margins or lava extrusion region, would experience greater shear (e.g., burial pressure and shear strain). With increasing time and depth a bomb would undergo re-homogenisation and densification; vesicles collating as volatiles are resorbed, and particle boundaries becoming obscured, or entirely overprinted, through shearing. Bombs that are sourced proximal to conduit margins are expected to be subject to greater shear and may undergo shear fragmentation. Conversely, bombs sourced further from the conduit margins (i.e., the interior of the breccia pack) are thought to undergo less densification and have greater volatile replenishment. Furthermore, bombs that contain a greater volume of lithic fragments (B09 \& B10) are expected to have formed proximal to conduit walls (Gardner et al., 2017), and bombs that have microlite-rich inclusions (i.e. lava fragments) presumably form in regions proximal to the lava effusion pathway. The ejection, fallback, and burial, and sintering of pyroclastic material from all regions of the conduit-tuffisite allows for the distinct textural crossover seen in B09, but would only occur in the surficial region of the conduit-tuffisite, and therefore would not be as common as other textures.

In this context the four bomb types are arranged in the conduit as follows: 1) composite bombs (type-2 and -4; Table 4.1), sourced from the central upper to middle regions of the breccia pack, with a short to moderate time delay between initial fragmentation and final ejection, 2) dense bombs (type-1; Table 4.1), from the marginal regions of the breccia pack, and ejected after a longer time delay, and 3) grey pumice bombs (type-3; Table 4.1) from deeper more central regions of the breccia pack and ejected after a long period of densification and re-homogenisation. All proposed regions of the breccia pack are expected to contain roughly comparable initial components, that become texturally distinct by virtue of varied conduit processes. Accordingly, the considerable textural variation between samples is the result of variable sampling during bomb ejections, both within, and between the proposed general regions of the conduit tuffisite. 


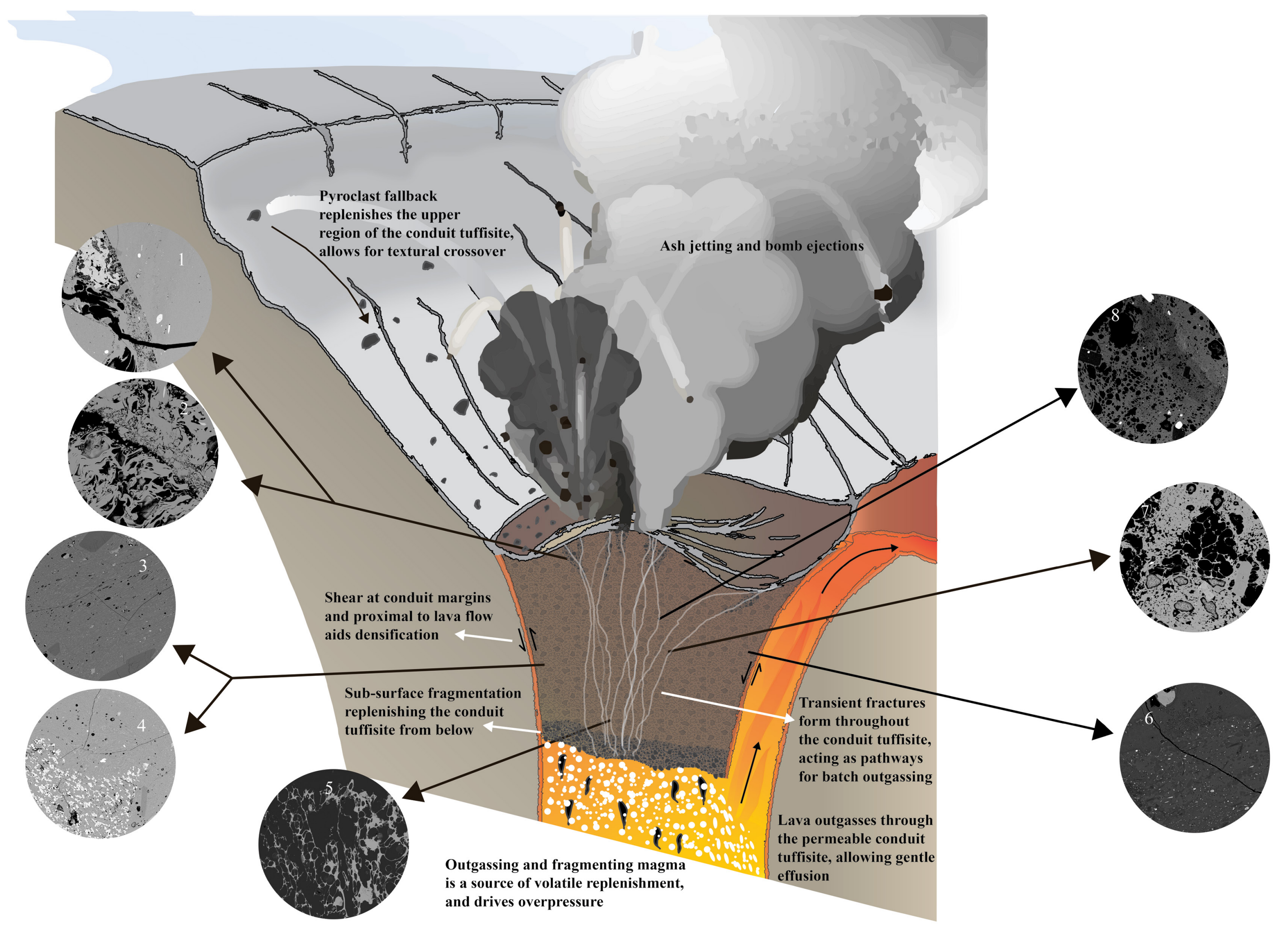

Fig. 7.2. Cartoon (not to scale) of the proposed conduit-scale tuffisite plug and general regions from which bomb types are sourced. Composite bombs such as B09, that have a distinct crossover of incompatible textures, and offen have

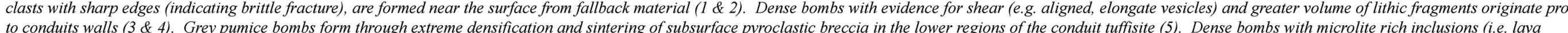
fragments) arise from shearing and densification proximal to the lava extrusion pathway (6). Other composite bombs (including honeycomb texture bombs) form in the middle regions of the conduit tuffisite and make up the bulk of material (7 \& 8 ). 


\section{Chapter 8: Conclusions and Future Work}

The detailed micro-textural analysis conducted in this study has shown that Vulcanian bombs produced during the 2011-2012 Cordón Caulle eruption are complex, multicomponent pyroclasts, that have experienced multiple episodes of fragmentation and sintering in a dynamic setting. The results of this study corroborate the assertion of Gardner et al. (2017) that obsidian pyroclasts form through repeated and protracted fragmentation, sintering, and shearing within the conduit. However, the evidence presented here shows that this process is far from limited to the formation of obsidian, instead, a continuum is suggested, wherein, greater time, depth, and shearing will form a denser, seemingly more homogeneous final product. The distribution of micro-oxides within different textural domains are suggested to be an important marker of fragmentation history in these bombs.

The finding of a mafic magmatic component in Cordón Caulle bombs is significant and sheds light on many aspects of the eruption. The mafic component may have thermally contributed to the surprisingly hot rhyolite temperature $\left(\sim 900^{\circ} \mathrm{C}\right)$ calculated by Castro et al. (2013b) and Jay et al. (2014). Thermal exchange between the two magmas may also have had a sustaining effect on the eruption, and furthermore, might have contributed to the onset of the hybrid explosive-effusive eruption phase. The expected increase in volatile outgassing from a magma that has been heated (i.e., lower viscosity) would correspondingly be a suitable contributing source of overpressure to drive the coeval bomb blasting. Chemical analyses of matrix glasses and three crystal phases (olivine, plagioclase, and orthopyroxene) did not reveal compelling evidence for any chemical interaction between the two magmas. However, further work is required to assess mixing signatures, especially the reversely zoned plagioclase crystals and anomalous plagioclase cores. These petrological features may be due to inheritance from wall rocks or some other lithic source during conduit ascent, but no lithic source for large crystals was preserved in any of the samples examined. It therefore seems likely that they are xenocrystic, either inherited and re-equilibrated from the basaltic-andesite during mingling, or from some other, as yet unknown magmatic source. The small number of compositionally anomalous plagioclase crystals, and the lack of inheritance of any other crystal types, suggests that crystal inheritance through mingling was not a significant, if it occurred at all. 
The textures observed in the Cordón Caulle bombs require multiple cycles of fragmentation, sintering, densification, shearing, volatile resorption, and vesiculation with crossover of essentially incompatible textures in a single bomb. This is not reconcilable with the current models of smaller scale tuffisite veins. Thus, the results of this study promote the idea of a conduit-scale tuffisite, containing multiple generations of fractures and ancillary tuffisite veins, that is supplied by sub-surface fragmentation and subaerial particle fallback. Furthermore, a tuffisite with greater volume, fine particle sizes (submillimetre for sintering ash), and multiple generations of transient permeable pathways could accommodate the outgassing required for the coeval lava flow.

Future work to elucidate the intricacies of the 2011-2012 Cordón Caulle eruption should focus on the presence of the anomalous crystals in the rhyolite, temperature estimates for the basaltic-andesite and subsequent contribution to the sustainment of the eruption, and signatures of chemical mixing between the basaltic-andesite and rhyolite. Additionally, a detailed chemical analysis and comparison of mafic components in the lava and bombs should be conducted to determine whether they are correspondent. In a grander sense, future work should focus on the composition of micro-oxides, the associated mechanisms and timing of growth in sintering environments, and the compaction, modification, and partial re-homogenisation of synthetic and natural samples with similar properties to the bombs of Cordón Caulle. Finally, future work on tuffisite veins should consider these features at a larger, conduit scale (i.e., tuffisite as conduit plug). 


\section{Reference List}

Alidibirov, M., \& Dingwell, D. B. (2000). Three fragmentation mechanisms for highly viscous magma under rapid decompression. Journal of Volcanology and Geothermal Research, 100(1), 413-421.

Alidibirov, M., \& Dingwell, D. B. (1996). Magma fragmentation by rapid decompression. Nature, 380(6570), 146-148.

Alloway, B.V., Pearce, N. J. G., Villarosa, G., Outes, V., \& Moreno, P. I. (2015). Multiple melt bodies fed the AD 2011 eruption of Puyehue-Cordón Caulle, Chile. Scientific reports, v. 5.

Anderson, A. (1976). Magma mixing: petrological process and volcanological tool. Journal of Volcanology and Geothermal Research, 1(1), 3-33.

Bacon, C. R. (1986). Magmatic inclusions in silicic and intermediate volcanic rocks. Journal of Geophysical Research: Solid Earth, 91(B6), 6091-6112.

Bacon, C. R., \& Metz, J. (1984). Magmatic inclusions in rhyolites, contaminated basalts, and compositional zonation beneath the Coso volcanic field, California. Contributions to Mineralogy and Petrology, 85(4), 346-365.

Benage, M. C., Dufek, J., Degruyter, W., Geist, D., Harpp, K., \& Rader, E. (2014). Tying textures of breadcrust bombs to their transport regime and cooling history. Journal of Volcanology and Geothermal Research, 274, 92-107.

Bertin, D., Amigo, A., Lara, L., Orozco, G., \& Silva, C. (2012). Erupción del Cordón Caulle 2011-2012: Evolución fase efusiva. Paper presented at the XIII Congreso Geológico Chileno, Antofagasta.

Bertin, D., Lara, L., Basualto, D., Amigo, Á., Cardona, C., Franco, L., . . L Lazo, J. (2015). High effusion rates of the Cordón Caulle 2011-2012 eruption (Southern Andes) and their relation with the quasi-harmonic tremor. Geophysical research letters, 42(17), 7054-7063.

Bertrand, S., Daga, R., Bedert, R., \& Fontijn, K. (2014). Deposition of the 20112012 Cordón Caulle tephra (Chile, $40 \mathrm{~S}$ ) in lake sediments: implications for tephrochronology and volcanology. Journal of Geophysical Research: Earth Surface, 119(12), 2555-2573.

Bignami, C., Corradini, S., Merucci, L., De Michele, M., Raucoules, D., De Astis, G., . . Piedra, J. (2014). Multisensor satellite monitoring of the 2011 Puyehue-Cordon Caulle eruption. IEEE journal of selected topics in applied earth observations and remote sensing, 7(7), 2786-2796. 
Blower, J., Keating, J., Mader, H., \& Phillips, J. (2003). The evolution of bubble size distributions in volcanic eruptions. Journal of Volcanology and Geothermal Research, 120(1), 1-23.

Botto, I. L., Canafoglia, M. E., Gazzoli, D., \& González, M. J. (2013). Spectroscopic and microscopic characterization of volcanic ash from Puyehue-(Chile) eruption: Preliminary approach for the application in the arsenic removal. Journal of Spectroscopy, 2013.

Browne, B., \& Szramek, L. (2015). Rates of magma ascent and storage. In H. Sigurdsson, B. Houghton, S. McNutt, H. Rymer, \& et al. (Eds.), Encyclopedia of Volcanoes (2nd ed.). Oxford, UK: Elsevier Science \& Technology.

Browne, B., \& Vitale, M. (2011). Formation and Significance of Magmatic Enclaves in From the 2006 Eruption of Augustine Volcano, Alaska. Paper presented at the AGU Fall Meeting Abstracts.

Bunsen, R. (1851). Ueber die Processe der vulkanischen Gesteinsbildungen Islands. Annalen der Physik, 159(6), 197-272.

Burgisser, A., \& Degruyter, W. (2015). Magma ascent and degassing at shallow levels. In H. Sigurdsson, B. Houghton, S. McNutt, H. Rymer, \& et al. (Eds.), Encyclopedia of Volcanoes (2nd ed.). Oxford, UK: Elsevier Science \& Technology.

Cabrera, A., Weinberg, R. F., \& Wright, H. M. (2015). Magma fracturing and degassing associated with obsidian formation: The explosive-effusive transition. Journal of Volcanology and Geothermal Research, 298, 71-84.

Campbell, I. H., \& Turner, J. (1985). Turbulent mixing between fluids with different viscosities. Nature, 313(5997), 39-42.

Campbell, I. H., \& Turner, J. S. (1986). The influence of viscosity on fountains in magma chambers. Journal of Petrology, 27(1), 1-30.

Cashman, K. V., \& Mangan, M. T. (1994). Physical aspects of magmatic degassing; II, Constraints on vesiculation processes from textural studies of eruptive products. Reviews in Mineralogy and Geochemistry, 30(1), 447-478.

Cashman, K. V., \& Scheu, B. (2015). Magmatic Fragmentation. In H. Sigurdsson, B. Houghton, S. McNutt, H. Rymer, \& e. al. (Eds.), Encyclopedia of volcanoes (2nd ed.). Oxford, UK: Elsevier Science \& Technology.

Cashman, K. V., \& Sparks, R. S. J. (2013). How volcanoes work: A 25 year perspective. Geological Society of America Bulletin, 125(5-6), 664-690.

Castro, J., M, Schipper, C. I., Tuffen, H., James, M., \& Militzer, A. (2013a). Reassembling a volcanic conduit using bombs at Cordón Caulle, Chile. Paper presented at the IAVCEI, Kagoshima, Japan. 
Castro, J. M., Bindeman, I. N., Tuffen, H., \& Schipper, C. I. (2014). Explosive origin of silicic lava: textural and $\delta \mathrm{D}-\mathrm{H} 2 \mathrm{O}$ evidence for pyroclastic degassing during rhyolite effusion. Earth and Planetary Science Letters, 405, 52-61.

Castro, J. M., Burgisser, A., Schipper, C. I., \& Mancini, S. (2012a). Mechanisms of bubble coalescence in silicic magmas. Bulletin of Volcanology, 74(10), 23392352.

Castro, J. M., Cordonnier, B., Tuffen, H., Tobin, M. J., Puskar, L., Martin, M. C., $\&$ Bechtel, H. A. (2012b). The role of melt-fracture degassing in defusing explosive rhyolite eruptions at volcán Chaitén. Earth and Planetary Science Letters, 333, 63-69.

Castro, J. M., \& Dingwell, D. B. (2009). Rapid ascent of rhyolitic magma at Chaitén volcano, Chile. Nature, 461(7265), 780-783.

Castro, J. M., \& Gardner, J. E. (2008). Did magma ascent rate control the explosiveeffusive transition at the Inyo volcanic chain, California? Geology, 36(4), 279-282.

Castro, J. M., Schipper, C., \& Tuffen, H. (2012c). Simultaneous pyroclastic and effusive venting at rhyolite volcanoes: the cases of Puyehue-Cordón Caulle and Chaitén. Paper presented at the EGU General Assembly Conference Abstracts.

Castro, J. M., Schipper, C. I., Mueller, S. P., Militzer, A., Amigo, A., Parejas, C. S., \& Jacob, D. (2013b). Storage and eruption of near-liquidus rhyolite magma at Cordón Caulle, Chile. Bulletin of Volcanology, 75(4), 702.

Clarke, A. B., Esposti Ongaro, T., \& Belousov, A. (2015). Vulcanian Eruptions. In H. Sigurdsson, B. Houghton, S. McNutt, H. Rymer, \& Stix, J. (Eds.), Encyclopedia of Volcanoes (2nd ed.). Oxford, UK: Elsevier Science \& Technology.

Collini, E., Osores, M. S., Folch, A., Viramonte, J. G., Villarosa, G., \& Salmuni, G. (2013). Volcanic ash forecast during the June 2011 Cordón Caulle eruption. Natural Hazards, 66(2), 389-412.

Coombs, M. L., Eichelberger, J. C., \& Rutherford, M. J. (2003). Experimental and textural constraints on mafic enclave formation in volcanic rocks. Journal of Volcanology and Geothermal Research, 119(1-4), 125-144.

Cordonnier, B., Schmalholz, S., Hess, K. U., \& Dingwell, D. (2012). Viscous heating in silicate melts: An experimental and numerical comparison. Journal of Geophysical Research: Solid Earth, 117(B2).

Couch, S., Sparks, R. S. J., \& Carroll, M. (2001). Mineral disequilibrium in lavas explained by convective self-mixing in open magma chambers. Nature, 411(6841), 1037. 
Daga, R., Guevara, S. R., Poire, D. G., \& Arribére, M. (2014). Characterization of tephras dispersed by the recent eruptions of volcanoes Calbuco (1961), Chaitén (2008) and Cordón Caulle Complex (1960 and 2011), in Northern Patagonia. Journal of South American Earth Sciences, 49, 1-14.

De Campos, C. P., Perugini, D., Ertel-Ingrisch, W., Dingwell, D. B., \& Poli, G. (2011). Enhancement of magma mixing efficiency by chaotic dynamics: an experimental study. Contributions to Mineralogy and Petrology, 161(6), 863881.

De Vivo, B., Grasemann, B., \& Stüwe, K. (2009). GEOLOGY-Volume II: Eolss Publ.

Dias, K., \& Leitch, A. (2015). Laboratory Modelling of Magma Mingling. Atlantic Geology, 51(1).

Dingwell, D. B. (1996). Volcanic dilemma: flow or blow? Science, 273(5278), 1054.

Dingwell, D. B., \& Webb, S. L. (1989). Structural relaxation in silicate melts and non-Newtonian melt rheology in geologic processes. Physics and Chemistry of Minerals, 16(5), 508-516.

Dingwell, D. B., \& Webb, S. L. (1990). Relaxation in silicate melts. European Journal of Mineralogy, (4), 427-449.

Donaldson, C. H., \& Brown, R. W. (1977). Refractory megacrysts and magnesiumrich melt inclusions within spinel in oceanic tholeiites: indicators of magma mixing and parental magma composition. Earth and Planetary Science Letters, 37(1), 81-89.

Dowty, E. (1980). Synneusis reconsidered. Contributions to Mineralogy and Petrology, 74(1), 75-84.

Dungan, M. A., \& Rhodes, J. (1978). Residual glasses and melt inclusions in basalts from DSDP Legs 45 and 46: evidence for magma mixing. Contributions to Mineralogy and Petrology, 67(4), 417-431.

Edmonds, M., \& Herd, R. A. (2007). A volcanic degassing event at the explosiveeffusive transition. Geophysical research letters, 34(21).

Eichelberger, J. (1980). Vesiculation of mafic magma during replenishment of silicic magma reservoirs. Nature, 288(5790), 446-450.

Eichelberger, J., Carrigan, C., Westrich, H., \& Price, R. (1986). Non-explosive silicic volcanism. Nature, 323(6089), 598-602.

Eichelberger, J., \& Westrich, H. (1981). Magmatic volatiles in explosive rhyolitic eruptions. Geophysical research letters, 8(7), 757-760. 
Eichelberger, J. C., Chertkoff, D. G., Dreher, S. T., \& Nye, C. J. (2000). Magmas in collision: rethinking chemical zonation in silicic magmas. Geology, 28(7), 603-606.

Elissondo, M., Baumann, V., Bonadonna, C., Pistolesi, M., Cioni, R., Bertagnini, A., Biasse, S., Herroro, J., \& Gonzalez, R. (2016). Chronology and impact of the 2011 Cordón Caulle eruption, Chile. Natural Hazards and Earth System Sciences, 16(3), 675-704.

Fagents, S., \& Wilson, L. (1993). Explosive volcanic eruptions-VII. The ranges of pyroclasts ejected in transient volcanic explosions. Geophysical Journal International, 113(2), 359-370.

Farquharson, J. I., Wadsworth, F. B., Heap, M. J., \& Baud, P. (2017). Time-dependent permeability evolution in compacting volcanic fracture systems and implications for gas overpressure. Journal of Volcanology and Geothermal Research, 339, 81-97.

Feeley, T. C., \& Dungan, M. A. (1996). Compositional and Dynamic Controls on Mafic - Silicic Magma Interactions at Continental Arc Volcanoes: Evidence from Cordón El Guadal, Tatara-San Pedro Complex, Chile. Journal of Petrology, 37(6), 1547-1577.

Fink, J. H. (1983). Structure and emplacement of a rhyolitic obsidian flow: Little Glass Mountain, Medicine Lake Highland, northern California. Geological Society of America Bulletin, 94(3), 362-380.

Fink, J. H., Anderson, S. W., \& Manley, C. R. (1992). Textural constraints on effusive silicic volcanism: Beyond the permeable foam model. Journal of Geophysical Research: Solid Earth, 97(B6), 9073-9083.

Fisher, R. V., \& Schmincke, H.-U. (1984). Pyroclastic Rocks and Tectonic Environment Pyroclastic rocks (pp. 383-409): Springer.

Flinders, J., \& Clemens, J. D. (1996). Non-linear dynamics, chaos, complexity and enclaves in granitoid magmas. Geological Society of America Special Papers, $315,217-223$.

Fournier, T., Pritchard, M., \& Riddick, S. (2010). Duration, magnitude, and frequency of subaerial volcano deformation events: New results from Latin America using InSAR and a global synthesis. Geochemistry, Geophysics, Geosystems, 11(1).

Fowler, A., Scheu, B., Lee, W., \& McGuinness, M. (2010). A theoretical model of the explosive fragmentation of vesicular magma. Paper presented at the Proceedings of the Royal Society of London A: Mathematical, Physical and Engineering Sciences.

Francis, P. (1993). Volcanoes. A planetary perspective. Oxford, UK: Clarendon Press. 
Fudali, R., \& Melson, W. (1971). Ejecta velocities, magma chamber pressure and kinetic energy associated with the 1968 eruption of Arenal volcano. Bulletin of Volcanology, 35(2), 383-401.

Gaitán, J., Ayesa, J., Umaña, F., Raffo, F., Bran, D., \& de Bariloche, E. S. (2011). Cartografía del área afectada por cenizas volcánicas en las provincias de Río Negro y Neuquén. INTA, SC de Bariloche, Argentina.

Gardner, J. E., Llewellin, E. W., Watkins, J. M., \& Befus, K. S. (2017). Formation of obsidian pyroclasts by sintering of ash particles in the volcanic conduit. Earth and Planetary Science Letters, 459, 252-263.

Gardner, J. E., Thomas, R. M., Jaupart, C., \& Tait, S. (1996). Fragmentation of magma during Plinian volcanic eruptions. Bulletin of Volcanology, 58(2), 144-162.

Gerlach, D. C. (1985). Geochemistry and petrology of recent volcanics of the Puyehue-Cordon Caulle Area, Chile (40.5 S). (Doctoral Dissertation, Massachusetts Institute of Technology).

Gerlach, D. C., Frey, F. A., Moreno-Roa, H., \& Lopez-Escobar, L. (1988). Recent Volcanism in the Puyehue - Cordon Caulle Region, Southern Andes, Chile $\left(40 \cdot 5^{\circ} \mathrm{S}\right)$ : Petrogenesis of Evolved Lavas. Journal of Petrology, 29(2), 333382.

Giachetti, T., Druitt, T. H., Burgisser, A., Arbaret, L., \& Galven, C. (2010). Bubble nucleation, growth and coalescence during the 1997 Vulcanian explosions of Soufrière Hills Volcano, Montserrat. Journal of Volcanology and Geothermal Research, 193(3), 215-231.

Ginibre, C., Kronz, A., \& Wörner, G. (2002). High-resolution quantitative imaging of plagioclase composition using accumulated backscattered electron images: new constraints on oscillatory zoning. Contributions to Mineralogy and Petrology, 142(4), 436-448.

Ginibre, C., Wörner, G., \& Kronz, A. (2002). Minor-and trace-element zoning in plagioclase: implications for magma chamber processes at Parinacota volcano, northern Chile. Contributions to Mineralogy and Petrology, 143(3), 300-315.

Global Volcanism Program. (2013). Puyehue-Cordon Caulle (357150). Retrieved May 2013, from Smithsonian Institution (http://volcano.si.edu/volcano. cfm?vn=357150). https://dx.doi.org/10.5479/si.GVP.VOTW4-2013

Gonnermann, H. M. (2015). Magma fragmentation. Annual Review of Earth and Planetary Sciences, 43, 431-458. 
Gonnermann, H. M., \& Manga, M. (2003). Explosive volcanism may not be an inevitable consequence of magma fragmentation. Nature, 426(6965), 432435.

Gonnermann, H. M., \& Manga, M. (2007). The fluid mechanics inside a volcano. Annu. Rev. Fluid Mech., 39, 321-356.

Grove, T. L., Baker, M. B., \& Kinzler, R. J. (1984). Coupled CaAl-NaSi diffusion in plagioclase feldspar: Experiments and applications to cooling rate speedometry. Geochimica et Cosmochimica Acta, 48(10), 2113-2121.

Heap, M., Kolzenburg, S., Russell, J., Campbell, M., Welles, J., Farquharson, J., \& Ryan, A. (2014). Conditions and timescales for welding block-and-ash flow deposits. Journal of Volcanology and Geothermal Research, 289, 202-209.

Heiken, G., \& Eichelberger, J. C. (1980). Eruptions at Chaos Crags, Lassen Volcanic National Park, California. Journal of Volcanology and Geothermal Research, 7(3-4), 443-481.

Herd, R. A., \& Pinkerton, H. (1993). Bubble coalescence in magmas. Paper presented at the Lunar and Planetary Science Conference.

Hoblitt, R. P., \& Harmon, R. S. (1993). Bimodal density distribution of cryptodome dacite from the 1980 eruption of Mount St. Helens, Washington. Bulletin of Volcanology, 55(6), 421-437.

Hodge, K. F., Carazzo, G., \& Jellinek, A. M. (2012). Experimental constraints on the deformation and breakup of injected magma. Earth and Planetary Science Letters, 325, 52-62.

Holloway, J. R., \& Blank, J. G. (1994). Application of experimental results to COH species in natural melts. Reviews in mineralogy, 30, 187-187.

Horwell, C. J., \& Baxter, P. J. (2006). The respiratory health hazards of volcanic ash: a review for volcanic risk mitigation. Bulletin of Volcanology, 69(1), 1-24.

Houghton, B., \& Wilson, C. (1989). A vesicularity index for pyroclastic deposits. Bulletin of Volcanology, 51(6), 451-462.

Huppert, H. E., Sparks, R. S. J., \& Turner, J. S. (1982). Effects of volatiles on mixing in calc-alkaline magma systems. Nature, 297(5867), 554-557.

Huppert, H. E., Sparks, R. S. J., \& Turner, J. S. (1983). Laboratory investigations of viscous effects in replenished magma chambers. Earth and Planetary Science Letters, 65(2), 377-381.

Huppert, H. E., Stephen, R., Sparks, R. S. J., \& Turner, J. S. (1984). Some effects of viscosity on the dynamics of replenished magma chambers. Journal of Geophysical Research: Solid Earth, 89(B8), 6857-6877. 
Hurwitz, S., \& Navon, O. (1994). Bubble nucleation in rhyolitic melts: Experiments at high pressure, temperature, and water content. Earth and Planetary Science Letters, 122(3-4), 267-280.

Isgett, S., Houghton, B., Fagents, S., Biass, S., Burgisser, A., \& Arbaret, L. (2017). Eruptive and shallow conduit dynamics during Vulcanian explosions: insights from the Episode IV block field of the 1912 eruption of Novarupta, Alaska. Bulletin of Volcanology, 79(8), 58.

Ittai, K., Vladimir, L., \& Oded, N. (2011). Bubble growth in visco-elastic magma: implications to magma fragmentation and bubble nucleation. Bulletin of Volcanology, 73(1), 39-54.

Jarosewich, E., Nelen, J., \& Norberg, J. A. (1980). Reference samples for electron microprobe analysis. Geostandards and Geoanalytical Research, 4(1), 43-47.

Jay, J., Costa, F., Pritchard, M., Lara, L., Singer, B., \& Herrin, J. (2014). Locating magma reservoirs using InSAR and petrology before and during the 20112012 Cordón Caulle silicic eruption. Earth and Planetary Science Letters, $395,254-266$.

Jones, T., \& Russell, J. (2017). Ash production by attrition in volcanic conduits and plumes. Scientific reports, 7(1), 5538.

Kameda, M., Kuribara, H., \& Ichihara, M. (2008). Dominant time scale for brittle fragmentation of vesicular magma by decompression. Geophysical research letters, 35(14).

Kaminski, É., \& Jaupart, C. (1997). Expansion and quenching of vesicular magma fragments in Plinian eruptions. Journal of Geophysical Research: Solid Earth, 102(B6), 12187-12203.

Kendrick, J. E., Lavallée, Y., Varley, N. R., Wadsworth, F. B., Lamb, O. D., \& Vasseur, J. (2016). Blowing off steam: tuffisite formation as a regulator for lava dome eruptions. Frontiers in Earth Science, 4, 41.

Kennedy, B., Spieler, O., Scheu, B., Kueppers, U., Taddeucci, J., \& Dingwell, D. B. (2005). Conduit implosion during Vulcanian eruptions. Geology, 33(7), 581584.

Kennedy, B. M., Wadsworth, F. B., Vasseur, J., Schipper, C. I., Jellinek, A. M., von Aulock, F. W.,Hess, K. U., Russell, J. K., Lavallée, Y., Nichols, A. R., \& Dingwell, D. B. (2016). Surface tension driven processes densify and retain permeability in magma and lava. Earth and Planetary Science Letters, 433, 116-124.

Klug, C., Cashman, K., \& Bacon, C. (2002). Structure and physical characteristics of pumice from the climactic eruption of Mount Mazama (Crater Lake), Oregon. Bulletin of Volcanology, 64(7), 486-501. 
Kouchi, A., \& Sunagawa, I. (1983). Mixing basaltic and dacitic magmas by forced convection. Nature, 304(5926), 527-528.

Koyaguchi, T. (1985). Magma mixing in a conduit. Journal of Volcanology and Geothermal Research, 25(3-4), 365-369.

Koyaguchi, T., Scheu, B., Mitani, N. K., \& Melnik, O. (2008). A fragmentation criterion for highly viscous bubbly magmas estimated from shock tube experiments. Journal of Volcanology and Geothermal Research, 178(1), 5871.

Krafft, M. (1993). Volcanoes: fire from the Earth: Thames and Hudson.

Kuşcu, G. G., \& Floyd, P. A. (2001). Mineral compositional and textural evidence for magma mingling in the Saraykent volcanics. Lithos, 56(2), 207-230.

Kushnir, A. R., Martel, C., Champallier, R., \& Arbaret, L. (2017). In situ confirmation of permeability development in shearing bubble-bearing melts and implications for volcanic outgassing. Earth and Planetary Science Letters, 458, 315-326.

Lara, L. E., Moreno, H., Naranjo, J. A., Matthews, S., \& de Arce, C. P. (2006). Magmatic evolution of the Puyehue-Cordón Caulle Volcanic Complex (40 S), Southern Andean Volcanic Zone: from shield to unusual rhyolitic fissure volcanism. Journal of Volcanology and Geothermal Research, 157(4), 343366.

Laumonier, M., Scaillet, B., Arbaret, L., \& Champallier, R. (2014). Experimental simulation of magma mixing at high pressure. Lithos, 196, 281-300.

Laumonier, M., Scaillet, B., Pichavant, M., Champallier, R., Andujar, J., \& Arbaret, L. (2014). On the conditions of magma mixing and its bearing on andesite production in the crust. Nature communications, 5, 5607.

Lavallée, Y., Hirose, T., Kendrick, J., De Angelis, S., Petrakova, L., Hornby, A., \& Dingwell, D. (2014). A frictional law for volcanic ash gouge. Earth and Planetary Science Letters, 400, 177-183.

Le Bas, M., Le Maitre, R., Streckeisen, A., \& Zanettin, B. (1986). A Chemical Classification of Volcanic Rocks Based on the Total Alkali-Silica Diagram. Journal of Petrology, 27(3), 745-750.

Legland, D., Arganda-Carreras, I., \& Andrey, P. (2016). MorphoLibJ: integrated library and plugins for mathematical morphology with ImageJ. Bioinformatics, 32(22), 3532-3534.

Luhr, J. F., \& Carmichael, I. S. (1980). The Colima volcanic complex, Mexico. Contributions to Mineralogy and Petrology, 71(4), 343-372. 
Lyakhovsky, V., Hurwitz, S., \& Navon, O. (1996). Bubble growth in rhyolitic melts: experimental and numerical investigation. Bulletin of Volcanology, 58(1), 1932.

Mackenzie, J., \& Shuttleworth, R. (1949). A phenomenological theory of sintering. Proceedings of the Physical Society. Section B, 62(12), 833.

Mangan, M., Sisson, T., \& Hankins, W. (2004). Decompression experiments identify kinetic controls on explosive silicic eruptions. Geophysical research letters, $31(8)$.

Martel, C., \& Iacono-Marziano, G. (2015). Timescales of bubble coalescence, outgassing, and foam collapse in decompressed rhyolitic melts. Earth and Planetary Science Letters, 412, 173-185.

McIntosh, I., Llewellin, E., Humphreys, M., Nichols, A., Burgisser, A., Schipper, C. I., \& Larsen, J. (2014). Distribution of dissolved water in magmatic glass records growth and resorption of bubbles. Earth and Planetary Science Letters, 401, 1-11.

Melekhova, E., Annen, C., \& Blundy, J. (2013). Compositional gaps in igneous rock suites controlled by magma system heat and water content. Nature Geoscience, 6(5), 385-390.

Melson, W. G., \& Saenz, R. (1973). Volume, energy and cyclicity of eruptions of Arenal Volcano, Costa Rica. Bulletin of Volcanology, 37(3), 416-437.

Mercalli, G., \& Silvestri, O. (1891). Le eruzioni dell'Isola di Vulcano incominciate il 3 agosto 1888 e terminate il 22 marzo 1890, relazione scientifica. Ann Ufficio Centrale Metereol Geodin Ital, 10, 1-213.

Miwa, T., Geshi, N., \& Shinohara, H. (2013). Temporal variation in volcanic ash texture during a vulcanian eruption at the Sakurajima volcano, Japan. Journal of Volcanology and Geothermal Research, 260, 80-89.

Morrissey, M. M., \& Mastin, L. G. (2000). Vulcanian eruptions. In H. Sigurdson (Ed.), Encyclopedia of Volcanoes (pp. 463-475). San Diego, Ca: Academic Press.

Mueller, S., Scheu, B., Spieler, O., \& Dingwell, D. B. (2008). Permeability control on magma fragmentation. Geology, 36(5), 399-402.

Nakada, S. (1991). Magmatic processes in titanite-bearing dacites, central Andes of Chile and Bolivia. American Mineralogist, 76(3-4), 548-560.

Namiki, A., \& Manga, M. (2008). Transition between fragmentation and permeable outgassing of low viscosity magmas. Journal of Volcanology and Geothermal Research, 169(1), 48-60. 
Navon, O., \& Lyakhovsky, V. (1998). Vesiculation processes in silicic magmas. Geological Society, London, Special Publications, 145(1), 27-50.

Newman, S., Epstein, S., \& Stolper, E. (1988). Water, carbon dioxide, and hydrogen isotopes in glasses from the ca. $1340 \mathrm{AD}$ eruption of the Mono Craters, California: constraints on degassing phenomena and initial volatile content. Journal of Volcanology and Geothermal Research, 35(1-2), 75-96.

Olgaard, D. L., \& Gerald, J. D. F. (1993). Evolution of pore microstructures during healing of grain boundaries in synthetic calcite rocks. Contributions to Mineralogy and Petrology, 115(2), 138-154.

Pallister, J. S., Hoblitt, R. P., \& Reyes, A. G. (1992). A basalt trigger for the 1991 eruptions of Pinatubo Volcano? Nature, 356(6368), 426-428.

Papale, P. (1999). Strain-induced magma fragmentation in explosive eruptions. Nature, 397(6718), 425-428.

Perret, F. A. (1935). The eruption of Mt. Pelée, 1929-1932. Carnegie Institution of Washington (No. 458).

Perugini, D., Busa, T., Poli, G., \& Nazzareni, S. (2003). The role of chaotic dynamics and flow fields in the development of disequilibrium textures in volcanic rocks. Journal of Petrology, 44(4), 733-756.

Perugini, D., \& Poli, G. (2012). The mixing of magmas in plutonic and volcanic environments: analogies and differences. Lithos, 153, 261-277.

Perugini, D., Poli, G., \& Mazzuoli, R. (2003). Chaotic advection, fractals and diffusion during mixing of magmas: evidence from lava flows. Journal of Volcanology and Geothermal Research, 124(3), 255-279.

Pichavant, M., Di Carlo, I., Le Gac, Y., Rotolo, S. G., \& Scaillet, B. (2009). Experimental constraints on the deep magma feeding system at Stromboli volcano, Italy. Journal of Petrology, 50(4), 601-624.

Pistolesi, M., Cioni, R., Bonadonna, C., Elissondo, M., Baumann, V., Bertagnini, A., Chiari, L., Gonzales, R., Rosi. M., \& Francalanci, L. (2015). Complex dynamics of small-moderate volcanic events: the example of the 2011 rhyolitic Cordón Caulle eruption, Chile. Bulletin of Volcanology, 77(1), 3.

Polacci, M., Papale, P., \& Rosi, M. (2001). Textural heterogeneities in pumices from the climactic eruption of Mount Pinatubo, 15 June 1991, and implications for magma ascent dynamics. Bulletin of Volcanology, 63(2), 83-97.

Polacci, M., Pioli, L., \& Rosi, M. (2003). The Plinian phase of the Campanian Ignimbrite eruption (Phlegrean Fields, Italy): evidence from density measurements and textural characterization of pumice. Bulletin of Volcanology, 65(6), 418-432. 
Pope, R., Tuffen, H., Owen, J., James, M., \& Wadsworth, F. (2016). The Glass Bead Game: experimental sintering of rhyolitic ash reveals complex behaviour of irregular multiphase particles. Paper presented at the EGU General Assembly Conference Abstracts.

Proussevitch, A. A., \& Sahagian, D. L. (1996). Dynamics of coupled diffusive and decompressive bubble growth in magmatic systems. Journal of Geophysical Research: Solid Earth, 101(B8), 17447-17455.

Proussevitch, A. A., Sahagian, D. L., \& Kutolin, V. A. (1993). Stability of foams in silicate melts. Journal of Volcanology and Geothermal Research, 59(1-2), 161-178.

Quane, S. L., \& Russell, J. (2005). Welding: insights from high-temperature analogue experiments. Journal of Volcanology and Geothermal Research, 142(1), 6787.

Rasband, W. S. (2011). ImageJ, U.S. National Institutes of Health. Bethesda, Maryland, USA, 1997-2014. URL: http://imagej. nih. gov/ij/.

Reed, S. J. B. (2005). Electron microprobe analysis and scanning electron microscopy in geology: Cambridge University Press.

Roberge, J., Delgado-Granados, H., \& Wallace, P. J. (2009). Mafic magma recharge supplies high $\mathrm{CO} 2$ and $\mathrm{SO} 2$ gas fluxes from Popocatépetl volcano, Mexico. Geology, 37(2), 107-110.

Rotella, M. D., Wilson, C. J., Barker, S. J., Cashman, K. V., Houghton, B. F., \& Wright, I. C. (2014). Bubble development in explosive silicic eruptions: insights from pyroclast vesicularity textures from Raoul volcano (Kermadec arc). Bulletin of Volcanology, 76(8), 826.

Ruprecht, P., \& Bachmann, O. (2010). Pre-eruptive reheating during magma mixing at Quizapu volcano and the implications for the explosiveness of silicic arc volcanoes. Geology, 38(10), 919-922.

Ruprecht, P., Winslow, H., Pritchard, M., Basualto, D., \& Garcia, F. (2017). Recharge of silicic magmatic systems - Mafic magmas driving the 2011 PuyehueCordón Caulle eruption?. Paper presented at the International Association of Volcanology and Chemistry of the Earths's Interior Portland, Or.

Rust, A., \& Cashman, K. (2007). Multiple origins of obsidian pyroclasts and implications for changes in the dynamics of the $1300 \mathrm{BP}$ eruption of Newberry Volcano, USA. Bulletin of Volcanology, 69(8), 825-845.

Rust, A., Cashman, K., \& Wallace, P. (2004). Magma degassing buffered by vapor flow through brecciated conduit margins. Geology, 32(4), 349-352. 
Rust, A., Manga, M., \& Cashman, K. V. (2003). Determining flow type, shear rate and shear stress in magmas from bubble shapes and orientations. Journal of Volcanology and Geothermal Research, 122(1), 111-132.

Ryan, A. G., Friedlander, E. A., Russell, J. K., Heap, M. J., \& Kennedy, L. A. (2018). Hot pressing in conduit faults during lava dome extrusion: Insights from Mount St. Helens 2004-2008. Earth and Planetary Science Letters, 482, 171180 .

Saar, M. O., Manga, M., Cashman, K. V., \& Fremouw, S. (2001). Numerical models of the onset of yield strength in crystal-melt suspensions. Earth and Planetary Science Letters, 187(3-4), 367-379.

Sahagian, D. L., \& Proussevitch, A. A. (1998). 3D particle size distributions from 2D observations: stereology for natural applications. Journal of Volcanology and Geothermal Research, 84(3), 173-196.

Sakuyama, M. (1981). Petrological study of the Myoko and Kurohime volcanoes, Japan: crystallization sequence and evidence for magma mixing. Journal of Petrology, 22(4), 553-583.

Saubin, E., Tuffen, H., Gurioli, L., Owen, J., Castro, J. M., Berlo, K., McGowan, E. M., Schipper, C. I., \& Wehbe, K. (2016). Conduit Dynamics in Transitional Rhyolitic Activity Recorded by Tuffisite Vein Textures from the 2008-2009 Chaitén Eruption. Frontiers in Earth Science, 4.

Schipper, C. I., Castro, J. M., Tuffen, H., James, M. R., \& How, P. (2013). Shallow vent architecture during hybrid explosive-effusive activity at Cordón Caulle (Chile, 2011-12): evidence from direct observations and pyroclast textures. Journal of Volcanology and Geothermal Research, 262, 25-37.

Schipper, C. I., Castro, J. M., Tuffen, H., Wadsworth, F. B., Chappell, D., Pantoja, A. E., Simpson, M. P., \& Le Ru, E. C. (2015). Cristobalite in the 2011-2012 Cordón Caulle eruption (Chile). Bulletin of Volcanology, 77(5), 34.

Schlinger, C. M., Griscom, D., Papaefthymiou, G. C., \& Veblen, D. R. (1988). The nature of magnetic single domains in volcanic glasses of the KBS Tuff. Journal of Geophysical Research: Solid Earth, 93(B8), 9137-9156.

Schlinger, C. M., Rosenbaum, J., \& Veblen, D. R. (1988). Fe-oxide microcrystals in welded tuff from southern Nevada: Origin of remanence carriers by precipitation in volcanic glass. Geology, 16(6), 556-559.

Schlinger, C. M., Smith, R. M., \& Veblen, D. R. (1986). Geologic origin of magnetic volcanic glasses in the KBS tuff. Geology, 14(11), 959-962.

Schneider, C. A., Rasband, W. S., \& Eliceiri, K. W. (2012). NIH Image to ImageJ: 25 years of image analysis. Nature methods, 9(7), 671. 
Schwindinger, K. R., \& Anderson, A. T. (1989). Synneusis of Kilauea Iki olivines. Contributions to Mineralogy and Petrology, 103(2), 187-198.

Self, S. (2006). The effects and consequences of very large explosive volcanic eruptions. Philosophical Transactions of the Royal Society of London A: Mathematical, Physical and Engineering Sciences, 364(1845), 2073-2097.

Self, S., Wilson, L., \& Nairn, I. A. (1978). Vulcanian eruption mechanisms.

Semenov, A., \& Polyansky, O. (2017). Numerical modeling of the mechanisms of magma mingling and mixing: A case study of the formation of complex intrusions. Russian Geology and Geophysics, 58(11), 1317-1332.

Silva Parejas, C., Lara, L., Bertin, D., Amigo, A., \& Orozco, G. (2012). The 20112012 eruption of Cordón Caulle volcano (Southern Andes): Evolution, crisis management and current hazards. Paper presented at the EGU General Assembly Conference Abstracts.

Singer, B. S., Jicha, B. R., Harper, M. A., Naranjo, J. A., Lara, L. E., \& MorenoRoa, H. (2008). Eruptive history, geochronology, and magmatic evolution of the Puyehue-Cordón Caulle volcanic complex, Chile. Geological Society of America Bulletin, 120(5-6), 599-618.

Skorokhod, V. (2017). Development of Sintering Theory at the Frantsevich Institute for Problems of Materials Science Under the National Academy of Sciences of Ukraine. Powder Metallurgy and Metal Ceramics, 56(7-8), 366-369.

Sparks, R. S. J. (1986). The dimensions and dynamics of volcanic eruption columns. Bulletin of Volcanology, 48(1), 3-15.

Sparks, R. S. J., \& Marshall, L. (1986). Thermal and mechanical constraints on mixing between mafic and silicic magmas. Journal of Volcanology and Geothermal Research, 29(1-4), 99-124.

Sparks, R. S. J., Tait, S., \& Yanev, Y. (1999). Dense welding caused by volatile resorption. Journal of the Geological Society, 156(2), 217-225.

Sparks, R. S. J. (1978). The dynamics of bubble formation and growth in magmas: a review and analysis. Journal of Volcanology and Geothermal Research, 3(12), 1-37.

Sparks, R. S. J., Sigurdsson, H., \& Wilson, L. (1977). Magma mixing: a mechanism for triggering acid explosive eruptions. Nature, 267(5609), 315-318.

Spera, F. J., Schmidt, J. S., Bohrson, W. A., \& Brown, G. A. (2016). Dynamics and thermodynamics of magma mixing: Insights from a simple exploratory model. American Mineralogist, 101(3), 627-643.

Spieler, O., Kennedy, B., Kueppers, U., Dingwell, D. B., Scheu, B., \& Taddeucci, 
J. (2004). The fragmentation threshold of pyroclastic rocks. Earth and Planetary Science Letters, 226(1), 139-148.

Spray, J. G., \& Rae, D. A. (1995). Quantitative electron-microprobe analysis of alkali silicate glasses; a review and user guide. The Canadian Mineralogist, 33(2), 323-332.

Stasiuk, M. V., Barclay, J., Carroll, M. R., Jaupart, C., Ratté, J. C., Sparks, R. S. J., \& Tait, S. R. (1996). Degassing during magma ascent in the Mule Creek vent (USA). Bulletin of Volcanology, 58(2-3), 117-130.

Stern, C. R., Moreno, H., López-Escobar, L., Clavero, J., Lara, L., Naranjo, J., Parada, M., \& Skewes, M. (2007). Chilean volcanoes. The geology of Chile, v. 5 , p. $149-180$.

Stimac, J. A., \& Pearce, T. H. (1992). Textural evidence of mafic-feslic magma interaction in dacite lavas, Clear Lake, California. American Mineralogist, 77 (7-8), 795-809.

Stimac, J. A., Pearce, T. H., Donnelly-Nolan, J. M., \& Hearn, B. C. (1990). The origin and implications of undercooled andesitic inclusions in rhyolites, Clear Lake volcanics, California. Journal of Geophysical Research: Solid Earth, 95(B11), 17729-17746.

Stix, J., Torres, R. C., Narváez, L., Raigosa, J. A., Gómez, D., \& Castonguay, R. (1997). A model of vulcanian eruptions at Galeras volcano, Colombia. Journal of Volcanology and Geothermal Research, 77(1), 285-303.

Stroncik, N. A., \& Schmincke, H.-U. (2002). Palagonite-a review. International Journal of Earth Sciences, 91(4), 680-697.

Stull, R. J. (1979). Mantled feldspars and synneusis. American Mineralogist, 64, 514-518.

Thomas, M. E., \& Neuberg, J. W. (2014). Understanding which parameters control shallow ascent of silicic effusive magma. Geochemistry, Geophysics, Geosystems, 15(11), 4481-4506.

Thomas, N., Jaupart, C., \& Vergniolle, S. (1994). On the vesicularity of pumice. Journal of Geophysical Research: Solid Earth, 99(B8), 15633-15644.

Toramaru, A. (1988). Formation of propagation pattern in two-phase flow systems with application to volcanic eruptions. Geophysical Journal International, 95(3), 613-623.

Tsuchiyama, A. (1985). Dissolution kinetics of plagioclase in the melt of the system diopside-albite-anorthite, and origin of dusty plagioclase in andesites.

Contributions to Mineralogy and Petrology, 89(1), 1-16. 
Tuffen, H., \& Dingwell, D. (2005). Fault textures in volcanic conduits: evidence for seismic trigger mechanisms during silicic eruptions. Bulletin of Volcanology, 67(4), 370-387.

Tuffen, H., Dingwell, D. B., \& Pinkerton, H. (2003). Repeated fracture and healing of silicic magma generate flow banding and earthquakes? Geology, 31(12), 1089-1092.

Vance, J. A. (1969). On synneusis. Contributions to Mineralogy and Petrology, 24(1), 7-29.

Vasseur, J., Wadsworth, F., Lavallée, Y., Hess, K., Wassermann, J., \& Dingwell, D. (2013). Sintering, deformation and failure of glassy volcanic ash analogues: Seismic precursors and damage mechanisms.

Vasseur, J., Wadsworth, F. B., Lavallée, Y., Hess, K. U., \& Dingwell, D. B. (2013). Volcanic sintering: Timescales of viscous densification and strength recovery. Geophysical Research Letters, 40(21), 5658-5664.

Villemant, B., \& Boudon, G. (1998). Transition from dome-forming to plinian eruptive styles controlled by $\mathrm{H} 2 \mathrm{O}$ and $\mathrm{Cl}$ degassing. Nature, 392(6671), 6569.

Vogt, J. H. L. (1921). The physical chemistry of the crystallization and magmatic differentiation of igneous rocks. The Journal of Geology, 29(4), 318-350.

Voight, B., Sparks, R. S. J., Miller, A., Stewart, R., Hoblitt, R., Clarke, A., Ewart, J., Aspinall, W. P., Baptie, B., \& Calder, E. (1999). Magma flow instability and cyclic activity at Soufriere Hills volcano, Montserrat, British West Indies. Science, 283(5405), 1138-1142.

von Aulock, F., Wadsworth, F., Lavallée, Y., \& Vasseur, J. (2014). Sintering of Glass in Hydrous Atmospheres and its Implications for Welding of Volcanic Deposits. Paper presented at the AGU Fall Meeting Abstracts.

Wadsworth, F. B., Vasseur, J., Aulock, F. W., Hess, K. U., Scheu, B., Lavallée, Y., \& Dingwell, D. B. (2014). Nonisothermal viscous sintering of volcanic ash. Journal of Geophysical Research: Solid Earth, 119(12), 8792-8804.

Wadsworth, F. B., Vasseur, J., Llewellin, E. W., Genareau, K., Cimarelli, C., \& Dingwell, D. B. (2017). Size limits for rounding of volcanic ash particles heated by lightning. Journal of Geophysical Research: Solid Earth, 122(3), 1977-1989.

Wadsworth, F. B., Vasseur, J., Llewellin, E. W., Schauroth, J., Dobson, K. J., Scheu, B., \& Dingwell, D. B. (2016). Sintering of viscous droplets under surface tension. Paper presented at the Proceedings of the Royal Society A: mathematical, physical, and engineering sciences, 472(2188), 20150780. 
Wadsworth, F. B., Vasseur, J., Scheu, B., Kendrick, J. E., Lavallée, Y., \& Dingwell, D. B. (2016). Universal scaling of fluid permeability during volcanic welding and sediment diagenesis. Geology, 44(3), 219-222.

Walker, G. (1969). The breaking of magma. Geological Magazine, 106(2), 166-173.

Wallace, P. J., \& Carmichael, I. S. (1994). Petrology of Volcán Tequila, Jalisco, Mexico: disequilibrium phenocryst assemblages and evolution of the subvolcanic magma system. Contributions to Mineralogy and Petrology, $117(4), 345-361$.

Wang, W., Fu, Z., Wang, H., \& Yuan, R. (2002). Influence of hot pressing sintering temperature and time on microstructure and mechanical properties of TiB2 ceramics. Journal of the European Ceramic Society, 22(7), 1045-1049.

Watkins, J., Gardner, J., \& Befus, K. (2017). Nonequilibrium degassing, regassing, and vapor fluxing in magmatic feeder systems. Geology, 45(2), 183-186.

Webb, S. L., \& Dingwell, D. B. (1990). The onset of non-Newtonian rheology of silicate melts. Physics and Chemistry of Minerals, 17(2), 125-132.

Webb, S. L., \& Dingwell, D. B. (1990). Non-Newtonian rheology of igneous melts at high stresses and strain rates: Experimental results for rhyolite, andesite, basalt, and nephelinite. Journal of Geophysical Research: Solid Earth, 95(B10), 15695-15701.

Welander, P. (1955). Studies on the General Development of Motion in a TwoDimensional, Ideal Fluid. Tellus, 7(2), 141-156.

Widiwijayanti, C., Clarke, A., Elsworth, D., \& Voight, B. (2005). Geodetic constraints on the shallow magma system at Soufrière Hills Volcano, Montserrat. Geophysical Research Letters, 32(11).

Wilcox, R. E. (1999). The idea of magma mixing: history of a struggle for acceptance. The Journal of Geology, 107(4), 421-432.

Wilson, L., Sparks, R. S. J., \& Walker, G. P. (1980). Explosive volcanic eruptionsIV. The control of magma properties and conduit geometry on eruption column behaviour. Geophysical Journal International, 63(1), 117-148.

Wolff, J. A., Ellwood, B. B., \& Sachs, S. D. (1989). Anisotropy of magnetic susceptibility in welded tuffs: application to a welded-tuff dyke in the Tertiary Trans-Pecos Texas volcanic province, USA. Bulletin of Volcanology, 51(4), 299-310.

Woods, A. W. (1995). The dynamics of explosive volcanic eruptions. Reviews of Geophysics, 33(4), 495-530. 
Wright, H. M., Cashman, K. V., Rosi, M., \& Cioni, R. (2007). Breadcrust bombs as indicators of Vulcanian eruption dynamics at Guagua Pichincha volcano, Ecuador. Bulletin of Volcanology, 69(3), 281-300.

Yamagishi, H. (1991). Morpholgoy of blocks ejected by the 1988- 1989 eruptions of Tokachi-dake Volcano, Hokkaido. Spec. Rep. Geol. Surv. Hokkaido, 20, 87107.

Yamagishi, H., \& Feebrey, C. (1994). Ballistic ejecta from the 1988-1989 andesitic Vulcanian eruptions of Tokachidake volcano, Japan: morphological features and genesis. Journal of Volcanology and Geothermal Research, 59(4), 269278.

Zhu, Y., Wang, L., \& Ma, C. (2017). An Unique Glomerophyric Diorite Porphyry from the Southern Margin of North China Craton: Geochronology, Geochemical and Quantitative Textural Analysis Constraints. Acta Geologica Sinica (English Edition). 


\section{Appendix 1: Hand Sample Descriptions}

Brief hand-sample descriptions for all samples initially examined are given below.

B01

A light grey and black, banded pumiceous rock with elongated vesicles, and a dense, black obsidian crust at one edge. Banding is defined by fine whisps/ lines of the darker obsidian material through the light-grey pumiceous material, and is both non-linear and sub-parallel. Both the banding and the direction of vesicle elongation are perpendicular to the obsidian crust, furthermore, the length of elongated vesicles is greater further away from the obsidian crust. A small quantity of $<1 \mathrm{~mm}$ red-orange crystals/pellets are present throughout the sample.

B05

A predominantly white, moderately vesicular pumiceous sample with a glassy black crust at one edge and a single $\sim 5 \mathrm{~mm}$ band of elongate clasts in a fine matrix. The white pumiceous material has some subtle reddish coloured areas and a sharp boundary with the obsidian crust.

B07

A pumiceous rock with variable vesicularity and banding both defined by colour changes between light-grey, dark-grey, and light-red-pink to reddish-orange. Some of the dark-grey areas are also characterised by an increased vesicularity relative to other zones, however there is no discernible vesicle alignment anywhere in the sample. All areas of the light-red-pink to reddish-orange material are contiguous and have a sharp boundary with light- and dark-grey material. Of note is that bands of the light-red-pink material are orientated in two perpendicular directions and contain plentiful elongate light-grey pumiceous clasts. In each of the two hand samples of this bomb there is a single dark-brown pumiceous clast visible that has a sharp boundary with all adjacent material. Also present are fine $(\leq 2 \mathrm{~mm})$ black fragments in small amounts, and small red-orange crystals, generally found within a larger pore in the reddish-orange material (more common in one sample bag over the other?). 
Black and dark-grey variably vesicular clasts contained within a dull red-grey coloured matrix. Black clasts are dense glassy material (obsidian), are generally larger than others $(\geq 2-3 \mathrm{~cm})$, and occur as both elongate and rounder clasts. Larger clasts are distinct from the matrix, whereas smaller clasts are not so much. These smaller clasts are highly variable in both size, colour, and vesicularity. Obsidian is also present as small black $(\leq 1 \mathrm{~cm})$ clasts, pumiceous clasts are present as both banded black and grey clasts of $\sim 2-3 \mathrm{~cm}$ and non-banded $<1.5$ cm clasts, and small (1-2 mm) dull-red pellets are present in small amounts $(<<1$ vol.\%). Overall the sample is dense despite the constituent parts having variable vesicularities.

$B 10$

A dense, non-vesicular black-and dark-grey banded sample with small $(\leq 3 \mathrm{~mm})$ crystals. Both black and dark-grey bands are glassy, however, the black material is only present as fine $<1 \mathrm{~cm}$ bands and is secondary to the dark-grey material. The majority of crystals are a white or clear glassy crystal, the remainder are a dull red-brown material of similar size.

$B 11$

A dense black sample with subtle banding and clear presence of white crystals. Some small sections around the edges of the sample have a red-orange colour and are marginally vesicular. Crystals are $\leq 3 \mathrm{~mm}$ across, elongated, and orientated sub-parallel to one another (i.e., no consistent orientation).

$B 12$

A pumiceous rock consisting of pumiceous clasts, with long axis measuring $<1$ $\mathrm{cm}$ to $\sim 9 \mathrm{~cm}$, suspended within a reddish-orange matrix. Clasts are mostly light to dark grey, with some grey and black banded clasts, and smaller $(<1 \mathrm{~cm})$ glassy black fragments. Large vesicles $(\sim 1-3 \mathrm{~cm})$ occur in the matrix. The largest clasts are orientated perpendicular to, and juxtaposed with a band of smaller clasts suspended within a matrix. 


\section{$B 13$}

A dense, dark grey and black banded sample with ubiquitous crystal presence. Sample is primarily a dark grey material, with sub-planar, sub-parallel $1-2 \mathrm{~cm}$ bands of black material; clear, white, and red-brown crystals are present in both dark-grey and black regions. Darker black material has a glassier lustre than does the dark-grey material.

\section{B14}

A glassy black, essentially non-vesicular sample with non-linear banding of a dark-grey material. Fine white crystalline material covers the sample in patches, and small dull red-brown crystals/microlites are present in sparse clumps. There is subtle linear banding apparent in the glassy black material, discernible by a slight colour change.

\section{$B 16$}

A black to dark-grey rock with a dull lustre and a honeycomb texture, wherein variably sized ( $\sim 1 \mathrm{~mm}$ to $3 \mathrm{~cm}$ ) holes in the dense material are filled with a lightgrey, highly vesicular material. Glassy black phenocrysts/fragments (size?) are present within the dense matrix material; the same glassy black material is found in 1-2 mm rings around some of the pumiceous material. A crust, composed of dull black material with a reddish hue in places, several 1-3 mm wide cracks, a smaller number of pumice filled pores, and a larger fraction of glassy black fragments, is present at one edge of the sample. The average size of vesicular clasts increases away from the crust, and larger vesicular clasts are encircled by much smaller vesicular clasts. There is no apparent alignment within the honeycomb structure.

\section{$B 17$}

A light- to dark-grey pumiceous sample with clasts suspended in a reddishorange matrix. Clasts are variably vesicular and either grey, brown, glassy banded, or black The majority of vesicles are $\leq 3-4 \mathrm{~mm}$ but some $1-3 \mathrm{~cm}$ size vesicles are present in the reddish-orange matrix, and contain small red-brown pellets. Curvilinear banding can be seen, defined by small $(<1 \mathrm{~cm})$ clasts and the reddish-orange matrix wrapping around larger clasts. 
Sample consisting of glassy and dull black material with small amounts of pinkish-red and white crystalline material present in the dull black areas. The boundaries between the dull and glassy black material is sharp, and within the dull black material are clasts of the glassy black material.

$B 20$

A composite rock composed of glassy black, dull dark-grey, and light-grey clasts, and a pinkish-red fine crystalline material. Clasts of different colours are also defined by apparent differences in vesicularity; glassy black clast are marginally vesicular, dark-grey clasts have low vesicularity and whisps of glassy black material within, light-grey clasts are generally moderately vesicular. Overall, the pinkish-red material (i.e., matrix) is a minor constituent of the sample relative to the other components (i.e., clasts). Smaller clasts are aligned roughly parallel to one another, whereas the larger clasts do not have an apparent alignment. One large clast, $\sim 3 \mathrm{~cm}$ long is heavily banded, such that it stands out as significantly different from all other clasts in the sample.

$B 21$

Light-grey coloured pumiceous sample with slight banding and a dense, glassy black crust (i.e., obsidian) at one edge. The banding is primarily defined but subtle colour and vesicle shape (flattened vs rounded in cross section) variations in the pumiceous material, however, some pieces of this sample also have whisps/ bands of denser obsidian extending into the pumiceous material. Vesicles are elongated, and aligned sub-parallel extending away from the obsidian crust/rind; vesicle size increases with distance from the obsidian crust. In some vesicles small mm-scale fragments of obsidian can be found. 


\section{Appendix 2 (Digital): Full Chemical Analyses}

Full analyses, minus those analyses removed due to poor totals or erroneous measurements for particular elements, are provided for rhyolite matrix glass, basaltic-andesite matrix glass, olivine, plagioclase, and ortho-pyroxene in excel spreadsheet format. All data are reported as raw, normalised values. 
